\title{
Ovarian tissue cryopreservation and transplantation : approaches and techniques
}

Citation for published version (APA):

Bedaiwy, M. A. (2007). Ovarian tissue cryopreservation and transplantation : approaches and techniques. [Doctoral Thesis, Maastricht University]. Universiteit Maastricht. https://doi.org/10.26481/dis.20071219mb

Document status and date:

Published: 01/01/2007

DOI:

10.26481/dis.20071219mb

Document Version:

Publisher's PDF, also known as Version of record

\section{Please check the document version of this publication:}

- A submitted manuscript is the version of the article upon submission and before peer-review. There can be important differences between the submitted version and the official published version of record.

People interested in the research are advised to contact the author for the final version of the publication, or visit the DOI to the publisher's website.

- The final author version and the galley proof are versions of the publication after peer review.

- The final published version features the final layout of the paper including the volume, issue and page numbers.

Link to publication

\footnotetext{
General rights rights.

- You may freely distribute the URL identifying the publication in the public portal. please follow below link for the End User Agreement:

www.umlib.nl/taverne-license

Take down policy

If you believe that this document breaches copyright please contact us at:

repository@maastrichtuniversity.nl

providing details and we will investigate your claim.
}

Copyright and moral rights for the publications made accessible in the public portal are retained by the authors and/or other copyright owners and it is a condition of accessing publications that users recognise and abide by the legal requirements associated with these

- Users may download and print one copy of any publication from the public portal for the purpose of private study or research.

- You may not further distribute the material or use it for any profit-making activity or commercial gain

If the publication is distributed under the terms of Article $25 \mathrm{fa}$ of the Dutch Copyright Act, indicated by the "Taverne" license above, 


\section{Ovarian Tissue Cryopreservation and Transplantation:}

\section{Approaches and Techniques}

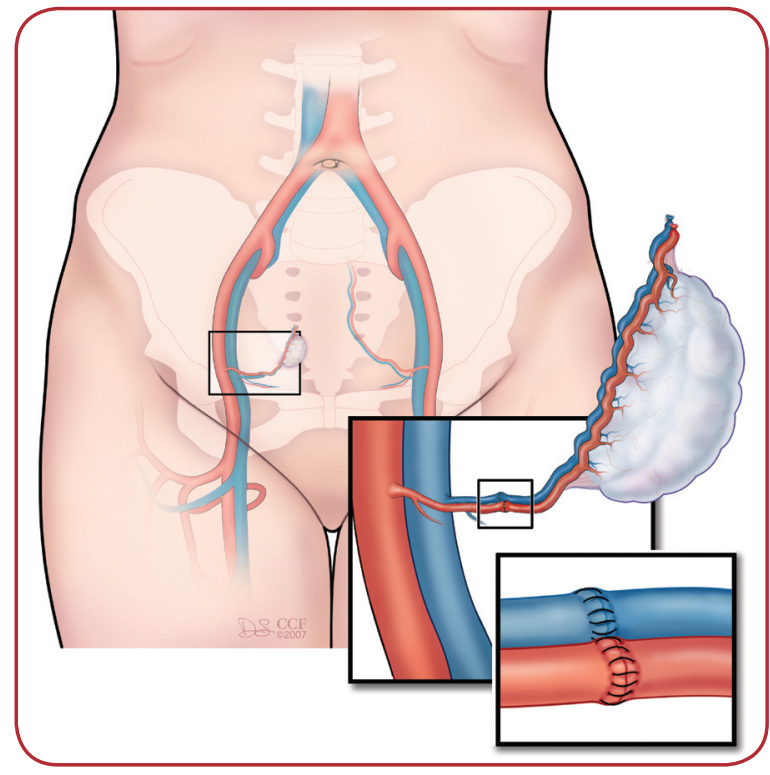

Mohamed Ali Bedaiwy 


\section{Cover Art}

Heterotopic transplantation of intact ovary with its vascular pedicle to the anterior abdominal wall with microvascular anastomosis to the inferior epigastric vessels using an end-to-end technique.

Library of Congress Cataloging-in-Publication Data

Bedaiwy, Mohamed Ali, 1968-

Ovarian tissue cryopreservation and transplantation : approaches and techniques / Mohamed Ali Bedaiwy.

p. ; cm.

Thesis (PhD)--University ofMaastricht, the Netherlands, 2007. Includes bibliographical references. Primarily English, some introductory thesis information in Dutch. ISBN 978-0-9800583-0-7 (alk. paper)

1. Ovaries--Transplantation. 2.Cryopreservation of organs, tissues, etc. I. Cleveland Clinic Foundation. II. Title.

[DNLM: 1. Ovary--transplantation. 2. Cryopreservation. 3. Infertility, Female--prevention \& control. 4. Ovarian Failure, Premature--prevention \& control. 5. Transplantation, Autologous. WP $320 \mathrm{~B} 3990$ 2007]

RD584.B43 2007

$618.1^{\prime} 10592--d c 22$

Financial support for the work presented in this thesis by the Research Program Council (RPC), The Cleveland Clinic Foundation, Cleveland, Ohio, USA, is greatly acknowledged.

Ministry of High Education Travel Award obtained from the School of Medicine, Assiut University, Assiut,

Egypt used - in part- to support the work presented in this thesis, is greatly acknowledged.

Publication of this thesis is supported by the Department of Obstetrics and Gynecology,

The Cleveland Clinic Foundation, Cleveland, Ohio, USA. 


\section{Ovarian Tissue Cryopreservation and Transplantation Approaches and Techniques}

\section{PROEFSCHRIFT}

ter verkrijging van de graad van doctor

aan de Universiteit Maastricht,

op gezag van de Rector Magnificus,

Prof. Mr. G.P.M.F. Mols,

volgens het besluit van het College van Decanen,

in het openbaar te verdedigen

op woensdag 19 december 2007 om 12:00 uur

door

Mohamed Ali Bedaiwy 


\section{Promotor:}

Prof. dr. J.L.H. Evers

\section{Beoordelingscommissie:}

Prof. dr J.P.M. Geraedts (voorzitter)

Dr J.C.M. Dumoulin

Prof. dr M.J. Heineman, Universiteit van Amsterdam

Prof. dr H.C. Schouten

Prof. dr A.C. van Steirteghem, Vrije Universiteit Brussel 


\section{CONTENTS}

Chapter $1 \quad$ General Introduction.

Chapter 2 Assessment of tissue injury in cryopreserved ovarian tissue.

Chapter 3 Analysis of apoptotic cell death, Bcl-2, and p53 protein expression in freshly fixed and cryopreserved ovarian tissue after exposure to warm ischemia.

Chapter $4 \quad$ Heterotopic autotransplantation of the ovary with microvascular anastomosis: a novel surgical technique.

Chapter 5 Restoration of ovarian function after autotransplantation of intact frozen-thawed sheep ovaries with microvascular anastomosis.

Chapter 6 Autologous transplantation of cryopreserved ovary induces the generation of antiovary antibodies in sheep.

Chapter 7 Cryopreservation of intact human ovary with its vascular pedicle.

Chapter 8 Harvesting and autotransplantation of vascularized ovarian grafts: approaches and techniques.

Chapter 9 Reproductive outcome after transplantation of ovarian tissue: a systematic review of observational studies and an individual patient data meta-analysis.

Chapter 10 General Discussion

Summary/Samenvatting

Abbreviations

Appendices

Curriculum Vitae

Publications 



\section{Chapter 1}

\section{General Introduction: Fertility preservation in cancer patients}

\section{Adapted from:}

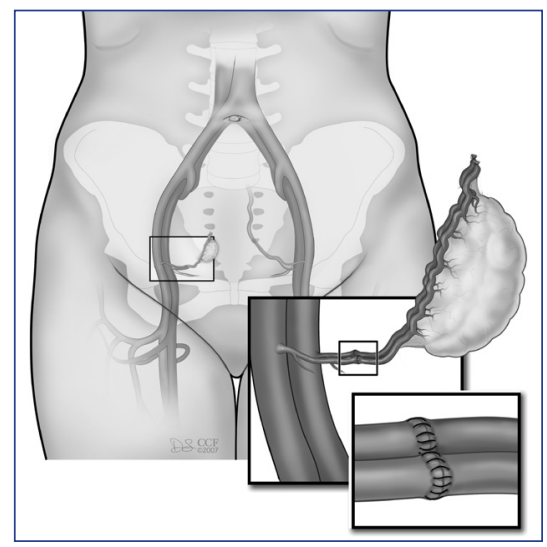

1. Bedaiwy MA, Falcone T. Ovarian tissue banking for cancer patients: reduction of post-transplantation ischaemic injury: intact ovary freezing and transplantation. Hum Reprod. 2004; 19 (6):1242-4.

2. Falcone T, Bedaiwy MA. Fertility preservation and pregnancy outcome after malignancy. In: Current Opinion in Obstetrics and Gynecology, Williams and Wilkins, London, 2005; 17(1):21-6.

3. Bedaiwy MA, Falcone T et al., Fertility preservation in cancer patients. In Textbook of Clinical Reproductive Medicine and Surgery. Tommaso Falcone and William W. Hurd, Elservier, 2007, 485-497.

4. Bedaiwy MA, Falcone T et al., Fertility preservation in Cancer patients. In: Textbook of Infertility and Assisted Reproduction. Editor: Botros Rizk, Juan Garcia-Velasco, Hassan Sallam, Antonis Makrigiannakis. Publisher: Cambridge University Press. 


\section{Introduction}

Female cancer patients between the ages of 15 and 49 years are expected to not only survive their disease but also lead normal lives, mainly because of newer, more effective cancer therapies such as sterilizing chemotherapy and/or radiotherapy. Consequently, fertility preservation has become an important quality-of-life issue. Problems with fertility and obstetric disorders such as early pregnancy loss, premature labor and low birth weight have all been described after cancer treatment (1).

Recent achievements in assisted reproductive technologies such as novel ovulation induction remedies, oocyte cryopreservation and ovarian tissue cryopreservation and transplantation have further expanded the options for fertility preservation in women scheduled to receive chemotherapy and/or radiotherapy. However, most fertility preservation strategies do not have long-term follow-up data. The latest committee report of the American Society of Reproductive Medicine (ASRM) states that embryo cryopreservation is the only option for these patients that has sufficient evidence of clinical utility. The remaining options, including orthotopic transplantation of cryopreserved ovarian tissue, are either experimental or have not been fully evaluated and thus can not be proposed to patients at this time.

\section{Basic oocyte biology}

In humans, primordial germ cells arrive in the gonadal ridge from the yolk sac endoderm by the 7th week of gestation. These germ cells become oogonia, which proliferate by mitosis before differentiating into primary oocytes. Some oogonia begin their transformation into primary oocytes and enter the first stages of meiosis at approximately 11-12 weeks of gestation. At 20 weeks gestation, the total germ cell number peaks at 6 to 7 million primordial follicles. Meiosis is arrested in Prophase I and only resumes around the time of ovulation. These arrested oocytes are referred to as primary oocytes. After this time, the rate of oogonial division declines. The postnatal germ cells do not undergo mitosis. This is contrary to spermatogenesis where mitosis occurs postnatally as well.

Primordial follicle formation begins around midgestation when a single flattened layer of granulosa cells surround each oocyte and continues until just after birth (2). After oocytes are surrounded within the primordial follicles, they remain arrested in the dictyate stage of meiosis I. From a peak of 6 to 7 million at 20 weeks gestation, the oocyte number falls dramatically so that at birth, only 300,000 to 400,000 remain $(2,3)$. The number of oocytes continues to fall throughout puberty so that only 200,000 follicles remain at puberty. 
The fate of each ovarian follicle is determined by endocrine, paracrine and autocrine factors (4). The follicles develop through primordial, primary and secondary stages before acquiring an antral cavity. Some books refer to antral follicles as tertiary follicles. By the antral stage, most follicles have already undergone atresia, and a few reach the preovulatory stage under the cyclic gonadotropin stimulation that occurs after puberty (4). The mature Graafian follicles are the main source of the cyclic secretion of ovarian estrogens in women of reproductive age. In response to preovulatory gonadotropin surges during each reproductive cycle, the dominant Graafian follicle ovulates to release the mature oocyte for fertilization, whereas the remaining theca and granulosa cells transform into the corpus luteum (5). The oocyte pool in the mammalian ovary becomes fixed early in life; thus, any factors affecting the follicular pool will lead to an early exhaustion and premature ovarian failure (POF).

Primordial follicles remain dormant under the continuous inhibitory influences of systemic and/or local origins (6). Acceleration of preantral and antral follicular growth depends on gonadotrophin stimulation. Follicle stimulating hormone (FSH) is capable of accelerating the development of preantral follicles. However, FSH and luteinizing hormone (LH) are unlikely to exert direct actions on primordial follicles because they have not yet developed functional gonadotropin receptors (7).

Many genes, proteins, hormones and factors are involved in the process of folliculogenesis. The most significant factors involved are summarized in Table 1 with their respective functions. Although follicles do not develop functional FSH receptors until the secondary stage, pregranulosa cells and primordial follicles respond to activators of the cAMP pathways by increasing expression of aromatase and FSH receptors (8). Factors involved in oocyte-granulosa cell communication in early follicles have also been proposed to have a role in initial recruitment. This interaction could also explain why if one cell dies due to cancer therapy or other causes, it leads to the death of the other.

The kit ligand is expressed by granulosa cells of growing follicles whereas c-kit, a tyrosine kinase receptor of the platelet-derived growth factor receptor family, is located on oocytes and theca cells. Mutations in mice that prevent the production of the soluble form of the kit ligand lead to failure of follicular growth beyond the primary stage. Mutations affecting the function of c-kit in humans, however, do not seem to affect female fertility (9).

The potential role of the oocyte in early follicle development was introduced by studies of a member of the transforming growth factor- $\beta$ (TGFß)/activin family called the growth differentiation factor-9 (GDF-9). It signals via serine-threonine kinase receptors and is produced by human oocytes (10) in primary and larger follicles but is absent in primordial follicles. In mutant mice, disruption of the GDF-9 gene prevents 
follicle development beyond the primary stage (11) and is associated with the absence of thecal cell markers and eventually oocyte death (12). Because kit ligand and GDF-9 are highly expressed in secondary follicles, they also are likely to play important roles in preantral follicle development. A homolog to GDF-9 called bone morphogenic protein BMP-15 (13) has also been identified, and it may exert similar functions. It is more than possible that multiple paracrine factors are involved in communication between oocyte and somatic cells during early follicle development.

A basic biological doctrine is that during the life of a female, there neither is nor can be any increase in the number of primary oocytes beyond those originally laid down when the ovary was formed. Although this dogma has persisted for more than 50 years, recent studies have shown that production of oocytes (oogenesis) in mice and their enclosure within somatic cells (folliculogenesis) persists in juvenile and adult life (14). Johnson and colleagues concluded that gonadal stem cells reside in the surface epithelium of mouse ovaries and are active throughout life (14). However, the same group modified this hypothesis by proposing that the bone marrow is a source of gonadal stem cells (15). This was done in response to several valuable critical comments $(16,17)$. However, many leading experts in the field of reproductive physiology expressed concerns about their second hypothesis regarding the putative role of bone marrow cells in reproduction (18). These hypotheses await independent confirmation.

Although these genes and their products provide insight into the growth process of very early follicles, the exact mechanisms by which the primordial follicles leave the resting pool remain unknown. With the secrets surrounding early folliculogenesis unraveling, new reproductive techniques could be developed. For instance, understanding the relationship between granulosa cells and oocytes could allow us to develop techniques that could put both cells in a dormant state at the time of sterilizing radiotherapy and or chemotherapy in order to limit the degree of damage. In addition, survival and long-term function of cryopreserved ovarian tissue necessitates resumption of all biological mechanisms involved in the initial and cyclic recruitment of follicles. Cryopreservation and thawing of ovarian tissue are associated with a significant loss of the growing cohort of follicles. Despite the fact that primordial follicles are the most resistant subtype to cryoinjury, 50-70\% of the follicular pool could be lost during the freeze-thawing and re-implantation steps. Better understanding of the basic follicular biology could help refine the currently available freezing and transplantation protocols to prevent the progressive loss of the primordial follicles. However, more studies are needed to reveal potential factors involved in the initial stage of follicle recruitment. 
Table 1. Regulatory genes of oogenesis and folliculogenesis

\begin{tabular}{|c|c|c|}
\hline Gene/proteins & Pattern of ovarian expression & Developmental role \\
\hline Bmp family & PGCs & Formation \\
\hline Smad family & & Migration \\
\hline SCf & & Proliferation \\
\hline C-kit & & Colonization of the forming gonads \\
\hline Integrin-B & & Survival \\
\hline Scp family & Meiotic prophase 1 oocytes & Preleptotene-DNA replication \\
\hline Mih family & & $\begin{array}{l}\text { Search and pairing of homologus } \\
\text { chromosomes and synapses }\end{array}$ \\
\hline \multirow[t]{2}{*}{ Msh family } & & $\begin{array}{l}\text { Crossing over, recombination and } \\
\text { DNA mismatch-repair }\end{array}$ \\
\hline & & Meiotic arrest \\
\hline Fig alpha & Primordial follicle & Maintenance of primordial follicles \\
\hline Nobox & Primary follicle & $\begin{array}{l}\text { Transition from the primordial and } \\
\text { primary follicle }\end{array}$ \\
\hline Connexins & Preantral follicles & Oocytes-granulosa cells interactions \\
\hline \multirow[t]{2}{*}{ Gdf9, Bmp 15} & & Granulosa cells proliferation \\
\hline & & Theca precursor formation \\
\hline FSH/FSHR & Antral/Graafian follicles & Antrum formation \\
\hline LH/LHR & & Follicular recruitment \\
\hline$E R-\alpha / \beta$ & & Pre-ovulatory changes \\
\hline PGE2, Cox2 & & Corpus luteum formation \\
\hline
\end{tabular}

PGCs, primordial germ cells; Bmp: Bone morphogenic protein; Smad: C.elegans gene Sma and Dorsophila gene mad; Scf: Stem cell factor; Scp; Synaptonemal complex protein; Mih \& Msh: mismatch recognition and repair proteins; FSH/FSHR: Follicle Stimulating hormone and receptor; LH/LHR; Luteinizing hormone and receptor; ER- $\alpha / \beta$ : Estrogen receptor alpha and beta; PGE2: prostaglandin E2 and Cyclo-oxygenase 2. 


\section{Chemotherapy/radiotherapy induced ovarian failure}

\section{A. Chemotherapy-induced POF}

Chemotherapy-induced POF has been documented in many publications (19). The exact incidence of POF following chemotherapy is difficult to establish since many factors contribute to ovarian failure. The most important factors are the patient's age at the time of treatment, the drug type and cumulative dose. The risk of gonadal damage increases with age. This is most likely due to the presence of only a few remaining oocytes. Cytotoxic chemotherapeutic agents are not equally gonadotoxic. Cell cycle non-specific chemotherapeutic agents are more gonadotoxic than cell cycle specific ones (Figure 1).

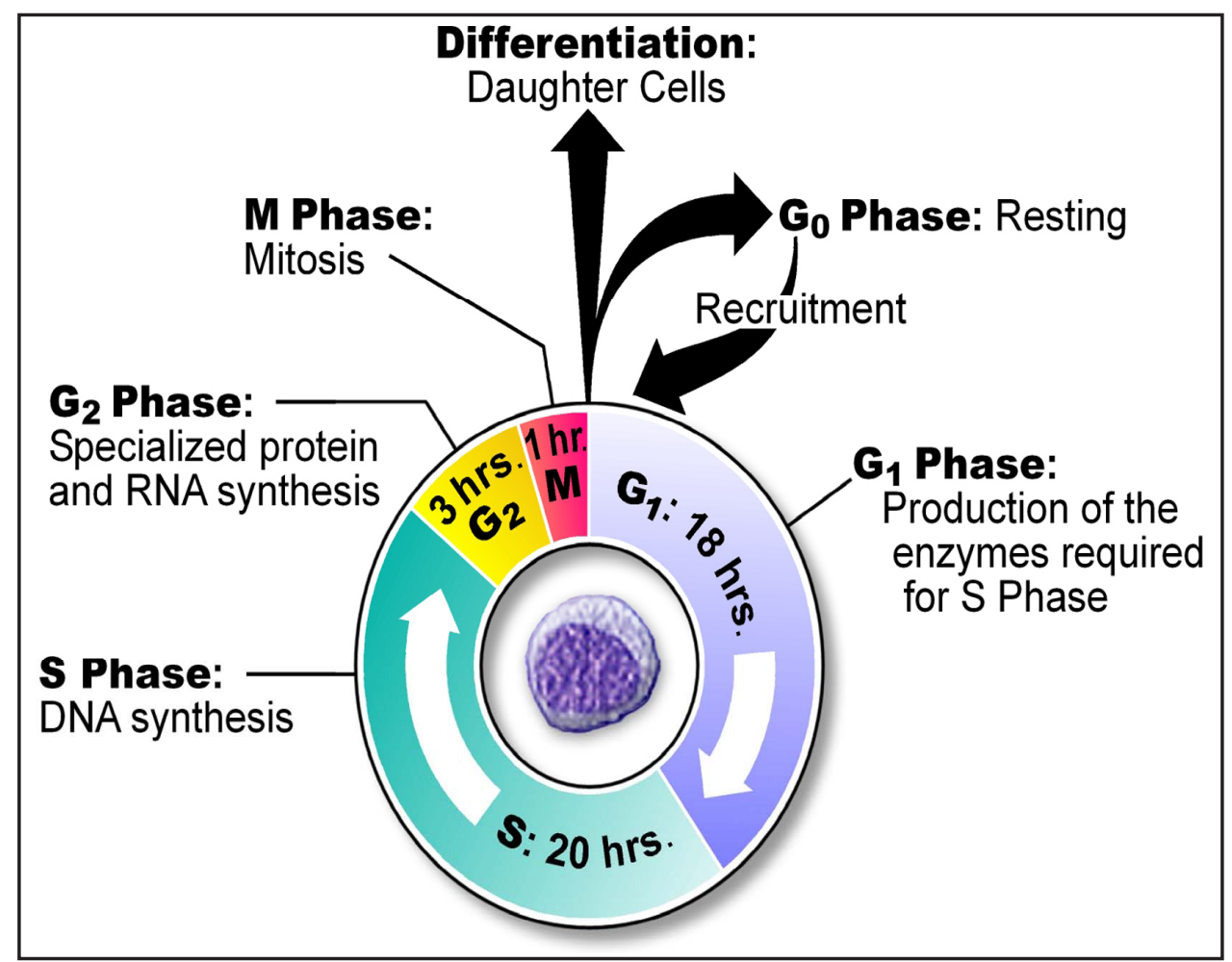

Figure 1: Schematic representation of the cell cycle. The relative gonadotoxicity and cell cycle specificity of the different chemotherapeutic agents are: Agents with phase specificity: M Phase: A- Podophyllotoxins as etoposide and teniposide. B- Taxanes as Docetaxel and Paclitaxel. C-Vinca Alkaloids as vinblastine, vincristine. G2 Phase: Bleomycin. S Phase: A- Antimetabolites as A-Anitfolates: methotrexate, Antipurines: mercaptopurine, thioguanine, B-Antinpyrimidines: cytarabine, fluorouracil, azacitidine and C-Miscellaneous: hydroxyurea, procarbazine, cisplatin and carboplatin.GO Phase: Nitrosoure as carmustine, lomustine, semustine. G1 Phase: Asparaginase as Diglycoaldehyde and Steroids. Agents without phase specificity: A- Alkylating Agents as bulsulfan, chlorambucil, cyclophosphamide, mechlorethamine, melphalan. BAnthracycline Antibiotics: doxorubicin, daunomycin, rubidazone,dactinomycin. C- Miscellaneous: DTIC, cisplatin, carboplatin and D- Nitrosoureas-also acts in GO Phase. 
Chemotherapeutic regimens that include a cell cycle non-specific alkylating agent are particularly gonadotoxic. Cyclophosphamide is the most gonadotoxic member of this category. It is commonly used in breast cancer treatment and consequently, it is the chemotherapeutic agent that most frequently induces ovarian failure. Manger et al., reported that in lupus patients treated with cyclophosphamide, $60 \%$ suffered from POF and hypergonadotropic amenorrhea. The POF rate was $<50 \%$ in women younger than 30 years of age and $60 \%$ in women between the ages of 30 and 40 years. The cumulative dose of cyclophosphamide also strongly influences the POF rate (19). Similar reports by many other investigators have documented the variable effects of different regimens on ovarian functions $(20,21)$.

Consequently, not all patients receiving multi-agent chemotherapy have the same risk for developing POF. Those at highest risk for POF after treatment for cancer include women who have received either high-dose alkylating agent therapy or pelvic or total body irradiation. Most young patients with Hodgkin's disease treated with multi-agent chemotherapy and radiation to a field that does not include the ovaries will remain fertile, albeit with a shorter window of fertility than age-matched controls (22). A recent case documented a spontaneous conception in a young woman with POF after 14 courses of ifosfamide chemotherapy combined with pelvic irradiation for Ewing's sarcoma of the pelvis (23).

\section{B. Radiotherapy-induced POF}

Pelvic radiotherapy can damage both the ovaries and uterus. Several reproductive age malignancies that affect pelvic organs can be cured with radiotherapy. These include cervical, vaginal and ano-rectal carcinomas, some germ cell tumors, Hodgkin's disease and central nervous system (CNS) tumors. Like chemotherapy, the degree and persistence of POF is related to the patient's age and the dose of radiation to the ovaries. The fractionation of the total dose plays an important role in determining the extent of ovarian damage because irradiation is more toxic when given as a single dose (24).

Two studies reported that the break point for radiation-induced ovarian failure is around 300 cGy to the ovaries. Only $11 \%-13 \%$ of women experienced ovarian failure below 300 cGy versus $60 \%-63 \%$ above that threshold value (25). The doses of radiation delivered to the ovaries with standard pelvic radiation therapy will uniformly induce ovarian failure. The addition of chemotherapy increases the risk of POF $(26,27)$. 
Ovarian follicles are remarkably vulnerable to DNA damage from ionizing radiation. Irradiation results in ovarian atrophy and reduced follicle stores (28). On the cellular level, oocytes show rapid onset of pyknosis, chromosome condensation, disruption of the nuclear envelope and cytoplasmic vaculization. Serum levels of FSH and LH rise progressively within 4-8 weeks following radiation exposure while serum E2 levels fall. A dose-dependant reduction in the primordial follicle pool was noted after ovaries were exposed to radiotherapy (29). It is estimated that $<2$ Gy is enough to destroy $50 \%$ of the oocyte population ( $\mathrm{LDL}_{50}<2 \mathrm{~Gy}$ ) (30).

\section{Diagnosis and Prediction of POF}

Prediction of POF in cancer survivors is not only of diagnostic importance but of prognostic value as well. So far, no ideal marker has been developed to predict chemotherapy/radiotherapy-induced POF. Bath et al., showed that serum FSH levels were elevated in cancer survivors with regular menstrual cycles while anti-Mullerian hormone $(\mathrm{AMH})$ levels were lower than those of the controls. Despite smaller ovarian volumes in cancer survivors than controls, the antral follicle count (AFC) was similar in both groups (31). In addition, cancer chemotherapy is associated with a transient suppression of inhibin B in prepubertal girls. Consequently, inhibin B, together with sensitive measurements of FSH, were proposed as a potential marker of the gonadotoxic effects of cancer chemotherapy in prepubertal girls (32). Basal AFC is another test of ovarian reserve that has been used extensively, either alone or with other markers.

Contrary to the majority of hormonal biomarkers that are dependent on the stage of the follicle development, specifically more mature stages, $\mathrm{AMH}$ is produced by the granulosa cells of a wide range of follicles from primary to the antral stages. Anti-Mullerian hormone seems to be independent of FSH, LH and inhibin levels and has been shown to have a stronger relationship with antral follicle counts than with other parameters. Given the fact that peripheral AMH concentrations decline during ovarian stimulation, growing follicles progressively lose their ability to produce $\mathrm{AMH}$. Accumulating evidence suggests that the measurement of $\mathrm{AMH}$ levels could be a quantitative and possibly qualitative marker of granulosa cell activity and health (33). It may also be a good marker of ovarian function in prepubertal girls undergoing sterilizing cancer therapy; no other markers are available for this group at risk.

\section{Indications of fertility preservation strategies}

Breast cancer is currently the most common malignancy in women of reproductive age that requires immediate fertility intervention (34). Fifteen per cent of all breast cancer cases are estimated to occur in women younger than 40 years of age (35). 
Cervical cancer is another common malignancy in women of reproductive age that may require fertility preserving intervention (36). The anatomic location renders fertility preservation even more challenging.

The list of indications for fertility preservation is expanding and currently includes gonadotoxic chemotherapy/radiotherapy not only for malignancies but also for the treatment of other systemic diseases as well including systemic lupus erythematosus, acute glomerulonephritis and Behcet's disease. In addition, a wide variety of cancer patients are candidates for fertility preservation including those with musculoskeletal cancers such as Ewing's sarcoma and osteosarcoma, hematopoietic cancers such as leukemias and lymphomas, neuroblastomas and Wilm's tumor. Chemotherapy in the context of bone marrow transplantation and umbilical cord stem cell transplantation could also be a possible indication as well. Patients with non-gynecologic cancers including colorectal carcinoma, lymphomas and sarcomas are candidates for fertility preservation as well.

\section{Fertility preservation options}

A wide variety of strategies have been assessed for fertility preservation. However, none of them has been tested in a prospective randomized controlled trial. Many of the available techniques are promising but are still highly experimental options.

\section{V.1 Chemo-protection}

Pre-treatment with a gonadotropin-releasing hormone $(\mathrm{GnRH})$ agonist has been attempted based on the observation that premenarchal female gonads appear to be less sensitive to cytotoxic drugs $(37,38)$. The goal is to keep the ovaries in a prepubertal quiescent state during chemotherapy treatment. This approach has also been tried with a variety of other medication that suppresses the hypothalamic pituitary ovarian axis. The few non-controlled observational studies that have been reported on this topic have produced conflicting conclusions regarding the effectiveness of this method.

Blumenfeld and colleagues reported on the largest group of females thus far (more than 90) who were exposed to both cytotoxic drugs and $\mathrm{GnRH}$-agonist. The rate of POF was $55 \%$ in the chemotherapy only group versus $5 \%$ in the GnRH-agonist/ chemotherapy group (39). However, the retrospective nature of the control group and the shorter follow-up in the group treated with the agonist makes the study less robust. Similar results were reported by Pereyra Pacheco (40) and Fox et al., (41). The only prospective controlled study showed that $\mathrm{GnRH}$ analogues were not effective in the prevention of POF. However, only 18 women were enrolled in this study (42). 
Criticism of this approach is also derived from the fact that if the mechanism of action is primarily through hypothalamic pituitary suppression, this should not protect against early follicle damage that is gonadotropin independent. However a direct gonadal effect is possible.

Given the poor evidence available, a prospective randomized study with sufficient power is needed to appropriately evaluate the effectiveness of $\mathrm{GnRH}$ agonist as a potential strategy for fertility preservation. However, this method is quite popular with patients and oncologists alike. Patients find it simple to initiate, which allows them to focus their energy on their lifesaving medical treatment. Oncologists can proceed to medical therapy without delay versus having to postpone treatment in cases where patients choose assisted reproductive technology. Suppressive therapy with a variety of other agents such as oral contraceptives or progestins has not been shown to be effective in preventing damage from chemotherapy or radiation therapy.

\section{V.2 Ovariopexy}

Moving the ovaries out of the field of irradiation can help maintain ovarian function in patients scheduled to undergo gonadotoxic radiotherapy. This significantly reduces ovarian radiation exposure in patients who receive pelvic irradiation such as those with Hodgkin's disease or genitourinary or low intestinal malignancies. For instance, the ovarian dose following transposition is reduced to approximately $5 \%$ $10 \%$ of the in situ ovaries (43). The dose to each transposed ovary is 126 cGy for intracavitary radiation, 135 - 190 cGy for external radiation therapy when the initial dose is 4500 cGy and 230-310 cGy with the addition of para-aortic node irradiation (4500 cGy) (44).

The initial experience with medial transposition, which was accomplished by suturing the ovaries posterior to the uterus and shielding them during treatment, showed that it was generally ineffective. Lateral transposition appears to be more effective $(45,46)$.

Lateral ovarian transposition is typically performed by laparotomy. This approach is used at the time of radical hysterectomy for cervical cancer and was used during staging laparotomy for Hodgkin's disease (47). Staging laparotomy for Hodgkin's is uncommon today. Ovarian transposition should be performed laparoscopically just prior to the initiation of radiation therapy. An important advantage of laparoscopic ovarian transposition is that radiation therapy can be initiated immediately after surgery; this helps prevent POF in ovaries that migrate back to the irradiation field $(27,48,49)$. In cases of vaginal or cervical cancers being treated by brachytherapy, laparoscopic ovarian transposition can be performed under the same anesthetic that is used for inserting the brachytherapy device (50). 
Since staging laparotomy and splenectomy are no longer required for Stage I and II Hodgkin's disease, ovarian transposition can be performed laparoscopically as an outpatient procedure, leading to a more rapid recovery, less discomfort, better cosmesis and lower cost. Nearly all women with Stage I and II Hodgkin's disease treated with radiation alone or with minimal chemotherapy following laparoscopic ovarian transposition retain their ovarian function and fertility (27).

Ovarian failure may occur if the ovaries are not moved far enough out of the radiation field or if they migrate back to their original position. The latter situation may occur if absorbable sutures are used. Ovarian failure following transposition may also occur if the ovarian vessels were compromised by the surgical technique or if radiation injured the vascular pedicle (51). Another concern with ovarian transposition is the development of symptomatic ovarian cysts. Why the cysts develop is not known, but they can be suppressed with oral contraceptives (52).

\section{V.3 Assisted Reproductive technologies}

Assisted reproductive technology is probably the most used modality in patients who wish to preserve their fertility.

\section{V.3.a Oocyte cryopreservation}

In women without a partner, freezing mature or immature oocytes may be the only practical option. The main factor that may influence the outcome in oocyte cryopreservation is the structural complexity. Oocyte subcellular organelles are far more complex--and perhaps more sensitive to thermal injury — than preimplantation embryos $(53,54)$. Porcu and colleagues cryopreserved the oocytes of 18 patients awaiting chemotherapy and radiotherapy for neoplastic disease. They found that the duration of oocyte storage did not seem to interfere with oocyte survival, as pregnancies occurred even after several years of gamete cryopreservation in liquid nitrogen (55). Pregnancy rates per vitrified-thawed oocyte are still quite low.

Given recent laboratory modifications resulting in improved oocyte survival, oocyte fertilization and pregnancy rates from frozen-thawed oocytes in in vitro fertilization (IVF), the practice committee of the ASRM has recently evaluated current evidence. They concluded that despite the limited number of established pregnancies and deliveries resulting from cryopreserved oocytes, no increase in chromosomal abnormalities, birth defects or developmental deficits have been noted in children born from cryopreserved oocytes to date. Therefore, they recommend that the option of oocyte cryopreservation should be considered as an experimental technique only to be performed under investigational protocol under the auspices of an internal review 
board (56). Oocyte cryopreservation can be used as an adjunct to conventional IVF and as an option for fertile women as well as those at risk of loosing their fertility.

Recent reports indicate that pregnancy rates are getting better, whether slowfreeze or vitrification methods are used (57). Larger prospective trials are needed to determine the efficacy and the long-term safety of oocyte cryopreservation. Until a sufficient number of births are reached and adequate outcome data are collected, oocyte cryopreservation should continue to be considered experimental and to be performed under the oversight of an institutional review board (58).

\section{V.3.b Embryo cryopreservation}

Embryo cryopreservation is the only fertility preservation option recommended by the ASRM. It is probably the most efficient technique that offers a reasonable opportunity for success for women who have a partner and can undergo ovarian stimulation regimens for IVF. According to Society for assisted reproduction technology (SART)(59), the delivery rate per embryo transfer utilizing cryopreserved embryos is $31.8 \%$ for those younger than the age of 35 years. The post-thaw survival rate of embryos ranges between $35 \%$ and $90 \%$. Implantation rates between $8 \%$ and $30 \%$ have been reported, and cumulative pregnancy rates can reach $>60 \%(60,61)$. This is the option with the best outcome for the patient. However, it may not be acceptable to prepubertal and adolescent females and women without a partner. If this option is acceptable to the patient, long-term data are available about the outcome of children born from these procedures that demonstrate developmental safety of the offspring.

The use of IVF may be problematic for patients with estrogen-sensitive tumors such as breast cancer because it results in extremely high estradiol levels. Typically, there is an interval of 6 weeks between the surgery and initiation of chemotherapy for breast cancer. Rather than using the standard protocol, a short flare protocol is used, which usually requires less time to achieve follicle recruitment (62). Conventional controlled ovarian stimulation (COS) is associated with a significant rise in serum estrogen, which might affect the overall prognosis (63). For this reason, some centers offer natural cycle (unstimulated) IVF. With this process, a single oocyte is aspirated. However, cancellation rates are high, and pregnancy rates are very low $(7.2 \%$ per cycle and $15.8 \%$ per embryo transfer) $(64,65)$. The non-steroidal anti-estrogen, tamoxifen, (65) and the aromatase P450 inhibitor, letrozole, (66) were introduced as possible ovulation induction agents for patients with breast cancer.

Oktay and associates compared tamoxifen and letrozole for ovarian stimulation in breast cancer patients using a prospective controlled study design. They noted that when combined with low-dose FSH; both drugs have a better outcome than when 
tamoxifen is used alone. However, letrozole is preferred because it is associated with lower peak serum estradiol levels (66). Further evidence on the safety and success of ovarian stimulation with letrozole and tamoxifen in breast cancer patients undergoing IVF to cryopreserve their embryos for fertility preservation was provided by Oktay and his associates. The cancer recurrence rates were similar between those who underwent COS and those who did not (67).

\section{V.3.c Cryopreservation and transplantation of ovarian tissue}

Ovarian tissue cryopreservation and transplantation are other experimental procedures for preserving fertility in women with threatened reproductive functions. The concept is related to the principle of autotransplantation rather than transplantation between two genetically distinct humans. For this reason, cryopreservation of ovarian tissue is a critical component so that the extirpated germ cells can be replaced after completion of medical therapy for their primary medical disorder requiring gonadotoxic drugs. Patients who undergo autotransplantation do not require immunosuppressant medication whereas transplantation of reproductive organs between genetically distinct humans would necessitate use of such medication long term.

Because cryopreservation of germ cells is an integral part of the potential autotransplantation procedure, it is expected that better survival will occur from primordial follicles in ovarian cortical strips because of their smaller size and lack of follicular fluid (68). Animal models have provided useful information regarding ovarian tissue cryopreservation and transplantation protocols. Using sheep ovaries, which provides a reliable tool, Gosden and associates established the sheep model for ovarian tissue cryopreservation and transplantation. Using cryopreserved-thawed ovarian cortical strips, they showed follicular survival and endocrine function as well as pregnancy and delivery after transplantation of cryopreserved-thawed ovarian cortical strips $(69,70)$.

\section{Transplantation: Prevention of ischemic damage}

The limited longevity of ovarian function in some human ovarian transplant cases using non-vascularized grafts may be partially due to the initial ischemic injury (7173). Immediate revascularization and ischemia time reduction may be essential for prolonging the functions of the grafts (74).

Almodin and associates proposed a technique to minimize ischemic damage in which frozen-thawed fragments of one ovary are injected into the cortex of the remaining sterile ovary. They administered radiotherapy to ewes to induce infertility on the remaining ovary while the fragments of the other ovary were frozen. Subsequently, 
the thawed fragments of the frozen ovary were injected inside the cortex of the irradiated remaining ovary in a "sowing" procedure that eliminated the need for sutures. Six months following the grafting, they used rams to impregnate the ewes. They concluded that intracortical grafting of the germinative tissue could prevent ischemic damage (75).

Another approach to preventing initial ischemic damage to oocytes is transplantation into angiogenic granulation tissue created during wound healing. This approach shortened the ischemic period by 24 hours and significantly increased the pool of healthy primordial follicles and the perfused area of the transplanted grafts. The authors were able to detect functional blood vessels within the grafts as early as 2 days after transplantation. They were also able to demonstrate the functionality of the graft (76).

\section{Human trials: limited graft longevity}

All human trials of cryopreserved autotransplanted tissue have used cortical strips. This concept was developed from previous work in animal models that have used cryopreserved-thawed ovarian cortical strips and reported follicular survival and endocrine function as well as restoration of fertility after transplantation of cryopreserved-thawed ovarian cortical strips $(69,70)$.

There are several potential uses of cryopreserved ovarian tissue: transplantation back into the host, in vitro maturation of primordial follicles and xenografting into a host animal. The potential for reintroduction of a cancer nidus may limit its use in malignancies that are known to have a predilection for the ovaries such as leukemias and potentially breast cancer. Using present techniques, ovarian tissue strips are removed from the patient prior to chemotherapy. They are frozen in small strips. When the patient is ready for pregnancy, they are transplanted back into the patient in a heterotopic or orthotopic site. Since this is an avascular graft, ischemic injury to the transplanted tissue results in the loss of virtually the entire growing follicle population and a significant number of primordial follicles.

Oktay and associates developed 3 different surgical techniques for ovarian cortical strips transplantation: orthotopic transplant into the pelvis and heterotopic transplant into the arm or abdominal wall. The orthotopic transplant ceased to function within the first 9 months (77) whereas the heterotopic transplant resulted in the generation of a 4-cell embryo that was transferred, but no pregnancy occurred (78). This one embryo was obtained after multiple cycles of ovarian stimulation.

More recently, a 32-year-old Belgian woman gave birth to a healthy baby 7 years after banking her ovarian tissue before starting chemotherapy for Hodgkin's lymphoma. Although she became infertile as a result of the chemotherapy, re-implantation of her 
ovarian tissue re-started ovulation 5 months later. She became pregnant 11 months after re-transplantation by natural fertilization. This is the first case of a human live birth after successful orthotopic autotransplantation of cryopreserved ovarian tissue in a patient from whom tissue was collected and cryopreserved before chemotherapy was initiated (79).

Another pregnancy was reported after a modified IVF cycle following orthotopic autotransplantation of cryopreserved-thawed ovarian cortical strips in a woman with non-Hodgkin's lymphoma (80). The fact that the tissue was transplanted to the native ovary does not exclude the possibility of resumption of native ovarian functions. With increasing reports of documented spontaneous pregnancies in women with POF after prolonged courses of gonadotoxic chemotherapy/radiotherapy, one should be cautious about the exact site of origin of the oocytes that led to both pregnancies in the aforementioned reports (23).

One of the potential limitations of ovarian tissue cryopreservation and transplantation is loss of a large fraction of follicles during the initial ischemia after transplantation. Previous work indicated that whereas the loss due to freezing is relatively small $(70,81,82)$, up to two-thirds of follicles are lost after transplantation. Given this limitation, it has been recommended that ovarian tissue freezing (77) should be restricted to patients $<35$ years of age.

Research should focus on refining the cryopreservation and transplantation protocols to nullify the destructive effect of ischemic injury on follicular viability. The use of vascularized grafts is a promising option in this regard (83-85). Selection of the transplantation site should consider an easy, simple and minimally invasive surgical approach to transplantation. Moreover, ample blood supply to the recipient site is important for graft establishment, survival and long-term function.

\section{Ovarian transplantation from one person to another}

Silber et al have reported ovarian transplantation between monozygotic 24-yearold twins who presented with discordant ovarian function. One had developed POF at the age of 14 years, whereas her sister had normal ovaries and three children that had been conceived naturally. The sterile twin received a transplant of ovarian cortical tissue from her sister by means of a minilaparotomy. Within three months after transplantation, the recipient's cycles resumed and serum gonadotropin levels fell to the normal range. During the second cycle, she conceived, and her pregnancy progressed uneventfully. At 38 weeks' gestation, she delivered a healthy appearing female infant (86). More recently, the same group reported on ovarian cortex transplantation in a cohort of 7 sets of twins discordant for POF. Ovarian cortical 
tissue was transplanted from the twin with normal ovarian functions to her sister with POF. Folliculogenesis, hormonal functions and menses were restored in all recipients. In addition, 5 spontaneous pregnancies were documented in this cohort (87).

This work should be seen as proof that transplantation of large segments of ovarian tissue can be successful. In cases of identical twins, no immunosuppressive drugs are necessary. A recent report in the media (newscientist.com) by Silber et al also has shown that transplantation into a genetically different person is possible. In that case, the patient had received a bone marrow transplant from her sister before a whole ovary transplant. In this way, she may avoid the need for long-term immunosuppressive medication. The possibility of acute graft rejection and risks of long-term immunosuppressive complications in the mother such as infection and obstetrical complications may limit its use.

Given the fact that ovarian function has been documented in a small number of cases following both orthotopic and heterotopic transplantation of thawed ovarian cortical strips, the ASRM practice committee recommended that ovarian tissue cryopreservation or transplantation procedures can be performed, but only as experimental procedures under the guidelines of an internal review board (56).

In the context of a multi-organ procurement surgery that took place in approximately 150 bodies, nine uteri were retrieved. Del Priore performed multi-organ harvesting that included the uterus without complications. Pedicles used included the ovarian, uterine, or internal iliac vessels. After retrieval, serial histology sections throughout the period of cold ischemia, taken every 15-30 minutes, showed no signs of change over 12 hours of cold ischemia. They concluded that the human uterus can be obtained from local organ donor networks using existing protocols (88). However, research for human uterus transplantation is in its infancy. Numerous methodological and technical aspects should be solved before this option could be considered.

\section{Problem}

Ovarian tissue cryopreservation and autotransplantation are viable options for restoring reproductive functions of female cancer survivors. One of the potential limitations of ovarian tissue cryopreservation and transplantation is loss of a large number of follicles during the initial ischemia after transplantation. Up to two-thirds of follicles are lost after transplantation. This loss is unlikely to be caused by freezing and subsequent thawing and more likely by post-transplantation ischemia. In mammals and humans, there are limited unsubstantiated models for cryopreservation of larger ovarian tissue pieces and intact ovaries with their vascular pedicles followed by subsequent transplantation using microvascular anastomosis. 


\section{Hypothesis}

Reducing the ischemia time and immediate revascularization using microvascular anastomosis determines the success of autotransplantation of fresh and cryopreservedthawed ovarian tissue.

\section{Objectives}

To test the hypothesis the following objectives were formulated:

1. To evaluate the impact of tissue size and the processing time interval before cryopreservation (warm ischemia time) on follicular survival.

2. To investigate the effect of ischemia time on the expression of $\mathrm{Bcl}-2$ and p53 proteins on freshly-fixed and cryopreserved-thawed ovarian tissue.

3. To test the feasibility of transplanting an entire ovary with anastomosis of the ovarian vascular pedicle.

4. To determine the feasibility of transplanting an intact frozen-thawed ovary with microvascular anastomosis of the ovarian vascular pedicle to the deep inferior epigastric vessels.

5. To examine whether orthotopic transplantation of a cryopreserved ovary or ovarian cortical strips can result in antibody formation against ovarian tissue antigens.

6. To assess the immediate post-thawing injury to the human ovary that was cryopreserved either as a whole with its vascular pedicle or as ovarian cortical strips.

7. To describe the different surgical approaches involved in the harvesting and the heterotopic autotransplantation of intact ovaries with microvascular anastomosis.

8. To evaluate the reproductive outcome after transplantation of ovarian tissue (OTT) for fertility preservation in women at high risk of premature ovarian failure (POF). 


\section{References}

1. Green DM, Whitton JA, Stovall M, Mertens AC, Donaldson SS, Ruymann FB, Pendergrass TW, et al. Pregnancy outcome of female survivors of childhood cancer: a report from the Childhood Cancer Survivor Study. Am J Obstet Gynecol 2002;187: 1070-1080.

2. Block E. A quantitative morphological investigation of the follicular system in newborn female infants. Acta Anat (Basel) 1953;17:201-206.

3. Forabosco A, Sforza C, De Pol A, Vizzotto L, Marzona L, Ferrario VF. Morphometric study of the human neonatal ovary. Anat Rec 1991;231:201-208.

4. Gougeon A. Regulation of ovarian follicular development in primates: facts and hypotheses. Endocr Rev 1996;17:121-155.

5. Fauser BC, Van Heusden AM. Manipulation of human ovarian function: physiological concepts and clinical consequences. Endocr Rev 1997;18:71-106.

6. Wandji SA, Srsen V, Voss AK, Eppig JJ, Fortune JE. Initiation in vitro of growth of bovine primordial follicles. Biol Reprod 1996;55:942-948.

7. Oktay K, Briggs D, Gosden RG. Ontogeny of follicle-stimulating hormone receptor gene expression in isolated human ovarian follicles. J Clin Endocrinol Metab 1997; 82:3748-3751.

8. Ahmed CE, Dees WL, Ojeda SR. The immature rat ovary is innervated by vasoactive intestinal peptide (VIP)-containing fibers and responds to VIP with steroid secretion. Endocrinology 1986;118:1682-1689.

9. Ezoe K, Holmes SA, Ho L, Bennett CP, Bolognia JL, Brueton L, Burn J, et al. Novel mutations and deletions of the KIT (steel factor receptor) gene in human piebaldism. Am J Hum Genet 1995;56:58-66.

10. Elvin JA, Clark AT, Wang P, Wolfman NM, Matzuk MM. Paracrine actions of growth differentiation factor-9 in the mammalian ovary. Mol Endocrinol 1999;13:1035-1048.

11. Dong J, Albertini DF, Nishimori K, Kumar TR, Lu N, Matzuk MM. Growth differentiation factor-9 is required during early ovarian folliculogenesis. Nature 1996;383:531-535.

12. Elvin JA, Yan C, Wang P, Nishimori K, Matzuk MM. Molecular characterization of the follicle defects in the growth differentiation factor 9-deficient ovary. Mol Endocrinol 1999;13:1018-1034.

13. Dube JL, Wang P, Elvin J, Lyons KM, Celeste AJ, Matzuk MM. The bone morphogenetic protein 15 gene is X-linked and expressed in oocytes. Mol Endocrinol 1998;12:1809-1817.

14. Johnson J, Canning J, Kaneko T, Pru JK, Tilly JL. Germline stem cells and follicular renewal in the postnatal mammalian ovary. Nature 2004;428:145-150.

15. Johnson J, Bagley J, Skaznik-Wikiel M, Lee HJ, Adams GB, Niikura Y, Tschudy KS, et al.Oocyte generation in adult mammalian ovaries by putative germ cells in bone marrow and peripheral blood. Cell 2005;122:303-315.

16. Gosden RG. Germline stem cells in the postnatal ovary: is the ovary more like a testis? Hum Reprod Update 2004;10:193-195.

17. Telfer EE. Germline stem cells in the postnatal mammalian ovary: a phenomenon of prosimian primates and mice? Reprod Biol Endocrinol 2004;2:24.

18. Telfer EE, Gosden RG, Byskov AG, Spears N, Albertini D, Andersen CY, Anderson R, et al. On regenerating the ovary and generating controversy. Cell 2005;122:821-822.

19. Manger K, Wildt L, Kalden JR, Manger B. Prevention of gonadal toxicity and preservation of gonadal function and fertility in young women with systemic lupusery the matosus treated by cyclophosphamide: the PREGO-Study. Autoimmun Rev 2006;5:269-272. 
20. Schilsky RL, Sherins RJ, Hubbard SM, Wesley MN, Young RC, DeVita VT. Long-term follow up of ovarian function in women treated with MOPP chemotherapy for Hodgkin's disease. Am J Med 1981;71:552-556.

21. Blumenfeld Z, Avivi I, Linn S, Epelbaum R, Ben-Shahar M, Haim N. Prevention of irreversible chemotherapy-induced ovarian damage in young women with lymphoma by a gonadotrophin-releasing hormone agonist in parallel to chemotherapy. Hum Reprod 1996;11:1620-1626.

22. BFS. MWGcbt. A strategy for fertility setvices for survivors of childhood cancer. Hum Fertil 2003;6:A1-40.

23. Bath LE, Tydeman G, Critchley HO, Anderson RA, Baird DT, Wallace WH. Spontaneous conception in a young woman who had ovarian cortical tissue cryopre served before chemotherapy and radiotherapy for a Ewing's sarcoma of the pelvis: case report. Hum Reprod 2004;19:2569-2572.

24. Meirow $D$, Nugent $D$. The effects of radiotherapy and chemotherapy on female reproduction. Hum Reprod Update 2001;7:535-543.

25. Husseinzadeh N, Nahhas WA, Velkley DE, Whitney CW, Mortel R. The preservation of ovarian function in young women undergoing pelvic radiation therapy. Gynecol Oncol 1984;18:373-379.

26. Gaetini A, De Simone M, Urgesi A, Levis A, Resegotti A, Ragona R, Anglesio S. Lateral high abdominal ovariopexy: an original surgical technique for protection of the ovaries during curative radiotherapy for Hodgkin's disease. J Surg Oncol 1988;39:22-28.

27. Williams RS, Littell RD, Mendenhall NP. Laparoscopic oophoropexy and ovarian function in the treatment of Hodgkin disease. Cancer 1999;86:2138-2142.

28. Meirow D, Schenker JG, Rosler A. Ovarian hyperstimulation syndrome with low oestradiol in non-classical 17 alpha-hydroxylase, 17,20-lyase deficiency: what is the role of oestrogens? Hum Reprod 1996;11:2119-2121.

29. Gosden RG, Wade JC, Fraser HM, Sandow J, Faddy MJ. Impact of congenital or experimental hypogonadotrophism on the radiation sensitivity of the mouse ovary. Hum Reprod 1997;12:2483-2488.

30. Wallace WH, Thomson AB, Kelsey TW. The radiosensitivity of the human oocyte. Hum Reprod 2003;18:117-121.

31. Bath LE, Wallace WH, Shaw MP, Fitzpatrick C, Anderson RA. Depletion of ovarian reserve in young women after treatment for cancer in childhood: detection by antiMullerian hormone, inhibin B and ovarian ultrasound. Hum Reprod 2003; 18:2368-2374.

32. Crofton PM, Thomson AB, Evans AE, Groome NP, Bath LE, Kelnar CJ, Wallace WH. Is inhibin $B$ a potential marker of gonadotoxicity in prepubertal children treated for cancer? Clin Endocrinol (Oxf) 2003;58:296-301.

33. Feyereisen E, Mendez Lozano DH, Taieb J, Hesters L, Frydman R, Fanchin R. Anti-Mullerian hormone: clinical insights into a promising biomarker of ovarian follicular status. Reprod Biomed Online 2006;12:695-703.

34. Weir HK, Thun MJ, Hankey BF, Ries LA, Howe HL, Wingo PA, Jemal A, et al. Annual report to the nation on the status of cancer, 1975-2000, featuring the uses of surveillance data for cancer prevention and control. J Natl Cancer Inst 2003;95: 1276-1299.

35. Jemal A, Murray T, Samuels A, Ghafoor A, Ward E, Thun MJ. Cancer statistics, 2003. CA Cancer J Clin 2003;53:5-26.

36. Waggoner SE. Cervical cancer. Lancet 2003;361:2217-2225. 
37. Chiarelli AM, Marrett LD, Darlington G. Early menopause and infertility in females after treatment for childhood cancer diagnosed in 1964-1988 in Ontario, Canada. Am J Epidemiol 1999;150:245-254.

38. Tangir J, Zelterman D, Ma W, Schwartz PE. Reproductive function after conservative surgery and chemotherapy for malignant germ cell tumors of the ovary. Obstet Gynecol 2003;101:251-257.

39. Blumenfeld Z, Dann E, Avivi I, Epelbaum R, Rowe JM. Fertility after treatment for Hodgkin's disease. Ann Oncol 2002;13:138-147.

40. Pereyra Pacheco B, Mendez Ribas JM, Milone G, Fernandez I, Kvicala R, Mila T, Di Noto A, et al. Use of GnRH analogs for functional protection of the ovary and preservation of fertility during cancer treatment in adolescents: a preliminary report. Gynecol Oncol 2001;81:391-397.

41. Fox K, Ball J, Mik R, Moore H. Prevention of chemotherapy-associated amenorrhea (CRA) with leuprolide in young women with early stage breast cancer (Abstract). Proc Ann Soc Clin Oncol 2001:25a.

42. Waxman JH, Ahmed R, Smith D, Wrigley PF, Gregory W, Shalet S, Crowther D, et al. Failure to preserve fertility in patients with Hodgkin's disease. Cancer Chemother Pharmacol 1987;19:159-162.

43. Howell SJ, Shalet SM. Fertility preservation and management of gonadal failure associated with lymphoma therapy. Curr Oncol Rep 2002;4:443-452.

44. Covens AL, van der Putten HW, Fyles AW, Leung PM, O'Brien PF, Murphy KJ, DePetrillo AD. Laparoscopic ovarian transposition. Eur J Gynaecol Oncol 1996; 17:177-182.

45. Hadar H, Loven D, Herskovitz P, Bairey O, Yagoda A, Levavi H. An evaluation of lateral and medial transposition of the ovaries out of radiation fields. Cancer 1994; 74:774-779.

46. Howard FM. Laparoscopic lateral ovarian transposition before radiation treatment of Hodgkin disease. J Am Assoc Gynecol Laparosc 1997;4:601-604.

47. Anderson B, LaPolla J, Turner D, Chapman G, Buller R. Ovarian transposition in cervical cancer. Gynecol Oncol 1993;49:206-214.

48. Treissman MJ, Miller D, McComb PF. Laparoscopic lateral ovarian transposition. Fertil Steril 1996;65:1229-1231.

49. Yarali H, Demirol A, Bukulmez O, Coskun F, Gurgan T. Laparoscopic high lateral transposition of both ovaries before pelvic irradiation. J Am Assoc Gynecol Laparosc 2000;7:237-239.

50. Clough KB, Goffinet F, Labib A, Renolleau C, Campana F, de la Rochefordiere A, Durand JC. Laparoscopic unilateral ovarian transposition prior to irradiation: prospective study of 20 cases. Cancer 1996;77:2638-2645.

51. Feeney DD, Moore DH, Look KY, Stehman FB, Sutton GP. The fate of the ovaries after radical hysterectomy and ovarian transposition. Gynecol Oncol 1995;56:3-7.

52. Chambers SK, Chambers JT, Holm C, Peschel RE, Schwartz PE. Sequelae of lateral ovarian transposition in unirradiated cervical cancer patients. Gynecol Oncol 1990;39: 155-159.

53. Magistrini M, Szollosi D. Effects of cold and of isopropyl-N-phenylcarbamate on the second meiotic spindle of mouse oocytes. Eur J Cell Biol 1980;22:699-707.

54. Stachecki JJ, Cohen J, Willadsen S. Detrimental effects of sodium during mouse oocyte cryopreservation. Biol Reprod 1998;59:395-400.

55. Porcu E, Fabbri R, Damiano G, Fratto R, Giunchi S, Venturoli S. Oocyte cryopreservation in oncological patients. Eur J Obstet Gynecol Reprod Biol 2004;113 Suppl 1:S14-16.

56. ASRM-Guidelines. Ovarian tissue and oocyte cryopreservation. Fertil Steril 2004;82: 993-998. 
57. Oktay K, Cil AP, Bang H. Efficiency of oocyte cryopreservation: a meta-analysis. Fertil Steril 2006;86:70-80.

58. Jain JK, Paulson RJ. Oocyte cryopreservation. Fertil Steril 2006;86 Suppl 4:1037-1046.

59. SART-ASRM. Assisted reproductive technology in the United States: 1998 results generated from the American Society for Reproductive Medicine/Society for Assisted Reproductive Technology Registry. Fertil Steril 2002;77:18-31.

60. Wang JX, Yap YY, Matthews CD. Frozen-thawed embryo transfer: influence of clinical factors on implantation rate and risk of multiple conception. Hum Reprod 2001;16: 2316-2319.

61. Son WY, Yoon SH, Yoon HJ, Lee SM, Lim JH. Pregnancy outcome following transfer of human blastocysts vitrified on electron microscopy grids after induced collapse of the blastocoele. Hum Reprod 2003;18:137-139.

62. Meniru GI, Craft I. In vitro fertilization and embryo cryopreservation prior to hysterectomy for cervical cancer. Int J Gynaecol Obstet 1997;56:69-70.

63. Pena JE, Chang PL, Chan LK, Zeitoun K, Thornton MH, 2nd, Sauer MV. Supraphysiological estradiol levels do not affect oocyte and embryo quality in oocyte donation cycles. Hum Reprod 2002;17:83-87.

64. Pelinck MJ, Hoek A, Simons AH, Heineman MJ. Efficacy of natural cycle IVF: a review of the literature. Hum Reprod Update 2002;8:129-139.

65. Oktay K, Buyuk E, Davis O, Yermakova I, Veeck L, Rosenwaks Z. Fertility preservation in breast cancer patients: IVF and embryo cryopreservation after ovarian stimulation with tamoxifen. Hum Reprod 2003;18:90-95.

66. Oktay K, Buyuk E, Akar Z, Rosenwaks N, Libertella N. Fertility Preservation in breast cancer patients: A prospective controlled comparison of ovarian stimulation with tamoxifen and letrozole for embryo cryopreservation. Fertil Steril 2004;82:s1 (Abstract).

67. Oktay K. Further evidence on the safety and success of ovarian stimulation with letrozole and tamoxifen in breast cancer patients undergoing in vitro fertilization to cryopreserve their embryos for fertility preservation. J Clin Oncol 2005;23:3858-3859.

68. Mazur P. The role of intracellular freezing in the death of cells cooled at supraoptimal rates. Cryobiology 1977;14:251-272.

69. Gosden RG, Baird DT, Wade JC, Webb R. Restoration of fertility to oophorectomized sheep by ovarian autografts stored at -196 degrees C. Hum Reprod 1994;9:597-603.

70. Baird DT, Webb R, Campbell BK, Harkness LM, Gosden RG. Long-term ovarian function in sheep after ovariectomy and transplantation of autografts stored at $-196 \mathrm{C}$. Endocrinology 1999;140:462-471.

71. Oktay K, Aydin BA, Karlikaya G. A technique for laparoscopic transplantation of frozen-banked ovarian tissue. Fertil Steril 2001;75:1212-1216.

72. Oktay K, Economos K, Kan M, Rucinski J, Veeck L, Rosenwaks Z. Endocrine function and oocyte retrieval after autologous transplantation of ovarian cortical strips to the forearm. Jama 2001;286:1490-1493.

73. Radford JA, Lieberman BA, Brison DR, Smith AR, Critchlow JD, Russell SA, Watson AJ, et al. Orthotopic reimplantation of cryopreserved ovarian cortical strips after high-dose chemotherapy for Hodgkin's lymphoma. Lancet 2001;357:1172-1175.

74. Aubard Y, Piver P, Cogni Y, Fermeaux V, Poulin N, Driancourt MA. Orthotopic and heterotopic autografts of frozen-thawed ovarian cortex in sheep. Hum Reprod 1999;14:2149-2154.

75. Almodin CG, Minguetti-Camara VC, Meister H, Ceschin AP, Kriger E, Ferreira JO. Recovery of natural fertility after grafting of cryopreserved germinative tissue in ewes subjected to radiotherapy. Fertil Steril 2004;81:160-164. 
76. Israely T, Nevo N, Harmelin A, Neeman M, Tsafriri A. Reducing ischaemic damage in rodent ovarian xenografts transplanted into granulation tissue. Hum Reprod 2006;21:1368-1379.

77. Sonmezer M, Oktay K. Fertility preservation in female patients. Hum Reprod Update 2004;10:251-266.

78. Oktay K, Buyuk E, Veeck L, Zaninovic N, Xu K, Takeuchi T, Opsahl M, et al. Embryo development after heterotopic transplantation of cryopreserved ovarian tissue. Lancet 2004;363:837-840.

79. Donnez J, Dolmans MM, Demylle D, Jadoul P, Pirard C, Squifflet J, Martinez-Madrid $B$, et al. Livebirth after orthotopic transplantation of cryopreserved ovarian tissue. Lancet 2004;364:1405-1410.

80. Meirow D, Levron J, Eldar-Geva T, Hardan I, Fridman E, Zalel Y, Schiff E, et al. Pregnancy after transplantation of cryopreserved ovarian tissue in a patient with ovarian failure after chemotherapy. N Engl J Med 2005;353:318-321.

81. Oktay K, Nugent D, Newton H, Salha O, Chatterjee P, Gosden RG. Isolation and characterization of primordial follicles from fresh and cryopreserved human ovarian tissue. Fertil Steril 1997;67:481-486.

82. Aubard Y. Ovarian tissue graft: from animal experiment to practice in the human. Eur J Obstet Gynecol Reprod Biol 1999;86:1-3.

83. Wang $X$, Chen $H$, Yin H, Kim SS, Lin Tan S, Gosden RG. Fertility after intact ovary transplantation. Nature 2002;415:385.

84. Jeremias E, Bedaiwy MA, Gurunluoglu R, Biscotti CV, Siemionow M, Falcone T. Heterotopic autotransplantation of the ovary with microvascular anastomosis: a novel surgical technique. Fertil Steril 2002;77:1278-1282.

85. Bedaiwy MA, Jeremias E, Gurunluoglu R, Hussein MR, Siemianow M, Biscotti C, Falcone T. Restoration of ovarian function after autotransplantation of intact frozenthawed sheep ovaries with microvascular anastomosis. Fertil Steril 2003;79:594-602.

86. Silber SJ, Lenahan KM, Levine DJ, Pineda JA, Gorman KS, Friez MJ, Crawford EC, et al. Ovarian transplantation between monozygotic twins discordant for premature ovarian failure. N Engl J Med 2005;353:58-63.

87. Silber SJ, Gosden RG. Ovarian transplantation in a series of monozygotic twins discordant for ovarian failure. N Engl J Med 2007;356:1382-1384.

88. Del Priore G, Stega J, Sieunarine K, Ungar L, Smith JR. Human uterus retrieval from a multi-organ donor. Obstet Gynecol 2007;109:101-104. 




\title{
Chapter 2
}

\author{
Assessment of tissue \\ injury in cryopreserved \\ ovarian tissue
}

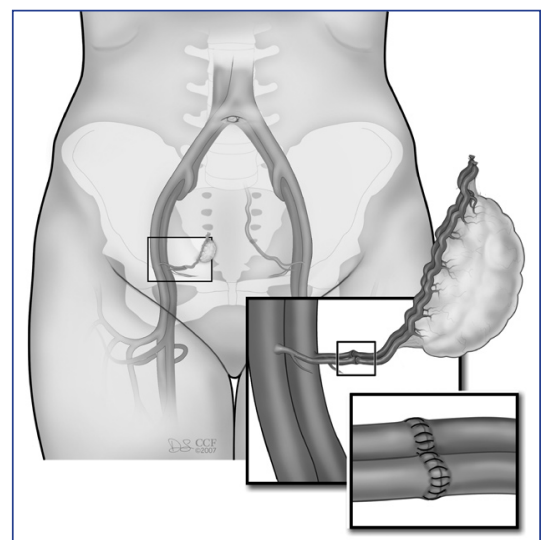

Elisabeth Jeremias, Mohamed A Bedaiwy, David Nelson. Charles V Biscotti, Tommaso Falcone

Fertility Sterility, 2003; 79(3):651-3 


\section{Abstract}

Objectives: Recent reports on ovarian auto-transplantation and interim cryopreservation have raised many hopes and expectations for women facing premature ovarian failure. However, little is known about optimizing procedure sequencing and the additional effects mechanical or ischemic injuries may have on ovarian tissue processed for cryopreservation. The objectives of this study were to evaluate the impact of tissue size and the processing time interval before cryopreservation (warm ischemia time) on follicular survival.

Design: Eight non-pregnant, adult, female farm pigs were utilized for this study. The bilateral oophorectomy was performed at the Cleveland Clinic Foundation Biological Resources Unit in accordance with their standard operating procedures.

Materials and Methods: Bilateral oophorectomy was performed in eight sows. The harvested ovaries were divided into five segments and subjected to assigned time intervals in warm ischemia $(1,5,10,20$ and $30 \mathrm{~min})$, after which one part was immediately fixed for pathohistological evaluation (F) and the other cryopreserved according to standard protocol and after thawing evaluated in the same fashion (C). For all samples a $1 \mathrm{~mm}$ thick cortical layer was obtained. Within the cryopreservation group one sample measuring $1-2 \mathrm{~mm} 2(\mathrm{C}-\mathrm{S})$ and a $5 \mathrm{~mm} 2$ section $(\mathrm{C}-\mathrm{I})$ were taken and compared.

Results: Although some histological features of the cryopreserved samples were not as well preserved, with the follicles displaying some degree of dyshesion and disorganization, overall the changes did not amount to significant autolysis or cell injury. The number of primordial follicles per high magnification field were significantly reduced in the cryopreserved group ( $C: 4.9 \pm 5.3$ vs. F: $7.2 \pm 5.4, p=0.03$ ), however, stratifying the cryopreserved group according to size showed a significant higher follicle count for larger tissue sections (C-I: $9.3 \pm 6.5$ vs. C-s: $2.1 \pm 2.4, p=0.002$ ). The number of primordial follicles was not significantly changed when comparing cryopreserved tissue segments measuring $5 \mathrm{~mm} 2$ to sections which were fixed without cryopreservation (C-I: $9.3 \pm 6.5$ vs. F: $7.2 \pm 5.4$, NS). Changes in the percentage of primary and secondary follicles were not significant. The time factor had no additional effect on any of the described changes in the cryopreserved group, nor did increasing exposure to warm ischemia (up to $30 \mathrm{~min}$ ) result in significant damage to the freshly fixed samples.

Conclusions: Handling larger ovarian cortical pieces facilitates cryopreservation as well as autotransplantation procedures. Our results show that cryopreserved pieces measuring $5 \mathrm{~mm} 2$ maintain more of their histological features compared to smaller 
pieces subject to more mechanical damage. Although the cryopreserved ovarian tissue displayed subtle histological changes, these did not amount to significant cell injury. Processing time up to 30 minutes will not have significant damaging effects on the ovarian tissue.

Key words: ovarian tissue, cryopreservation, ischemia. 


\section{Introduction}

Ovarian tissue banking is a developing technique aimed to preserve fertility in women at risk for premature ovarian failure (1-3). It entails cryopreservation of ovarian tissue with the option of autografting. Reports on the autografting of cryopreserved ovarian cortex segments describe the resumption of steroid production (4), follicle development $(5,6)$, and (in sheep) model successful pregnancies $(7,8)$. However, tissue loss due to procedural steps is expected to have detrimental effects on the reproductive potential of frozen-thawed ovarian grafts. We conducted a study in a porcine model to investigate how freezing and thawing affects ovarian tissue and whether warm ischemia time before the cryopreservation process has any added detrimental effects.

\section{Materials and Methods}

\section{Animals:}

Bilateral oophorectomy was performed in eight adult, non pregnant sows at the Cleveland Clinic Foundation Biological Resources Unit in accordance with the clinic's standard operating procedures. The animals were cared for according to the standards of the U.S. Public Health Policy of the Humane Care and Use of Laboratory Animals and the study was approved by the institutional review board.

\section{Ovarian tissue preparation:}

The harvested ovaries were divided into five segments and subjected to assigned time intervals of warm ischemia at $21^{\circ} \mathrm{C}(1,5,10,20$, and 30 minutes $)$. At each interval one part was fixed for histologic study (freshly fixed group) and the other section was cryopreserved (cryopreserved group). For all samples a 1-mm thick cortical layer was obtained. To compare the effects of tissue size on the outcome, within the cryopreservation group one sample measuring $1-2 \times 1 \times 1 \mathrm{~mm} 2$ and a section measuring $5 \times 1 \times 1 \mathrm{~mm} 2$ were taken and compared. In the freshly fixed group, all samples measured $1-2 \times 1 \times 1 \mathrm{~mm} 2$ and were used for reference.

\section{Ovarian tissue cryopreservation:}

Porcine ovarian cortical fragments measuring $1-2 \times 1 \times 1 \mathrm{~mm} 2$ and $5 \times 1 \times$ $1 \mathrm{~mm} 2$ were transferred into cryovials (Nalgene; New York, NY) containing $1 \mathrm{~mL}$ of Leibovitz L-15 medium (Sigma Chemical Co. Ltd.; St Louis, MO), 10\% calf serum, and 1.5 M DMSO (dimethylsulfoxide) (Sigma) and kept on ice for 30 minutes. The cryovials were placed into cryocanes and cryosleeves and kept in a freezer at $-20{ }^{\circ} \mathrm{C}$ for 30 minutes. Subsequently they were placed into a receptacle with the vials on top 
and inserted into a SM43 liquid nitrogen vapor tank for an additional 30 minutes. Then they were flipped by submerging the specimens into liquid nitrogen for 3-week storage at $-196^{\circ} \mathrm{C}$.

\section{Ovarian tissue thawing and histological evaluation:}

The specimens were then removed and held at room temperature for 1 minute. The tissue was thawed in a water bath within 2 minutes. The thawed tissue was transferred to Petri dishes for three washes with Leibovitz L-15 medium and subsequently fixed in Bouin's solution, paraffin-embedded, and stained with hematoxylin and eosin for histological evaluation.The tissue was assessed by primordial follicle count per high magnification field, presence of primary and secondary follicles, and signs of autolysis.

\section{Statistical analysis:}

Repeated measures analysis of variance (ANOVA) were used to simultaneously examine the role of method of preservation, time, and left vs. right side with follicle number, while controlling for multiple use of each animal. From the ANOVA tests, examination of significance at each time point was performed with Student's t-test. The sample size had $90 \%$ power to detect an overall difference of two or more follicles between the cryopreserved and fresh methods. $\mathrm{P}<.05$ was considered statistically significant.

\section{Results}

In the cryopreserved group, the follicles displayed some degree of dyshesion and disorganization; however, overall changes did not amount to substantial autolysis or cell injury. As compared to the freshly fixed group, in cryopreserved samples the number of primordial follicles per high magnification field was significantly reduced $(4.9 \pm$ 5.3 vs. $7.2 \pm 5.4, P=.03$ ). However, when the cryopreserved samples were stratified according to specimen size, there was no statistically significant difference between the follicle count in the larger tissue sections $(5 \times 1 \times 1 \mathrm{~mm} 3)$ and the freshly fixed group ( $9.3 \pm 6.5$ vs. $7.2 \pm 5.4, P=.87$, Figure 1 ). The follicle count in the $1 \times 1 \times 1$ mm3 cryopreserved group displayed significantly fewer follicles per high magnification field than the larger samples $(2.1 \pm 2.4$ vs. $9.3 \pm 6.5, P=.002)$.

Changes in the percentage of primary and secondary follicles were not statistically significant. Warm ischemia time had no additional effect on any of the described changes in either group (see figure 1 ). 


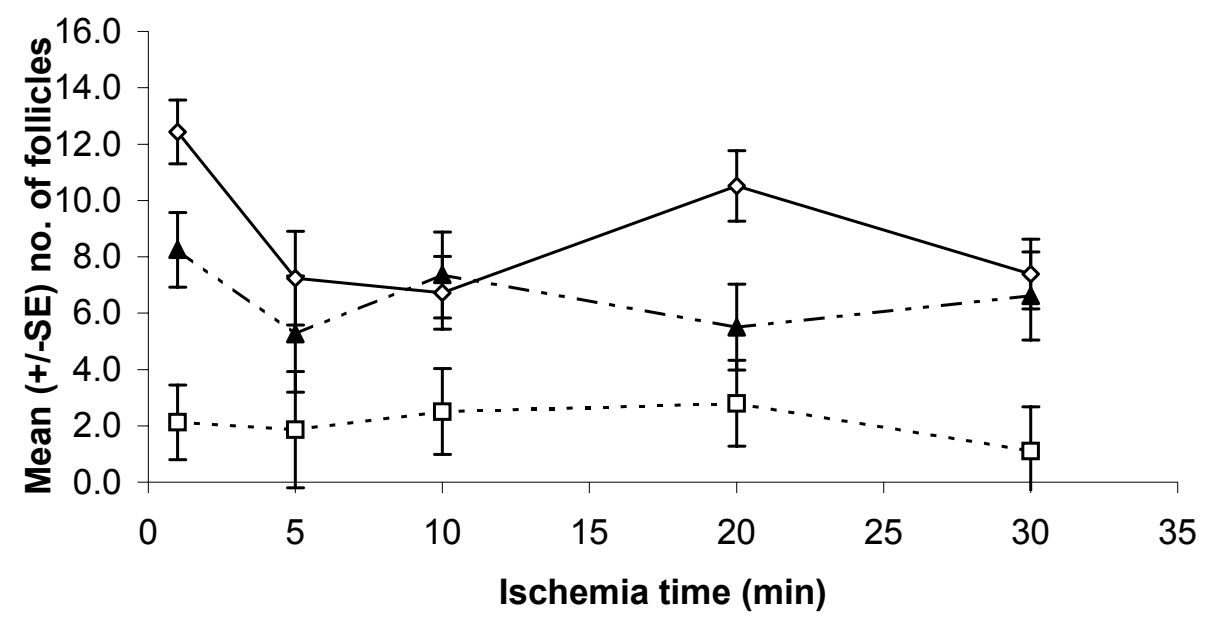

$\multimap$ Cryo-5mm2 - - - - Cryo-1mm2 - - - Fixed

Figure 1: Number of primordial follicles in cryopreserved and freshly fixed ovarian tissue.

\section{Disscusion}

Ovarian tissue banking and autografting of ovarian cortical segments are promising treatment options for premature ovarian failure (9). Ovarian cortical tissue has to be grafted to allow the follicles to mature in vivo. Grafting procedures include autografts, xenografts, and allografts in heterotopic and orthotopic locations (10-14). To ensure long-term function of the grafts, sources of tissue injury during each procedural step must be identified and minimized. Although the resumption of steroid production and follicle development have been described in frozen-thawed ovarian grafts $(4,6)$, tissue damage is significant and jeopardizes in particular long-term fecundity.

Frozen-thawed ovaries have given rise to pregnancies in several reports on multiple species documenting the potential of cryopreservation and autografting procedures; however, even in such successful cases the tissue loss is substantial. Human trials have also demonstrated significant tissue loss and poor oocyte quality with no reported pregnancy. We found that exposure to warm ischemia for up to 30 minutes was tolerable. The freezing and thawing methods applied in this study did not add any significant damage to the tissue, and our data indicated that preserving larger pieces ( $5 \mathrm{~mm} 2$ ) is preferable. Investigating follicle counts and function of fresh ovarian grafts compared to frozen-thawed heterotopic grafts in ewes. Aubard et al. (5) concluded that the key factor for follicle survival and resumption of ovulation was the postgrafting ischemia time. 
Thus, the future of ovarian transplantation will depend on minimizing postgrafting ischemia time. Recent reports from studies on mice ovaries also confirmed that with shorter ischemia times more tissue survives $(15,16)$. This can be most effectively achieved by transplanting ovarian segments with preserved vasculature and immediate revascularization by vascular anastomosis (17). The cryopreservation of larger ovarian segments requires an adapted protocol that is based on cryoperfusion rather than passive diffusion $(18,19)$. These techniques are developing and may offer more effective ways for long-term tissue preservation in the future.

In summary, although optimizing the procedural steps involved in cryopreservation and thawing of ovarian tissue will improve the tissue survival rate, procedures before grafting, including cryopreservation, account for relatively little tissue injury in ovarian grafts. 
Chapter 2

\section{Acknowledgment}

The first and the second author contributed equally to this study. This study was financially supported by internal funding from the Research Programs Council (RPC) of the Research Institute and the Minimally Invasive Surgery Center at the Cleveland Clinic Foundation (RPC number 6558). 


\section{References}

1. Meirow D., "Ovarian injury and modern options to preserve fertility in female cancer patients treated with high dose radio-chemotherapy for hemato-oncological neoplasias and other cancers", Leuk Lymphoma, Volume: 33, (1999), 65-76.

2. Dobson R., "Ovarian transplant raises hope for women facing cancer treatment", BMI, Volume: 319, (1999), 871.

3. Donnez J., Bassil S., "Indications for cryopreservation of ovarian tissue", Hum Reprod Update, Volume: 4, (1998), 248-259

4. Salle B., Lornage J., Demirci B., Vaudoyer F., Poirel M.T., Franck M., et al. "Restoration of ovarian steroid secretion and histologic assessment after freezing, thawing, and autograft of a hemi-ovary in sheep", Fertil Steril, Volume: 72, (1999), 366-370.

5. Aubard Y., Piver P., Cogni Y., Fermeaux V., Poulin N., Driancourt M.A., "Orthotopic and heterotopic autografts of frozen-thawed ovarian cortex in sheep", Hum Reprod, Volume: 14, (1999), 2149-2154.

6. Baird D.T., Webb R., Campbell B.K., Harkness L.M., Gosden R.G., "Long-term ovarian function in sheep after ovariectomy and transplantation of autografts stored at -196 C", Endocrinology, Volume: 140, (1999), 462-471.

7. Gosden R.G., Baird D.T., Wade J.C., Webb R., "Restoration of fertility to oophorectomized sheep by ovarian autografts stored at -196 degrees C", Hum Reprod, Volume: 9, (1994), 597-603.

8. Salle B, Demirci B, Franck M, Rudigoz RC, Guerin JF, Lornage J. Normal pregnancies and live births after autograft of frozen-thawed hemi-ovaries into ewes. Fertil Steril 2002; 77:403-408.

9. Picton H.M., Kim S.S., Gosden R.G., "Cryopreservation of gonadal tissue and cells", Br Med Bull, Volume: 56, (2000), 603-615.

10. Weissman A., Gotlieb L., Colgan T., Jurisicova A., Greenblatt E.M., Casper R.F., "Preliminary experience with subcutaneous human ovarian cortex transplantation in the NOD-SCID mouse", Biol Reprod, Volume: 60, (1999), 1462-1467.

11. Horvath E., Kovacs K., Garg B.D., Tuchweber B., "Ultrastructure of the rat ovary transplanted into the spleen", Gynecol Invest, Volume: 4, (1973), 73-83.

12. Nisolle M., Casanas-Roux F., Qu J., Motta P., Donnez J., "Histologic and ultrastructural evaluation of fresh and frozen-thawed human ovarian xenografts in nude mice", Fertil Steril, Volume: 74, (2000), 122-129.

13. Oktay K., Economos K., Kan M., Rucinski J., Veeck L., Rosenwaks Z., "Endocrine function and oocyte retrieval after autologous transplantation of ovarian cortical strips to the forearm", JAMA, Volume: 286, (2001), 1490-149.

14. Gosden R.G., Boulton M.I., Grant K., Webb R., "Follicular development from ovarian xenografts in SCID mice", J Reprod Fertil, Volume: 101, (1994), 619-623.

15. Cleary M., Snow M., Paris M., Shaw J., Cox S.L., Jenkin G., "Cryopreservation of mouse ovarian tissue following prolonged exposure to an ischemic environment", Cryobiology, Volume: 42, (2001), 121-133.

16. Snow M., Cleary M., Cox S.L., Shaw J., Paris M., Jenkin G., "Comparison of the effects of in vitro and in situ storage on the viability of mouse ovarian tissue collected after death", Reprod Fertil Dev, Volume: 13, (2001), 389-394.

17. Jeremias E., Bedaiwy M.A., Gurunluoglu R., Biscotti C.V., Siemionow M., Falcone T., "Novel surgical technique for ovarian autotransplantation", Fertil Steril, Volume: 77, (2002), 1278-1282.

18. Bedaiwy M.A., Jeremias E., Gurunluoglu R., Miller K.F., Harasaki H., Falcone T., "Cryoperfusion protocol for the long-term preservation of an entire ovary", Fertil Steril, Volume: 76, (2001), S79.

19. Wang X., Chen H., Yin H., Kim S.S., Lin Tan S., Gosden R.G., "Fertility after intact ovary transplantation", Nature, Volume: 415, (2002), 385 . 



\section{Chapter 3}

Analysis of apoptotic cell death, Bcl-2, and p53 protein expression in freshly fixed and cryopreserved ovarian tissue after exposure to warm ischemia

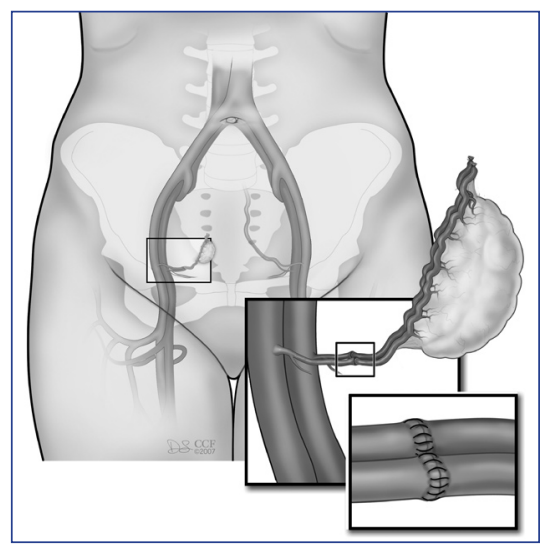

Mahmoud R Hussein, Mohamed A Bedaiwy, Tommaso Falcone.

Fertility Sterility, 2006; 85 Suppl 1:1082-92. 


\section{Abstract}

Objectives: Ischemia is associated with alteration of the survival (Bcl-2) and apoptotic (p53) molecules. The objective of this study was to evaluate the effect of ischemia time on the expression of $\mathrm{Bcl}-2$ and p53 proteins on freshly-fixed and cryopreservedthawed ovarian tissue.

Design: Experimental study using porcine animal model.

Setting: Biological Resources Unit, Cleveland Clinic Foundation.

Interventions: Bilateral oophorectomy was performed in eight sows and the ovaries were subjected to time-dependent $(1,10,20$ and $30 \mathrm{~min}$ ) warm ischemia (room temperature). Each specimen was divided into 2 parts, one was fixed as a fresh tissue (freshly-fixed) and the other was subjected to cryopreservation, thawing and fixation (cryopreserved).

Main outcome Measures: Apoptosis (TUNEL assay) and Bcl-2, p53 protein expression (immunoperoxidase method) were assessed.

Results: At 1, 10, 20, 30 min. of warm ischemia, the apoptotic indices were statistically: 1$)$ significantly higher in the atretic $(1.36 \pm 0.20,1.59 \pm 0.20,1.67 \pm$ $0.22,1.67 \pm 0.24)$ than in the non-atretic follicles $(0.69 \pm 0.06,0.69 \pm 0.06,0.76$ $\pm 0.06,0.71 \pm 0.06, p<0.05), 2)$ no significant differences between freshly-fixed and cryopreserved tissues and 3) non significant rise of apoptotic indices with the increased duration of ischemia. Bcl-2 expression was seen in the granulosa, but not in the theca cells, of most of the healthy and occasional atretic follicles. P53 expression was seen only in few atretic follicles. Increased duration of ischemia was associated with insignificant incremental rise of the number of follicles with $\mathrm{Bcl}-2$ expression $(1.82 \pm 0.30,2.01 \pm 0.44,2.02 \pm 0.35,2.05 \pm 0.42$, for healthy follicles at 1,10 , 20 , and 30 min, respectively, $p=0.99$ ).

Conclusions: 1) apoptosis is involved in follicular atresia 2) Bcl-2 is induced by warm ischemia and 3) cryopreservation insult does not alter the apoptotic signals with short tissue preparation time.

Key words: ovarian tissue, cryopreservation, Bcl-2, p53. 


\section{Introduction}

The structural homeostasis of tissues is regulated by a delicate balance between cell survival and apoptotic cell death. Apoptosis is a genetically determined, biologically meaningful and active choice of death. In tissues, several molecules share to live (survival or anti-apoptotic molecules) or to die (apoptotic or anti-survival molecules) decisions. The survival molecules include several proteins such as Bcl-2. The Bcl-2 gene is a survival molecule identified through its involvement in B-cell lymphomas. It is a membrane-associated protein that resides in the nuclear envelope and mitochondria. It exerts its survival functions by modulating the mitochondrial release of cytochrome $\mathrm{c}$ and antagonizing the effects of Bax gene (Bcl-2 Associated $\mathrm{X}$ ). $\mathrm{Bcl}-2$ is expressed in granulosa cells of both fetal and adult ovaries. Its expression is found in all components of the human fetal ovaries (19-33 gastational weeks) to overcome extensive apoptotic activity (1-3).

P53 gene is a transcription factor that maintains genomic integrity either by inducing cell cycle arrest or apoptosis. Also, it is a stress response gene that encodes a $53 \mathrm{kDa}$ oncosuppressive nuclear protein with a Mr of 53,000. The p53 protein exists as a tetramer that accumulates in the cytoplasm during the G1 (Gap1) phase and migrates to the nucleus at the start of the $S$ (Synthesis) phase. It functions through antagonizing the effects of Bcl-2. Moreover, p53 can induce apoptotic cell death by the activation of Bax gene, which encodes an apoptosis-inducing factor. In the ovary, p53 protein is expressed in the apoptotic granulosa cells of atretic follicles (3-5).

During ovarian cryopreservation and subsequent transplantation, ovarian tissues are subjected to ischemic injury throughout the procedure. This ischemia is associated with induction of $\mathrm{Bcl}-2$ (within $30 \mathrm{~min}$ ) and p53 (within $60 \mathrm{~min}$ ) protein expression in several organs such as the heart (6), liver (7), and brain (8). The induction of these molecules may have far-reaching effects on the outcome of the subsequent ovarian transplantation. In the present study, we hypothesized that ischemic injury of the ovary is associated with altered expression of the survival and apoptotic molecules. To examine this hypothesis, we carried out this investigation using fresh and cryopreserved-thawed sows ovarian tissue subjected to time-dependent warm ischemia (1,10,20 and $30 \mathrm{~min})$. The rational behind using sows ovaries stems from the fact that both the human and porcine ovaries have relatively similar ovarian dynamics and mechanisms of apoptosis (3).

\section{Materials and methods}

Tissue specimens: Bilateral oophorectomy was performed in eight non-pregnant adult 
sows at the Cleveland Clinic Foundation Biological Resources Unit in accordance with their standard operating procedures and with the approval of the Animal Review Committee. Institutional Review Board (IRB) approval was obtained. The harvested ovaries were divided into five segments and subjected to warm ischemia intervals (the time between devascularization of the specimen at room temperature and its cryopreservation, for the cryopreserved group, or fresh fixation, for the freshly-fixed group) of $1,10,20$ and 30 minutes.

The ovaries were sectioned as follows: 1) for both groups, samples of a $1 \mathrm{~mm} 2$ thick cortex layer were obtained; 2) for the freshly-fixed group, samples measuring 1-2 mm2 were obtained; and 3) for cryopreserved group, one sample measuring 1-2 $\mathrm{mm} 2$ and another $5 \mathrm{~mm} 2$ sections were obtained (9).

Cryopreservation: Ovarian tissue fragments measuring 1-2mm2 and a $5 \mathrm{~mm} 2$ were transferred into cryovials (Nalgene; New York, NY) containing $1 \mathrm{~mL}$ of Leibovitz L-15 medium (Sigma Chemical Co. Ltd.; St Louis, MO) supplemented with $10 \%$ calf serum and 1.5M DMSO (dimethylsulfoxide) (Sigma) and were kept on ice at $5{ }^{\circ} \mathrm{C}$ for 30 minutes. The cryovials were then placed into cryocanes, cryosleeves and kept in a freezer at $-20{ }^{\circ} \mathrm{C}$ for 30 minutes. Subsequently, the cryocanes were placed into a receptacle and inserted into a SM43 liquid nitrogen vapor tank for an additional 30 minutes (9).

Thawing: After three weeks of storage at $-196{ }^{\circ} \mathrm{C}$, the specimens were removed and held at room temperature for one minute. The tissue was thawed in a water bath at $21{ }^{\circ} \mathrm{C}$ within two minutes and transferred to petri dishes, washed three times with fresh Leibovitz L-15 medium (Sigma) at $10{ }^{\circ} \mathrm{C}$ for 30 minutes and finally incubated at $37^{\circ} \mathrm{C}$ for 30 minutes (9).

Histological evaluation of follicular health and atresia: The specimens were evaluated for follicular health or atresia and therefore the follicles were categorized into two groups; healthy and atretic following the established morphological criteria. The healthy follicles were those with intact membrana granulosa and few pyknotic nuclei ( $<5 \%$ pyknotic nuclei), in this layer. Alternatively, atretic follicles were evident with their attenuated membrana granulosa; loosely attached granulosa cells and increased number of pyknotic nuclei (> 5\% pyknotic nuclei) (10).

Histological evaluation of apoptosis: Hematoxylin and eosin sections were examined in all specimens. Histological evaluation of apoptosis followed the established criteria reported in the original paper by Kerr and his colleagues. They include cytoplasmic vacuolization, chromatin condensation as well as the appearance of eosinophilic apoptotic bodies as round cytoplasmic masses or as masses of pyknotic chromatin surrounded by a narrow rim of the cytoplasm (11). 
DNA fragmentation assay for detection of apoptotic cells: To evaluate the apoptotic response in the sows' ovarian tissue, we applied terminal deoxynucleotidyl transferase (TdT)-mediated dUTP-digoxigenin nick-end labeling (TUNEL assay) technique using the commercially available QIA33TDT-FragELTM kits (Oncogen Research products, Boston, MA 02118, USA). Briefly, sections ( 4-5 um) mounted on glass slides were deparaffinized, rehydrated through graded alcohols to water, treated with $20 \mu \mathrm{g} /$ $\mathrm{ml}$ proteinase $\mathrm{K}$ ( $37^{\circ} \mathrm{C}, 20 \mathrm{~min}$ ) and then washed in $1 \mathrm{X}$ Tris buffer. Endogenous peroxidase activity was blocked with $3 \% \mathrm{H} 202$ in methanol. Sections were then rinsed in $1 \mathrm{X}$ Tris buffer and covered with $5 \mathrm{X}$ TdT Equilibration buffers at $37^{\circ} \mathrm{C}$ for 30 min. The buffer was blotted from the slides and TdT labeling reaction mixtures $(57.0 \mu \mathrm{l}$ TdT labeling solution and $3.0 \mu \mathrm{l}$ TdT Enzyme) was added at $37^{\circ} \mathrm{C}$ for 1.5 hours.

The reaction was terminated by rinsing in $1 \mathrm{X}$ Tris buffer and covering the sections with $100 \mu \mathrm{l}$ stop solution for $5 \mathrm{~min}$. Then the sections were incubated with blocking buffer and 50X conjugate solution for 10 and 30 min respectively. The slides were rinsed in $1 X$ Tris buffer and the entire specimen was covered with DAB solution for $15 \mathrm{~min}$. The nuclei were counterstained with $5 \%$ methyl green and the sections were treated with $100 \%$ ethanol, cleared in xylene and covered (12).

Positive and negative controls: Positive controls were obtained from manufacturer, by using formaldehyde-fixed, paraffin embedded sections from HL60 promylocytic leukemia cells and HL60 cells incubated with $0.5 \mu \mathrm{g} / \mathrm{ml}$ actinomycin D for 19 hours to induce apoptosis. Some ovarian tissue specimens were used as negative controls by substituting microliter of distilled water for deoxynucleotidyl transferase from protocol.

Evaluation of DNA fragmentation (TUNEL assay): Initially, following other groups (12), the results of TUNEL assay were evaluated according to the signal intensity as follows: absent $(-, 0.0)$; weak, $(+, 1)$; moderate, $(++, 2)$ and intense, $(+++$, 3). Then, all slides were examined at 400X magnification. Positively labeled cells were counted in defined visual field. Ten different areas of each follicular wall were examined and mean number of positively stained cells was determined.

Immunohistochemical analysis: Sections mounted on glass slides were deparaffinized and rehydrated through graded alcohols to water. Endogenous peroxidase activity was blocked with $0.6 \% \mathrm{H} 202$. Sections were then immersed in the retrieval solution (10 $\mathrm{mM}$ sodium citrate buffer, $\mathrm{pH}$ 6.0) and subjected to heat-induced antigen retrieval for 20 minutes. The slides, in plastic Coplin jars containing retrieval solution, were microwaved in a microwave set at high ( 750 watts) for 4 cycles of 5 minutes duration each. Non-specific protein binding was blocked with 10 minutes exposure to $10 \%$ normal goat serum. 
Sections were then incubated with monoclonal antibodies for 30 minutes at 37 ${ }^{\circ} \mathrm{C}$. A catalyzed signal amplification system (K1500, DAKO) was used according to the manufacturer instructions. Sections were next treated with peroxidase-labeled streptavidin for 30 minutes at $37{ }^{\circ} \mathrm{C}$ and incubated with 14-diaminobenzidine and $0.06 \%$ $\mathrm{H} 202$ for 5 minutes. They were counterstained with hematoxylin, dehydrated in alcohol, cleared in xylene and covered. Two observers (blinded) independently evaluated the slides.

Negative controls: Additional sections, running in parallel but with omission of the primary antibodies, served as the negative controls.

Positive controls: Specimens used as positive controls consisted of spleen (for Bcl-2) and squamous cell carcinoma (for p53). To evaluate the p53 staining, we adopted the following strategy: 1) two observers (blinded) independently evaluated the stained slides and 2) the presence of cells with clear and unequivocal nuclear staining identified positive cases. We adopted this scoring system because nuclear rather than the cytoplasmic staining is usually indicative of associated underlying p53 gene mutations.

Evaluation of p53 and Bcl-2 staining: For every designated time interval, a total of 80 segments were analyzed on the immunohistological level. In each segment, a total of 20 follicles (primordial, primary, secondary and atretic follicles, five each) were assessed. The numbers of follicles with positive and negative reactivity were counted in the ovarian tissues. The presence of cells with clear and unequivocal nuclear staining identified p53 positive cells. Alternatively, expression of Bcl-2 proteins was identified as diffuse golden yellow cytoplasmic staining.

Photography: All photographs were taken using an Olympus C35AD-4 camera attached to Olympus AHBT3 microscope.

Statistical analysis: Repeated measures analysis of variance (ANOVA) was used to simultaneously examine the effects of preservation method, ischemia time, and left versus right side on TUNEL, Bcl-2 and p53 staining signals, while controlling for multiple use of each animal. Examination of significance at each time interval was performed with Student's T-Test resulting from the ANOVA tests. Results were considered significant at $p<0.05$ with two-tailed tests. Computations were performed with SAS version 8.1 Software (SAS Institute Inc, Cary, NC).

\section{Results}

\section{Histological evaluation:}

Granulosa cells with features of apoptosis were observed in atretic follicles either within the central region of membrana granulosa layer, or loosely attached with membrana granulosa near its antral surface or in the antral cavity (Figure $1 \mathrm{E}$ and $\mathrm{F}$ ). 
Helthy follicle
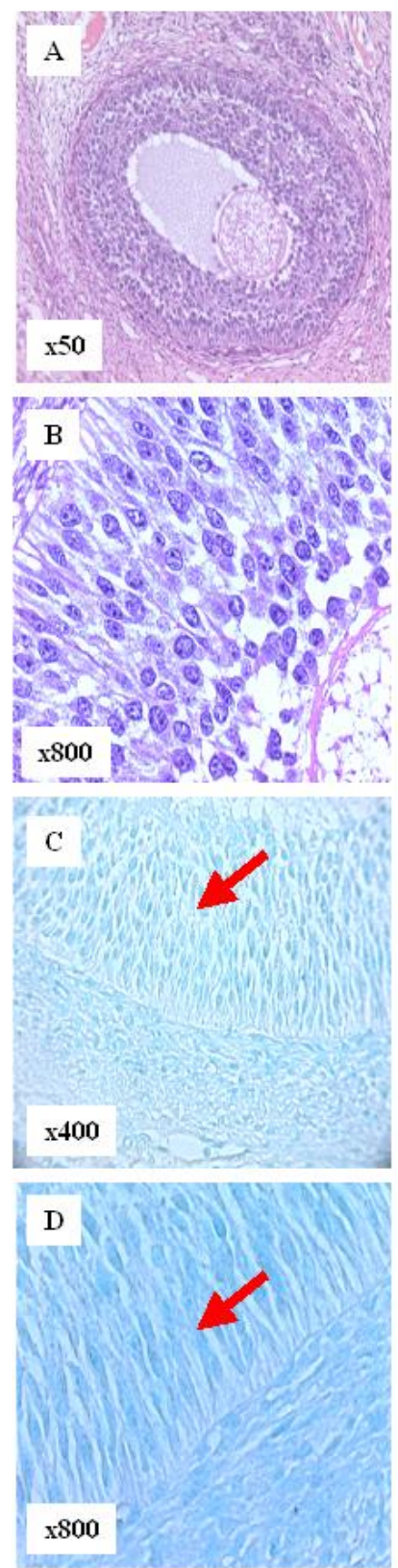

Atretic follicle
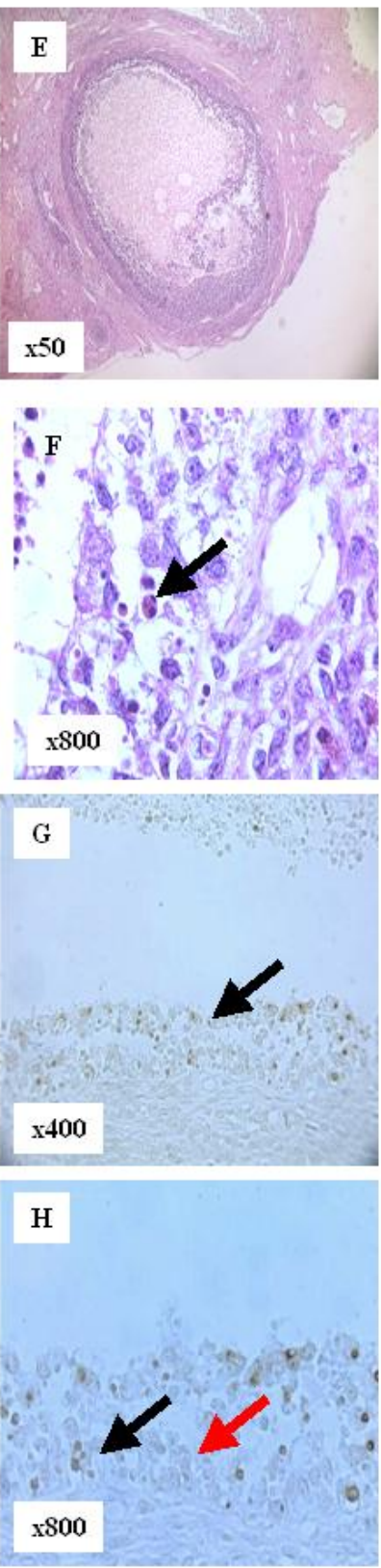

HL 60 cells (Control)
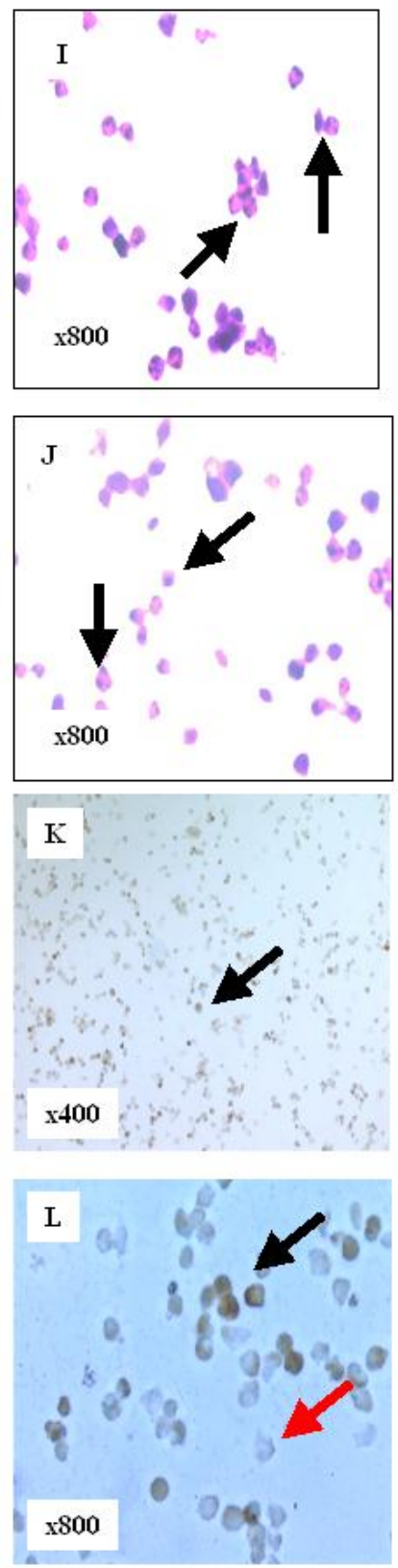

Figure 1: Apoptosis in healthy (A-D), and atretic $(E-H)$ ovarian follicles and HL60 promylocytic leukemia cells (I-L, control). A, B, E, F, I, and J: hematoxylin-eosin stained; C, D, G, H, K, and L: TUNEL stained. Black arrow $=$ TUNEL signal-positive cell; red arrow $=$ TUNEL signal-negative cell. 


\section{DNA Fragmentation Assay (TUNEL):}

None of the negative controls stained with TUNEL technique showed immunoreactivity while signal positive TUNEL staining was observed in the positive controls (Figure $1 \mathrm{I}-\mathrm{K}$ ). These findings indicate the validity of our results. The two observers were in agreement. The evaluation of apoptosis in ovarian tissues revealed several observations. First, at 1,10, 20 and 30 minutes respectively, the apoptotic signals were statistically: 1) significantly higher in the atretic than in the non-atretic follicles in both types of ovarian tissues, and 2 ) insignificantly higher in cryopreserved than the in freshly-fixed ones for both atretic and non-atretic follicles.

A summary of these results is presented in Table 1. The TUNEL positive signals were detected in the atretic follicles as depicted by the punctuated brown staining of the fragmented nuclei of granulosa cells (Figure $1 \mathrm{G}-\mathrm{H}$ ). The positively stained nuclei were observed either in the central layers of the membrana granulosa, at the antral surface or floating in the follicular antrum. DNA fragmentation was absent both in the interstitial cells and in the theca cells of the atretic follicles. In the atretic follicles, many of the pyknotic nuclei and the DNA globules, sloughed in their cavities, stained intensely with hematoxylin were TUNEL negative. Finally, during the warm ischemia, although the mean values of apoptotic cells gradually increased with time, these differences, even after 30 min. were not statistically significant $(p=0.67$ and 0.20$)$ for freshly fixed and cryopreserved tissues, respectively.

\begin{tabular}{lllllll}
\hline Time & \multicolumn{4}{l}{ Non-atretic follicles } & \multicolumn{4}{l}{ Atretic follicles } \\
& Freshly- & Cryopreserved & Total & Freshly- Cryopreserved & Total \\
\hline & fixed & & \multicolumn{5}{c}{ fixed } \\
$1 \mathrm{~min}$. & $0.70 \pm 0.15$ & $0.85 \pm 0.10$ & $0.69 \pm 0.06$ & $1.15 \pm 0.20$ & $1.58 \pm 0.30$ & $1.36 \pm 0.20$ \\
$10 \mathrm{~min}$. & $0.70 \pm 0.15$ & $0.92 \pm 0.70$ & $0.69 \pm 0.06$ & $1.23 \pm 0.31$ & $1.96 \pm 0.28$ & $1.59 \pm 0.20$ \\
$20 \mathrm{~min}$. & $0.70 \pm 0.15$ & $0.92 \pm 0.07$ & $0.76 \pm 0.06$ & $1.23 \pm 0.31$ & $2.10 \pm 0.30$ & $1.67 \pm 0.22$ \\
$30 \mathrm{~min}$. & $0.70 \pm 0.15$ & $1.00 \pm 0.00$ & $0.71 \pm 0.06$ & $1.27 \pm 0.32$ & $2.27 \pm 0.35$ & $1.67 \pm 0.24$ \\
\hline
\end{tabular}

Table 1: The values of TUNEL positive signals in freshly fixed and cryopreserved ovarian tissues at the different time intervals

\section{B- Immunohistochemical staining results:}

The positive and negative controls were positive and negative, respectively indicating the validity of our results. The two observers were in agreement. 


\section{p53 protein expression:}

In both freshly fixed and cryopreserved tissues, p53 expression (nuclear) was occasionally found in some of the granulosa cells of the atretic follicles. Its expression was virtually absent in the healthy primordial, primary, and secondary follicles, corpora lutea, germinal epithelium and stromal cells subjected to warm ischemia (Figure 3).

\section{Bcl-2 protein expression:}

In both freshly fixed and cryopreserved tissues, Bcl-2 immunoreactivity was observed with significant likelhood in the secondary follicles followed by primary and primordial follicles. In these follicles, Bcl-2 immunoreactivity was restricted to granulosa cells (Figure $2 \mathrm{~A}-\mathrm{C}$ ). The theca cells were never immunoreactive regardless of the developmental stage of the follicles. The atretic follicles, were occasionally positive for $\mathrm{Bcl}-2$ expression in this investigation (Figure 2-D).
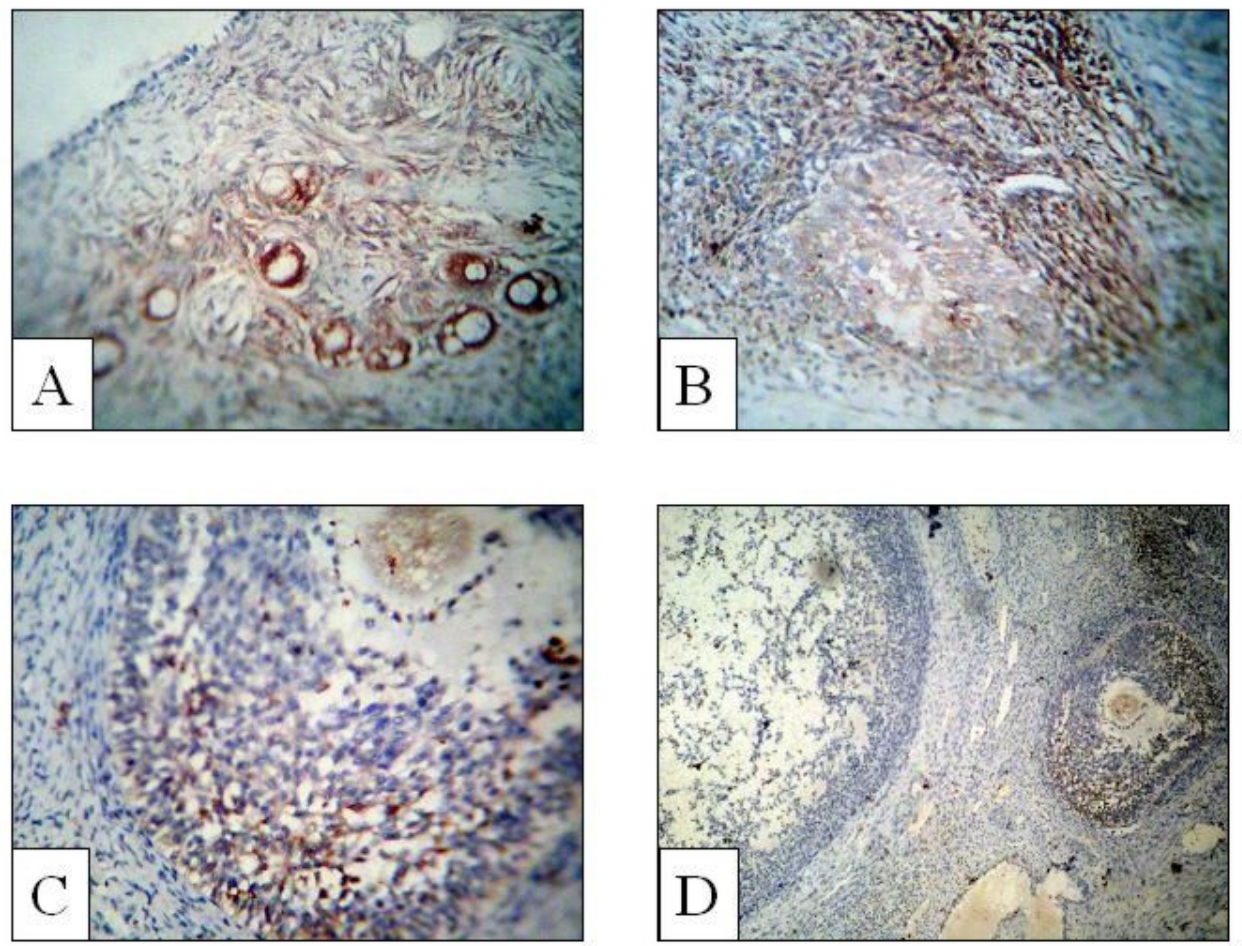

Figure 2: $\mathrm{Bcl}-2$ protein expression (cytoplasmic) in the primary $(A, 400 \times)$, secondary $(B, 400 \times)$, graafian $(C, 400 \times)$, and atretic $(D, 100 \times)$ follicles. 


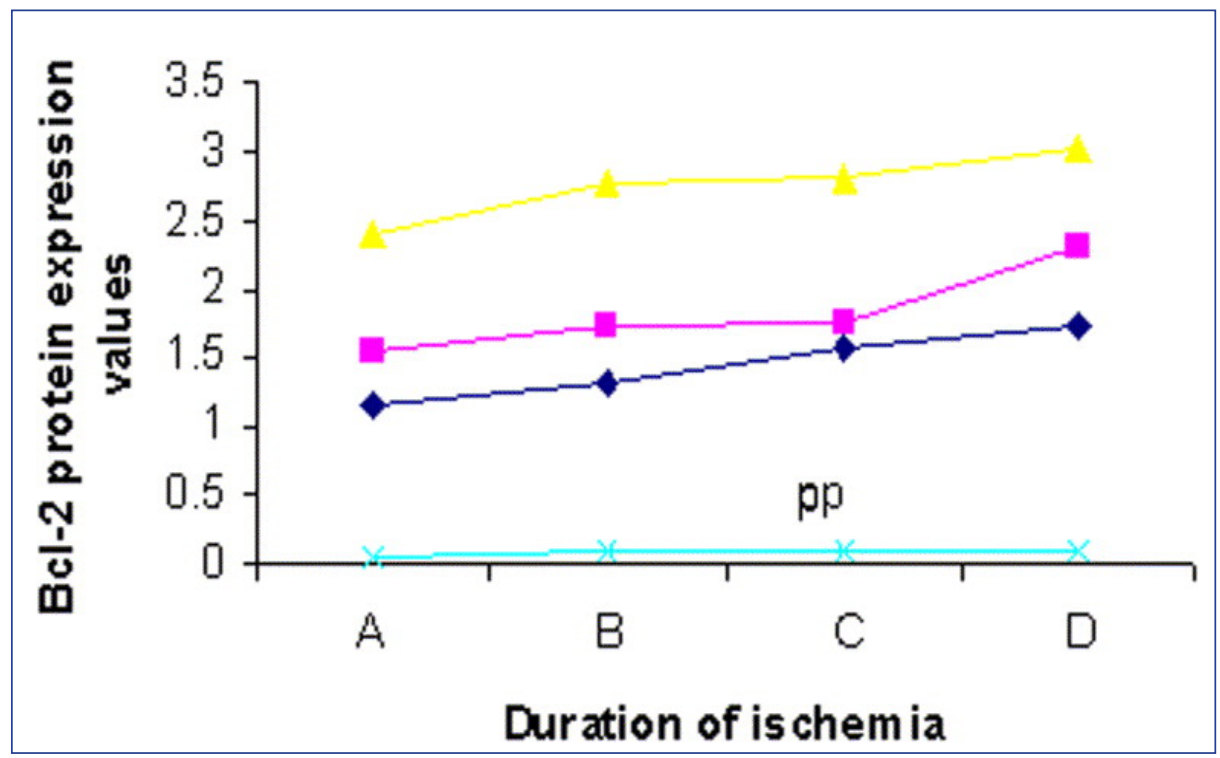

Figure 3: $\mathrm{Bcl}-2$ protein expression in the different types of the ovarian follicles (freshly fixed and cryopreserved). The data are presented as a function of time as a continuous variable. The letters A, B, C, and $D$ correspond to $0,10,20$, and 30 min, respectively. Dark blue = primordial follicles; pink = primary follicles; yellow = secondary follicles; light blue = atretic follicles.

\section{Bcl-2 expression value gradually increased with increased duration of ischemia:}

Initially, the number of primordial, primary and secondary follicles with $\mathrm{Bcl}-2$ protein expression was examined in the healthy and atretic follicles. In both freshly fixed and cryopreserved tissues, we found that the increased duration of ischemia was associated with statistically insignificant increase in the number of primordial, primary and secondary follicles with $\mathrm{Bcl}-2$ protein expression. A summary of these results was presented in Tables 2-3 and Figure 2.

When the total numbers of the healthy follicles with $\mathrm{Bcl}-2$ signals was examined in the cryopreserved-thawed tissues, gradual incremental rise, however non-significant, was found with the increasing duration of ischemia for both healthy and atretic follicles at $1,10,20$, and 30 min., respectively; p 0.99 and 0.97). Similarily, when the total healthy follicles with $\mathrm{Bcl}-2$ signals was examined in the freshly-fixed tissues, a gradual increment, however non-significant, was found with the increased in the duration of ischemia for healthy and atretic follicles at $1,10,20$, and 30 min., respectively; $p$ 0.99 and 0.55 ). A summary of these results was shown in Table 3 and Figure 2). 
High Bcl-2 protein expression value was seen in the healthy than the atretic follicles:

In both freshly fixed and cryopreserved tissues, examination of the Bcl-2 protein expression in the different types of follicles revealed the highest expression values (number of follicles with Bcl-2 reactivity) to be in the secnodary follicles, followed by the primary, primordial and atretic ones. A summary of these results was presented in Table 2 and Figure 4).

\begin{tabular}{llllll}
\hline \multicolumn{7}{c}{ Duration of ischemia } \\
Aspect & 1 min. & 10 min. & 20 min. & 30 min. & p value \\
\hline Primordial follicles & $1.17 \pm 0.39$ & $1.33 \pm 0.44$ & $1.58 \pm 0.45$ & $1.75 \pm 0.49$ & 0.89 \\
Primary follicles & $1.56 \pm 0.61$ & $1.72 \pm 0.51$ & $2.31 \pm 0.73$ & $2.62 \pm 0.53$ & 0.65 \\
Secondary follicles & $2.4 \pm 0.67$ & $2.78 \pm 0.84$ & $2.80 \pm 1.09$ & $3.04 \pm 1.34$ & 0.99 \\
Atretic follicles & $0.07 \pm 0.7$ & $0.11 \pm 0.03$ & $0.11 \pm 0.10$ & $0.11 \pm 0.10$ & 0.55
\end{tabular}

Table 2: The values of Bcl-2-positive follicles after exposure to ischemia in both freshly fixed and cryopreserved ovarian tissues.

\section{Duration of ischemia}

\begin{tabular}{lllllc} 
Aspect & $1 \mathrm{~min}$ & $10 \mathrm{~min}$ & $20 \mathrm{~min}$ & $30 \mathrm{~min}$ & $p$ value \\
\hline Cryopreserved tissues & & & & & \\
Non-atretic follicles & $1.82 \pm 0.30$ & $2.01 \pm 0.44$ & $2.02 \pm 0.35$ & $2.05 \pm 0.42$ & 0.99 \\
Atretic follicles & $0.07 \pm 0.70$ & $0.11 \pm 0.03$ & $0.11 \pm 0.10$ & $0.11 \pm 0.10$ & 0.97
\end{tabular}

\section{Freshly-fixed tissues}

Non-atretic follicles

$1.81 \pm 0.82$

$2.06 \pm 0.57$

$2.06 \pm 2.08$

$2.06 \pm 0.44$

0.99

Atretic follicles

$0.06 \pm 0.25$

$0.13 \pm 0.35$

$0.13 \pm 0.35$

$0.13 \pm 0.35$

0.55

Table 3: The values of $\mathrm{Bcl}-2-$ positive healthy and atretic follicles of cryopreserved and freshly fixed ovarian tissues after exposure to warm ischemia. 

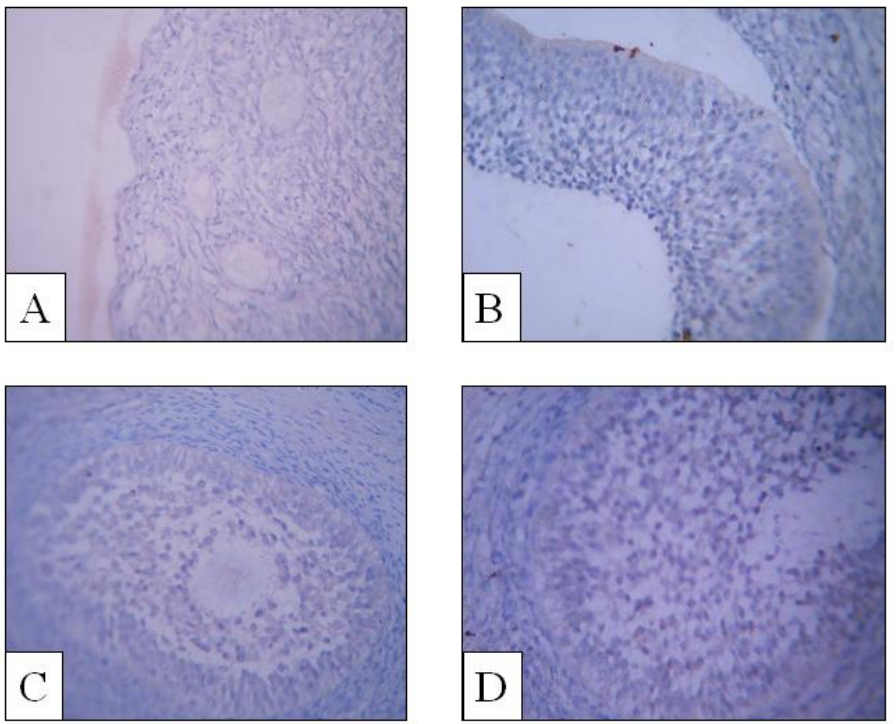

Figure 4: Lack of p53 protein expression (cytoplasmic) in the primary (A), secondary (B), graafian (C), and atretic (D) follicles $(400 \times)$. p53 and $\mathrm{Bcl}-2$ proteins in cryopreserved ovaries.

\section{Correlations between $\mathrm{p} 53, \mathrm{Bcl}-2$ protein expression and apoptotic cell death:}

Finally, when in both freshly fixed and cryopreserved tissues, the distribution of $\mathrm{Bcl}-2$ and p53 expression was compared with apoptotic changes, Bcl-2 expression was found in the healthy follicles (lacking apoptotic changes). Alternatively, occasional p53 expression was seen in the atretic ones (having apoptotic changes). Summaries of these results were presented in Figures 5-6.

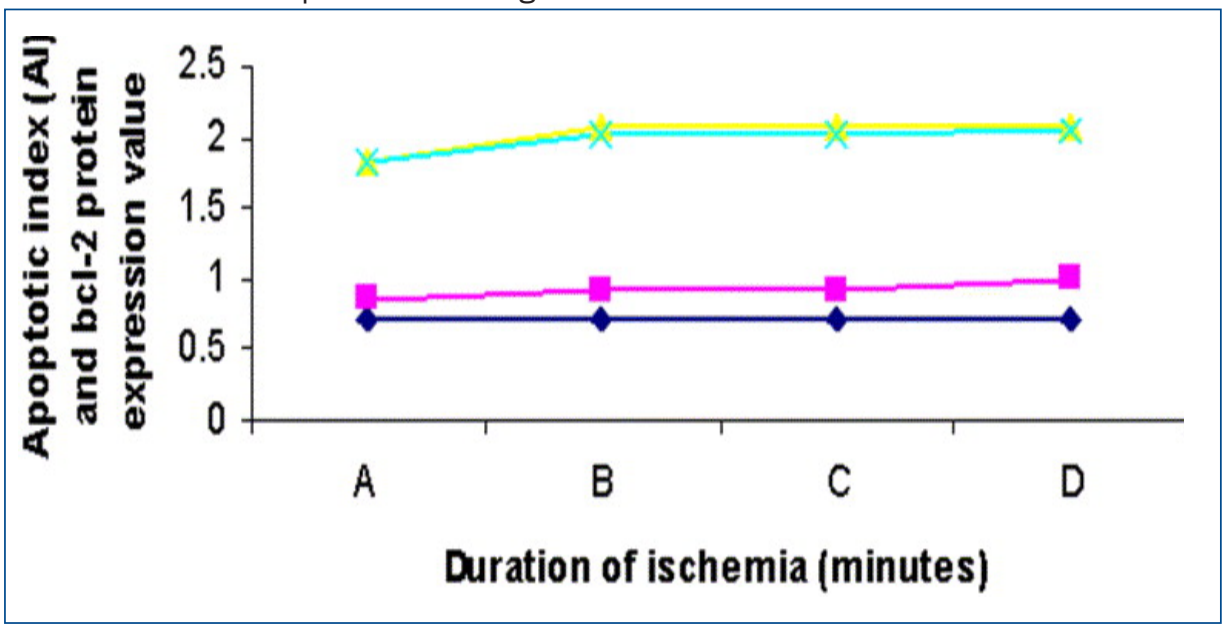

Figure 5: Apoptotic index (Al) and $\mathrm{Bcl}-2$ protein expression in the healthy follicles (freshly fixed and cryopreserved ovarian tissues). The data are presented as a function of time as a continuous variable. The letters $A, B, C$, and D correspond to $0,10,20$, and $30 \mathrm{~min}$, respectively. Dark blue $=A l$ in freshly fixed tissue; pink = Al in cryopreserved-thawed tissue; yellow = $\mathrm{Bcl}$-2 in freshly fixed-thawed tissue; light blue $=\mathrm{Bcl}-2$ in cryopreserved-thawed tissue. 


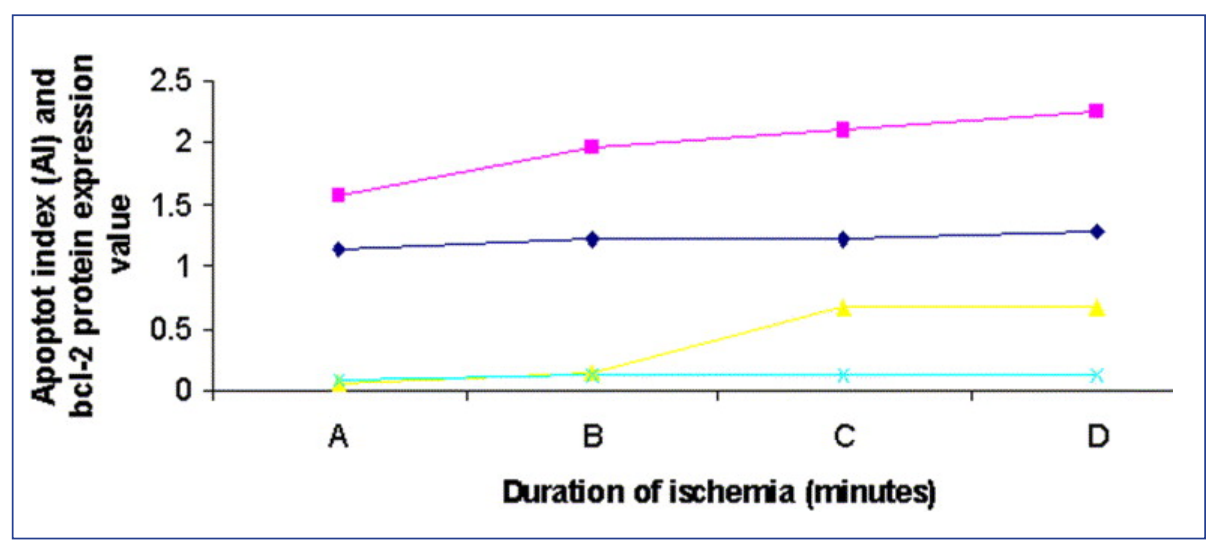

Figure 6: Apoptotic index ( $\mathrm{Al})$ and $\mathrm{Bcl}-2$ protein expression in the atretic follicles (freshly fixed and cryopreserved ovarian tissues). The data are presented as a function of time as a continuous variable. The letters $A, B, C$, and $D$ correspond to $0,10,20$, and 30 min, respectively. Dark blue $=A$ in freshly fixed tissue; pink = Al in cryopreserved-thawed tissue; yellow = $\mathrm{Bcl}-2$ in freshly fixed-thawed tissue; light blue $=\mathrm{Bcl}-2$ in cryopreserved-thawed tissue.

\section{Discussion}

The reproductive outcome of the ovarian transplantation depends on the degree of cell damage inflicted over the transplanted tissues upon harvesting, processing and subsequent transplantation. In this regard, ovaries destined for ovarian transplantation are exposed to variable durations of ischemia injury during this process. Ischemia injury is associated with alteration of survival and apoptotic molecules (Bcl-2 and p53 proteins) in several organs (6-8). Whether an ischemic insult of the ovarian tissues is associated with comparable alterations of these molecules is still unknown. Moreover the added insults of the cryopreservation thawing might cause further change in the expression of these molecules.

In this work, we hypothesized that ischemia of the ovarian tissues can induce altered expression of $\mathrm{p} 53$ and $\mathrm{Bcl}-2$ proteins. The objective of this study was to evaluate the effect of different ischemia times on the expression of $\mathrm{Bcl}-2$ and $\mathrm{p} 53$ expression on freshly-fixed and cryopreserved-thawed ovarian tissue. Our study clearly demonstrate the following observations: 1 ) apoptosis is involved in the process of follicular atresia, 2) Bcl-2 and p53 may be involved in the apoptotic cell death in the ovary in both freshly fixed and cryopreserved tissues, 3) Bcl-2, but not p53, can be induced by warm ischemic injury of the ovary mostly in the healthy follicles, 4) Bcl-2 induction is more marked in the secondary follicles, 5) cryopreservation has little effects on the $\mathrm{Bcl}-2 / \mathrm{p} 53$ protein expression, and 6) Bcl-2 protein expression commences very early in ovarian folliculogenesis i.e. at the stage of primordial follicles. All these observation are only true within the ischemia time frame studied (30 minutes). 
Apoptosis was found in the atretic follicles but not in the healthy ones: In agreement with previous studies, our study revealed that the non-atretic follicles had negligible levels of DNA fragmentation as compared to the atretic follicles (12). These findings support the link between ovarian follicular atresia and apoptosis. Of note, the relatively low apoptotic indices detected by TUNEL assay alone in the atretic follicles could be explained by the fact that there is always a population of TUNEL negative apoptotic cells in almost all systems studied, likely due to inaccessibility of supercondensed DNA to the TdT enzyme (13).

Our findings of slightly higher mean apoptotic values in the granulosa cells of cryopreserved tissues lend further support to the notion that cryopreservation can induce apoptosis $(14,15)$. Alternatively, they raise the concern about the suitability of the current cryopreservation techniques for subsequent ovarian transplantation. We propose two possibilities to account for the higher levels of apoptosis in the cryopreserved ovarian tissues in our series.

First, during cryopreservation process, the ovarian tissues receive apoptosistriggering signals. With a further freeze-thaw trauma; apoptotic cell death occurred in the primed cells in the cryopreserved tissues. It is still possible that cryopreservation of these tissues was associated with degradation of apoptosis related proteins (caspase-3, caspase-8, Bcl-2 and actin) with subsequent alteration of their function and enhancement of apoptotic activity (16). Second, since apoptosis is an active process and it takes some time until it can be executed, thus, if any TUNEL positive cells would be observed at this time, it would likely be a result of direct tissue damage caused by cryopreservation. The slightly increased apoptotic indices with increased durations of ischemia may be explained by the gradually increased generation of oxygen free radicals (17).

The clinical relevance of our data stems from three factors. First, the critical impact of apoptosis on the outcome of fertilization and oocyte development. In this regard, the inability to conceive is associated with a higher rate of apoptosis in the granulosalutein cells. Second, our study proposes the combined morphology and TUNEL assay as useful and simple strategy for the detection of apoptosis in ovarian tissue being exposed to freeze-thaw trauma. Third, warm ischemia and cryopreservation have little detrimental effects on the ovarian tissues.

High Bcl-2 expression values in the healthy follicles: The presence of $\mathrm{Bcl}-2$ protein expression in the secondary follicles of the healthy ovarian follicles concurs with recent reports $(3,18-20)$. Alternatively, in contrast with these reports, we found $\mathrm{Bcl}-$ 2 expression in the primordial, primary and atretic follicles. The presence of $\mathrm{Bcl}-$ 2 expression in the healthy follicles raises several notions. First, Bcl-2 expression 
commences very early during folliculogenesis i.e. at the stage of the primordial follicles. Second, the persistent Bcl-2 expression in the primary and secondary follicles suggests a possible physiologic role in the maintenance of follicular integrity. In support, mice lacking functional $\mathrm{Bcl}-2$ protein posses reduced numbers of primordial follicles relative to their wild type sisters (21).

Alternatively, the findings of reduced $\mathrm{Bcl}-2$ expression in the atretic follicles also support a possible role for loss of Bcl-2 protein in follicular atresia. The lack of statistically significant differences in the $\mathrm{Bcl}-2$ expression values between the freshlyfixed and the cryopreserved tissues suggests the lack of the detrimental effects of cryopreservation on the atretic follicles.

$\mathrm{Bcl}-2$ expression may be induced by ischemia injury in the healthy follicles: The presence of gradual increment of the mean counts of $\mathrm{Bcl}-2$ positive follicles with increased duration of ischemia is in agreement with similar findings in other organs $(6-8)$. This incremental increase could be explained by: 1 ) a cell cycle fluctuation in the Bcl-2 expression, 2) generation of oxygen free radicals with resultant tissue damage which in turn induced $\mathrm{Bcl}-2$ expression. As $\mathrm{Bcl}-2$ has strong antioxidant properties, Bcl-2 induction can offer cytoprotection to the ovarian follicles either upon exposure to ischemia or after cryopreservation insults. Also, the cytoprotective role of $\mathrm{Bcl}-2$ may be explained by blockage of cytochrome $\mathrm{c}$ release and a delay of caspase activation (17).

The lack of p53 expression in the healthy follicles and most of the atretic ones suggest genomic integrity following ischemia injury: The lack of p53 expression in the healthy follicles versus its presence atretic ones concurs with previous studies (3). This lack of p53 in the healthy ovarian follicles following exposure to warm ischemia suggests the lack of underlying DNA damage and therefore implies integrity of the genome in these follicles. Interestingly, recent studies suggest that after transient focal brain ischemia, p53 prevents rather than aggravates brain injury. This effect is brought about by mechanisms that are unrelated to the apoptotic properties of this gene (5). In the same vein, the wild-type p53 protein is normally present in very small amounts (a few thousand molecules) in normal tissue.

Similarly, p53 protein occurs at immunohistochemically undetectable levels in normal tissues. The wild-type protein is characterized by: 1) location predominantly in the nucleus; 2) action as an onco-suppressor protein; and 3) short half-life of about 25 minutes. When p53 gene mutations occur, mutant- type p53 protein is formed. The latter differs from the wild-type p53 protein in several aspects including: 1) it can appear both in the nucleus and in the cytoplasm; 2) it can destroy the function of wildtype protein and ; 3 ) it has conformational changes and therefore can oligomerize with 
both wild-type and mutant proteins, forming inactive complexes with prolonged halflife $(3,5)$. In this investigation, we propose that p53 mediate apoptosis in the ovarian tissues through interaction with several effector genes residing in the granulosa cells such as bcl-2 family of genes $(3,5)$.

To summarize, here we report the apoptotic changes upon exposure to warm ischemia alone or with subsequent cryopreservation and thawing. These changes were associated with altered $\mathrm{Bcl}-2$ and p53 protein expression after exposure to warm ischemia. Cryopreservation and thawing of the tissues did not seem to have effects on this altered protein expression. Our data suggest that induction of p53 and Bcl-2 protein overexpression in ovaries destined for transplantation might improve their future post-transplantation reproductive outcome.

Also, targeting $\mathrm{Bcl}-2$ and p53 molecules may have therapeutic ramifications in the treatment of the ovarian disorders resulting from ischemia. Further investigations are mandated to examine the possibility of conducting different duration of ischemic warming and then transplanting these ovaries into sows. The endocrinological and ovulatory success of the transplants may be measured both against the duration of ischemia and levels of $\mathrm{Bcl}-2$ and p53 protein expression. Also, it would be interesting to examine the effects of cooler temperature (32-40 F) in the future investigations.

\section{Acknowledgments}

The first and the second authors contributed equally to the manuscript. The authors would like to thank Elisabeth Jeremias M.D, for helping with tissue procurement. 


\section{References}

1. Tilly JL. Molecular and genetic basis of normal and toxicant-induced apoptosis in female germ cells. Toxicol Lett 1998;102-103:497-501.

2. Andreu-Vieyra CV, Habibi HR. Factors controlling ovarian apoptosis. Can J Physiol Pharmacol 2000;78:1003-12.

3. Hussein MR. Apoptosis in the ovary: molecular mechanisms. Hum Reprod Update 2005; 11:162-77.

4. Tilly JL. Apoptosis and ovarian function. Rev Reprod 1996;1:162-72.

5. Hussein MR. The TP53 tumor suppressor gene and melanoma tumorigenesis: is there a relationship? Tumour Biol 2004;25:200-7.

6. Wang $\mathrm{F}$, Hu YL, Li YH. [The expression of $\mathrm{Bcl}-2$ protein on acute myocardial ischemia/ reperfusion and the significance in forensic pathology]. Fa Yi Xue Za Zhi 2003; 19:207-8, 211.

7. Peralta C, Perales JC, Bartrons R, Mitchell C, Gilgenkrantz H, Xaus C, et al. The combination of ischemic preconditioning and liver $\mathrm{Bcl}-2$ overexpression is a suitable strategy to prevent liver and lung damage after hepatic ischemia-reperfusion. Am J Pathol 2002;160:2111-22.

8. Prakasa Babu P, Yoshida Y, Su M, Segura M, Kawamura S, Yasui N. Immunohistochemical expression of Bcl-2, Bax and cytochrome c following focal cerebral ischemia and effect of hypothermia in rat. Neurosci Lett 2000;291:196-200.

9. Jeremias E, Bedaiwy MA, Nelson D, Biscotti CV, Falcone T. Assessment of tissue injury in cryopreserved ovarian tissue. Fertil Steril 2003;79:651-3.

10. Wood TC, Montali RJ, Wildt DE. Follicle-oocyte atresia and temporal taphonomy in cold-stored domestic cat ovaries. Mol Reprod Dev 1997;46:190-200.

11. Kerr JF, Wyllie AH, Currie AR. Apoptosis: a basic biological phenomenon with wideranging implications in tissue kinetics. Br J Cancer 1972;26:239-57.

12. Bedaiwy MA, Jeremias E, Gurunluoglu R, Hussein MR, Siemianow M, Biscotti C, et al. Restoration of ovarian function after autotransplantation of intact frozen-thawed sheep ovaries with microvascular anastomosis. Fertil Steril 2003;79:594-602.

13. Bacci ML, Barazzoni AM, Forni M, Costerbosa GL. In situ detection of apoptosis in regressing corpus luteum of pregnant sow: evidence of an early presence of DNA fragmentation. Domest Anim Endocrinol 1996;13:361-72.

14. Borderie VM, Lopez M, Lombet A, Carvajal-Gonzalez S, Cywiner C, Laroche L. Cryopreservation and culture of human corneal keratocytes. Invest Ophthalmol Vis Sci 1998;39:1511-9.

15. Baust JM, Van B, Baust JG. Cell viability improves following inhibition of cryopreservation-induced apoptosis. In Vitro Cell Dev Biol Anim 2000;36:262-70.

16. Schmidt-Mende J, Hellstrom-Lindberg E, Joseph B, Zhivotovsky B. Freezing induces artificial cleavage of apoptosis-related proteins in human bone marrow cells. J Immunol Methods 2000;245:91-4.

17. Pfister Y, Savioz A, Vallet PG, Dubois-Dauphin M. Permanent cerebral ischemia induces sustained procaspase 9L increase not controlled by Bcl-2. Brain Res 2003;966:26-39.

18. Tilly JL, Tilly KI, Kenton ML, Johnson AL. Expression of members of the bcl-2 gene family in the immature rat ovary: equine chorionic gonadotropin-mediated inhibition of granulosa cell apoptosis is associated with decreased bax and constitutive bcl-2 and bcl-xlong messenger ribonucleic acid levels. Endocrinology 1995;136:232-41.

19. Tilly JL. The molecular basis of ovarian cell death during germ cell attrition, follicular atresia, and luteolysis. Front Biosci 1996;1:d1-11.

20. Felici MD, Carlo AD, Pesce M, Iona S, Farrace MG, Piacentini M. Bcl-2 and Bax regulation of apoptosis in germ cells during prenatal oogenesis in the mouse embryo. Cell Death Differ 1999;6:908-15.

21. Ratts VS, Flaws JA, Kolp R, Sorenson CM, Tilly JL. Ablation of bcl-2 gene expression decreases the numbers of oocytes and primordial follicles established in the post-natal female mouse gonad. Endocrinology 1995;136:3665-8. 



\section{Chapter 4}

Heterotopic autotransplantation of the ovary with

microvascular anastomosis:

a novel surgical technique

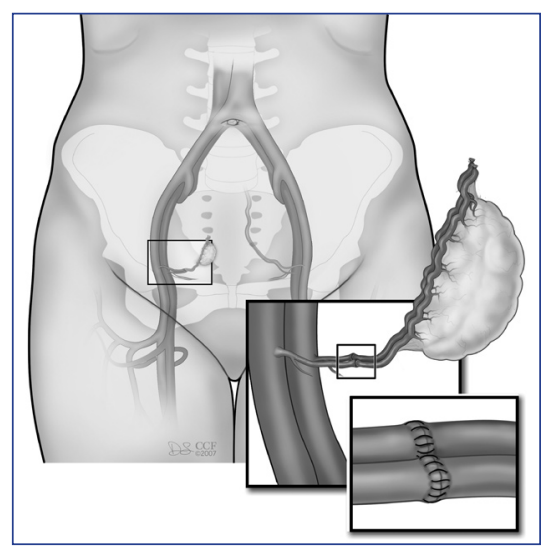

Elisabeth Jeremias, Mohamed A Bedaiwy, Raffi Gurunluoglu, Charles V Biscotti Maria Siemionow, Tommaso Falcone

Fertility Sterility, 2002; 77(6):1278-82. 


\section{Abstract}

Objective: To test the feasibility of transplanting an entire ovary with anastomosis of the ovarian vascular pedicle.

Design: Long-term survival study.

Setting: Biological Resources Unit, Cleveland Clinic Foundation.

Animal(s): Five adult, nonpregnant ewes.

Intervention(s): Laparoscopic bilateral oophorectomy was performed. Ovaries were autotransplanted into the abdominal wall, and microsurgical vascular anastomosis of the ovarian to the inferior epigastric vessels was performed. The transplant was removed and evaluated after $7 \pm 1$ days.

Main Outcome Measure(s): Blood flow, serum E2 and FSH levels, and histologic characteristics.

Result(s): At follow-up three transplants were viable; they showed no signs of necrosis, and patency of the vascular anastomosis was confirmed. Serum E2 levels did not change significantly after transplantation in the patent vessel group $(155.3 \pm 46.1$ vs. $125.7 \pm 44.6 \mathrm{pg} / \mathrm{mL}$ ) or the non patent vessel group (99 vs. $158 \mathrm{pg} / \mathrm{mL}$ ). Serum FSH level in the patent vessel group did not change significantly from before to after transplantation $(70.6 \pm 37.2 \mathrm{ng} / \mathrm{mL}$ vs. $95.1 \pm 17.7 \mathrm{ng} / \mathrm{mL})$, whereas a large increase in FSH level was observed in the non patent vessel group $(52.3 \mathrm{ng} / \mathrm{mL}$ vs. $522 \mathrm{ng} /$ $\mathrm{mL}$ ). The patent vessel group had significantly more follicles after transplantation than did the non patent vessel group ( $6 \pm 1$ vs. $1 \pm 1$ ).

Conclusion(s): In conjunction with improved protocols for cryopreservation, ovarian autotransplantation with vascular anastomosis may be superior to current ovarian tissue banking and grafting techniques.

Keywords: Ovarian transplantation; vascular anastomosis and heterotopic autotransplantation. 


\section{Introduction}

Ovarian tissue grafting in conjunction with cryopreservation may preserve fertility in patients at risk of premature ovarian failure. Because an increasing number of women delay childbearing, the fact that $1 \%$ of women experience ovarian failure before 40 years of age (in patients with primary amenorrhea, the proportion ranges from $10 \%$ to $28 \%$ ) has gained more clinical significance (1). In addition, advances in oncologic diagnostic techniques and treatment of cancer have improved survival rates of the disease. However, many treatment regimens damage germ cells and lead to insufficient ovarian function or ovarian failure in these patients (2). Ovarian tissue grafting may also be of benefit in other clinical conditions associated with premature menopause, such as repeated surgery on the ovaries, genetic abnormalities, and autoimmune disorders (3).

Autotransplantation procedures have historically been limited almost exclusively to non-vascular cortex segments grafted to orthotopic or heterotopic locations (4). In animal models, tissue pieces as large as ovine hemiovaries have been autotransplanted without vascular anastomosis, and resumption of endocrine function has been documented (5). Gosden et al., (6) described a live birth resulting from autotransplantation of a hemiovary in the ewe. However, since a sheep ovary is about the tenth of the size of a human ovary (3-8 g vs. 20-35 g), this technique may have more limitations in humans.

Non vascular grafts sustain significant ischemic injury until revascularization of the tissue takes place. Reduction of the ischemic interval after reimplantation is crucial for the reproductive potential of these transplants (7). Vascular transplantation would be the logical approach.

To study reproductive physiology in the sheep, Goding (8) performed autotransplantation of an intact ovary with its vascular pedicle, including an aortic patch for reanastomosis of the ovarian artery to the carotid artery. Scott et al. (9) tested the technical feasibility of microsurgical reanastomosis of the ovarian blood vessels as part of an orthotopic transplantation technique in a primate model. These procedures are technically challenging but provide immediate blood supply to the transplants, thus minimizing ischemic injury. Since both techniques require an aortic patch for the anastomosis, they are unlikely to be applied in surgical practice.

We sought to develop a technique for ovarian autotransplantation and vascular anastomosis at a site that permits easy access for microsurgical procedures as well as future egg retrievals in a sheep model. The abdominal wall was chosen because branches of the inferior epigastric vessels are suitable for anastomosis with ovarian vessels. 


\section{Materials and methods}

Five adult, non pregnant merino ewes weighing 55-70 kg were included in this long-term survival study. Surgical procedures were performed at the Cleveland Clinic Foundation Biological Resources Unit, in accordance with the facility's standard operating procedures [Institutional Animal Care and Ewe Committee (IACUC) protocol]. The animals were cared for according to the standards of the U.S. Public Health Policy of the Humane Care and Use of Laboratory Animals. The study protocol was approved by the institutional animal research committee.

\section{Surgical procedure}

Laparoscopic bilateral oophorectomy was performed in a sterile manner by using routine instrumentation and a bipolar electrocoagulation forceps for coagulation. The mesovarium was coagulated and dissected until $2-3 \mathrm{~cm}$ of the ovarian pedicle was cleared. At this location, the ovarian vessels in the sheep are tortuous and measure 1-2 mm. The vessels were ligated and cut without obtaining an aortic patch (Fig 1). Subsequently, the right ovary (and the right and left ovary in one animal) was reimplanted into the abdominal wall by using a microsurgical technique (six animals) (Fig 2). 


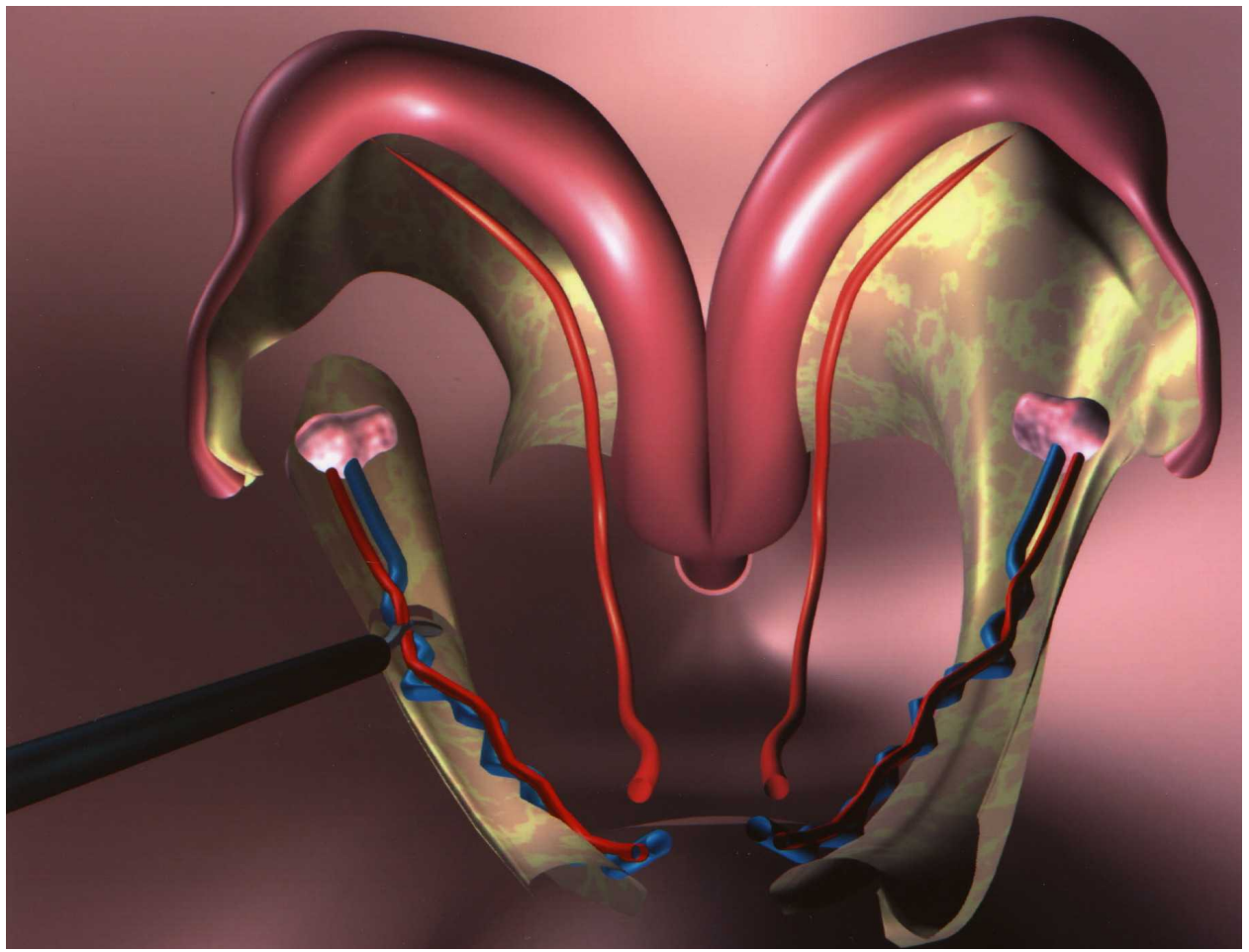

Figure 1: The female reproductive tract in the ewe. The bicornous uterus with no supportive ligaments is evident. Removal of the ovary with its vascular pedicle is shown.

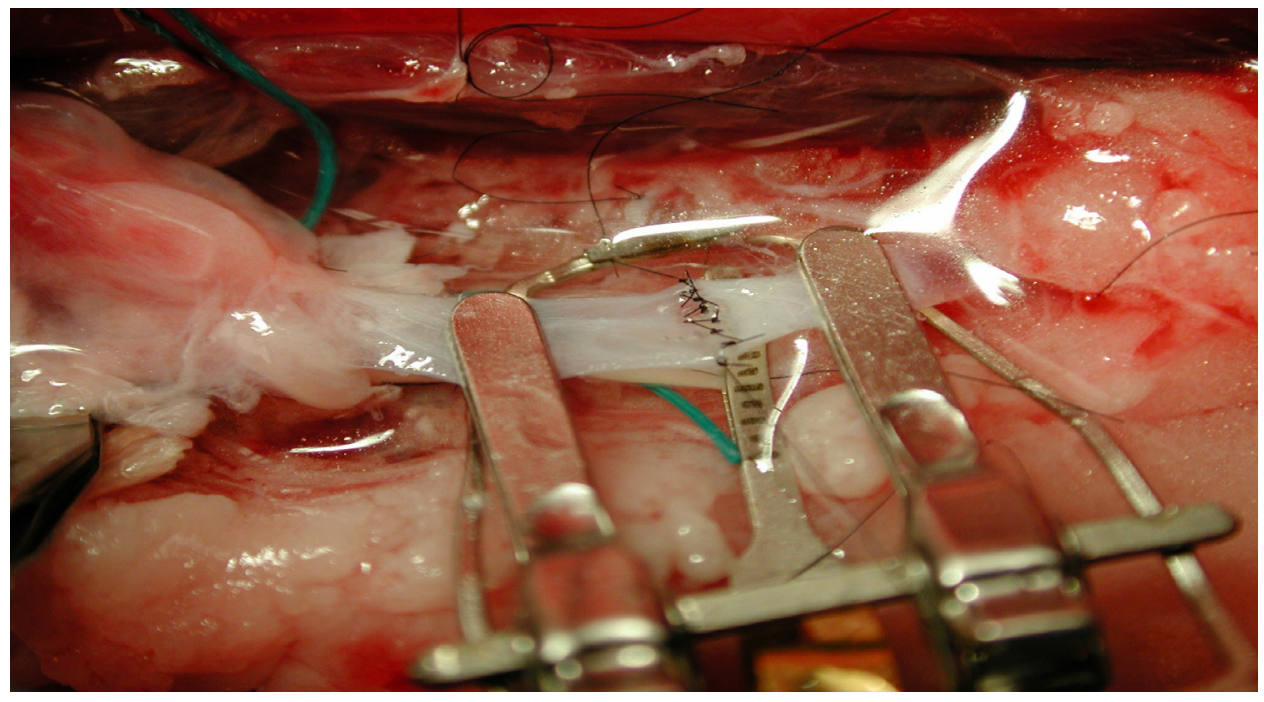

Figure 2: End-to-end anastomosis. In cases of discrepant vessel caliber, end-to-side anastomosis was performed by using the microsurgical technique. 
Standard microsurgical instrumentation and Acland vascular clamps were used for anastomosis (10). Each anastomosis required 8 to 10 interrupted sutures with 9-0 or 10-0 Prolene (U.S. Surgical Co., Norwalk, CT; Fig. 2).

Diluted heparin and papaverine was applied topically as required. The ovary was fixed between bundles of the rectus muscle. Warm ischemia time was measured in all surgical procedures and was defined as the interval between oophorectomy and completed anastomosis.

After removal of the clamps, the site of anastomosis was inspected and blood flow was documented for at least 20 minutes. After surgery, three animals received 5,000 IU of sodium heparin (Eli Lilly Company, Indianapolis, IN) s.C., for 3 days. One animal received 30mg of enoxaparin sodium (Lovenox; Aventis Pharmaceuticals, Collegeville, PA) s.c., b.i.d. for 3 days, as anticoagulant.

After $7 \pm 1$ days, the transplant was inspected for macroscopic appearance, presence of visible mature follicles, pulse at the arterial anastomosis, and bleeding at a small incision. The transplant was then removed and dissected for further evaluation. Outcome measures were blood flow immediately after surgery and at 1 week of followup, serum estradiol and FSH level, and histologic characteristics.

\section{Serum estradiol}

Serum estradiol was measured quantitatively by using the Automated Chemiluminescence Immunoassay System 180 (Bayer, Tarrytown, NY).

\section{Radioimmunoassay for FSH}

A radioimmunoassay to determine ovine serum $\mathrm{FSH}$ levels was performed at the reproductive endocrinology laboratory at Colorado State University (Fort Collins, CO). The assay was performed as described elsewhere (11) by using National Institutes of Health anti-ovine FSH (A780) as an FSH antibody and A853 (ARGG) as a second antibody. The data were analyzed by using the RIANAL program (Colorado State University). Follicle-stimulating hormone was measured on the day of surgery before the procedure and 7 days after transplantation.

\section{Histologic characteristics}

Ovarian tissue was fixed in Bouin's solution, embedded in paraffin, and stained with hematoxylin and eosin for histologic evaluation. Primordial follicle count per highpower field, presence of primary and secondary follicles, and presence of infarction 
were assessed. Follicle counts were obtained for all specimens in at least three different high-power fields, and counts were averaged. Infarcted areas were rated as having significant necrosis if $>90 \%$ necrosis was visualized in multiple high-power fields or as not having significant necrosis if necrosis in these fields was $<10 \%$.

\section{Statistical analysis}

Repeated-measures analysis of variance was used to simultaneously compare preoperative and postoperative values. Using a two-tailed test, $\mathrm{P}<.05$ was considered statistically significant. Summary statistics are presented as means ( $\pm S D$ ). Computations were performed by using SAS software, version 8.1 (SAS Institute, Inc., Cary, NC).

\section{Results}

After completion of microsurgical anastomosis, the clamps were removed and blood flow was documented for at least 20 minutes in all transplants, showing immediate postoperative success. In the first three cases, microsurgical anastomosis of the ovarian artery and vein to branches of the inferior epigastric vessels was performed in end-to-end fashion. For the first and third transplants, a substantial discrepancy in the caliber of the vessels led to lumen adaptation by creating a "fish-mouth incision" at the smaller stump. At removal of the transplant, both of these animals had occlusion of the anastomosed vessels. In subsequent transplants, end-to-side-anastomosis was performed in cases of substantial discrepancy in the size of the arterial lumen $(n=2)$.

\section{Long-term vascular patency}

At $7 \pm 1$ days after transplantation, the transplanted ovaries were evaluated in situ and were then removed for further evaluation. At follow-up, three transplants were viable and showed no sign of necrosis. Depending on the phase of the menstrual cycle, mature follicles were visible on the surface. In these cases, arterial bleeding occurred at incision, documenting the long-term patency of the anastomosis; these animals formed the patent vessel group. In two animals, the anastomosed vessels occluded completely, leading to great tissue loss. In these animals, the discrepancy in the caliber of the vessels was compensated for by creating a fish-mouth incision. In one animal, venous thrombosis led to major hemorrhaging and tissue injury; however, arterial blood flow was observed at transplant removal. These three animals formed the non patent vessel group (Table: 1 ). 
Table 1: Outcome of variables for each transplant

\begin{tabular}{|c|c|c|c|c|c|c|}
\hline $\begin{array}{l}\text { Arteria } \\
\text { anastomosis }\end{array}$ & $\begin{array}{l}\text { Transplant } 1 \\
\text { End-to-end } \\
\text { (fish mouth) }\end{array}$ & $\begin{array}{l}\text { Transplant } 2 \\
\text { end-to-end }\end{array}$ & $\begin{array}{l}\text { Transplant } 3 \\
\text { end-to-end } \\
\text { (fish mouth) }\end{array}$ & $\begin{array}{l}\text { Transplant } 4 \\
\text { end-to-side }\end{array}$ & $\begin{array}{l}\text { Transplant } 5 \\
\text { end-to-end }\end{array}$ & $\begin{array}{l}\text { Transplant } \mathbf{6} \\
\text { end-to-side }\end{array}$ \\
\hline Ischemia time & 4.25 hours & 3 hours & 1.83 hours & 3 hours & 3.2 hours & 2.1 hours \\
\hline $\begin{array}{l}\text { Immediate } \\
\text { vascular patience }\end{array}$ & $20 \mathrm{~min}$ & $20 \mathrm{~min}$ & $20 \mathrm{~min}$ & $20 \mathrm{~min}$ & $20 \mathrm{~min}$ & $20 \mathrm{~min}$ \\
\hline $\begin{array}{l}\text { Vascular } \\
\text { compromise }\end{array}$ & $\begin{array}{l}\text { Complete } \\
\text { ooculsion }\end{array}$ & no & $\begin{array}{l}\text { Complete } \\
\text { ooculsion }\end{array}$ & no & no & $\begin{array}{l}\text { venous } \\
\text { ooculsion }\end{array}$ \\
\hline $\begin{array}{l}\text { Estradiol } \\
\text { (pre-op) * }\end{array}$ & -- & $114 \mathrm{pg} / \mathrm{ml}$ & $99 \mathrm{pg} / \mathrm{ml}$ & $147 \mathrm{pg} / \mathrm{ml}$ & {$[205 \mathrm{pg} / \mathrm{ml}$} & same animal] \\
\hline $\begin{array}{l}\text { stradiol (post-op) } \\
\text { FSH (preop) } \\
\text { FSH (postop) }\end{array}$ & $\begin{array}{l}115 \mathrm{pg} / \mathrm{ml} \\
\mathrm{N} / \mathrm{A} \\
\mathrm{N} / \mathrm{A}\end{array}$ & $\begin{array}{l}83 \mathrm{pg} / \mathrm{ml} \\
103.8 \mathrm{ng} / \mathrm{ml} \\
100.4 \mathrm{ng} / \mathrm{ml}\end{array}$ & $\begin{array}{l}158 \mathrm{pg} / \mathrm{ml} \\
52.3 \mathrm{ng} / \mathrm{ml} \\
522.0 \mathrm{ng} / \mathrm{ml}\end{array}$ & $\begin{array}{l}122 \mathrm{pg} / \mathrm{ml} \\
30.4 \mathrm{ng} / \mathrm{ml} \\
75.4 \mathrm{ng} / \mathrm{ml}\end{array}$ & $\begin{array}{l}{[172 \mathrm{pg} / \mathrm{ml}} \\
{[77.5 \mathrm{ng} / \mathrm{ml}} \\
{[109.6 \mathrm{ng} / \mathrm{ml}}\end{array}$ & $\begin{array}{l}\text {-same animal] } \\
\text {-same animal] } \\
\text {-same animal] }\end{array}$ \\
\hline $\begin{array}{l}\text { Primordial } \\
\text { follicle count** }\end{array}$ & 2 & 5 & 0 & 7 & 6 & 1 \\
\hline Infarction size $e^{* * *}$ & yes & no & yes & no & no & yes \\
\hline
\end{tabular}

* Pre-operative mean estradiol: $141.3 \pm 47.0 \mathrm{pg} / \mathrm{ml} \quad * *$ per high magnification field $* * * 0=$ not significant, $1=$ focal, $2=$ severe, $3=$ massive

\section{Serum estradiol and FSH levels}

Serum $\mathrm{E}_{2}$ levels did not differ significantly before and after transplantation in the patent vessel group $(155.3 \pm 46.1$ vs. $125.7 \pm 44.6 \mathrm{pg} / \mathrm{mL})$ or the non patent vessel group (99 vs. $158 \mathrm{pg} / \mathrm{mL}$ ). This finding indicates that a small remnant of surviving ovarian cortex tissue is sufficient for resumption of E2 production - (Table: 1).

The serum FSH level did not change significantly from before to after transplantation in the patent vessel group (70.6 \pm 37.2 vs. $95.1 \pm 17.7 \mathrm{ng} / \mathrm{mL} ; \mathrm{P}=.22)$. In contrast, a large increase in FSH level was observed in the non patent vessel group (52.3 vs. $522 \mathrm{ng} / \mathrm{mL}$ ), suggesting ovarian failure.

\section{Histologic characteristics}

The warm ischemia interval in the patent vessel group and the non patent vessel group did not differ significantly ( $3.1 \pm 0.1$ vs. $2.7 \pm 1.3$ hours), but the ischemia interval varied more widely in the non patent vessel group, as indicated by the large standard SD.

The mean primordial follicle count per high-power field after transplantation revealed significantly more follicles in the patent vessel group than in the non patent vessel group ( $6 \pm 1$ vs. $1 \pm 1 ; \mathrm{P}=.004$; Table: 1 ). 
No significant necrosis was noted in the patent vessel group, whereas transplants in the non patent vessel group showed severe necrosis with focal viable tissue. Two of the three transplants in the non patent vessel group (transplants 1 and 3 ) had only a 1-mm surface rim of viable tissue; however, signs of tissue loss were evident throughout these remnants of identifiable ovarian tissue.

\section{Discussion}

Our study demonstrates the feasibility of ovarian autotransplantation with vascular anastomosis into the abdominal wall. In sheep with adequate vascular patency, loss of ovarian tissue was minimal, the primordial follicle count was high, and hormonal function resumed completely. With further advances in surgical technique and increasing experience, this novel method may be a viable alternative to current protocols for preserving ovarian function.

Banking of ovarian tissue has been proposed as a means to preserve fertility in women at risk for premature ovarian insufficiency or failure $(12,13)$. Premature ovarian failure can occur for various reasons but is most commonly seen after chemotherapy, radiation therapy, or repeated surgery on the ovary. Because in vitro maturation of human primordial follicles is currently not an option (14), techniques to graft frozenthawed ovarian fragments are being tested.

Several experimental approaches have been attempted to address this clinical problem. Two cases have been reported in which autologous transplantation of cortical strips to the forearm has resulted in ovarian function (15). In one patient, the ovaries were removed and cortical strips were placed in the forearm before radiotherapy. Spontaneous ovulation did not occur over the observation period of 18 months. High-dose gonadotropin stimulation for one IVF cycle produced three oocytes, but no fertilization occurred. Spontaneous ovulation was documented in another patient who underwent the same procedure. In both patients, it took many weeks for FSH levels to normalize, indicating that the ovarian graft experiences significant ischemia before revascularization is established.

The current experience with non vascular grafts demonstrates that most tissue loss occurs after transplantation owing to postgrafting ischemia. In contrast, freezing, storage at $-196^{\circ} \mathrm{C}$, and thawing injure ovarian cortex grafts relatively little $(16,17)$. Minimization of ischemia between grafting of the organ and revascularization of the tissue is therefore crucial for tissue survival and the reproductive potential of ovarian transplants. 
To promote revascularization, vascular areas such as under the capsule of the kidney or the spleen have been selected for heterotopic ovarian autograft placement $(18,19)$. These locations, however, are difficult to access in clinical practice. Some investigators are exploring the possibility of enhanced angiogenesis (20) or stimulation of the ovarian graft (21) to accelerate revascularization. Thus far, none of these treatments have sufficiently improved survival of the tissue.

We believe that immediate revascularization of ovarian transplants can be achieved by performing vascular anastomosis. In our study, the interval from the removal of the ovary until reperfusion of the organ (warm ischemia time) was about 3 hours. This interval seems to be acceptable: Only minimal injury to tissue was noted in the ovaries, and vascular patency was sustained. Measurement of hormone levels 7 days after transplantation already showed normalization of FSH and estradiol levels.

On the other hand, this technique requires removal and storage of an intact ovary or an ovarian segment with its vasculature. Cryopreservation protocols are currently almost exclusively limited to fragmented non vascular cortex pieces. However, in recent years, improvements in freezing protocols for vessel grafts (22) and reports of cryopreservation of composite tissue and animal organs $(23,24)$ indicate that organ cryopreservation may be possible.

We improved the long-term outcome of transplants by performing end-to-side anastomosis, rather than fish-mouth incisions, in cases of caliber discrepancy. Further advances in the anastomosis technique may help to improve long-term patency. We achieved long-term patency of the anastomosis in three of the six animals. The transplanted ovary showed no significant signs of tissue damage. We also observed one case of veinous thrombosis. At the time of reimplantation, a leak from the ovary (from a biopsy site) was noted; this may have decreased venous pressure and led to occlusion of the venous lumen.

The abdominal wall proved to be a favorable site for autotransplantation procedures in the shee. It is clinically accessible, and branches of the inferior epigastric vessels are suitable for vascular anastomosis to ovarian vessels. If placement of the ovary between bundles of the rectus muscle proves to be not practical in humans, intraperitoneal placement using the same access and anastomosis site can be tested.

Because the sheep is an accepted model in reproductive endocrinology, we performed the microsurgical anastomosis procedures in ewes. The tortuosity and small caliber of the ovarian vessels in the sheep added to the technical challenge of the microsurgical procedure. We believe that anastomosis of the ovarian vessels in humans would be less technically challenging. Furthermore, the ovarian cycle of the ewes was not synchronized, leading to a cycle-dependent variability of hormone levels. 
In conclusion, we found that ovarian autotransplantation with anastomosis of the ovarian artery and vein to branches of the inferior epigastric vessels is technically feasible. In conjunction with improved and adapted protocols for cryopreservation, ovarian autotransplantation with vascular anastomosis may be superior to current ovarian tissue banking and grafting techniques.

\section{Acknowledgements}

The first and the second authors contributed equally to the manuscript. The authors thank David Nelson, M.S., Department for Biostatistics and Epidemiology, Cleveland Clinic Foundation, for assistance with statistical testing and Marc Sabo, M.I., Department for Medical Illustrations, Cleveland Clinic Foundation, for creating the figures.

\section{Footnotes}

Supported by grant 6558 from the Research Programs Council of the Research Institute and the Minimally Invasive Surgery Center at the Cleveland Clinic Foundation. 


\section{References}

1. Anasti J.N., "Premature ovarian failure - an update", Fertil Steril, Volume: 70, (1998), 1-15.

2. Byrne J., "Long-term genetic and reproductive effects of ionizing radiation and chemotherapeutic agents on cancer patients and their offspring", Teratology, Volume: 59, (1999), 210-215

3. Kalantaridou S.N., Davis S.R., Nelson L.M., "Premature ovarian failure", Endocrinol Metab Clin North Am, Volume: 27, (1998), 989-1006.

4. Nugent D., Meirow D., Brook P.F., Aubard Y., Gosden R.G., "Transplantation in reproductive medicine - previous experience, present knowledge and future prospects", Hum Reprod Update, Volume: 3, (1997), 267-280.

5. Salle B., Lornage J., Demirci B., Vaudoyer F., Poirel M.T., Franck M., et al. "Restoration of ovarian steroid secretion and histologic assessment after freezing, thawing, and autograft of a hemi-ovary in sheep", Fertil Steril, Volume: 72, (1999), 366-370.

6. Gosden R.G., Baird D.T., Wade J.C., Webb R., "Restoration of fertility to oophorectomized sheep by ovarian autografts stored at -196 degrees C", Hum Reprod, Volume: 9, (1994), 597-603

7. Aubard Y., Piver P., Cogni Y., Fermeaux V., Poulin N., Driancourt M.A., "Orthotopic and heterotopic autografts of frozen-thawed ovarian cortex in sheep", Hum Reprod, Volume: 14, (1999), 2149-2154

8. Goding J.R., "Ovarian autotransplantation with vascular anastomoses, and its application to the study of reproductive physiology in the ewe", J Physiol, Volume: 186, (1966), 86-87.

9. Scott J.R., Keye W.R., Poulsen A.M., Reynolds W.A., "Microsurgical ovarian transplantation in the primate", Fertil Steril, Volume: 36, (1981), 512-515.

10. Acland R.D., (Ed.) Microsurgery practice manual, (1980), 38-64 Mosby, St. Louis.

11. McNeilly J.R., McNeilly A.S., Walton J.S., Cunningham F.J., "Development and application of a heterologous radioimmunoassay for ovine follicle-stimulating hormone", J Endocrinol, Volume: 70, (1976), 69-79.

12. Meirow D., "Ovarian injury and modern options to preserve fertility in female cancer patients treated with high dose radio-chemotherapy for hemato-oncological neoplasias and other cancers", Leuk Lymphoma, Volume: 33, (1999), 65-76.

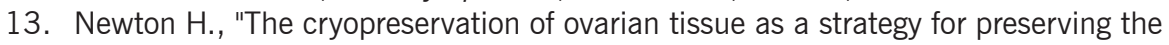
fertility of cancer patients", Hum Reprod Update, Volume: 4, (1998), 237-247.

14. Picton H.M., Gosden R.G., "In vitro growth of human primordial follicles from frozen-banked ovarian tissue", Mol Cell Endocrinol, Volume: 166, (2000), 27-35.

15. Oktay K., Economos K., Kan M., Rucinski J., Veeck L., Rosenwaks Z., "Endocrine function and oocyte retrieval after autologous transplantation of ovarian cortical strips to the forearm", JAMA, Volume: 26, (2001), 1490-1493 286.

16. Baird D.T., Webb R., Campbell B.K., Harkness L.M., Gosden R.G., "Long-term ovarian function in sheep after ovariectomy and transplantation of autografts stored at $-196^{\circ} \mathrm{C} "$, J Endocrinol, Volume: 140, (1999), 462-471.

17. Newton H., Fisher J., Arnold J.R., Pegg D.E., Faddy M.J., Gosden R.G., "Permeation of human ovarian tissue with cryoprotective agents in preparation for cryopreservation", Hum Reprod, Volume: 13, (1998), 376-380.

18. Horvath E., Kovacs K., Garg B.D., Tuchweber B., "Ultrastructure of the rat ovary transplanted into the spleen", Gynecol Invest, Volume: 4, (1973), 73-83.

19. Cox S.L., Shaw J., Jenkin G., "Transplantation of cryopreserved fetal ovarian tissue to adult recipients in mice", J Reprod Fertil, Volume: 107, (1996), 315-322. 
20. Schnorr J.A., Oehninger S.C., Toner J.P., Hsiu J.G., Williams R.F., Hodgen G.D., "Fresh and cryopreserved extrapelvic primate ovarian transplantation in non-human primates - folliculogenesis, ovulation, corpus luteum function, endometrial development and menstrual patterns", Fertil Steril, Volume: 74, (2000), S1.

21. Imthurn B., Cox S.L., Jenkin G., Trounson A.O., Shaw J.M., "Gonadotrophin administration can benefit ovarian tissue grafted to the body wall - implications for human ovarian grafting", Mol Cell Endocrinol, Volume: 163, (2000), 141-146.

22. Song Y.C., Hagen P.O., Lightfoot F.G., Taylor M.J., Smith A.C., Brockbank K.G., "In vivo evaluation of the effects of a new ice-free cryopreservation process on autologous vascular grafts", J Invest Surg, Volume: 13, (2000), 279-288.

23. Zhang F., Attkiss K.J., Walker M., Buncke H.J., "Effect of cryopreservation on survival of composite tissue grafts", J Reconstr Microsurg, Volume: 14, (1998), 559-564.

24. Suzuki H., Imada M., Sano T., Hattori Y., Harada Y., Okamura H., et al. "Ultrastructural and functional studies of cryopreserved rat lungs for transplantation using a new hyperosmolal solution", Kaibogaku Zasshi, Volume: 75, (2000), 275-283. 



\section{Chapter 5}

Restoration of ovarian function after autotransplantation of intact frozen-thawed sheep ovaries with microvascular anastomosis

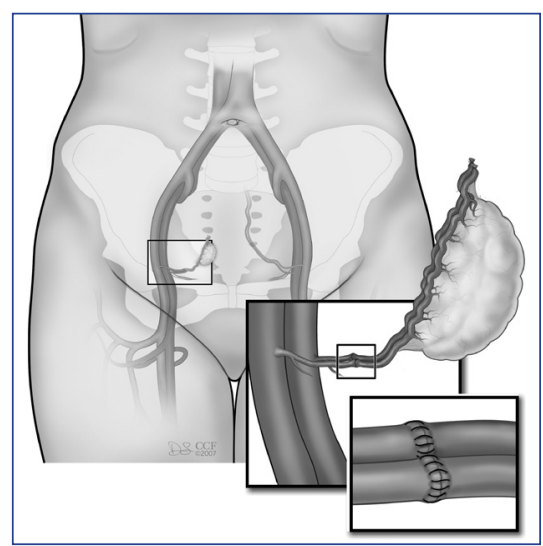

Mohamed A Bedaiwy, Elisabeth Jeremias, Raffi Gurunluoglu, Mahmoud R Hussein, Maria Siemianow, Charles Biscotti Tommaso Falcone

Fertility Sterility, 2003; 79(3): 594-602 


\section{Abstract}

Objective: To test the feasibility of transplanting an intact frozen-thawed ovary with microvascular anastomosis of the ovarian vascular pedicle to the deep inferior epigastric vessels.

Design: Chronic survival study.

Setting: Biological Resources Unit, the Cleveland Clinic Foundation.

Animal(s): Adult merino ewes.

Intervention(s): Bilateral laparoscopic oophorectomy was performed on 17 synchronized ewes. In one group of animals (Group I, $\mathrm{n}=11$ ), both ovaries were cryopreserved intact with their vascular pedicles. In another group of animals (Group II, $\mathrm{n}$ $=6$ ), ovarian cortical strips were prepared from each ovary and cryopreserved. After thawing, follicular viability and apoptosis rates were assessed using one ovary. The other ovary was transplanted to the abdominal wall with microvascular anastomosis (Group I). In Group II, the ovarian cortical strips were placed in the anterior abdominal wall. Ovaries were harvested after $8-10$ days in situ and subjected to histological evaluation.

Main Outcome Measure(s): Blood flow, apoptotic signals, follicular viability, serum estradiol (E2), follicle stimulating hormone (FSH), and histology.

Result(s): No significant differences were found in the mean values of apoptosis (mostly in the atretic and some secondary follicles) and follicular viability in both groups. In Group I, immediate and long-term patencies were documented in 100\% and $27 \%(3 / 11)$ of the grafts, respectively; and postoperative FSH levels were similar to preoperative values in animals with patent vessels. In Group II, postoperative FSH levels were significantly higher than the preoperative ones $(P=.03)$.

Conclusion(s): Transplantation of an intact frozen-thawed ovary is technically feasible. Using this approach, immediate restoration of vascular supply and ovarian hormonal functions is possible.

Key Words: Cryopreservation, ovarian transplantation, vascular anastomosis, apoptosis, follicular viability. 


\section{Introduction}

Cryopreservation of ovarian tissues carries the hope of safeguarding the reproductive potential for women receiving sterilizing cancer therapy (1). Transplantation of frozenthawed ovarian cortical strips and hemiovaries without vascular anastomosis gave rise to pregnancies/ live births in many studies in several species such as sheep (2, 3 ), mouse (4), mouse intact ovaries (5), and rats (6). The human trials have shown promising results that have some limitations that require some more research. The limited length of ovarian function in some human ovarian transplant cases using non vascularized grafts may be partially due to ischemic injury until revascularization occurs (7-9). Therefore, the reduction of ischemia time and immediate revascularization are crucial for long-term survival and function of the grafts (10). We postulate that transplanting intact ovaries with vascular anastomosis may circumvent the problems associated with the use of the ovarian tissue slices. A previous study demonstrated that a successful pregnancy was achieved after transplantation of intact frozen-thawed rat ovaries in the upper genital tract (11).

Autotransplantation of intact fresh sheep ovaries with vascular anastomosis to the deep inferior epigastric vessels is technically feasible (12). In this study, long-term patency of the anastomosis was achieved in three of the six cases, with an excellent outcome of the transplanted ovary showing no significant signs of tissue damage. The cryopreservation of an intact ovary with its vascular pedicle is quite a challenging procedure due to: 1 . Factors affecting the cryosurvival of ovarian tissues are mostly unknown. 2. Tissue cryopreservation presents serious physical constraints related to heat and mass transfer. 3 . The dynamics of cryoprotective agents are poorly understood (13). 4. Adequate diffusion of cryoprotectant into large tissue masses is difficult. We postulated that it would be feasible to transplant an intact cryopreserved-thawed ovary with a vascular anastomosis. To test this hypothesis, the study was designed to: 1 . Evaluate the feasibility of cryopreservation and transplantation of intact sheep ovary with vascular anastomosis. 2. Compare it with transplantation of frozen-thawed ovarian cortical strips without vascular anastomosis.

\section{Materials and methods}

\section{Animals}

This study was approved by the Institutional Animal Research Committee of the Cleveland Clinic Foundation. Seventeen adult, non pregnant merino ewes, weighing 55-70 kg, were included in this chronic survival study. Surgical procedures were performed at the Cleveland Clinic Foundation Biological resources Unit, in accordance 
with the facility's standard operating procedures (IACUC protocol).

The animals were cared for according to the standards of the U.S. Public Health Policy of the Humane Care and Use of Laboratory Animals (PHS Manual, Ch. 143). All animals were synchronized by using megestrol acetate, Ovaban (Schering Plough, Kenilworth, NJ) in a dose of $0.55 \mathrm{mg} / \mathrm{kg} /$ day for 10-12 days, followed by 5,000-10,000 IU Profasi (Serono, Randolph, MA) 34-36 hours before surgery. Animals were divided into two groups: 1. Animals for intact ovary cryopreservation and transplantation (Group I, $n=11$ ). 2. Animals for ovarian cortical strips cryopreservation and transplantation (Group II, $\mathrm{n}=6$ ).

\section{Laparoscopic oophorectomy}

After induction of general anesthesia and endotracheal intubation, the animal was secured on the operating table. A $10-\mathrm{mm}^{\circ}$ laparoscope was inserted through an umbilical incision. Pneumoperitoneum was created with $\mathrm{CO} 2$ at $10 \mathrm{~L} / \mathrm{min}$ and 12 $\mathrm{mm} \mathrm{Hg}$ of intraperitoneal pressure. The animal was placed in a slight Trendelenburg position, and inspection of the pelvis was performed. Ancillary 5-mm trocars were inserted through the right and left lateral skin incisions $5 \mathrm{~cm}$ below and $8 \mathrm{~cm}$ lateral to the umbilicus. A third 5-mm trocar was placed at the level of the camera port. The ovarian vessels were identified, and their course was traced from the hilum cephalad. The ovary was dissected off the uterine horn oviduct, and the infudibulopelvic blood vessels were dissected of the surrounding tissue. The skeletonized blood vessels were double ligated as proximal as possible with non absorbable 1-0 multifilament silk suture using intracorporeal ligature technique. The ovary was removed through one of the 5-mm trocars and biopsied. The same process was repeated on the other side.

\section{Cryopreservation}

\section{Cryopreservation of the intact ovary}

The grafts were perfused with heparinized Ringer's solution, followed by perfusion and immersion in a bath containing Leibovitz L-15 medium (Irvine Scientific, Santa Ana, CA), 10\% fetal calf serum (Irvine Scientific), and $1.5 \mathrm{M}$ dimethyl sulphoxide (DMSO) (Sigma, St. Louis, MO) immediately after oophorectomy. The ovarian vessels and excess hilar tissue were dissected, and ovarian ligaments were trimmed. The grafts were perfused via the ovarian artery with the cryoprotective mixture using Horizon Nxt. Modular Infusion System (McGaw Inc., Irvine, CA) to maintain a flow rate at 1.3 $\mathrm{mL} / \mathrm{min}-1$ with continuous replenishment of the reservoir. After perfusion, the ovary was transferred to a $5 \mathrm{~mL} 12.7 \mathrm{~mm}$ x $92 \mathrm{~mm}$ cryovial (Corning Coaster Corporation, 
Cambridge, MA) containing the cryoprotective mixture for controlled freezing using Planer cryochamber (Planer Freezer Ltd., Middlesex, United Kingdom). Cooling began at $4{ }^{\circ} \mathrm{C}$ and at $2{ }^{\circ} \mathrm{C}$. min- 1 until ice nucleation was induced at $-7^{\circ} \mathrm{C}$. The temperature was then reduced at $2{ }^{\circ} \mathrm{C}$. min- 1 until $-35^{\circ} \mathrm{C}$ and, subsequently, at $25^{\circ} \mathrm{C}$. min- 1 until $-140^{\circ} \mathrm{C}$ before the cryovials were plunged into liquid nitrogen.

\section{Cryopreservation of the ovarian cortical strips}

The ovarian cortical strips were prepared as described by Gosden et al. (2) and cryopreserved using the previously mentioned protocol but without perfusion.

\section{Thawing}

Thawing of the intact ovary

One week later, the vial was removed from the Dewar and held for 1 minute at room temperature before plunging and swirling it in a bath of water at $37^{\circ} \mathrm{C}$ with gentle shaking. The contents of the vial were quickly emptied into a Petri dish containing Leibovitz L-15 medium supplemented with $10 \%$ fetal calf serum. The ovary was washed and immediately perfused with Leibovitz L-15 medium supplemented with $10 \%$ fetal calf serum, using the same flow rate as described earlier, for 20 minutes. The cryoprotectant was gradually eliminated by pumping Leibovitz L-15 medium, supplemented with $10 \%$ fetal calf serum, into the reservoir.

\section{Thawing of the ovarian cortical strips}

Ovarian strips were thawed using the same procedure described previously with Group I. Then, they were washed and held in Leibovitz L-15 medium containing 10\% fetal calf serum for 20 minutes, and then transplanted.

\section{In vitro assessment of the cryopreserved-thawed ovarian tissue}

For each animal, one ovary was transplanted while the other was used for in vitro studies including viability and apoptosis assays.

\section{Evaluation of the ovarian follicular viability using Trypan blue test}

In both groups, ovarian fragments were thinly sectioned in Leibovitz L-15 medium supplemented with $1 \mathrm{mg} / \mathrm{mL}$ (200 IU/mL) type 1 collagenase (Sigma), incubated at $37^{\circ} \mathrm{C}$ for 2 hours, and pipetted every 30 minutes. Collagenase activity was inhibited by $50 \%$ fetal calf serum. The suspension was filtered through a $70-m$ nylon filter (Becton Dickinson Labware, Franklin Lakes, NJ) and centrifuged at $400 \mathrm{~g}$ for 5 minutes. The precipitate was diluted with $50 \mathrm{~mL}$ of Leibovitz L-15 medium and conserved in a water bath at $37^{\circ} \mathrm{C}$. Trypan blue $(0.4 \%$, Sigma) was added to the 
suspension containing the follicles $(20 \mathrm{~L})$, deposited on a glass slide, and examined under an inverted microscope (400x). For each fragment, 100 small, intact follicles (6 $\mathrm{mm}$ in diameter) were examined, while the partially or completely denuded oocytes were excluded.

Evaluation of the ovarian apoptosis using terminal deoxynucleotidyl transferase (TdT)mediated deoxyuridine triphosphate (dUTP)-digoxigenin nick-end labeling (TUNEL)

The corresponding tissue sections were used for the TUNEL assay to detect apoptosis (QIA33TDT-FragEL ${ }^{\mathrm{T} M}$ kits; Oncogen Research Products, Boston, MA). Briefly, after deparaffinization and dehydration, the sections were rinsed in phosphate- buffered

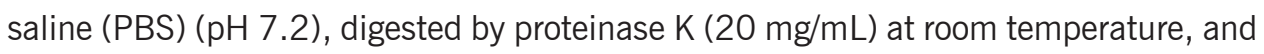
then rinsed in distilled water. The peroxidase activity was blocked by $2 \%$ hydrogen peroxide. After the application of an equilibration buffer, slides were incubated in TdT enzymes for 1.5 hours (at $37^{\circ} \mathrm{C}$ ). The reaction was halted by a stop solution; then, the slides were rinsed in PBS. The incorporated nucleotides were identified by adding peroxidase streptavidine-conjugate.

Slides were then incubated with 3, 3-diaminobenzidine and counterstained with $5 \%$ methyl green. Positive controls were obtained from the manufacturer. The controls consisted of formaldehyde-fixed, paraffin-embedded sections from HL60 promyelocytic leukemia cells and HL60 cells, which were incubated with $0.5 \mathrm{~g} /$ $\mathrm{mL}$ actinomycin D for 19 hours in order to induce apoptosis. Some ovarian tissue specimens were used as negative controls by substituting a microliter of distilled water for the deoxynucleotidyl transferase from the protocol, as suggested by others (14, 15). For the initial assessment of TUNEL-positive cells, following other researchers $(16,17)$, the results of TUNEL assay were evaluated according to the signal intensity as follows: -, weak; + , moderate; ++ , intense; +++ , very intense. Then, all slides were examined at 400 magnification. Positively labeled cells were counted in a defined visual field. Ten different areas of each follicular wall were examined, and the mean number of positively stained cells was determined.

\section{Autotransplantation}

\section{Autotransplantation of the intact ovary (Group I)}

The animal was prepared as mentioned previously. An incision (3-4 cm) was made on the anterior abdominal wall, near the site of the 5-mm trocar, in order to expose the deep inferior epigastric vessels. A branch with a caliber matching that of the ovarian vessels was identified and dissected. Standard microsurgical instrumentation and Acland vascular microclamps were used for the anastomosis. Microvascular 
anastomosis was performed using 8-10 interrupted sutures (9-0 or 10-0 prolene) in an end-to-end fashion under Zeiss surgical microscope (Carl Zeiss, Oberikochen, Germany). Diluted heparin was applied topically as required. The ovary was fixed between the bundles of the rectus muscle. After surgery, all animals were anticoagulated using 5,000 IU sodium heparin (Eli Lilly and Company, Indianapolis, IN) s.c., b.i.d., for 3 days.

\section{Autotransplantation of the ovarian cortical strips (Group II)}

A small incision was made and a segment of the deep inferior epigastric vessels was dissected in order to create a pocket in the rectus abdominis muscle. The cortical strips of one ovary were aligned in the created pocket and fixed using few sutures (9-0 or10-0 prolene).

\section{Postoperative assessments}

After 8-10 days, the transplant was inspected for macroscopic appearance, presence of visible follicles, and pulsations at the arterial anastomosis and patency of microvascular anastomoses. Viability of the ovarian transplant was also evaluated by checking the bleeding from the edges at a small incision. The transplant was then removed and dissected for further evaluation.

\section{Hormonal assay}

Venous blood from the animal was aseptically drawn in sterile $10-\mathrm{mL}$ tubes, containing $0.2 \mathrm{~mL}$ of heparin at a concentration of $1,000 \mathrm{U} / \mathrm{mL}$, before laparoscopic oophorectomy and before removal of the graft. The collected blood samples were centrifuged at 1,600 rpm for 7 minutes, and the serum was isolated and stored at -70 ${ }^{\circ} \mathrm{C}$ until examination.

\section{Evaluation of the serum estradiol (E2)}

Quantitative measurement of serum E2 was performed using the Automated Chemiluminescence Immunoassay System (ACS: 180; Bayer, Tarrytown, NY).

\section{Evaluation of follicle-stimulating hormone (FSH)}

The measurement of the ovarian FSH levels, by radioimmunoassay, was performed at the Reproductive Endocrinology Laboratory at Colorado State University, Fort Collins, Colorado, as previously described. This measurement was performed using NIH antiovine FSH (A780) as an FSHantibody and A853 (ARGG) as a second 
antibody. The data were analyzed using the RIANAL program (Colorado State University). Baseline FSH levels were obtained on the day of surgery (before oophorectomy) and on the day the transplant was removed.

\section{Histological evaluation}

The ovarian tissues were Bouin-fixed, paraffin-embedded, H\&E stained for histological evaluation of the primordial follicle count, presence of primary and secondary follicles, infarction, and apoptosis following previously established criteria (18). These criteria included: condensed nuclear fragments nuclei with marginated chromatin, multiple nuclear fragments; a single condensed nucleus, membrane bound structures containing variable amounts of chromatin and/or cytoplasm, and eosinophilic cytoplasm (19).

\section{Statistical analysis}

Analysis of variance (ANOVA) was used to compare the preoperative to postoperative values $(P=.05)$ using SAS version 8.1 software (SAS Institute Inc., Cary, NC).

\section{Results}

\section{The follicular viability}

The primordial follicular viability in cryopreserved intact ovaries $(83.2 \pm 3.79)$ was comparable to that of the ovarian cortical strips $(82.2 \pm 4.12)$ as evidenced by viability staining $(P=621$; Table 1 and Fig. 1$)$. 


\begin{tabular}{|c|c|c|c|c|c|c|c|c|c|}
\hline \multicolumn{7}{|c|}{ Intact ovary (group I, $\mathrm{n}=11$ ) } & \multicolumn{3}{|c|}{$\begin{array}{l}\text { Ovarian cortical strips } \\
\quad \text { (group II, } n=6 \text { ) }\end{array}$} \\
\hline & \multicolumn{3}{|c|}{$\begin{array}{l}\text { Patent vascular anastomosis } \\
\qquad(\mathrm{n}=3)\end{array}$} & \multicolumn{3}{|c|}{$\begin{array}{l}\text { Occluded vascular anastomosis } \\
\qquad(\mathrm{n}=8)\end{array}$} & \multirow[b]{2}{*}{$\begin{array}{l}\text { Baseline } \\
\text { mean } \\
\pm S D \\
\end{array}$} & \multirow[b]{2}{*}{$\begin{array}{l}\text { Post-grafting } \\
\text { mean } \pm \text { SD }\end{array}$} & \multirow[b]{2}{*}{ p-value } \\
\hline & $\begin{array}{l}\text { Baseline } \\
\text { mean } \\
\pm S D \\
\end{array}$ & $\begin{array}{l}\text { Post-grafting } \\
\text { mean } \pm \text { SD }\end{array}$ & p-value & $\begin{array}{l}\text { Baseline } \\
\text { mean } \\
\pm S D \\
\end{array}$ & $\begin{array}{l}\text { Post-grafting } \\
\text { mean } \\
\pm \text { SD } \\
\end{array}$ & p-value & & & \\
\hline $\begin{array}{l}\text { FSH } \\
(\mathrm{pg} / \mathrm{mL})\end{array}$ & $\begin{array}{l}182 \pm \\
70.3\end{array}$ & $\begin{array}{l}172 \pm \\
42.0\end{array}$ & 0.84 & $\begin{array}{l}103 \pm \\
89.7\end{array}$ & $268 \pm 109$ & 0.005 & $\begin{array}{l}147 \pm \\
66.1\end{array}$ & $\begin{array}{l}249 \pm \\
80.8\end{array}$ & 0.03 \\
\hline $\begin{array}{l}\text { E2 } \\
(\mathrm{ng} / \mathrm{mL})\end{array}$ & $\begin{array}{l}166 \pm \\
50.0\end{array}$ & $\begin{array}{l}163 \pm \\
32.6\end{array}$ & 0.94 & $\begin{array}{l}199 \pm \\
115\end{array}$ & $282 \pm 132.0$ & 0.25 & $\begin{array}{l}129 \pm \\
33.4\end{array}$ & $\begin{array}{l}154 \pm \\
28.9\end{array}$ & 0.19 \\
\hline \multicolumn{10}{|c|}{ In-vitro assessment of follicular viability and apoptosis assay } \\
\hline \multicolumn{6}{|c|}{ Intact ovary (group I, $\mathrm{n}=11$ ) } & \multicolumn{3}{|c|}{$\begin{array}{l}\text { Ovarian cortical strips } \\
\text { (group } \|, n=6 \text { ) }\end{array}$} & $p$-value \\
\hline \multirow{2}{*}{\multicolumn{3}{|c|}{$\begin{array}{l}\text { Follicular viability (\%) } \\
\text { Apoptotic signals }\end{array}$}} & \multirow{2}{*}{\multicolumn{3}{|c|}{$\begin{array}{l}83.2 \pm 3.79 \\
2.44 \pm 0.86\end{array}$}} & \multirow{2}{*}{\multicolumn{3}{|c|}{$82.2 \pm 4.12$}} & 0.62 \\
\hline & & & & & & & & & 0.12 \\
\hline
\end{tabular}

Note: SD _ standard deviation; FSH _ follicle-stimulating hormone; E2 _ estradiol.

Table 1: Assessment of baseline and post-grafting endocrine functions and in-vitro assessment of follicular viability and apoptosis assay of both groups.

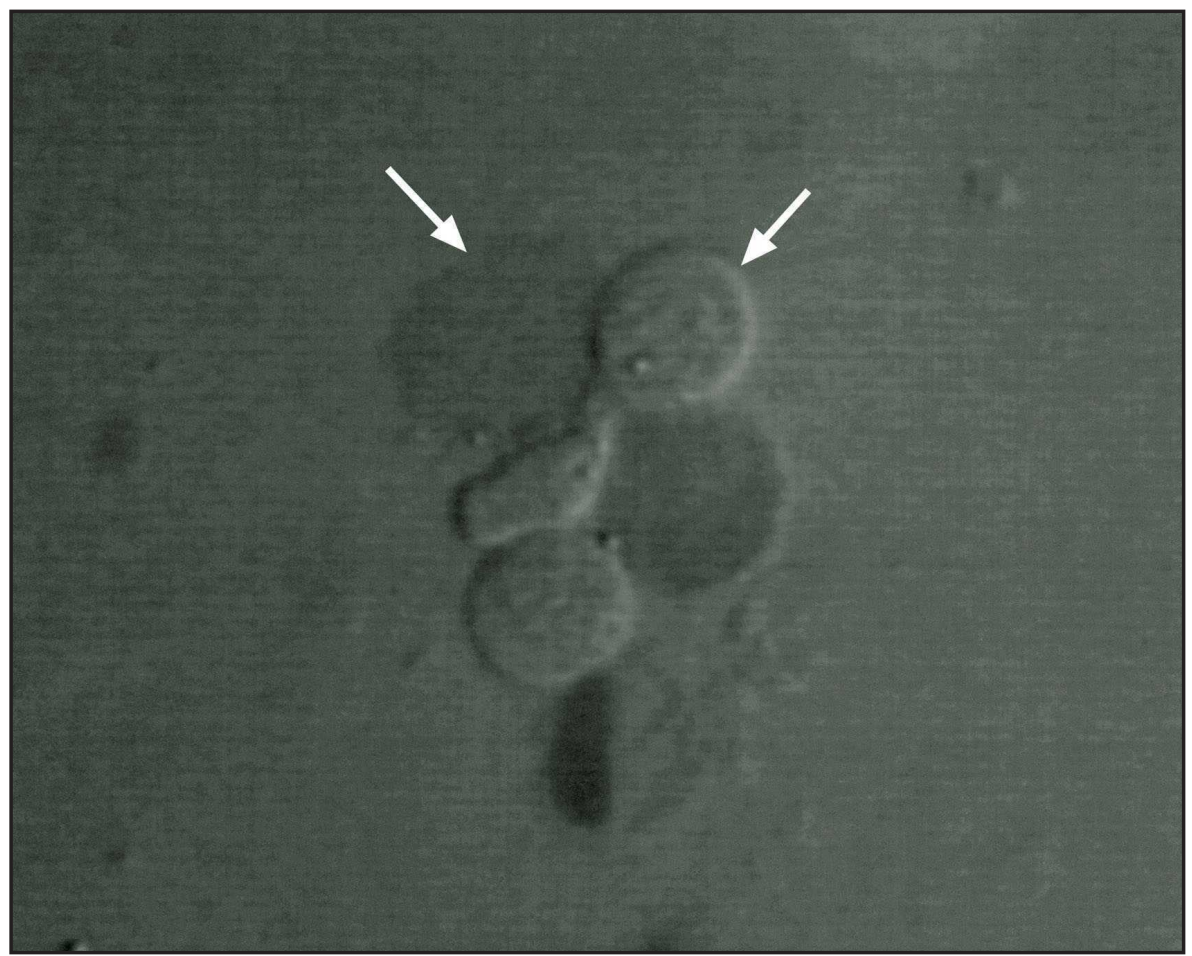

Figure 1: Results of Trypan blue staining, (left arrow), Dead follicles; (right arrow), live follicles. 


\section{TUNEL assay}

None of the negative controls showed TUNEL-positive immunoreactivity, while positive signals were consistently observed in the positive controls. The evaluation of apoptosis in ovarian tissues revealed the lack of apoptotic signals in the healthy (primordial, primary, and most of the secondary) follicles. The TUNEL-positive signals were mainly detected in the nuclei of granulosa cells of the atretic and, occasionally, in some secondary follicles. These positively stained nuclei were observed either in the central layers of the membrana granulosa, at the antral surface, or floating in the follicular antrum. Apoptosis was absent both in the interstitial cells and in the theca cells of the atretic follicles. The mean values of apoptotic cells in cryopreserved intact ovaries $(2.44 \pm 0.867)$ were comparable to that of the ovarian cortical strips $(2.05 \pm$ $0.99)$ as evidenced by combined histological assessment and TUNEL assay $(P=.12)$. Most of the apoptotic bodies were observed in secondary and atretic follicles (Table 1 and Figs. 2A and 2B).

\section{Immediate vascular patency}

Upon removing the microclamps at the end of the microvascular anastomosis, blood flow was documented for at least 20 minutes in all 11 transplants, documenting immediate postoperative success. In all transplants, microsurgical anastomosis of the ovarian artery and vein to branches of the deep inferior epigastric vessels was performed in end-to-end fashion. Matched segments of the deep inferior epigastric vessels were selected to avoid any caliper discrepancy.

\section{Long-term vascular patency}

Eight to ten days following transplantation, the previously vascularized grafts were evaluated in situ and then removed for further evaluation. At the follow-up, 27\% (3/11) of the transplants were viable and did not show any signs of necrosis. Arterial bleeding was documented at an incision made at the surface of the ovaries, documenting long-term patency of the anastomosis. In eight cases, the anastomosed vessels were completely occluded, leading to immense tissue loss. The ischemia time, which was defined as the sum of the time from removal of the ovary to cryopreservation plus the time from thawing to transplantation, was not significantly different between patent and occluded vessel groups ( $3.92 \pm 0.355$ vs. $4.03 \pm 0.162)$. 

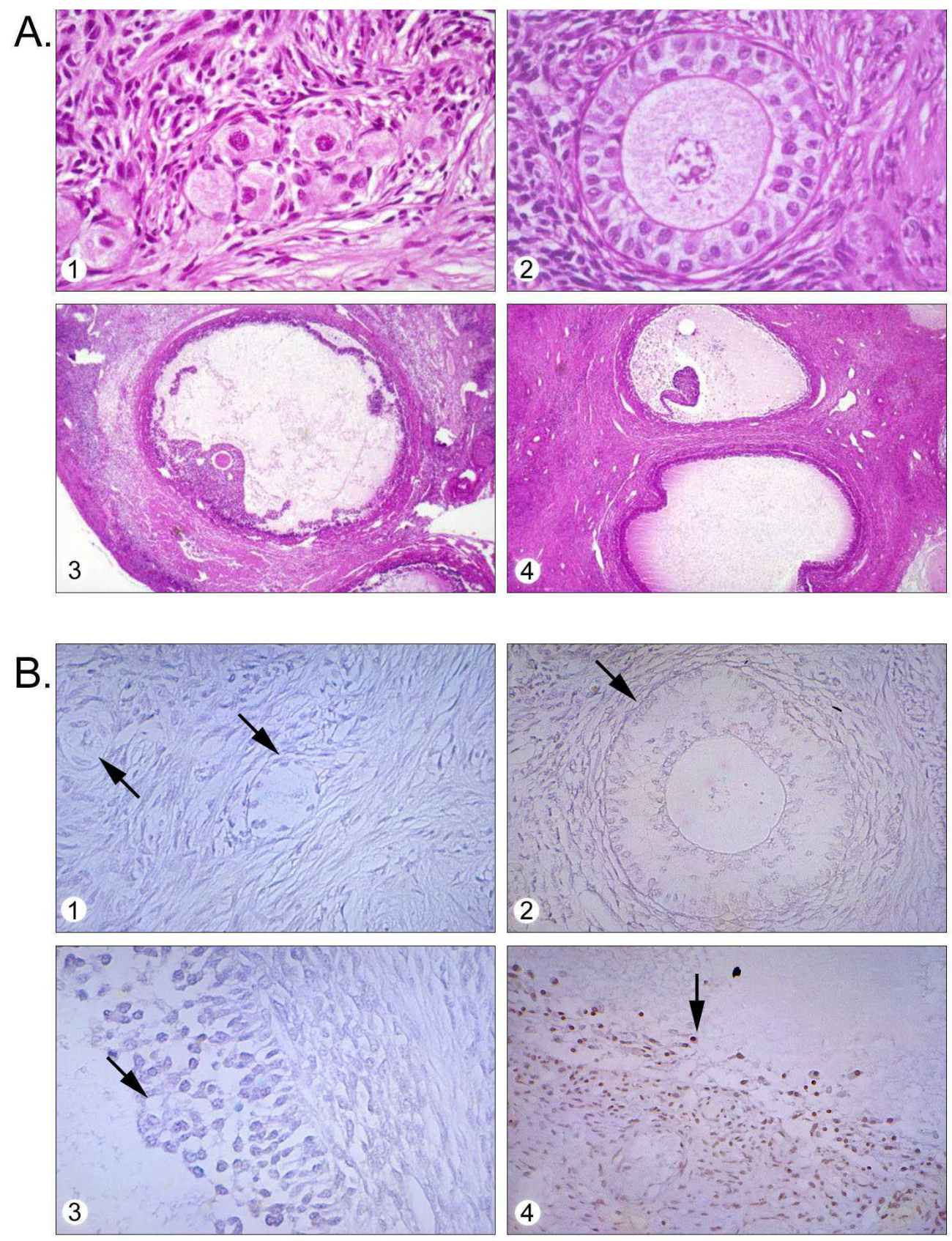

Figure 2: (A) The post-thaw histological characteristics of the primordial (1), primary (2), secondary (3) and atretic (4) ovarian follicles from intact ovary, (B) TUNEL assay: Arrows in figure B-1 show primordial follicles, B-2 secondary follicles and B-3 granulosa cells next to follicular antrum, all of which showed TUNEL negative signals. Arrow in B-4 shows positive apoptotic signals in atretic follicle. All the photographs were obtained from group I. 


\section{Serum E2 and FSH}

In Group I, no significant change occurred in serum E2 levels before and after transplantation in either the patent vessel group $(166.0 \pm 50.0 \mathrm{pg} / \mathrm{mL}$ vs. 163.0 $\pm 32.6 \mathrm{pg} / \mathrm{mL})$ or the non patent vessel group $(199.0 \pm 115.0 \mathrm{pg} / \mathrm{mL}$ vs. $282.0 \pm$ $132.0 \mathrm{pg} / \mathrm{mL}$ ), indicating that a small remnant of surviving ovarian cortex tissue was sufficient for the resumption of E2 production (Table 1). In Group II, no significant

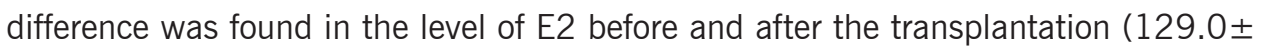
$33.4 \mathrm{pg} / \mathrm{mL}$ vs. $154.0 \pm 28.9 \mathrm{pg} / \mathrm{mL}$ ).

Serum FSH in the patent vessel group did not change significantly from pre- to posttransplantation (182.0 $\pm 70.3 \mathrm{ng} / \mathrm{mL}$ vs. $172.0 \pm 42.0 \mathrm{ng} / \mathrm{mL}, \mathrm{P}=.84$ ), whereas a significant rise was observed in the non patent vessel group $(103.0 \pm 89.7 \mathrm{ng} / \mathrm{mL}$ vs. $268.0 \pm 109.0 \mathrm{ng} / \mathrm{mL}, \mathrm{P}=.0053)$, suggesting ovarian failure. In Group II, a significant difference was also found in the level of FSH after the transplant $(147.0 \pm 66.1 \mathrm{ng} /$ $\mathrm{mL}$ vs. $249.0 \pm 80.8 \mathrm{ng} / \mathrm{mL}, \mathrm{P}=.038$; Table 1 ).

\section{Histology}

In Group I, the mean count of primordial follicle number, per high magnification field after transplantation, revealed a significantly higher number of follicles in the patent as compared with the non patent vessel group $(3.67 \pm 2.08$ vs. $0.250 \pm 0.463, P=.001$; Fig. 3A ). Scattered areas of necrosis were observed on histological assessment of the patent vessel group, whereas transplants in the non patent vessel group showed severe necrosis with thin peripheral rim of viable tissue. For the patent vessel group, histological evaluation revealed: 1 . No signs of necrosis in the 1 -mm cortex rim. 2 . Necrosis of most of the growing follicles, denoting that they did not survive the freezethaw process and the ischemia reperfusion injury (Fig. 3B). 3. Viable patent vessels with an intact muscularis layer; however, some of the intraovarian vessels showed partial transmural necrosis. These vessels showed active regeneration of the vascular endothelium over the necrosed segment (Fig. 3C).

In both groups, the granulosa cells with the histological features of apoptosis were mostly observed in atretic and occasionally in some secondary follicles. These cells were observed either within the central region of the membrane granulosa layer or loosely attached to the membrana granulose near its antral surface or in the antral follicular fluid (Figs. 3B and 3C). 

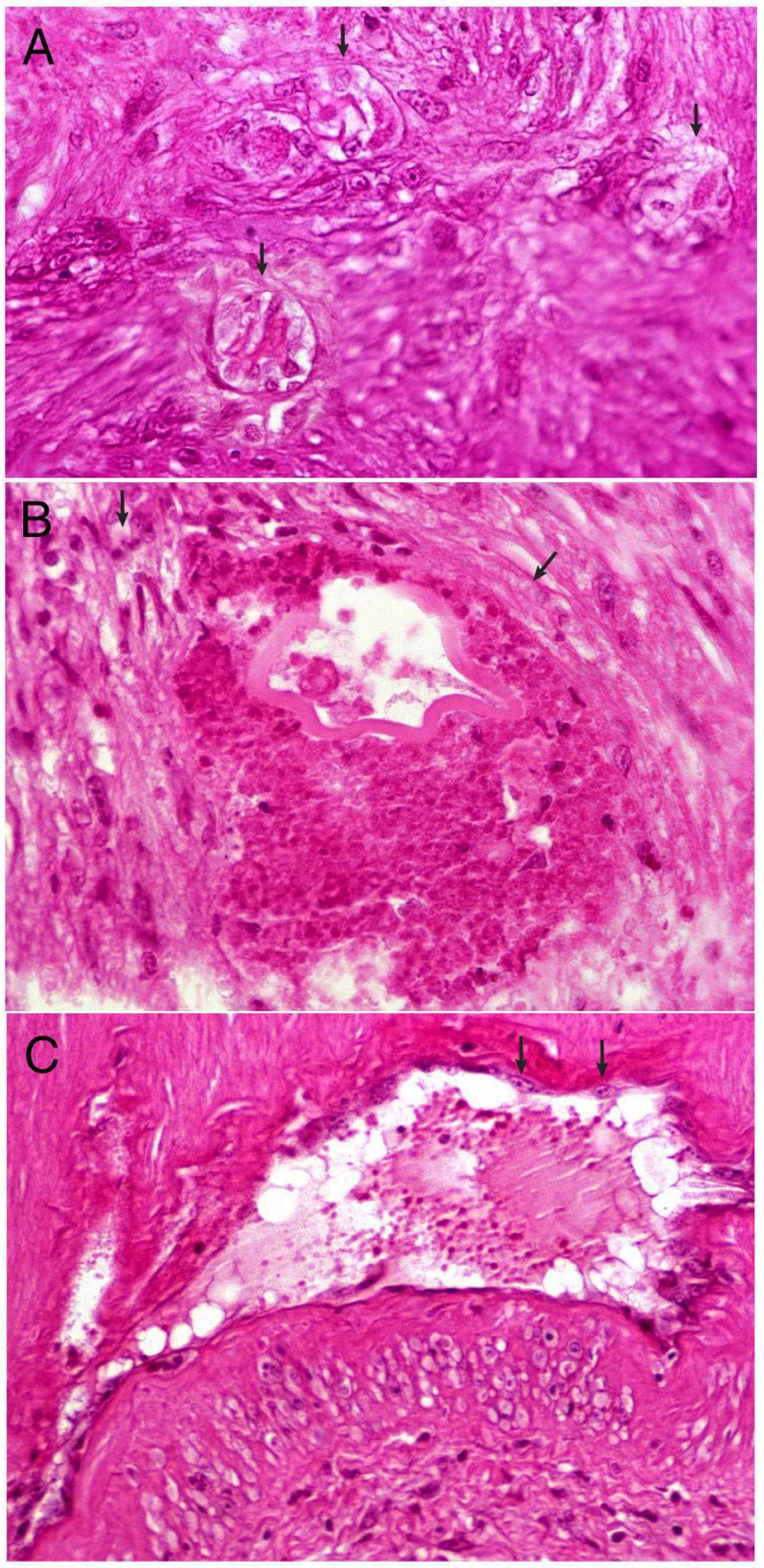

Figure 3: The histological characteristics of ovaries with patent vascular anastomosis. Arrows show numerous viable primary follicles $(A)$, necrotic secondary follicle $(B)$. In $C$, there is patent intraovarian vessel with partial transmural necrosis that shows regeneration of the vascular endothelium over the necrotic segment (magnification X 79). 


\section{Discussion}

Although the intact small-sized ovaries from mice and rats can survive freezing, successful cryopreservation of intact large-sized ovaries from other mammals such as human is still challenging due to: heat and mass transfer limitations; ischemia reperfusion injury; and, more important, intravascular ice-formation problems (20). The rate of cryoprotective agent/cellular water exchange is affected by the amount of tissue through which that agent must diffuse.

During the cooling stage of cryopreservation, the relative distance of cells in the interior of the ovary from the exterior affects the rate at which these cells undergo cooling. Therefore, cryopreserving small pieces (1-2 mm3) of ovarian cortex is considered technically necessary. Because current transplantation procedures do not utilize vascular anastomosis, grafts are completely dependent on post transplantation vascularization. In this regard, the ability of the cells in the graft to obtain nutrients from their surroundings before permanent revascularization depends upon: the vascularity of the transplant recipient site; the diffusion rate of these nutrients to the transplant; and the time needed for full revascularization to be completed. The process of graft preparation from removal of the ovary to the end of the cryopreservation steps was not associated with increased apoptosis in either group, emphasizing the impact of postgrafting revascularization in graft survival.

These results are in agreement with a recent report by Liu and associates (21). Many reports in the literature have attributed a high rate of follicular loss to post grafting ischemia $(13,22)$. The practical solutions for this problem are to:

1. Develop an efficient cryopreservation protocol that allows cryopreservation of an entire ovary, with its vascular pedicle, with minimal tissue damage. 2. Develop a surgical technique that allows successful transplantation of the frozen/thawed ovary with microvascular anastomosis to an anatomically suitable site. In this study, we tried to address these problems. Previous studies proved that cryoinjury mainly affects the central part of the ovary. To diminish this problem, we perfused the ovary with the cryoprotectant via its vascular channel. Optimum cryoprotectant, perfusion volume, perfusion temperature, and perfusion pressure are mandatory for the success of this procedure. Using a special pump system to deliver the cryoprotectant in the ovarian vascular network might be of value to ensure even diffusion among ovarian tissue.

Our cryopreservation protocol proved to be satisfactory as evidenced by the in vitro studies performed. Primordial follicle viability in an intact cryopreserved ovary proved to be comparable to that of ovarian cortical strips, proving that cryopreservation by perfusion does not affect the immediate post thaw viability of the primordial follicles. 
Moreover, in agreement with a previous study (23), cryopreservation and freezethaw trauma were associated with insignificant apoptotic changes. In our study, the mean values of these apoptotic changes in the secondary and atretic follicles of intact frozen-thawed ovaries were insignificantly higher as compared with those in frozen-thawed ovarian cortical strips. The underlying mechanisms of such a lack of significant increase in the apoptotic activity in the intact ovary group, as compared with the ovarian cortical slices, are still open for further investigations. Although the effects of freeze-thaw trauma could not be refuted (24-26), these insignificantly higher apoptosis mean values, mostly observed in the atretic follicles, may reflect the preexisting atretic changes instead of the effect of cryopreservation or the occasional apoptosis in the endothelial cells. The absence of apoptotic signals in the primordial follicles lends further support to the fact that apoptosis is a downstream event that requires active metabolism and usually takes several hours or even days to become manifest (27-29).

In the second part of this experiment, we vascularized thawed ovaries using the deep inferior epigastric vessels by means of microvascular anastomosis under surgical microscope. Immediate patency of the vascular pedicle of all transplanted ovaries confirmed that the ovarian vascular channel system was not grossly damaged by the cryopreservation protocol used; however, long-term patency was obtained in $27 \%$ of the vascularized grafts. The possible explanations for the long-term failure in eight cases are: 1. the extreme tortouisty of the ovarian vessels, making them at high risk for thrombosis. 2. Cryopreservation might have had adverse effects on the intima of the blood vessels, predisposing them to thrombosis and anastomotic failure.

No significant rise of postoperative FSH occurred in sheep with patent anastomosis, denoting that, within 1 week of the transplant, the hypothalamo-pituitary ovarian axis was intact and little tissue damage occurred. Although secondary follicles were necrotic, tissue survival was excellent in the cortical part of the ovaries but with areas of necrosis near center.

A recent primate study showed spontaneous ovulation after subcutaneous transplantation of ovarian cortical strips (30). Furthermore, spontaneous ovulation occurred in a recently reported human case (8). Overall, pregnancy was not achieved in the primate study or in the human case, where pregnancy was desired. This may be partially explained by the initial postransplant ischemic injury of the graft or inadequate follicular maturation. Although no significant difference in E2 levels between animals with patent anastomoses and those with occluded ones, FSH levels were significantly lower in animals with patent anastomoses. This could be explained by lack of inhibin production in animals with occluded anastomosis (31). 
Spontaneous recovery of ovarian function after transplantation can be delayed by 3 to 4 months because ischemia results in the loss of virtually the entire growing follicle population, in addition to the $50 \%$ of the primordial follicles. The growth of a primordial follicle to a large preantral stage takes about 85 days. Some animal studies, however, have shown secretion of progesterone after 4 weeks (32) and, therefore, a return to normal FSH levels before the 3- to 4-month period. Rapid regeneration of the intimal layer of the blood vessels over a partially necrotic vascular wall was a striking feature among the deeper vessels of the ovaries. This observation confirms that, even when tissue damage is induced by the cryopreservation insult and ischemia-reperfusion injury, it still has the potential to regenerate. This is particularly important for the supporting tissue of the ovary. It appears that complex mechanisms from ice formation during the freezing process, and from reperfusion injury, play a role in cellular or architectural damage to the capillary bed as well as the vascular endothelium. This is also evidenced by our observation in histological examinations of specimens from the patent vessel group that demonstrated the presence of partial transmural necrosis, indicating cryoinjury. Although our study did not evaluate the long-term vascular patency and viability of ovarian tissue, based on some evidence in the literature that cryopreserved vessels can completely reendothelialize within 1 to 2 months postoperatively, it can be speculated that the damaged vessels observed in our study would normally heal and further contribute to ovarian viability (33).

In conclusion, we have shown that an intact ovary of a sheep can survive cryopreservation-thawing insults with reasonable tissue viability. This may be due, in part, to the perfusion of the cryoprotectant through the vascular channel.

Autotransplantation of an intact, frozen-thawed ovary with microvascular anastomosis is technically feasible with good short-term results; however, long-term survival and function of these ovaries should be investigated.

\section{Acknowledgments}

The authors thank Sidney C. Abreu, M.D., Fellow in the Minimally Invasive Surgery Center, The Cleveland Clinic Foundation, Cleveland, Ohio, and Crystal G. Thomas, medical student, for their great help and kind assistance. The authors also thank Xiaoming Sha from Colorado State University, Fort Collins, Colorado, for performing the hormonal assays. 


\section{References}

1. Boring CC, Squires TS, Tong T, Montgomery S. Cancer statistics, 1994. CA Cancer J Clin 1994;44:7-26.

2. Gosden RG, Baird DT, Wade JC, Webb R. Restoration of fertility to oophorectomized sheep by ovarian autografts stored at_196 ${ }^{\circ}$ C. Hum Reprod 1994; 9:597-603.

3. Salle B, Demirci B, Franck M, Rudigoz RC, Guerin JF, Lornage J. Normal pregnancies and live births after autograft of frozen-thawed hemi-ovaries into ewes. Fertil Steril 2002;77:403-8.

4. Sztein J, Sweet H, Farley J, Mobraaten L. Cryopreservation and orthotopic transplantation of mouse ovaries: new approach in gamete banking. Biol Reprod 1998;58:1071-4.

5. Candy CJ, Wood MJ, Whittingham DG. Restoration of a normal reproductive lifespan after grafting of cryopreserved mouse ovaries. Hum Reprod 2000;15:1300-4.

6. Aubard Y, Newton H, Scheffer G, Gosden R. Conservation of the follicular population in irradiated rats by the cryopreservation and orthotopic autografting of ovarian tissue. Eur J Obstet Gynecol Reprod Biol 1998;79:83-7.

7. Oktay K, Aydin BA, Karlikaya G. A technique for laparoscopic transplantation of frozen-banked ovarian tissue. Fertil Steril 2001;75:1212-6.

8. Oktay K, Economos K, Kan M, Rucinski J, Veeck L, Rosenwaks Z. Endocrine function and oocyte retrieval after autologous transplantation of ovarian cortical strips to the forearm. JAMA 2001;286:1490-3.

9. Radford JA, Lieberman BA, Brison DR, Smith AR, Critchlow JD, Russell SA, et al. Orthotopic reimplantation of cryopreserved ovarian cortical strips after high-dose chemotherapy for Hodgkin's lymphoma. Lancet 2001;357:1172-5.

10. Aubard Y, Piver P, Cogni Y, Fermeaux V, Poulin N, Driancourt MA. Orthotopic and heterotopic autografts of frozen-thawed ovarian cortex in sheep. Hum Reprod 1999;14:2149-54.

11. Wang X, Chen H, Yin H, Kim SS, Lin Tan S, Gosden RG. Fertility after intact ovary transplantation. Nature 2002;415:385.

12. Jeremias E, Bedaiwy MA, Gurunluoglu R, Biscotti CV, Siemionow M, Falcone T. Heterotopic autotransplantation of the ovary with microvascular anastomosis: a novel surgical technique. Fertil Steril 2002;77:1278-82.

13. Baird DT, Webb R, Campbell BK, Harkness LM, Gosden RG. Longterm ovarian function in sheep after ovariectomy and transplantation of autografts stored at $196^{\circ} \mathrm{C}$. Endocrinology 1999;140:462-71.

14. Gavrieli Y, Sherman Y, Ben-Sasson SA. Identification of programmed cell death in situ via specific labeling of nuclear DNA fragmentation. J Cell Biol 1992;119:493-501.

15. Wijsman JH, Jonker RR, Keijzer R, van de Velde CJ, Cornelisse CJ, van Dierendonck JH. A new method to detect apoptosis in paraffin sections: in situ end-labeling of fragmented DNA. J Histochem Cytochem 1993;41:7-12.

16. Li J, Kim JM, Liston P, Li M, Miyazaki T, Mackenzie AE, et al. Expression of inhibitor of apoptosis proteins (IAPs) in rat granulose cells during ovarian follicular development and atresia. Endocrinology 1998;139:1321-8.

17. Kim JM, Yoon YD, Tsang BK. Involvement of the Fas/Fas ligand system in p53-mediated granulosa cell apoptosis during follicular development and atresia. Endocrinology 1999;140:2307-17.

18. Kerr JF, Wyllie AH, Currie AR. Apoptosis: a basic biological phenomenon with wideranging implications in tissue kinetics. Br J Cancer 1972;26:239-57. 
19. Yang MY, Rajamahendran R. Morphological and biochemical identification of apoptosis in small, medium, and large bovine follicles and the effects of follicle-stimulating hormone and insulin-like growth factor-I on spontaneous apoptosis in cultured bovine granulosa cells. Biol Reprod 2000;62:1209-17.

20. Jacobsen IA, Pegg DE, Starklint H, Chemnitz J, Hunt C, Barfort P, et al. Effect of cooling and warming rate on glycerolized rabbit kidneys. Cryobiology 1984; 21:637-53.

21. Liu J, Van Der Elst J, Van Den Broecke R, Dhont M. Early massive follicle loss and apoptosis in heterotopically grafted newborn mouse ovaries. Hum Reprod 2002; 17:605-11.

22. Gosden RG. Low-temperature storage and grafting of human ovarian tissue. Mol Cell Endocrinol 2000;163:125-9.

23. Demirci B, Salle B, Frappart L, Franck M, Guerin JF, Lornage J. Morphological alterations and DNA fragmentation in oocytes from primordial and primary follicles after freezing-thawing of ovarian cortex in sheep. Fertil Steril 2002;77:595-600.

24. Yagi T, Hardin JA, Valenzuela YM, Miyoshi H, Gores GJ, Nyberg SL. Caspase inhibition reduces apoptotic death of cryopreserved porcine hepatocytes. Hepatology 2001;33:1432-40.

25. Borderie VM, Lopez M, Lombet A, Carvajal-Gonzalez S, Cywiner C, Laroche L. Cryopreservation and culture of human corneal keratocytes. Invest Ophthalmol Vis Sci 1998;39:1511-9.

26. Schmidt-Mende J, Hellstrom-Lindberg E, Joseph B, Zhivotovsky B. Freezing induces artificial cleavage of apoptosis-related proteins in human bone marrow cells. J Immunol Methods 2000;245:91-4.

27. Stammberger U, Gaspert A, Hillinger S, Vogt P, Odermatt B, Weder W, et al. Apoptosis induced by ischemia and reperfusion in experimental lung transplantation. Ann Thorac Surg 2000;69:1532-6.

28. Scarabelli T, Stephanou A, Rayment N, Pasini E, Comini L, Curello S, et al. Apoptosis of endothelial cells precedes myocyte cell apoptosis in ischemia/reperfusion injury. Circulation 2001;104:253-6.

29. Stephanou A, Scarabelli TM, Brar BK, Nakanishi Y, Matsumura M, Knight RA, et al. Induction of apoptosis and Fas receptor/Fas ligand expression by ischemia/reperfusion in cardiac myocytes requires serine 727 of the STAT-1 transcription factor but not tyrosine 701. J Biol Chem 2001;276:28340-7.

30. Schnorr J, Oehninger S, Toner J, Hsiu J, Lanzendorf S, Williams R, et al. Functional studies of subcutaneous ovarian transplants in nonhuman primates: steroidogenesis, endometrial development, ovulation, menstrual patterns and gamete morphology. Hum Reprod 2002;17:612-9.

31. Callejo J, Salvador C, Miralles A, Vilaseca S, Lailla JM, Balasch J. Long-term ovarian function evaluation after autografting by implantation with fresh and frozen-thawed human ovarian tissue. J Clin Endocrinol Metab 2001;86:4489-94.

32. Salle B, Lornage J, Demirci B, Vaudoyer F, Poirel MT, Franck M, et al. Restoration of ovarian steroid secretion and histologic assessment after freezing, thawing, and autograft of a hemi-ovary in sheep. Fertil Steril 1999;72:366-70.

33. Zhang F, Attkiss KJ, Walker M, Buncke HJ. Effect of cryopreservation on survival of composite tissue grafts. J Reconstr Microsurg 1998;14: 559-64. 




\section{Chapter 6}

Autologous transplantation of cryopreserved ovary induces the generation of antiovary antibodies in sheep

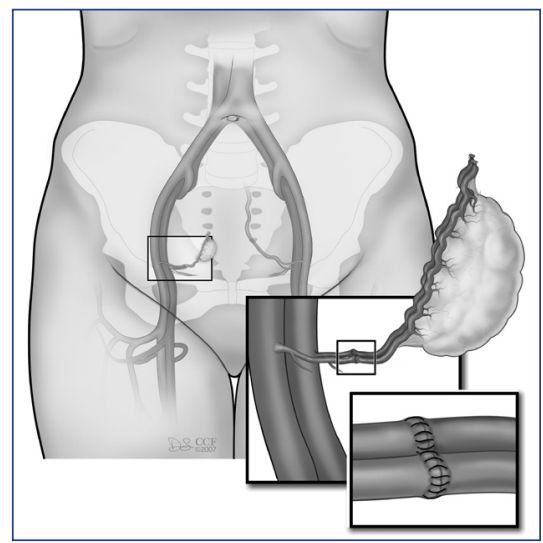

Navid Esfandiari, Tommaso Falcone, Mohamed A. Bedaiwy, Ashok Agarwal, Elisabeth Jeremias, Rakesh K. Sharma

Fertility \& Sterility, 2003; 80(4):1062-4 


\section{Abstract}

Objective: Cryopreservation and autologous transplantation of the ovary has been recognized as an encouraging technique for preservation of reproductive function and fertility for female cancer patients. Ovarian tissue in human and some laboratory animals has been cryopreserved and autografted for some time, but there are no studies on the immunological consequences following ovarian transplantation. In this study using sheep as a model, we examined whether orthotopic transplantation of cryopreserved entire ovary or ovarian cortical strips can result in antibody formation against ovarian tissue antigens.

Design: Experimental study involving 16 sheep.

Materials/Methods: Sixteen adult, non-pregnant merino ewes were included in this study. After perfusion by dimethyl sulfoxide (DMSO), entire ovary $(n=11)$ or ovarian cortical strips $(n=5)$ were cryopreserved using a programmable freezer. After thawing these were transplanted back to the same animal and then removed 7-10 days later for further assessment. Blood was withdrawn from all animals, preoperatively, at transplantation and at removal of the transplant. Anti-ovarian antibodies (AOA) in serum were detected by indirect immunofluorescence assay using commercially available slides of monkey ovarian sections and unfixed 5-mm-thick frozen section of sheep ovary as antigen. Following incubation of antigen with diluted serum samples (1:10 in PBS) and fluorescein isothiocyanate conjugated-mouse anti-sheep immunoglobulin, the sections were mounted in PBS-glycerine mixture. The slides examined in a blinded manner under a fluorescent microscope at a X 400 magnification. Both a positive control (antibody positive serum) and a non-serum negative control were included in each experiment.

Results: Ovarian antibody was found only in 1 serum sample obtained from an intact ovary with occluded vessels at follow up compared to none in the sera obtained preoperatively or at transplantation. This serum was positive both for monkey ovary sections and frozen section of sheep ovary at a dilution of 1/10.

Conclusions: Our data suggest that heterotopic transplantation of entire ovary or ovarian cortical strips do not induce the immune responses against the ovarian antigens. Perhaps long term exposure, rather than short term exposure, will induce the immune response.

Key words: Ovarian tissue, cryopreservation, autoantibodies. 


\section{Introduction}

Ovarian cryopreservation and grafting has resulted in successful ovulation, pregnancy, and live-born animals including mice and sheep $(1,2)$. The procedure is currently being offered experimentally to humans as a new method for fertility preservation. However, its value frequently has been questioned because of a potential to reintroduce the malignant cells, viral infections, and induction of immune responses against the transplanted ovarian tissue $(3,4)$. In this study using sheep as a model, we examined whether heterotopic transplantation of cryopreserved entire ovary or ovarian cortical strips can result in antibody formation against ovarian tissue antigens.

\section{Materials and Methods}

This study was conducted using 16 adult female, non pregnant merino ewes. Surgical procedures were performed at the Cleveland Clinic Foundation Biological Resources Unit in accordance with the facility's Standard Operating Procedures (Institutional Animal Care and Ewe Committee). The institutional animal research committee approved the study protocol.

All animals underwent bilateral laparoscopic oophorectomy. Ovarian cortex fragments ( $5 \mathrm{~mm} 2$ ) from 5 sheep and whole ovaries from 11 sheep were removed and cryopreserved using a controlled rate freezer (Planer Kryo 10, Series II; TS Scientific, Perkasie, PA). After 7 days of storage in liquid nitrogen $\left(-196^{\circ} \mathrm{C}\right)$, the specimens were thawed. All 5 ovarian cortex fragments and 11 whole ovaries were transplanted back into their original donors. The grafts were removed 7 days later for histological evaluations. Blood samples were withdrawn preoperatively, at transplantation, and at transplant removal. Positive sera was treated for possible heterophilic interference using heterophilic blocking tube (Scantibodies Lab. Inc., Santee, CA) before repeating the test both for monkey and sheep ovarian tissue.

Antiovary antibodies in serum were detected by indirect immunofluorescence assay using commercial slides of monkey ovaries (Immco Diagnostics, Buffalo, NY) and frozen sections of fresh sheep ovary as antigen. The slides were read in a blind fashion. Although laparoscopic oophorectomy, cryopreservation, and transplantation were done by one individual (M.A.B.), the tissue and serum samples were coded before the slides were coated, stained, and read by another individual (N.E.). Serial dilutions of the serum samples (1:2 to 1:32) in phosphate-buffered saline were prepared and applied to unfixed 5 - $\mu$ m-thick sections of sheep and monkey ovary. 
The slides were washed in phosphate-buffered saline, and the presence of antiovary antibodies was detected by a second incubation with fluorescein isothiocyanateconjugated rabbit anti-sheep immunoglobulin (Jackson Immunoresearch Lab., Inc., West Grove, PA). The sections were examined under a fluorescent microscope (Leitz Dialux model; Leitz Wetzlar, GmBH, Wetzlar, Germany) at $\times 400$ magnification in a blinded fashion. Each sample was tested in duplicate in parallel with positive and negative controls according to the manufacturer's instructions. We determined the isotype of the antibody formation in the three animals, and in all positive sera, the antibody isotype was IgM. This again provided additional information that the autoimmune response was beginning to develop.

\section{Results}

We detected antiovary antibodies in three serum samples obtained at transplant removal: two weakly positive samples (titer of 1:2) from sheep that received sliced tissue autograft and one positive sample (titer of $1: 8$ ) from a sheep that received an intact ovary autograft. All three sera were positive on the monkey and frozen sheep ovary slides (Fig 1). There were no antibodies in the sera obtained preoperatively and at transplantation.
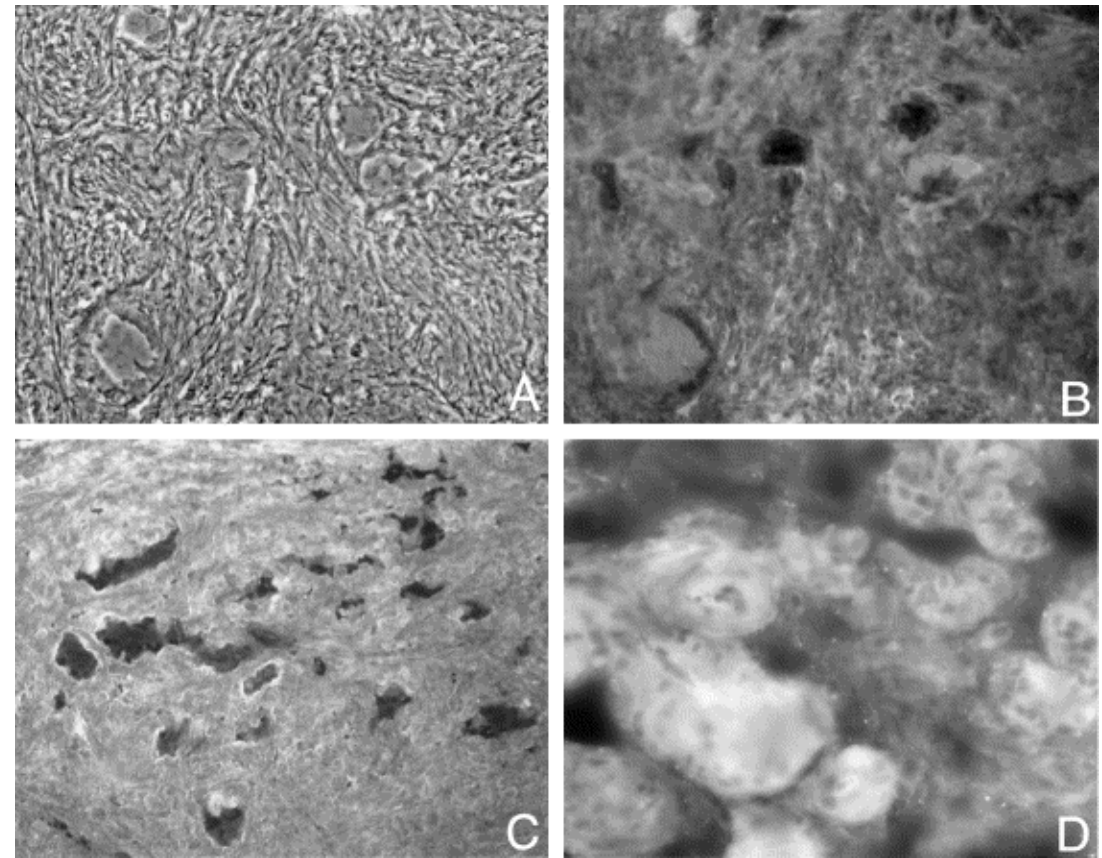

Figure 1: Immunofluorescent analysis of antiovary antibodies using slide preparation of monkey ovaries. (A), Phase contrast. (B), Negative control. (C), Positive control. (D), Sheep ovary. (Magnification, $\times 20$ in A-C; $\times 40$ in D.) 


\section{Discussion}

Anti-ovary antibodies have been reported in patients undergoing repeated IVF and in patients with systemic lupus erythematosus, premature ovarian failure, and endometriosis (5). These reports suggest that the ovary is either an immune target or an organ that contains autoantigens. During oocyte retrieval for IVF, autoantigens and altered immunogenic proteins may be released from internal ovarian layers, which may induce the immune response and result in ovarian antibodies.

It is not known which ovarian antigens are responsible for the induction of antiovary antibodies, but proteins derived from ovarian cells such as granulosa, interstitial cells, epithelial cells, and luteal cells, as well as zona pellucida and receptor sites for FSH and $\mathrm{LH}$ have been implicated $(5,6)$. Several factors may cause immune dysregulation and antibody formation, such as differences in autoantigen response and the duration of antigen exposure to the immune system.

Although the ovary does not have an immunological barrier that is equivalent to the blood-testis barrier in males and cannot be considered an immunologically privileged site, there have been a number of observations that ovary may be compartmentalized with respect to its exposure to the immune system (7). Also it has been speculated that release of self-antigens and altered immunogenic proteins from internal ovarian layers during oocyte retrieval may induce the immune responses and result in formation of ovarian antibodies (8).

Several mechanisms may generate ovary autoantibodies: defects in the selftolerance mechanism of the immune system; exposure of the immune system to large amounts of ovarian autoantigens after repeated follicular puncture or hormonal therapy; and dysfunction of regulatory $T$ cells, which appears to inactivate self-reacting T-cell clones $(5,9)$. When antiovary antibodies are produced, they may negatively affect reproduction by [1] interfering with follicle function and oocyte maturation; [2] coating the surface of the oocyte and preventing sperm from penetrating the zona pellucida, [3] destroying the zona pellucida through complement-mediated cytotoxicity, and [4] preventing hatching from the zona pellucida, thereby impairing implantation.

Moreover, because the primary functions of the ovary are to produce the gametes and provide an endocrine function to support the developing gametes, the antibodies directed to FSH and/or LH receptors may block the receptors and affect normal follicular growth and function.

Several surgical manipulations during ovarian autotransplantation may expose large amounts of ovarian antigens and molecules to the immune system. More important, altered expression of self-antigens that result from physical damage to 


\section{Chapter 6}

ovary cells during in vitro handling, cryopreservation, and heterotopic transplantation may encourage the development of autoantibodies. The fact that three ewes in our study developed antiovary antibodies after ovary autotransplantion supports the above hypothesis. However, this observation raises two further questions: [1] if ovary autografting provokes an immune response, why there is no evidence of their presence in other cases? and [2] what is the relationship between antiovary antibody production and transplant survival and its normal function?

Antibody production triggers soon after antigen exposure, and levels become detectable in serum after about a week. Although we were able to detect the antibody titer in one animal, perhaps longer exposure ( $>7$ days to 1 month) will induce the immune response more efficiently. Additional prospective studies are needed to evaluate the possible role of antiovary antibodies in fertilization and pregnancy outcome in patients undergoing ovarian autotransplantation. 


\section{References}

1. Carroll J., Wood M.J., Whittingham D.G., "Normal fertilization and development of frozen thawed mouse oocytes - protective action of certain macromolecules", Biol Reprod, Volume: 48, (1993), 606-612.

2. Gosden R.G., Baird D.T., Wade J.C., Webb R., "Restoration of fertility to oophorectomised sheep by ovarian autografts stored at $-196^{\circ}$ C", Hum Reprod, Volume: 9, (1994), 597-603.

3. Kim S.S., Battaglia D.E., Soules M.R., "The future of human ovarian cryopreservation and transplantation - fertility and beyond", Fertil Steril, Volume: 75, (2001), 1049-1056.

4. Oktay K., "Ovarian tissue cryopreservation and transplantation - preliminary findings and implications for cancer patients", Hum Reprod Update, Volume: 7, (2001); 7:526-34.

5. Narayanan M., Murthy P.S., Munaf S.A., Shah L.C., Kini M.D., "Antiovarian antibodies and their effect on the outcome of assisted reproduction", J Assist Reprod Genet, Volume: 12, (1995), 599-605 526-534.

6. Moncayo H., Moncayo R., Benz R., Wolf A., Lauritzen C., "Ovarian failure and autoimmunity. Detection of autoantibodies directed against both the unoccupied luteinizing hormone/human chorionic gonadotropin receptor and the hormone-receptor complex of bovine corpus luteum", J Clin Invest, Volume: 84, (1989), 1857-1865.

7. Dunbar B.S., Prasad S., Carino C., Skinner S.M., "The ovary as an immune target", J Soc Gynecol Invest, Volume: 8, (2001), S43-48.

8. Gobert B., Barbarino-Monnier P., Guillet-May F., Bene M.C., Faure G.C., "Anti-ovary antibodies after attempts at human in vitro fertilization induced by follicular puncture rather than hormonal stimulation", J Reprod Fertil, Volume: 96, (1992), 213-218.

9. Ishikawa F., Shigematsu H., Gondo H., Okamura T., Niho Y., "Autoreactive antibodies following autologous peripheral blood stem cell transplantation", Bone Marrow Transplant, Volume: 22, (1998), 729-731. 



\section{Chapter 7}

\section{Cryopreservation of intact human ovary with its vascular pedicle}

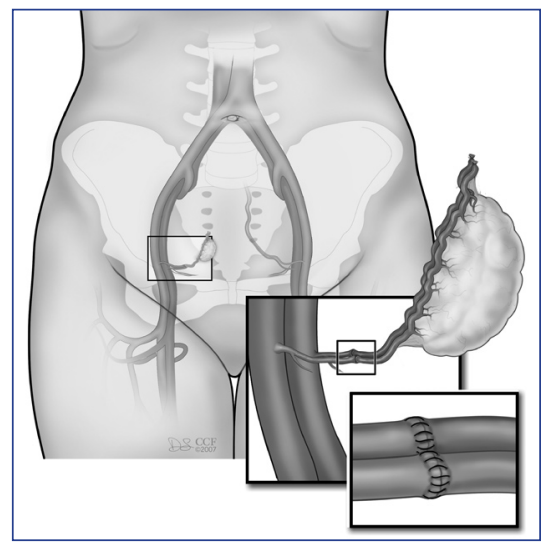

Mohamed A.Bedaiwy, Mahmoud R.Hussein, Charles Biscotti and Tommaso Falcone

Human Reproduction, 2006; 21(12):3258-69 


\section{Abstract}

Background: The aim of this study was to assess the immediate post-thawing injury to the human ovary that was cryopreserved either as a whole with its vascular pedicle or as ovarian cortical strips.

Materials and methods: Bilateral oophorectomy was performed in two women (46 and 44 years old) undergoing vaginal hysterectomy and laparoscopic hysterectomy, respectively. Both women agreed to donate their ovaries for experimental research. In both patients, one of the harvested ovaries was sectioned and cryopreserved (by slow freezing) as ovarian cortical strips of $1.0 \times 1.0 \times 5.0 \mathrm{~mm} 3$ each. The other ovary was cryopreserved intact with its vascular pedicle. After thawing 7 days later, follicular viability, histology, terminal deoxynucleotidyl transferase (TdT)-mediated dUTP-digoxigenin nick-end labelling (TUNEL) assay (to detect apoptosis) and immunoperoxidase staining (to define $\mathrm{Bcl}-2$ and p53 protein expression profiles) of the ovarian tissue were performed. Tissues from non-cryopreserved ovaries served as control specimens (two cases).

Results: The overall viability of the primordial follicles was 75 and $78 \%$ in intact cryopreserved-thawed (C-T) ovaries and 81 and $83 \%$ in ovarian cortical strips in the 46- and 44-year-old patients, respectively. Comparable primordial follicle counts, absence of features of necrosis, mean values of apoptosis and weak $\mathrm{Bcl}-2$ and p53 protein expressions were observed both in the intact $\mathrm{C}-\mathrm{T}$ ovary and in the $\mathrm{C}-\mathrm{T}$ ovarian cortical strips.

Conclusions: Cryoperfusion and cryopreservation of entire human ovary can be achieved with the maintenance of excellent viability of the superficial and the deeper tissues using a slow-freezing protocol. Cryopreservation injury is associated neither with significant alteration in the expression pattern of Bcl-2 and p53 proteins in the ovarian tissues nor with significant follicular damage.

Key words: apoptosis/Bcl-2/cryopreservation/follicular viability/intact human ovary. 


\section{Introduction}

Although many reproductive-age patients can survive their cancers and lead normal lives, they are at increased risk of impaired reproductive functions. Consequently, fertility preservation is an important quality-of-life issue for them. Fertility preservation strategies were introduced to protect and/or regain reproductive function in patients exposed to cancer chemotherapy and/or radiotherapy. Advances in assisted reproductive technologies (ART), such as ovarian tissue cryopreservation and transplantation, oocyte cryopreservation and novel ovulation induction regimens, have renewed interest in fertility preservation in women scheduled to receive gonadotoxic chemotherapy and/or radiotherapy (Falcone et al., 2004).

Of these technologies, ovarian tissue cryopreservation may be a viable option for women who cannot delay treatment to undergo ovarian stimulation to create embryos or obtain oocytes for freezing. In this entirely experimental process, thawed tissue can be implanted after cancer treatment as an autograft to an orthotopic or a heterotopic site. Immature oocytes derived from thawed tissue can be matured in vitro if appropriate protocols are developed in the future. Also, the maturation process of the immature oocytes could be achieved by xenografting in immunodeficient mice (Gook et al., 2003). To date, ovulation and creation of a human embryo from heterotopic ovarian transplant have been reported (Oktay et al., 2004). Moreover, two live births from orthotopic ovarian transplants following spontaneous (Donnez et al., 2004) and IVF (Meirow et al., 2005) cycles were reported, following modified cryopreservation and surgical protocols pioneered, in sheep, by Gosden and associates (Gosden et al., 1994; Baird et al., 1999). Despite these advances, ischaemic damage to the tissue and revascularization injury and the theoretical possibility of reintroducing malignant tumour cells remain as the main limitations for this option (Bedaiwy and Falcone, 2004).

The ischaemic damage to ovarian tissues can induce a high rate of follicular loss (Baird et al., 1999; Demirci et al., 2002). Therefore, eliminating this ischaemic damage could maintain both the viability and the functional integrity of the transplant. Ideally, this could be achieved by transplantation of an intact ovary with vascular anastomosis. Transplantation of an intact ovary with its vascular pedicle using microvascular anastomosis was achieved both in murine species (Yin et al., 2003) and in mammals (Jeremias et al., 2002; Bedaiwy et al., 2003). Partial restoration of hormonal functions in sheep (Bedaiwy et al., 2003) and pregnancy (Wang et al., 2002) after transplantation of intact cryopreserved-thawed (C-T) ovaries in rats were also reported. Recently, cryopreservation of intact human ovary with its vascular pedicle resulting in high post-thaw survival rates of follicles, small vessels and stromal cells 
as well as a normal histological structure in all the ovarian components was reported using a slow-freezing protocol. Slow freezing was achieved using a cryofreezing onedegree container (Martinez-Madrid et al., 2004).

The structural homeostasis of tissues is regulated by a delicate balance between cell survival and apoptotic cell death. In tissues, several molecules are involved in the survival (survival molecules such as Bcl-2) or cell death (apoptotic molecules such as p53) processes. $\mathrm{Bcl}-2$ is a membrane-associated protein that resides in the nuclear envelope and mitochondria. It exerts its survival functions by modulating the mitochondrial release of cytochrome $\mathrm{c}$ and antagonizing the effects of Bax gene (Bcl-2-associated X). Bcl-2 is expressed in granulosa cells of both fetal and adult ovaries. p53 gene encodes a $53-k D a$ oncosuppressive nuclear protein that functions to antagonize Bcl-2 effects. In the ovary, p53 protein is expressed in the apoptotic granulosa cells of atretic follicles. In several organs such as the heart, ischaemia is associated with the induction of Bcl-2 and p53 protein expressions.

Similarly, the induction of these molecules following ovarian ischaemia may have far-reaching effects on the outcome of the subsequent ovarian transplantation (Hussein, 2005). Although previous studies examined the long-term effects of cryopreservation-thawing procedure injury on the ovarian cortical strips (Gosden et al., 1994), our understanding of the injury caused to ovarian tissue in the period immediately after thawing is still incomplete. The aims of this study were to: (i) describe a cryopreservation protocol using the programmable freezer allowing freezing and thawing of an intact human ovary with its vascular pedicle; (ii) assess the survival (viability) of the ovarian elements in the $\mathrm{C}-\mathrm{T}$ tissues using Trypan Blue method; (iii) examine the frozen- thawed ovarian tissues for features of follicular health and atresia using the histological methods; (iv) evaluate the apoptotic changes in the ovarian tissues using combined histological methods and terminal deoxynucleotidyl transferase(TdT)-mediated dUTP-digoxigenin nick-end labeling (TUNEL) assay, immunoperoxidase method (p53 and Bcl-2 protein alterations, i.e. apoptotic and survival proteins) and (v) examine the status of the blood vessels using both histochemical [periodic acid Schiff (PAS) and Masson's trichrome] and immunohistochemical (CD34, marker of vascular endothelium) staining methods.

\section{Materials and methods}

The study group included both control (non-cryopreserved) and cryopreserved human ovaries. Also tissue sections from lymph nodes, squamous cell carcinoma, leukaemia cell lines, normal skin and liver were used as tissue-specific positive controls for Bcl-2, p53, apoptotic cells, PAS and Masson's trichrome staining. 


\section{Patients in the cryopreservation group}

The Institutional Review Board of The Cleveland Clinic Foundation approved this study. The first patient, aged 46 years, presented with menorrhagia and symptomatic fibroid uterus, who underwent total vaginal hysterectomy with bilateral salpingooophorectomy, McCall culdoplasty and cystoscopy. Intraoperative findings included an 8-10 week-sized bulky uterus and normal-appearing ovaries. The second patient, aged 44 years, presented with severe premenstrual dysphoric disorders, who underwent laparoscopic bilateral salpingo-oophorectomy. Normal-appearing uterus, tubes and ovaries were detected. Both ovaries and their pedicles, from both patients, were processed immediately as detailed below.

\section{Patients in the control group}

In the control group, formalin-fixed paraffin-embedded ovarian tissue was obtained from the Archives of the Department of Pathology, Assiut University Hospitals. Four ovarian tissue specimens were obtained from two women, 44 and 47 years old. The first was diagnosed with irregular uterine bleeding due to uterine fibroids and was treated by total abdominal hysterectomy with bilateral salpingo-oophorectomy. The second underwent total vaginal hysterectomy with bilateral salpingo-oophorectomy due to pelvic organ prolapse. The ovaries obtained from both patients appeared normal with a smooth white convoluted surface and firm consistency.

\section{Cryopreservation}

\section{Cryopreservation of the intact ovary}

We adopted our previous protocol described in 2003 (Bedaiwy et al., 2003). Briefly, immediately after oophorectomy, one ovary from each patient was perfused with heparinized Ringer's solution followed by perfusion and immersion in a bath containing the cryoprotective mixture which was composed of Leibovitz L-15 medium (Irvine Scientific, Santa Ana, CA, USA), 10\% fetal calf serum (FCS) (Irvine Scientific) and $1.5 \mathrm{M}$ dimethylsulphoxide (DMSO) (Sigma, St. Louis, MO, USA). Both the ovarian vessels and excess hilar tissue were dissected, and ovarian ligaments were trimmed. The ovaries were perfused via the ovarian artery with the cryoprotective mixture using Horizon Modular Infusion System (McGaw, Irvine, CA, USA) to maintain a flow rate at $1.3 \mathrm{ml} / \mathrm{min}$ with continuous replenishment of the reservoir. After perfusion, the ovary was bisected and transferred to two cryovials 12.7 x $92 \mathrm{~mm}$ (Corning Coaster Corporation, Cambridge, MA, USA) containing the cryoprotective mixture for controlled freezing using Planer cryochamber (freezer; Planer, Middlesex, UK). Cooling began at 
$+4{ }^{\circ} \mathrm{C}$ and continued at $2{ }^{\circ} \mathrm{C}$ per minute until ice nucleation was induced at $-7{ }^{\circ} \mathrm{C}$. The temperature was then reduced at $2{ }^{\circ} \mathrm{C}$ per minute until $-35^{\circ} \mathrm{C}$ and subsequently at $25^{\circ} \mathrm{C}$ per minute until $-140^{\circ} \mathrm{C}$ before cryovials were plunged into liquid nitrogen.

\section{Cryopreservation of the ovarian cortical strips}

The other ovary, for each patient, was divided into ovarian cortical strips of 1.0 $\mathrm{X} 1.0 \times 5 \mathrm{~mm} 3$ each. The ovarian cortical strips were prepared as described by Gosden et al. (1994) and cryopreserved using the previously mentioned protocol but without perfusion.

\section{Thawing}

Thawing of the intact ovary

One week later, the vials were removed from the Dewar and held for $1 \mathrm{~min}$ at room temperature before plunging in a bath of water at $37{ }^{\circ} \mathrm{C}$ with gentle shaking. The contents of the vials were quickly emptied into a Petri dish containing Leibovitz L-15 medium supplemented with $10 \%$ FCS. The ovaries were washed and immediately perfused with Leibovitz L-15 medium supplemented with 10\% FCS using a flow rate of $1.3 \mathrm{ml} / \mathrm{min}$ for $20 \mathrm{~min}$. The cryoprotectant was gradually eliminated by pumping Leibovitz L-15 supplemented with 10\% FCS into the reservoir (Bedaiwy et al., 2003).

\section{Thawing of the ovarian cortical strips}

Ovarian cortical strips were thawed using the same procedure as for intact ovary. Then, the strips were washed and held in Leibovitz L-15 containing 10\% FCS for $20 \mathrm{~min}$.

\section{In vitro assessments of the $C-T$ and control ovarian tissues}

Evaluation of the ovarian follicular viability in the $C-T$ ovarian tissue

The cryopreserved thawed ovarian tissues were evaluated for follicular viability in terms of plasma membrane function and structural integrity by the Trypan Blue exclusion test. Ovarian fragments were thinly sectioned in Leibovitz L-15 medium supplemented with $1 \mathrm{mg} / \mathrm{ml}$ (200 IU/ml) type 1 collagenase (Sigma), incubated at $37^{\circ} \mathrm{C}$ for 2 hs and pipetted every 30 min. Collagenase activity was inhibited by $50 \%$ FCS. The suspension was filtered through a $700^{\circ} \mathrm{m}$ nylon filter (Becton Dickinson Labware, Frankline Lakes, NJ, USA) and centrifuged at $400 \mathrm{~g}$ for $5 \mathrm{~min}$. The precipitate was diluted with $50 \mathrm{ml}$ of Leibovitz L-15 medium and kept in a water bath at 37 ${ }^{\circ} \mathrm{C}$. $20 \mu \mathrm{l}$ of $0.4 \%$ Trypan Blue (Sigma) was added to the suspension containing the 
follicles deposited on a glass slide and examined under inverted microscope $(\times 400)$. For each fragment, 100 small intact follicles were examined while the partially or completely denuded oocytes were excluded. Both the number of stained cells and the total number of cells were counted. The percentage of viable follicles was determined by calculating the percentage of unstained cells.

\section{Histological evaluation of the ovarian tissues for the features of follicular health and atresia in the $C-T$ and control ovarian tissues}

The maturing follicle is composed of an oocyte with granulose layer and lacks reticulum. The hallmarks of the healthy follicles include intact oocyte, intact membrana granulosa, lack of necrosis and the presence of few pyknotic nuclei $(<5 \%$ pyknotic nuclei) in this layer. The atretic follicles are characterized by the presence of attenuated membrana granulosa, loosely attached granulosa cells and increased number of pyknotic nuclei (>5\% pyknotic nuclei) (Wood et al., 1997). Initially, the ovarian follicles were sorted into two groups, healthy and atretic, following Wood et al. (1997). Histological evaluation of apoptotic changes in the $C-T$ and control ovarian tissues:

Evaluation of apoptosis was performed using combined histological and TUNEL assays. The results were expressed as mean and SEM. The histological criteria of apoptosis included condensed nuclear fragments, nuclei with marginated chromatin, multiple nuclear fragments, a single condensed nucleus, membrane bound structures containing variable amounts of chromatin and eosinophilic cytoplasm (Kerr et al., 1972).

\section{DNA fragmentation assay for the detection of apoptotic cells in the C-T and control ovarian tissues}

To evaluate the apoptotic changes, we examined cellular morphology with the TUNEL assay, using the commercially available QIA33TDT-FragEL ${ }^{\text {TM }}$ kit (Oncogen Research Products, Boston, MA, USA) following other groups (Hussein et al., 2006). Positive controls consisted of HL60 promyelocytic leukaemia cells and HL60 cells incubated with $0.5 \mu \mathrm{g} / \mathrm{ml}$ actinomycin D for $19 \mathrm{~h}$ to induce apoptosis. Some ovarian specimens were used as negative controls by substituting distilled water for deoxynucleotidyl transferase (Gavrieli et al., 1992; Liu et al., 1995). Results of the TUNEL assay were evaluated following other groups (Hussein et al., 2006). All slides were examined at x400 magnification. Ten different areas of each follicular wall were examined, and apoptotic index was determined as mean number of positively stained cells (Hussein et al., 2006). 


\section{Immunohistochemical evaluation of $p 53, \mathrm{Bcl}-2$ and $\mathrm{CD} 34$ protein expressions in the C-T and control ovarian tissues}

To examine the prosurvival, proapoptotic proteins and the status of the blood vessels, we used immunoperoxidase staining methods and monoclonal antibodies targeting p53, Bcl-2 and CD34 proteins. Briefly, ovary sections mounted on glass slides were deparaffinized and rehydrated. Endogenous peroxidase activity was blocked with $0.6 \% \mathrm{H} 202$. Sections were then immersed in the retrieval solution (10 mM sodium citrate buffer, $\mathrm{pH}$ 6.0) and subjected to heat-induced antigen retrieval for 20 min (microwave at $750 \mathrm{~W}$ ). Non-specific protein binding was blocked with 10 min exposure to $10 \%$ normal goat serum. Sections were then incubated with primary antibodies for $1 \mathrm{~h}$ at room temperature. The following primary mouse monoclonal antibodies were used: clone D0-7, catalogue No. M7001 and clone 124, catalogue No. M0889 for p53 and Bcl-2, respectively (DAKO, Carpinteria, CA, USA). Anti-CD34 monoclonal QBEnd/10 (Novocastro, Newcastle, UK) was used to examine the blood vessels. After brief rinsing in phosphate-buffered saline (PBS), a catalyzed signal amplification system (K1500, DAKO) was used according to the manufacturer's instructions. Two observers independently evaluated the stained slides.

\section{Positive controls}

Sections from reactive lymphoid hyperplasia (lymph node), p53-positive squamous cell carcinoma and haemangioma were used as positive controls for Bcl-2, p53 and CD34 staining, respectively.

\section{Negative controls}

Additional sections of the tissues were stained in parallel but with omission of the primary antibody.

\section{PAS and Masson's trichrome stains}

PAS stains carbohydrate moieties and basement membrane reticulin and therefore delineates the wall of the blood vessels. Masson's trichrome stains myofibres, indicating skeletal or smooth muscle differentiation (versus non-muscle fibres). Thus, it stains the smooth muscle of the blood vessels.

\section{Evaluation of $\mathrm{Bcl}-2$ and p53 immunostaining}

For the evaluation of Bcl-2 and p53 immunoreactivities, several rules were followed: (i) corresponding sections stained by haematoxylin and eosin were examined; (ii) sections were examined to detect the sites of the antibody positivity; (iii) a higher power magnification was used to evaluate the immunostaining; (iv) sections were examined 
independently by two observers and (v) Bcl-2 and p53 positivity was identified as diffuse brown cytoplasmic and nuclear staining, respectively. The numbers of follicles with positive and negative reactivity were counted in the ovarian tissues (Hussein et al., 2006).

\section{Evaluations of the status of the blood vessels in the $C-T$ and control ovarian tissues}

We chose CD34, as it is more sensitive than other markers for the detection of endothelial cells in the ovary. Microvessel density (MVD) was assessed by light microscopy following Weidner et al.(1991). Ovarian tissue was scanned at low magnification ( $\mathrm{x} 40$ and $\mathrm{x} 100$ ) to select the areas that showed the most intense vascularization (hot spots). Individual microvessels were counted in three fields at x200 magnification (x20 objective lens and x10 ocular lens; 0.7386 mm2/field). The final MVD was the mean value obtained from the counts of the three fields. SEM was expressed as mean (SD) (vessel/mm2). Any immunostained endothelial cells or endothelial cell clusters that were clearly separated from the adjacent microvessels were considered as a single and countable microvessel. Vessel lumens were not a prerequisite for a structure to be defined as a microvessel, and red blood cells were not used to define a vessel lumen (Weidner et al., 1991).

\section{Statistical analysis}

Analysis of variance (ANOVA) and Student's t-tests with a statistical significance of $\mathrm{P}<0.05$ were performed. Calculations were done with the Statistical Package for the Social Sciences for Windows, version 10.0.

\section{Results}

\section{Follicular viability in the $C-T$ ovarian tissue}

In the 46-year-old patient, the primordial follicular viability was 75 and $81 \%$ in $\mathrm{C}-\mathrm{T}$ intact ovary and $\mathrm{C}-\mathrm{T}$ ovarian cortical strips, respectively. In the 44-year-old patient, these values were 78 and $83 \%$, respectively. The average value for both intact ovaries $(76.5 \%)$ was comparable with that for cortical strips (82\%). A summary of these data is presented in Table I. 


\begin{tabular}{|c|c|c|c|c|c|}
\hline \multirow[b]{2}{*}{ Aspects } & \multicolumn{3}{|c|}{ Cryopreserved ovarian tissue } & \multirow{2}{*}{$\begin{array}{l}\begin{array}{l}\text { Non- } \\
\text { cryopreserved } \\
\text { ovarian tissue }\end{array} \\
\text { Control group }\end{array}$} & \multirow[t]{2}{*}{$\mathrm{p}$ value } \\
\hline & $\begin{array}{l}\text { Ovarian cortical } \\
\text { strips }\end{array}$ & Intact ovary & $\begin{array}{l}\text { Cortical strips } \\
\text { and intact ovaries }\end{array}$ & & \\
\hline $\begin{array}{l}\text { Follicular viability } \\
\text { (unstained cells/total cells) } \\
\text { Counts of follicles }\end{array}$ & $(82 / 100) 82 \%$ & (76/100) $76.5 \%$ & $(79 / 100) 79 \%$ & NA & NA \\
\hline$($ Mean \pm SEM) & $3 / \mathrm{HPF}$ & 4.5/HPF & 3.7/HPF & 4.0/HPF & NS \\
\hline Healthy follicles (Mean SEM) & 1/HPF & $1 / \mathrm{HPF}$ & $1 / \mathrm{HPF}$ & $1 / \mathrm{HPF}$ & NS \\
\hline Atretic follicles (Mean \pm SEM) & $2 / \mathrm{HPF}$ & $3 / \mathrm{HPF}$ & $3 / \mathrm{HPF}$ & $3 / \mathrm{HPF}$ & NS \\
\hline Apoptotic index (Mean \pm SEM) & $1.7 \pm 0.1$ & $1.8 \pm 0.1$ & $1.7 \pm 0.1$ & $1.8 \pm 0.1$ & NS \\
\hline \multicolumn{6}{|l|}{ Apoptotic changes } \\
\hline Healthy follicless & Absent & Absent & Absent & Absent & NA \\
\hline Atretic follicles & Present & Present & Present & Present & NS \\
\hline \multicolumn{6}{|l|}{ Bcl-2 protein expression } \\
\hline Healthy follicles & $1.75 \pm 0.3$ & $1.70 \pm 0.3$ & $1.70 \pm 0.3$ & $1.76 \pm 0.3$ & NS \\
\hline Atretic follicles & $0.06 \pm 0.7$ & $0.06 \pm 0.7$ & $0.06 \pm 0.7$ & $0.06 \pm 0.7$ & NS \\
\hline p53 protein expression & & & & & \\
\hline Healthy follicles & Absent & Absent & Absent & Absent & NA \\
\hline Atretic follicles & Absent & Absent & Absent & Occasional & NA \\
\hline Status of the blood vessels & $\begin{array}{l}\text { Persistent } \\
\text { vascularity }\end{array}$ & $\begin{array}{l}\text { Persistent } \\
\text { vascularity }\end{array}$ & $\begin{array}{l}\text { Persistent } \\
\text { vascularity }\end{array}$ & $\begin{array}{l}\text { Persistent } \\
\text { vascularity }\end{array}$ & \\
\hline $\begin{array}{l}\text { Microvessel density } \\
\text { (Mean } \pm \text { SEM) }\end{array}$ & $5.1 \pm 0.7$ & $5.0 \pm 0.6$ & $5.3 \pm 0.8$ & $5.6 \pm 0.9$ & NS \\
\hline Peeriodic acid stain & $\begin{array}{l}\text { Persistent y } \\
\text { vascularity }\end{array}$ & $\begin{array}{l}\text { Persistent } \\
\text { vascularity }\end{array}$ & $\begin{array}{l}\text { Persistent } \\
\text { vascularity }\end{array}$ & $\begin{array}{l}\text { Persistent } \\
\text { vascularity }\end{array}$ & NA \\
\hline Masson's trichrome stain & $\begin{array}{l}\text { Persistent } \\
\text { vascularity }\end{array}$ & $\begin{array}{l}\text { Persistent } \\
\text { vascularity }\end{array}$ & $\begin{array}{l}\text { Persistent } \\
\text { vascularity }\end{array}$ & $\begin{array}{l}\text { Persistent } \\
\text { vascularity }\end{array}$ & NA \\
\hline
\end{tabular}

Table 1: Morphological analysis of the control cryopreserved intact ovary and cortical ovarian tissue strips. The healthy follicles include primordial follicles, primary follicles, and secondary follicles. Plasma membrane function and structural integrity was determined by the Trypan blue exclusion test (viability assay) in which both the number of stained cells and the total number of cells were counted. The percentage of viable cells was determined by calculating the percentage of unstained cells. Follicular health and atresia were determined using the histological methods. Apoptotic index was evaluated using combined TUNEL and histological methods where ten different areas of each follicular wall were examined. The apoptotic index was calculated as mean number of positively stained cells. For evaluation of bcl-2 and p53 immunoreactivities, the numbers of follicles with positive and negative reactivity were counted in the ovarian tissues. HPF, high power field, NA, not applicable; and NS, not significant ( $p>0.05)$.

\section{Histological changes in the control and C-T ovarian tissues}

In the control ovarian tissues, evaluation of the cortex and medulla revealed the absence of the histological features of necrosis such as: (i) swelling and clumping of the chromatin, (ii) pyknosis (condensation of the chromatin and shrinkage of the nucleus), (iii) karyorrhexis (fragmentation of the nucleus), (iv) karyolysis (dissolution of the nucleus) and (v) cytoplasmic opacification or eosinophilia (Figure 1). Similarly, in the cryopreserved ovaries, evaluation of the cortex and medulla of C-T intact ovaries and cortical strips revealed the absence of these histological features (Figure 2). Moreover, the blood vessels were not only viable and patent but also had intact muscle coat and endothelium (Figure 2). 
In every sample, the primordial follicles were counted in 10 different fields and mean values were reported for the cryopreservation and control groups. Histological evaluation of the count of the primordial follicles revealed a trend towards higher values in the intact C-T ovary as compared with the cortical strips (4.5/high-power field versus 3/high-power field, respectively) (Figure 2). However, differences among these values did not reach the level of statistical significance, probably due to small sample size (two patients). Histological features of apoptosis were seen in the granulosa cells of atretic follicles either within the central region of the membrana granulosa layer or loosely attached to the membrana granulosa near its antral surface. A summary of these data is presented in Table 1.

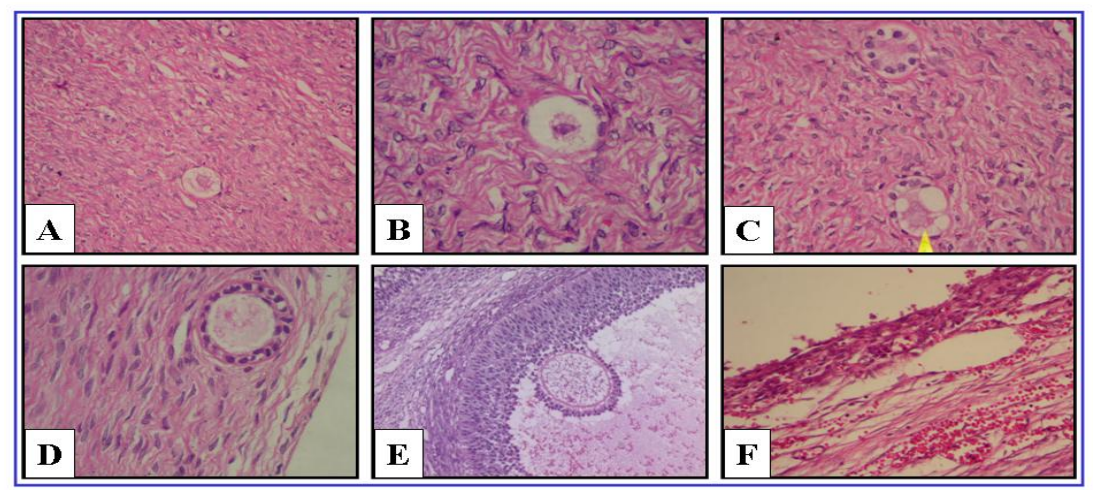

Figure 1: Histological features of the control (non-cryopreserved) ovarian tissue. The figures show primordial follicle (A); primary; B-C); Secondary, D); Graffian , E) ; and atretic follicles F).

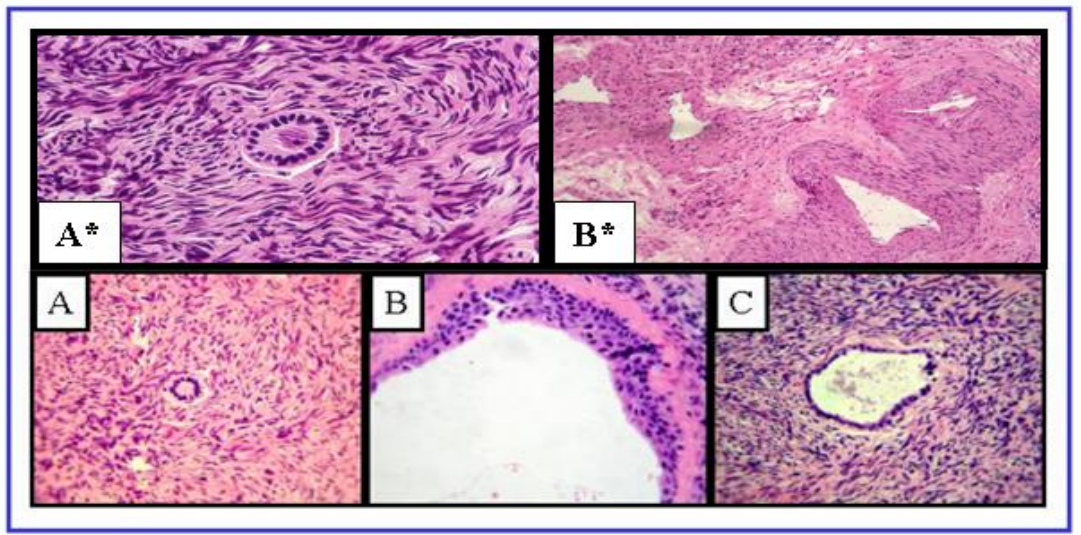

Figure 2 (Upper panel): Histological features of both cryopreserved-thawed intact ovary and ovarian cortical strips). The figures show primordial follicle (A), and intact intraovarian blood vessels (B). The primordial follicle is formed of primary oocyte, surrounded by a single layer of flattened mitotically inactive, granulosa cells resting on a thin basal lamina.

Figure 2 (Lower panel): Histological features of the human ovarian follicles in both cryopreserved intact ovary and ovarian cortical strips. The follicles include A) primary; B), Graffian; and C) atretic follicles. A), the primary follicle is formed of enlarged oocyte, surrounded by a single layer of a cuboidal to columnar mitotically inactive granulosa cells. B), the Graffian follicle is formed of an antrum, several layers of granulosa cells and theca layers. C), the atretic follicle is formed of thin inner layer of small, exfoliating granulosa cells and an outer theca layer. 


\section{$\mathrm{Bcl}-2$ and p53 protein expressions in the control and C-T ovarian tissues}

The positive and negative controls were positive and negative, respectively, indicating the validity of our results. In both control and cryopreserved ovarian tissues, rare weak $\mathrm{Bcl}-2$ expression was seen both in the healthy follicles and in the stromal cells (Figures 3 and 4). p53 expression (nuclear) was virtually absent in the healthy primordial, primary and secondary follicles, germinal epithelium and stromal cells subjected to warm ischaemia (Figures 3 and 4). Bcl-2 immunoreactivity was observed more frequently in the secondary follicles, followed by primary and primordial follicles. In these follicles, $\mathrm{Bcl}-2$ immunoreactivity was restricted to granulosa cells. The theca cells were never immunoreactive regardless of the developmental stage of the follicles (Figures 3 and 4).
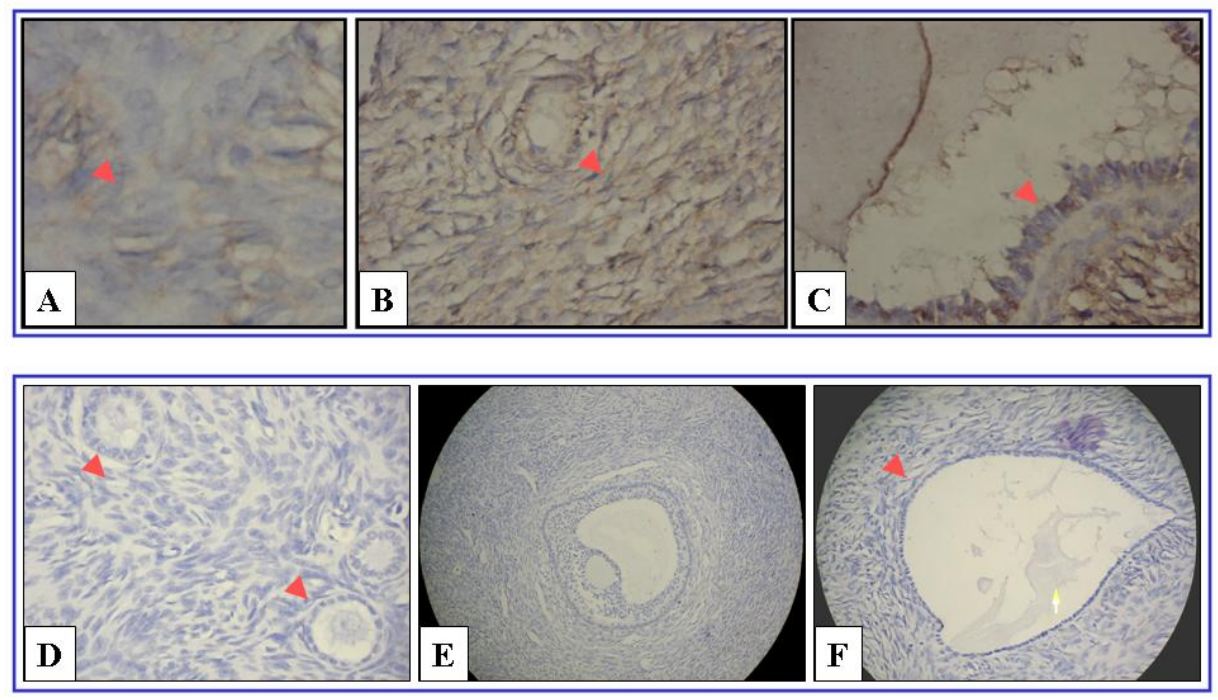

Figure 3: Bcl-2 and p53 protein expression in the control (non-cryopreserved) ovarian tissue. Bcl-2 protein expression in the primary, $(A)$; secondary, $(B)$; and atretic $(C)$ follicles and the ovarian stroma (C). The expression appears as golden yellow cytoplasmic staining. Note Lack of p53 protein expression in the the primary (D); Greffian (E); and atretic (F) follicles and the ovarian stroma (F) (Arrowheads). 


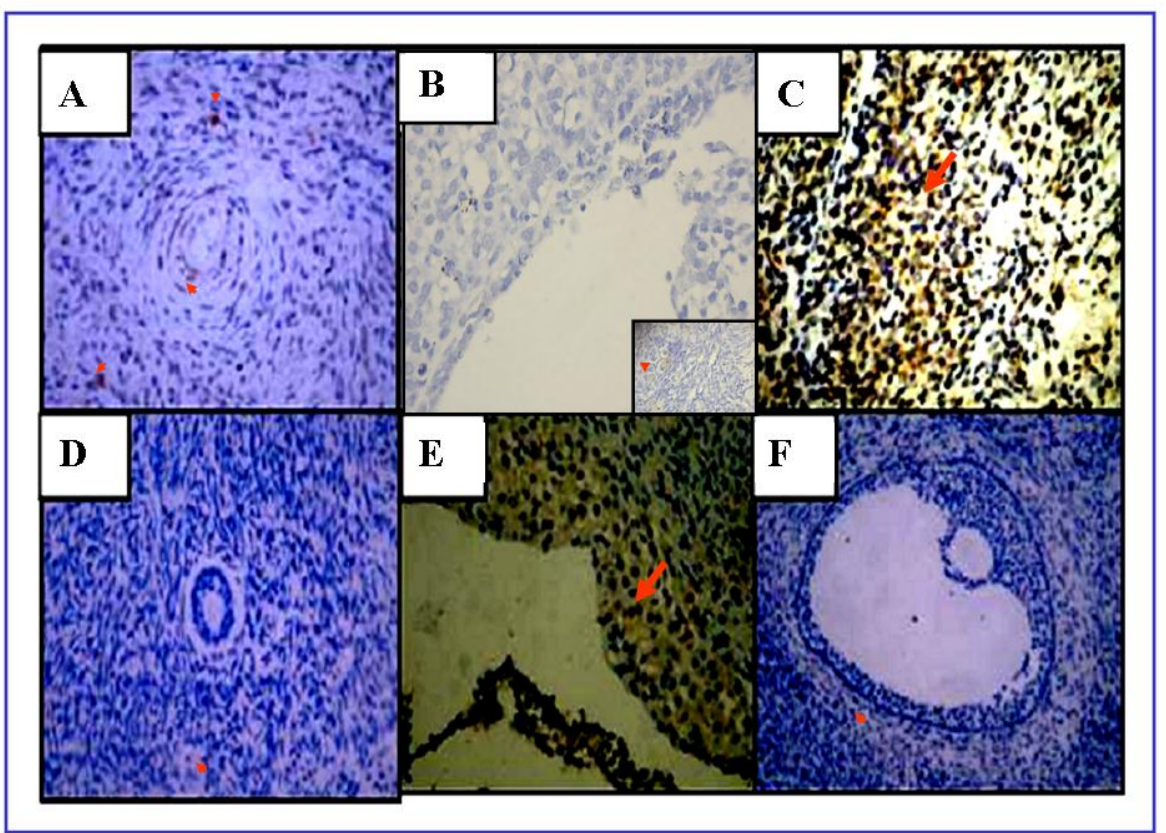

Figure 4 (Upper panel): $\mathrm{Bcl}-2$ and p53 protein expression both in cryopreserved intact ovary and ovarian cortical strips. Bcl-2 protein expression in the primordial $(A)$; atretic $(B)$ follicles and the ovarian stroma $(\mathrm{C})$. The expression appears as golden yellow cytoplasmic staining. Note the lack of p53 protein expression in the primordial (D); atretic follicles (E) and the ovarian stroma/ Graffinan follicle (F) (Arrowheads).

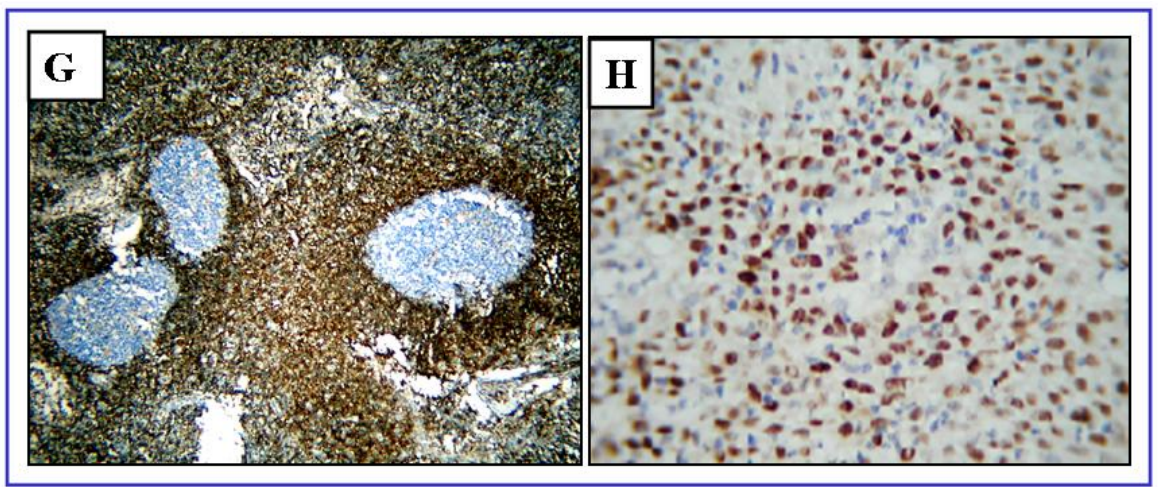

Figure 4 (Lower panel): Bcl-2 and p53 protein expression in positive controls. Bcl-2 protein expression in the lymph node with reactive hyperplasia $(G)$, and p53 protein expression in the cells of squamous cell carcinoma $(H)$ (Arrowheads). 


\section{DNA fragmentation assay (TUNEL) in the control and C-T ovarian tissues}

None of the negative controls stained with TUNEL technique showed any immunoreactivity, whereas signal-positive TUNEL staining was observed in the positive controls (Figure 5). In the control ovarian tissues, granulosa cells with the histologic features of apoptosis were observed in the atretic follicles, either within the central region of membrana granulosa layer or loosely attached with membrana granulosa near its antral surface or in the antral follicular fluid. The healthy (primordial, primary and secondary) follicles were TUNEL negative. TUNEL-positive signals were detected in the atretic follicles.

This was evident as punctuated brown staining of the fragmented nuclei of granulosa cells. The positively stained nuclei were observed either in the central layers of the membrana granulosa, at the antral surface or floating in the follicular atrium. DNA fragmentation was absent both in the interstitial cells and in the theca cells of the atretic follicles. Evaluation of apoptosis in the cryopreserved ovaries revealed similar findings: (i) the healthy (primordial, primary and secondary) follicles were TUNEL negative; (ii) TUNEL-positive signals were detected in the atretic follicles as indicated by the punctuated brown staining of the fragmented nuclei of granulosa cells (Figure 5) and (iii) the mean values of apoptotic cells in the intact cryopreserved ovarian tissues were comparable with those in the ovarian cortical strips and control ovarian tissues ( $1.8 \pm 0.1$ versus $1.7 \pm 0.1$ versus $1.8 \pm 0.1$, respectively). The results are summarized in Table I.

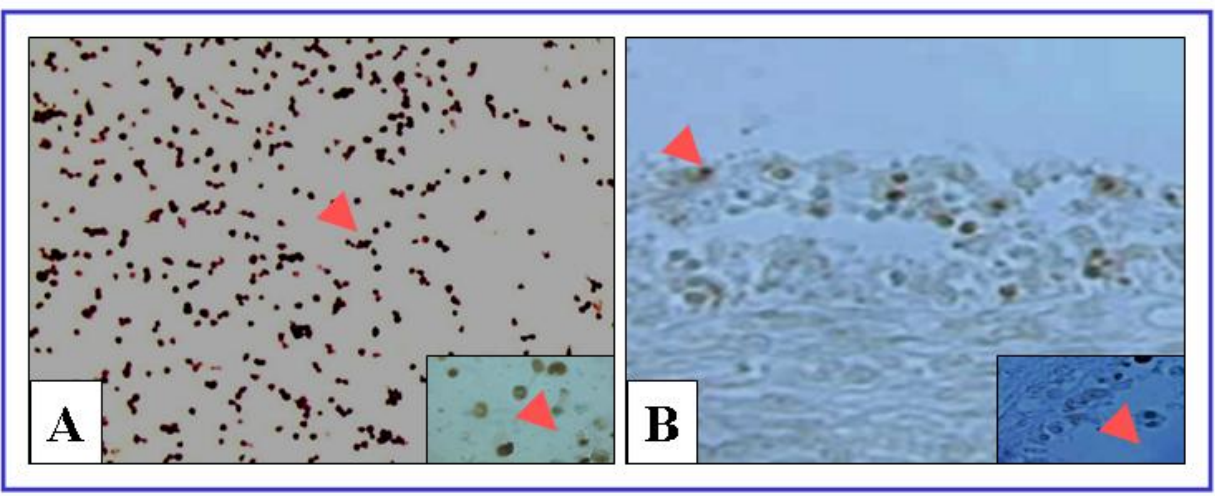

Figure 5: Apoptotic changes in the HL60 promyelocytic leukemia cells cryopreserved intact ovary and ovarian cortical strips. A), Apoptosis in the HL60 promyelocytic leukemia cells (Control), with positive staining (Inset, arrowhead), and B), Apoptosis in atretic ovarian follicles, TUNEL-positive cells (Arrowheads). 


\section{Evaluation of $C D 34$ protein expression in the control and $C-T$ ovarian tissues}

Endothelial immunostaining with anti-CD34 as well as evaluation of the basement membrane (PAS) and muscle coat (Masson's trichrome) of ovarian blood vessels demonstrates persistent vascularity in both cryopreserved and control ovarian tissues. Microvessels are heterogeneously distributed within the ovarian tissue. The mean values of ovarian MVD were $5.6 \pm 0.9,5.3 \pm 0.8$ and $5.3 \pm 0.8$ for control, cryopreserved intact and cortical ovarian tissues, respectively. A summary of these results is presented in Table I and figures 6-8.

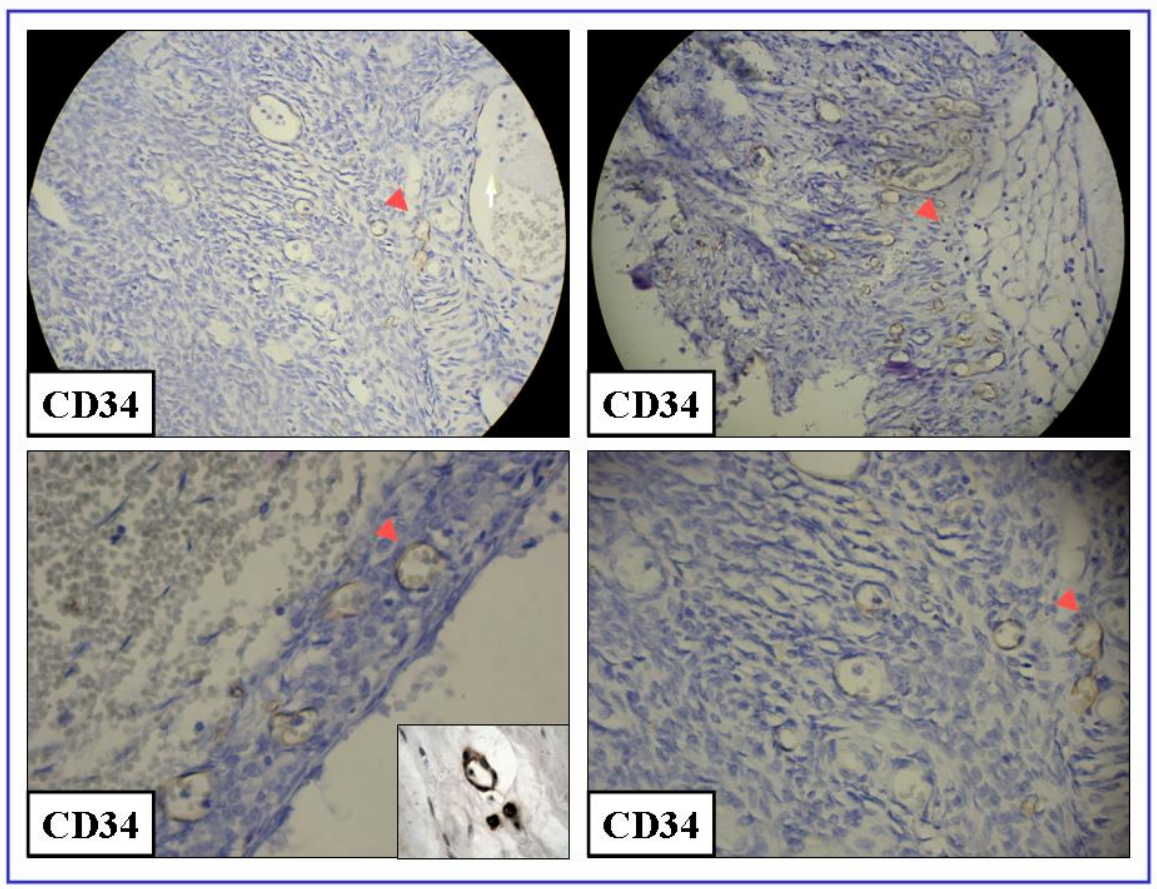

Figure 6 (Upper panel): Evaluation of the status of the blood vessels in the control (non-cryopreserved) ovarian tissue. CD34 protein expression in the ovarian stroma. The ovarian blood vessels show persistent vascularity and moderate density of microvessels. The endothelial cells of the microvessels are decorated brown by anti-CD34 antibodies. The inset represents CD34 staining in the control (hemangioma) (Arrowheads). 


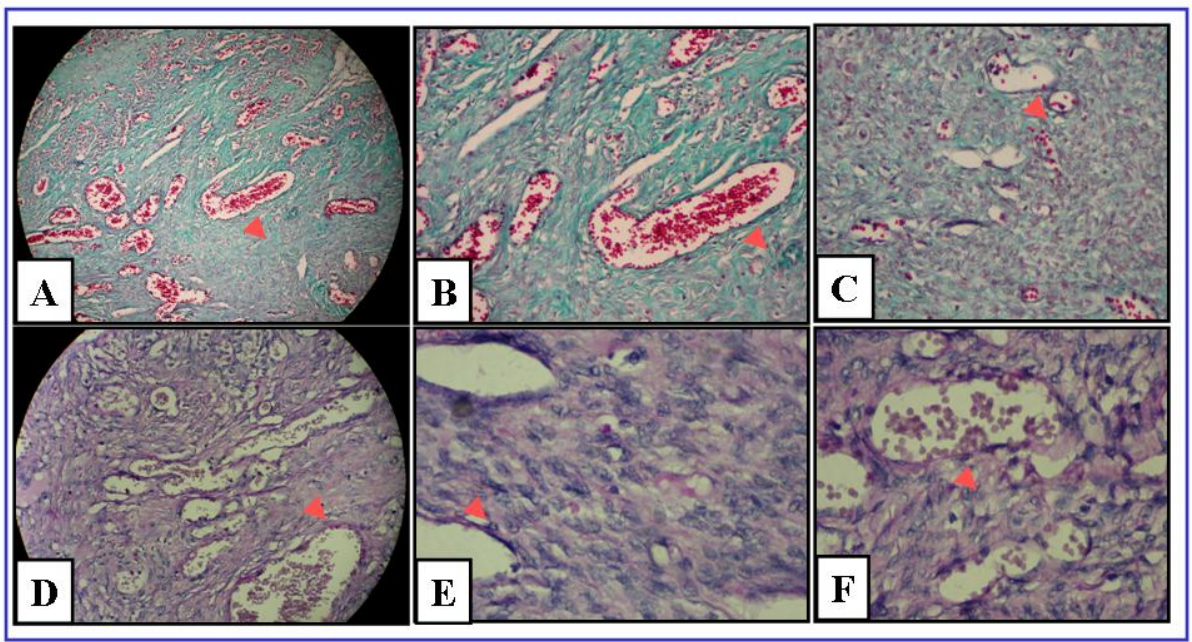

Figure 6 (Lower panel): Evaluation of the status of the blood vessels in the control (non-cryopreserved) ovarian tissue. Periodic acid Schiff (A,B and C) and Masson' trichrome (D, E, and F) stains within the ovarian stroma. The ovarian blood vessels show persistent vascularity and moderate density of microvessels. The muscle coate (Masson's trichrom) and basement membrane (Periodic acid Schiff stain) outline the blood vessels (Arrowheads).

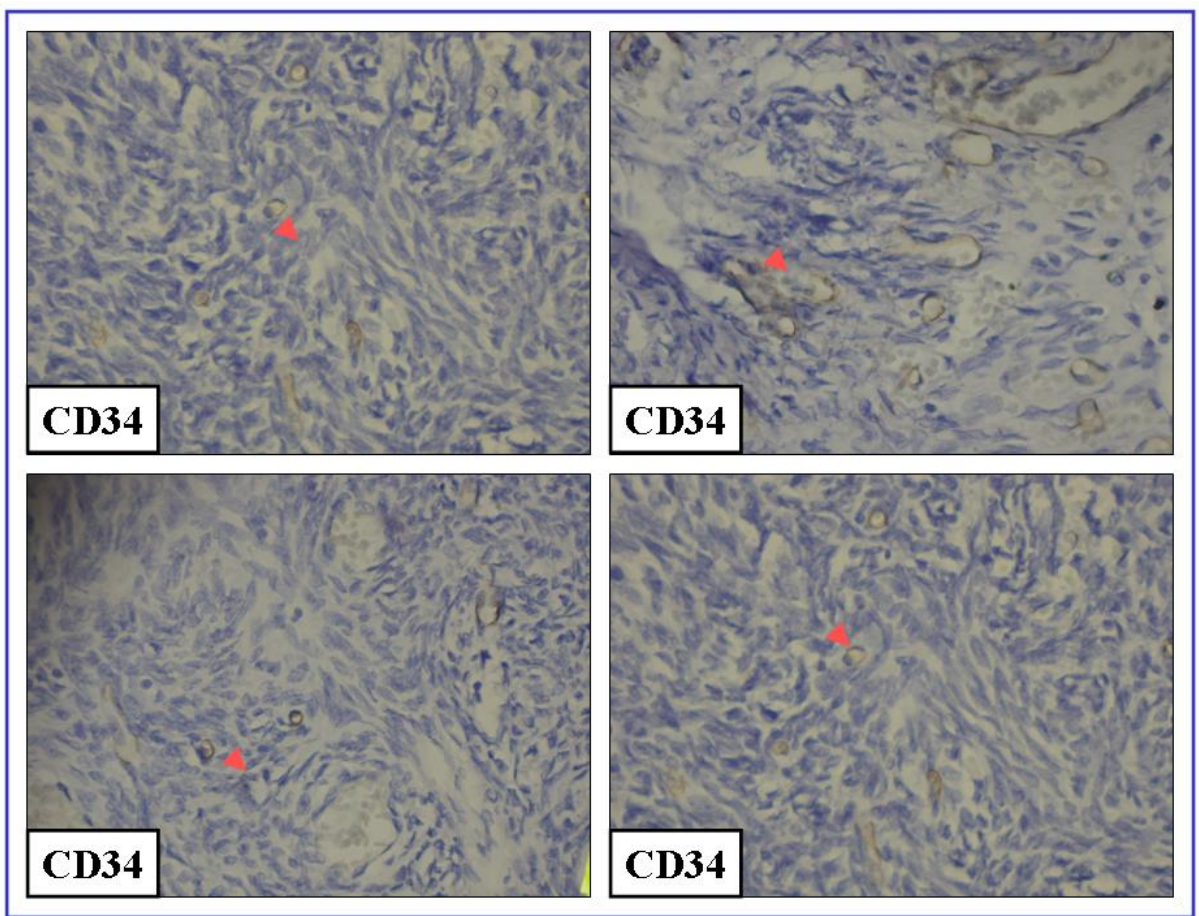

Figure 7 (Upper panel): Evaluation of the status of the blood vessels both in cryopreserved intact ovary and ovarian cortical strips. CD34 protein expression within the ovarian stroma. The ovarian blood vessels show persistent vascularity and moderate density of microvessels. The endothelial cells of the microvessels are decorated brown by anti-CD34 antibodies (Arrowheads). 


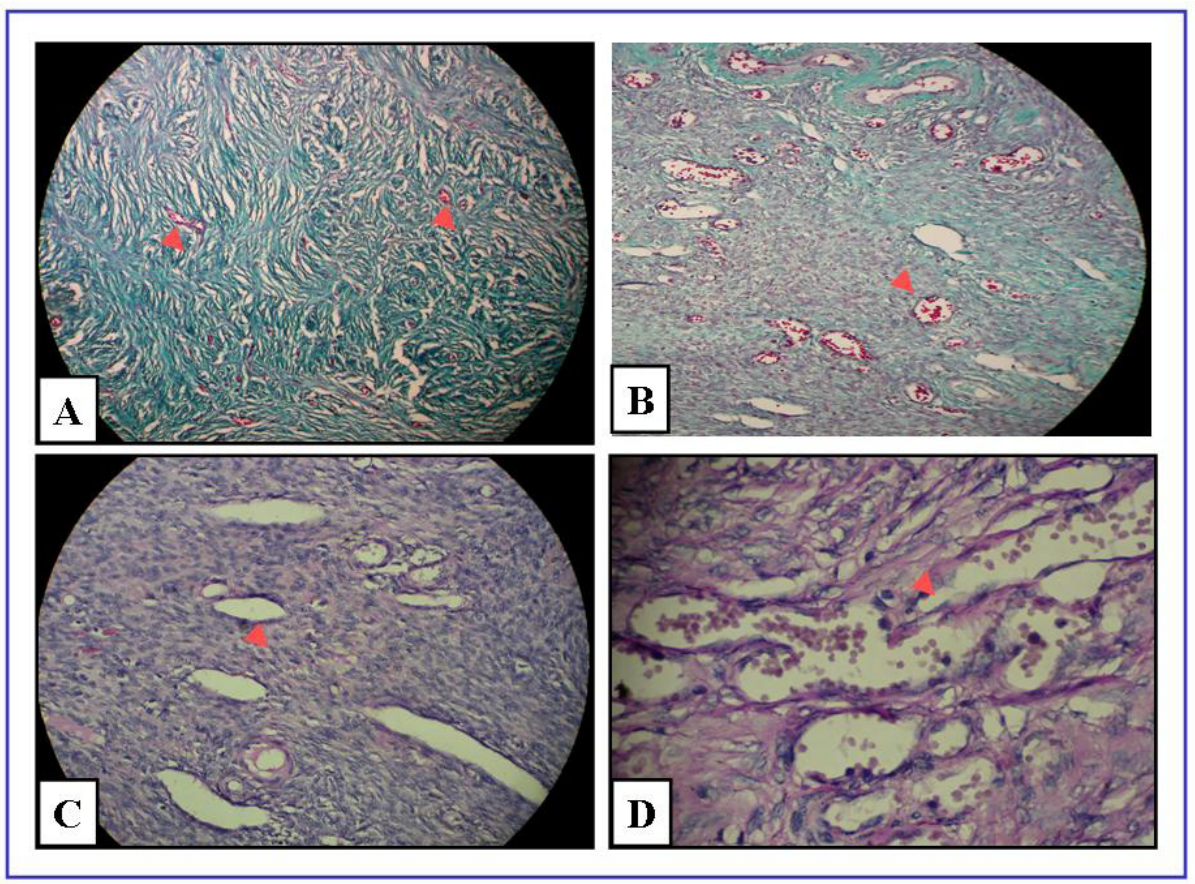

Figure 7 (Lower panel): Evaluation of the status of the blood vessels both in cryopreserved intact ovary and ovarian cortical strips. Periodic acid Schiff and Masson' trichrome stains within the ovarian stroma. The ovarian blood vessels show persistent vascularity and moderate density of microvessels. The muscle coate (Masson's trichrom) and basement membrane (Periodic acid Schiff stain) outline the blood vessels (Arrowheads).

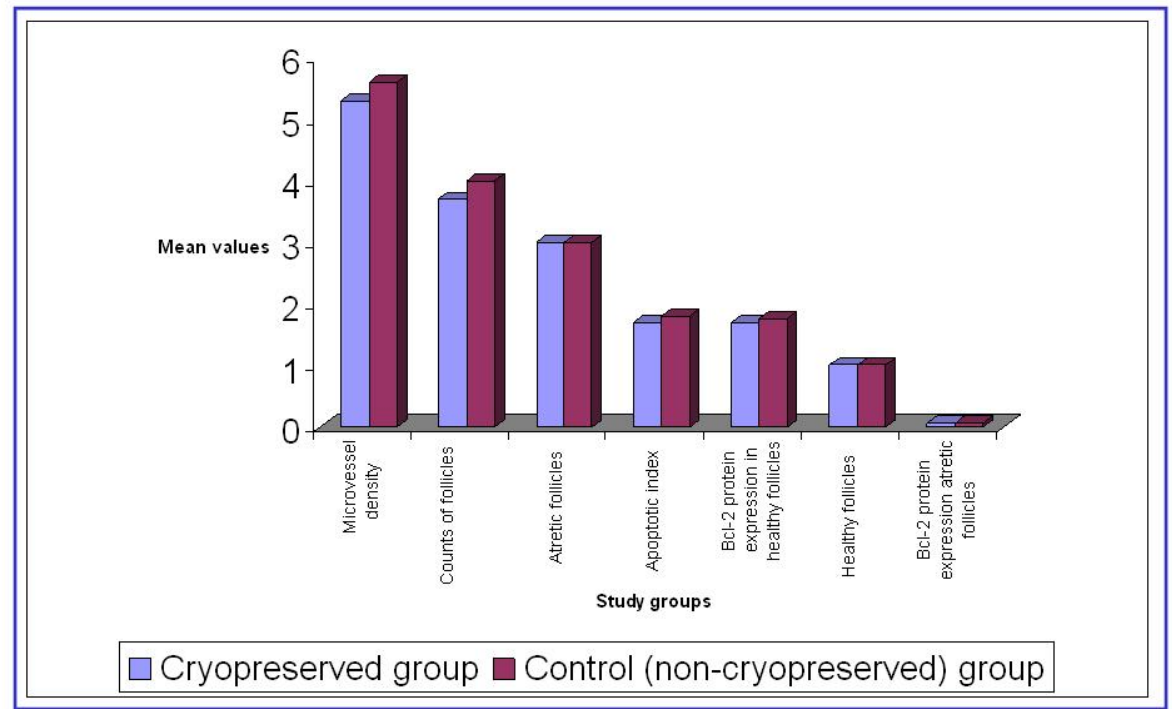

Figure 8: Morphological analysis of the control cryopreserved intact ovary and cortical ovarian tissue strips. The differences between the two groups did not reach the level of statistical significance $(p>0.05)$. 


\section{Discussion}

In this investigation, the immediate post-thawing injury to the human ovary (cryopreserved both as a whole with its vascular pedicle and as ovarian cortical strips) was assessed using both histological and immunohistological methods. To achieve our goals, we established a study group formed of four patients. It included both control (non-cryopreserved) and cryopreserved human ovaries. Tissue sections from lymph nodes, squamous cell carcinoma, leukaemia cell lines, normal skin and liver were used as tissue-specific positive controls for the histochemical (PAS and Masson's trichrome staining) and immunohistochemical (Bcl-2, p53 and apoptotic cells) parameters. Our investigation demonstrated the following findings: (i) the mean values of MVD, follicle counts and $\mathrm{Bcl}-2$ protein expression were comparable between the cryopreserved and the control groups and (ii) no differences were seen between the two groups for the following parameters: healthy and atretic follicle counts, apoptotic index and $\mathrm{Bcl}-2$ protein expression in the atretic follicles. Ovarian tissue banking is more popular as a fertility preservation option for patients without a partner or those who cannot delay gonadotoxic chemotherapy for the sake of ovarian stimulation to produce oocytes for freezing or embryos for cryopreservation.

With the limited long-term survival upon reimplantation with ovarian tissue strips, ovarian transplantation with microvascular anastomosis could help avoid accelerated follicular loss and improve the longevity of the ovarian grafts. This helps to guarantee an immediate revascularization and establishment of the graft function. Although successful in rat and sheep animal models (Wang et al., 2002; Bedaiwy et al., 2003), microvascular anastomosis of intact frozen-thawed ovaries remains technically challenging. Moreover, cryopreservation of an entire organ with its vascular pedicle is much more complicated than ovarian cortical strips or suspended cell (oocyte) or group of cells (embryo). In our previous study, we reported a close to $30 \%$ long-term patency rate of the ovarian vessels upon reimplantation of an intact frozen-thawed ovary in merino sheep (Bedaiwy et al., 2003).

However, human ovaries are larger and may not be amenable to the same protocol. The technical challenges of the microvascular anastomosis could be circumvented adequately by appropriate training. On the contrary, the main determinant of success would be to develop an appropriate cryopreservation protocol of an entire ovary with its vascular pedicle. Adequate delivery of the cryoprotective agent (CPA) to almost every cell of the ovary is mandatory to guarantee an adequate post-thaw survival. Aiming at adequate CPA permeation to virtually every cellular component of the ovary, we used the Horizon Modular Infusion pump to ensure adequate CPA distribution 
throughout the ovarian substance. Infusing the CPA slowly through the ovarian artery and allowing it to come out of the ovarian vein ensures adequate use of the ovarian vascular channel as a delivery vehicle. To avoid intracellular ice formation, we used a slow-freezing protocol using the Planer freezer.

The use of constant infusion pressure during the freezing and thawing phases ensured adequate distribution and clearance of the CPA. The selection of DMSO as a CPA of choice was based on the initial observation by Newton et al. (1998) that exposure for $30 \mathrm{~min}$ to $1.5 \mathrm{M}$ solutions of DMSO at $4{ }^{\circ} \mathrm{C}$ achieved a mean tissue concentration that was almost $80 \%$. In our study, $1.5 \mathrm{M}$ DMSO was tolerated comparably by both an intact ovary and ovarian cortical strips. Interestingly, in a recent report where ovarian tissue was exposed to $10 \%$ DMSO for 15 min at $4{ }^{\circ} \mathrm{C}$, no significant differences in follicular viability before (99.4\%) or after cryoprotectant exposure (98.1\%) were documented. This could probably mean that ovarian tissue could tolerate adequately varying concentrations of DMSO with comparable post-thaw survival (Martinez-Madrid et al., 2004).

After thawing, viability assessment of the primordial follicles was comparable between intact ovaries and ovarian cortical strips. This demonstrates that delivering the CPA using an infusion pump was as efficient as the permeation of the ovarian cortical strips with the CPA avoiding cryoinjury to the follicles as well as the intraovarian vessels. The viable primordial follicular count in the intact ovaries in both of our patients (75 and $78 \%$ ) was comparable with the $75.1 \%$ follicular viability reported by MartinezMadrid et al. (2004), who tried a different freezing protocol for intact human ovary.

In this investigation, the presence of apoptotic activity in the ovarian follicles may be attributed to the presence of apoptosis triggering signals and/or degradation of apoptosis-related proteins (caspase-3, caspase-8, Bcl-2 and actin) (Zhu et al., 1999; Schmidt-Mende et al., 2000). At the molecular level, cryopreservation and thawing had no effects on the values of apoptotic cell death and Bcl-2 and p53 protein expressions in both ovarian cortical strips and intact ovaries. A hypothesis to be tested is that cryopreservation and thawing can induce some effects on these values (apoptotic cell death and $\mathrm{Bcl}-2$ and p53 protein expressions) over longer time intervals. This hypothesis stems from the fact that apoptosis is a dynamic process that requires active metabolism and usually takes several hours or even days to be executed (Hussein et al., 2006). These questions are open for future investigations. Apoptosis in the atretic follicles can effectively be present before the cryopreservation, but it does not seem to be increased by the cryopreservation process.

Moreover, the presence of apoptotic changes in the atretic follicles supports the link between apoptosis and ovarian follicular atresia. It is also possible that substances 
which stimulate apoptosis may have atretogenic effects on the ovarian follicles. The presence of $\mathrm{Bcl}-2$ protein expression in the healthy ovarian follicles concurs with other reports (Tilly, 1996a,b; Felici et al., 1999) and suggests its possible physiologic role in the maintenance of follicular integrity. In support, mice lacking functional Bcl2 protein possess reduced numbers of primordial follicles relative to their wild-type sisters (Ratts et al., 1995).

The lack of p53 protein expression in the healthy follicles versus its presence of atretic ones concurs with previous studies and suggests lack of underlying DNA damage and therefore implies integrity of the genome in the healthy follicles (Hussein, 2005). During organ transplantation, tissues are subjected to variable duration of ischaemic injury. In the heart, retina, liver and brain, ischaemic injury is associated with apoptosis as well as Bcl-2 and p53 alterations. Namely, the induction of $\mathrm{Bcl}-2$ and p53 can occur as early as 0.5 and $1 \mathrm{~h}$, respectively, following ischaemia (Peralta et al., 2002; Wang et al., 2003). Apoptosis requires active cell metabolism that could not be complete within $30 \mathrm{~min}$ and could therefore not alter the status of the follicles within an ovary. A hypothesis to be tested is that the differences observed in this investigation are the result of outright lysis (ischaemia could make cells more prone to lysis). It would be interesting for future investigations to examine this hypothesis.

Our investigation revealed the presence of persistent vascularity and comparable MVD in both control and cryopreserved groups. These findings indicate that our freezethawing protocol has no detrimental effects on the integrity of the vascular network of the ovarian tissue. Of note, the status of the ovarian vascular supply is central to dynamic changes occurring during the normal ovarian cycle. Follicular growth and the development of the corpus luteum are dependent on intact vasculature.

The selection of a dominant follicle in monovular species is associated with angiogenesis. Moreover, selected follicles possess a more elaborate microvascular network than other follicles. The vasculature also plays a key role in the delivery of cholesterol to luteal cells for progesterone biosynthesis (Carret al., 1981; Goede et al., 1998). Many studies indicate that the ovaries of older women are smaller than those of young women. They are composed mainly of stromal cells that have receptors for, and respond to, gonadotrophins and secrete testosterone and lesser amounts of other androgens and estrogens. These ovaries remain gonadotrophin-driven, androgenproducing glands. Also, they are characterized by the presence of prominent cystic follicles, thick-walled vessels, granulomas, hyaline scars and low number of follicles. However, these follicles are not necessarily more sensitive to the freezing-thawing process (Couzinet et al., 2001; Longcope, 2001). 
In this investigation, the study group was formed of older patients knowing in advance the histopathological and follicular implications of ageing on the ovarian structure. Whether the aforementioned age-related changes have an impact on our results awaits further confirmation in younger age group upon ethical approval.

In this study, we assessed injury of the ovarian tissue in the period immediately after thawing. Our investigation provides further evidence that intact human ovary could be cryopreserved using a slow-freezing protocol. We have demonstrated comparable survival rates of follicles and limited molecular alterations between $\mathrm{C}$ $\mathrm{T}$ intact ovaries and $\mathrm{C}-\mathrm{T}$ ovarian cortical strips. The information herein reported is provided for the period immediately after thawing. The changes associated with longterm injury mandates further investigations.

\section{Acknowledgements}

The financial support for this study was a research grant from the Minimally Invasive Surgery Center, The Cleveland Clinic Foundation, Cleveland, OH, USA. 


\section{References}

Baird DT, Webb R, Campbell BK, Harkness LM and Gosden RG (1999) Long-term ovarian function in sheep after ovariectomy and transplantation of autografts stored at $-196^{\circ} \mathrm{C}$. Endocrinology $140,462-471$.

Bedaiwy MA and Falcone T (2004) Ovarian tissue banking for cancer patients: reduction of post-transplantation ischaemic injury: intact ovary freezing and transplantation. Hum Reprod 19,1242-1244.

Bedaiwy MA, Jeremias E, Gurunluoglu R, Hussein MR, Siemianow M, Biscotti C and Falcone T (2003) Restoration of ovarian function after autotransplantation of intact frozenthawed sheep ovaries with microvascular anastomosis. Fertil Steril 79,594-602.

Carr BR, Sadler RK, Rochelle DB, Stalmach MA, MacDonald PC and Simpson ER (1981) Plasma lipoprotein regulation of progesterone biosynthesis by human corpus luteum tissue in organ culture. J Clin Endocrinol Metab 52,875-881.

Couzinet B, Meduri G, Lecce MG, Young J, Brailly S, Loosfelt H, Milgrom E and Schaison $\mathrm{G}$ (2001) The postmenopausal ovary is not a major androgenproducing gland. J Clin Endocrinol Metab 86,5060-5066.

Demirci B, Salle B, Frappart L, Franck M, Guerin JF and Lornage J (2002) Morphological alterations and DNA fragmentation in oocytes from primordial and primary follicles after freezing-thawing of ovarian cortex in sheep. Fertil Steril 77,595-600.

Donnez J, Dolmans MM, Demylle D, Jadoul P, Pirard C, Squifflet J, Martinez- Madrid B and van Langendonckt A (2004) Livebirth after orthotopic transplantation of cryopreserved ovarian tissue. Lancet 364,1405-1410.

Falcone T, Attaran M, Bedaiwy MA and Goldberg JM (2004) Ovarian function preservation in the cancer patient. Fertil Steril 81,243-257.

Felici MD, Carlo AD, Pesce M, Iona S, Farrace MG and Piacentini M (1999) Bcl-2 and Bax regulation of apoptosis in germ cells during prenatal oogenesis in the mouse embryo. Cell Death Differ 6,908-915.

Gavrieli Y, Sherman Y and Ben-Sasson SA (1992) Identification of programmed cell death in situ via specific labeling of nuclear DNA fragmentation. J Cell Biol 119,493-501.

Goede V, Schmidt T, Kimmina S, Kozian D and Augustin HG (1998) Analysis of blood vessel maturation processes during cyclic ovarian angiogenesis. Lab Invest 78, 1385-1394.

Gook DA, Edgar DH, Borg J, Archer J, Lutjen PJ and McBain JC (2003) Oocyte maturation, follicle rupture and luteinization in human cryopreserved ovarian tissue following xenografting. Hum Reprod 18,1772-1781.

Gosden RG, Baird DT, Wade JC and Webb R (1994) Restoration of fertility to oophorectomized sheep by ovarian autografts stored at -196 degrees $C$. Hum Reprod 9,597-603.

Hussein MR (2005) Apoptosis in the ovary: molecular mechanisms. Hum Reprod Update 11,162-177.

Hussein M, Bedaiwy M and Falcone T (2006) Analysis of apoptotic cell death, Bcl-2, and p53 protein expression in freshly fixed and cryopreserved ovarian tissue after exposure to warm ischemia. Fertil Steril, 85,1082-92.

Jeremias E, Bedaiwy MA, Gurunluoglu R, Biscotti CV, Siemionow M and Falcone T (2002) Heterotopic autotransplantation of the ovary with microvascular anastomosis: a novel surgical technique. Fertil Steril 77,1278-1282.

Kerr JF, Wyllie AH and Currie AR (1972) Apoptosis: a basic biological phenomenon with wide-ranging implications in tissue kinetics. Br J Cancer 26,239-257. 
Liu TJ, el-Naggar AK, McDonnell TJ, Steck KD, Wang M, Taylor DL and Clayman GL (1995) Apoptosis induction mediated by wild-type p53 adenoviral gene transfer in squamous cell carcinoma of the head and neck. Cancer Res 55,3117-3122. Longcope C (2001) Endocrine function of the postmenopausal ovary. J Soc Gynecol Invest 8,S67-S68.

Martinez-Madrid B, Dolmans MM, Van Langendonckt A, Defrere S and Donnez J (2004) Freeze-thawing intact human ovary with its vascular pedicle with a passive cooling device. Fertil Steril 82,1390-1394.

Meirow D, Levron J, Eldar-Geva T, Hardan I, Fridman E, Zalel Y, Schiff E and Dor J (2005) Pregnancy after transplantation of cryopreserved ovarian tissue in a patient with ovarian failure after chemotherapy. N Engl J Med, 353,318-321.

Newton H, Fisher J, Arnold JR, Pegg DE, Faddy MJ and Gosden RG (1998) Permeation of human ovarian tissue with cryoprotective agents in preparation for cryopreservation. Hum Reprod 13,376-380.

Oktay K, Buyuk E, Veeck L, Zaninovic N, Xu K, Takeuchi T, Opsahl M and Rosenwaks Z (2004) Embryo development after heterotopic transplantation of cryopreserved ovarian tissue. Lancet 363,837-840.

Peralta C, Bulbena O, Xaus C, Prats N, Cutrin JC, Poli G, Gelpi E and Rosello- Catafau J (2002) Ischemic preconditioning: a defense mechanism against the reactive oxygen species generated after hepatic ischemia reperfusion. Transplantation 73,1203-1211.

Ratts VS, Flaws JA, Kolp R, Sorenson CM and Tilly JL (1995) Ablation of Bcl-2 gene expression decreases the numbers of oocytes and primordial follicles established in the post-natal female mouse gonad. Endocrinology 136,3665-3668.

Schmidt-Mende J, Hellstrom-Lindberg E, Joseph B and Zhivotovsky B (2000) Freezing induces artificial cleavage of apoptosis-related proteins in human bone marrow cells. J Immunol Methods 245,91-94.

Tilly JL (1996a) Apoptosis and ovarian function. Rev Reprod 1,162-172. Tilly JL (1996b) The molecular basis of ovarian cell death during germ cell attrition, follicular atresia, and luteolysis. Front Biosci 1,d1-d11.

Wang X, Chen H, Yin H, Kim SS, Lin Tan S and Gosden RG (2002) Fertility after intact ovary transplantation. Nature 415,385.

Wang F, Hu YL and Li YH (2003) The expression of Bcl-2 protein on acute myocardial ischemia/reperfusion and the significance in forensic pathology. Fa Yi Xue Za Zhi 19,207-208, 211.

Weidner N, Semple JP, Welch WR and Folkman J (1991) Tumor angiogenesis and metastasis - correlation in invasive breast carcinoma. N Engl J Med 324,1-8.

Wood TC, Montali RJ and Wildt DE (1997) Follicle-oocyte atresia and temporal taphonomy in cold-stored domestic cat ovaries. Mol Reprod Dev 46,190-200.

Yin H, Wang X, Kim SS, Chen H, Tan SL and Gosden RG (2003) Transplantation of intact rat gonads using vascular anastomosis: effects of cryopreservation, ischaemia and genotype. Hum Reprod 18,1165-1172.

Zhu L, Yu X, Akatsuka Y, Cooper JA and Anasetti C (1999) Role of mitogenactivated protein kinases in activation-induced apoptosis of T cells. Immunology 97,26-35. 



\section{Chapter 8}

Harvesting and

Autotransplantation of

Vascularized Ovarian Grafts:

Approaches and Techniques

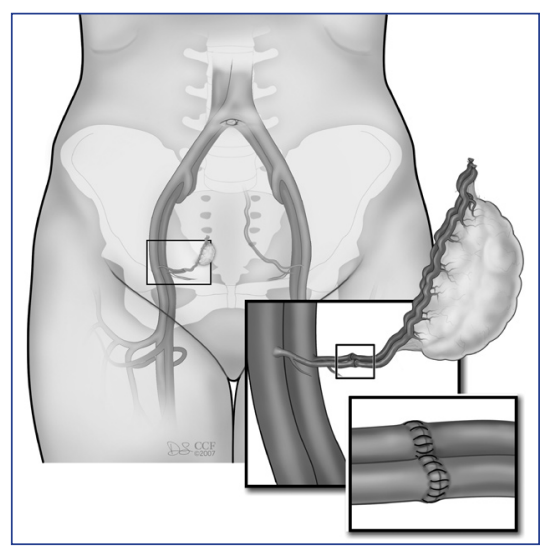

Mohamed A. Bedaiwy, Tommaso Falcone

Reprod Biomed Online, 2007; 14(3):360-71 


\section{Abstract}

The broad objective of this study was to describe the different surgical approaches involved in the harvesting and the heterotopic autotransplantation of intact ovaries with microvascular anastomosis. Twenty-one synchronized Merino sheep underwent harvesting of their intact ovaries along with their vascular pedicles. Autotransplantation of fresh ovaries was performed in 6 while autotransplantation of cryopreservedthawed ovaries (C-T) was performed in 15 animals. The ovarian vessels were anastomosed to the deep inferior epigastric vessels using end-to-end, end-to side and fish mouth modification techniques in 8, 6 and 7 animals respectively. Patency of the anastomosis, ischemia time, hormonal functions and histology were evaluated. In addition, ovarian harvesting techniques in 2 human subjects were described. Possible autotransplanation sites in humans were suggested. 33.3\% (7/21) of all fresh and C-T transplants showed patency after 10 days of follow-up. Patency was observed in $5 / 8,2 / 6$ and 0/7 animals using end-to-end, end-to side and fish mouth modification for completion of the microvascualr anastomosis respectively. In addition, use of the fish mouth modification technique was associated with significantly higher ischemia time compared to end-to-end $(P<0.01)$ and to end-to-side $(P=0.05)$ anastomosis. A laparoscopic approach appears to be a convenient approach for ovarian harvesting in humans. In addition, the inferior epigastric vessel is probably the most suitable heterotopic vascularizing vessel. The inferior epigastric vessel may be the most feasible heterotopic site to vascularize ovarian grafts. End to end anastomosis approach yields the highest patency rate of vascularized grafts. End to side anastomosis is superior to fish mouth modification in overcoming vascular discrepancy during transplantation.

Key Words: Ovarian harvesting, transplantation, vascular anastomosis, vascular discrepancy, deep inferior epigastric vessels. 


\section{Introduction}

Auto transplantation, xenografting and follicular culture (Scott et al. 2004) have been suggested as experimental strategies for restoring ovarian functions in female cancer survivors to make use of their own cryopreserved-thawed (C-T) ovarian tissue. Many orthotopic and heterotopic transplantation techniques have been described for fresh and C-T ovarian cortical strips (Oktay et al. 2001a). Two pregnancies and deliveries have been reported after orthotopic autotransplantation of C-T ovarian cortical strips in patients with Hodgkin's and non- Hodgkin's lymphoma (Donnez et al. 2004; Meirow et al. 2005). On the other hand, only one four-cell stage embryo was developed from 20 oocytes retrieved from heterotopically transplanted C-T ovarian cortical strips in a breast cancer survivor (Oktay et al. 2004).

Various orthotopic autotransplantation techniques have been described. The technique described by Donnez and associates was based on creating a peritoneal window very close to the ovarian vessels and fimbria and the thawed strips were placed in the created furrow (Donnez et al. 2004). A second technique was adopted by Meirow who inserted ovarian strips in cavities created by blunt dissection beneath the ovarian cortex on one side or smaller fragments immersed in oocyte wash buffer beneath the cortex in the other ovary (Meirow et al. 2005).

A third technique was described for transplantation of fresh ovarian cortex donated by a fertile monozygotic 24-year-old twin to her sister who presented with discordant ovarian function. The sterile twin received a transplant of ovarian cortical tissue from her sister by means of a minilaparotomy, where the stump left after excision of the streak ovaries was used as the recipient site. During her second cycle, she conceived, and subsequently delivered a healthy infant (Silber et al. 2005). All techniques described above were following the pioneering technique for autotransplantation of the ovarian cortical strips described in sheep by Gosden and associates (Gosden et al. 1994).

The limited longevity of ovarian function in some human ovarian transplants using non-vascularized grafts may be partially due to the initial ischemic injury (Oktay et al. 2001a; Oktay et al. 2001b; Radford et al. 2001) because of the time needed for re-vasculariztion of the grafts. Consequently, immediate revascularization and ischemia time reduction may be essential to maintain the different functions of the autografts (Aubard et al. 1999). In a trail to use vascularized grafts instead, we did a series of experiments with several observations. First, we demonstrated that larger ovarian cortical strips could withstand ischemia for variable durations (Jeremias et al. 2003) without changing the histological architecture or inducing molecular 
damage (Hussein et al. 2006). Second, an intact fresh ovary could be transplanted with its vascular pedicle using microvascualr anastomosis without jeopardizing the graft function (Jeremias et al. 2002). Third, cryopreservation of an intact sheep ovary with its vascular pedicle followed by transplantation could restore ovarian function (Bedaiwy et al. 2003). Lastly, an intact human ovary with its vascular pedicle could be cryopreserved without affecting the follicular viability, vascular density or molecular integrity of different ovarian components (Bedaiwy et al. 2006).

From all these observations we concluded that transplantation of fresh as well as $\mathrm{C}-\mathrm{T}$ intact ovaries to heterotopic sites is technically feasible with easy accessibility and shorter operative time. A detailed technique for orthotopic autotransplantation of an intact frozen-thawed ovary together with the upper genital tract using microvascular anastomosis in rats was provided (Wang et al. 2002). So far, there is no detailed description of the different techniques of heterotopic autotransplantation of an intact fresh or frozen-thawed ovary together with its vascular pedicle using microvascular anastomosis in animal models. If autotransplantation of intact ovaries with their vascular pedicle proved effective in animal models, there will be a need for identification of heterotopic locations that could be used to vascularize human ovarian grafts.

With this background in mind, the broad objective of this study was to describe the different surgical approaches involved in the harvesting and the heterotopic autotransplantation of intact ovaries with microvascular anastomosis. The specific aims of this study were 1) to describe the different surgical techniques of harvesting and heterotopic transplantation of intact ovaries with their vascular pedicle, 2) to provide information on additional experiments performed to validate this technique, and 3) to describe techniques for harvesting human ovaries for the same purpose and provide a model for human intact ovary autotransplantation based on the human vascular anatomy guided by the results of our animal experiments.

\section{Methods}

\section{Animals experiments}

The Institutional Animal Research Committee of the Cleveland Clinic Foundation approved all our animal experiments. Twenty-one adult, non-pregnant merino ewes, weighing 55-70 kg, were included. Surgical procedures were performed at the Cleveland Clinic Foundation Biological Resources Unit, in accordance with the facility's Standard Operating Procedures (IACUC protocol). The animals were cared for according to the standards of the US Public Health Policy of the Humane Care and Use of Laboratory Animals (PHS Manual, Ch. 143). Animals were synchronized 
by using megestrol acetate, (Ovaban; Scherring Plough, Kennilworth, NJ, USA) at a dose of $0.55 \mathrm{mg} / \mathrm{kg} /$ day for 10-12 days followed by 5000-10,000 IU Profasi (Serono Randolph, MA, USA) 34-36 hours before surgery. Two groups of animals were used. Group I ( $n=6)$ underwent autotransplantation of fresh ovary and (group II, $n=15$ ) underwent intact ovary cryopreservation and transplantation.

\section{Harvesting the ovaries}

The procedure was performed with sterile techniques using Storz surgical laparoscope under general endotracheal anaesthesia. The animal was secured on the operating table. The abdomen was shaved, prepared, and draped surgically. A $1-\mathrm{cm}$ horizontal umbilical skin incision was made. A $10 \mathrm{~mm}$ trocar was inserted and a pneumoperitoneum was created with $\mathrm{CO} 2$ at $10 \mathrm{~L} / \mathrm{min}$ and $12 \mathrm{~mm} \mathrm{Hg}$ of intra-peritoneal pressure. The animal was placed in a slight Trendelenburg position. A10-mm $0^{\circ}$ laparoscope was inserted through an umbilical incision and inspection of the pelvis was performed.

Secondary 5-mm trocars were inserted through the right and left lateral skin incisions $5 \mathrm{~cm}$ below and $8 \mathrm{~cm}$ lateral to the umbilicus. A left upper quadrant 5-mm trocar was placed at the level of the camera port. The ovarian vessels were identified, and their course was traced from the hilum cephalad. The ovary was dissected off the uterine horn; oviduct and the infudibulopelvic blood vessels were dissected off the surrounding tissue. The skeletonized blood vessels were double ligated as proximal as possible with non-absorbable 1-0 multifilament silk suture using intracorporeal ligature technique. The connective tissues around the vessels were carefully isolated, and the ovary was then resected and extirpated. The ovary was removed through one of the 10-mm trocars. The same process was repeated on the other side. After homeostasis was ascertained, the umbilical and the other incisions were closed using a single 1-0 silk stitch.

Cryopreservation, thawing and evaluation were performed as we described earlier (Bedaiwy et al. 2003). Briefly, the grafts were perfused with a mixture of Leibovitz L15 medium ( Irvine scientific, Santa Ana, CA, USA), 10\% fetal calf serum (Irvine Scientific) and 1.5 M dimethyl sulphoxide (DMSO) (Sigma, ST. Louis, MO, USA) immediately after oophrectomy via the ovarian vessels. The perfusion rate was maintained at $1.3 \mathrm{mLmin}-1$ with continuous replenishment of the reservoir. After perfusion, the ovary was transferred to $5 \mathrm{~mL}, 12.7 \times 92 \mathrm{~mm}$ cryovial (Corning Coaster Corporation, Cambridge, MA, USA) containing the cryoprotective mixture for controlled freezing using Planer cryochamber (Planer Freezer Ltd., Middlesex, UK) following the freezing protocol described earlier. On thawing, the ovary was washed and immediately per- 
Chapter 8
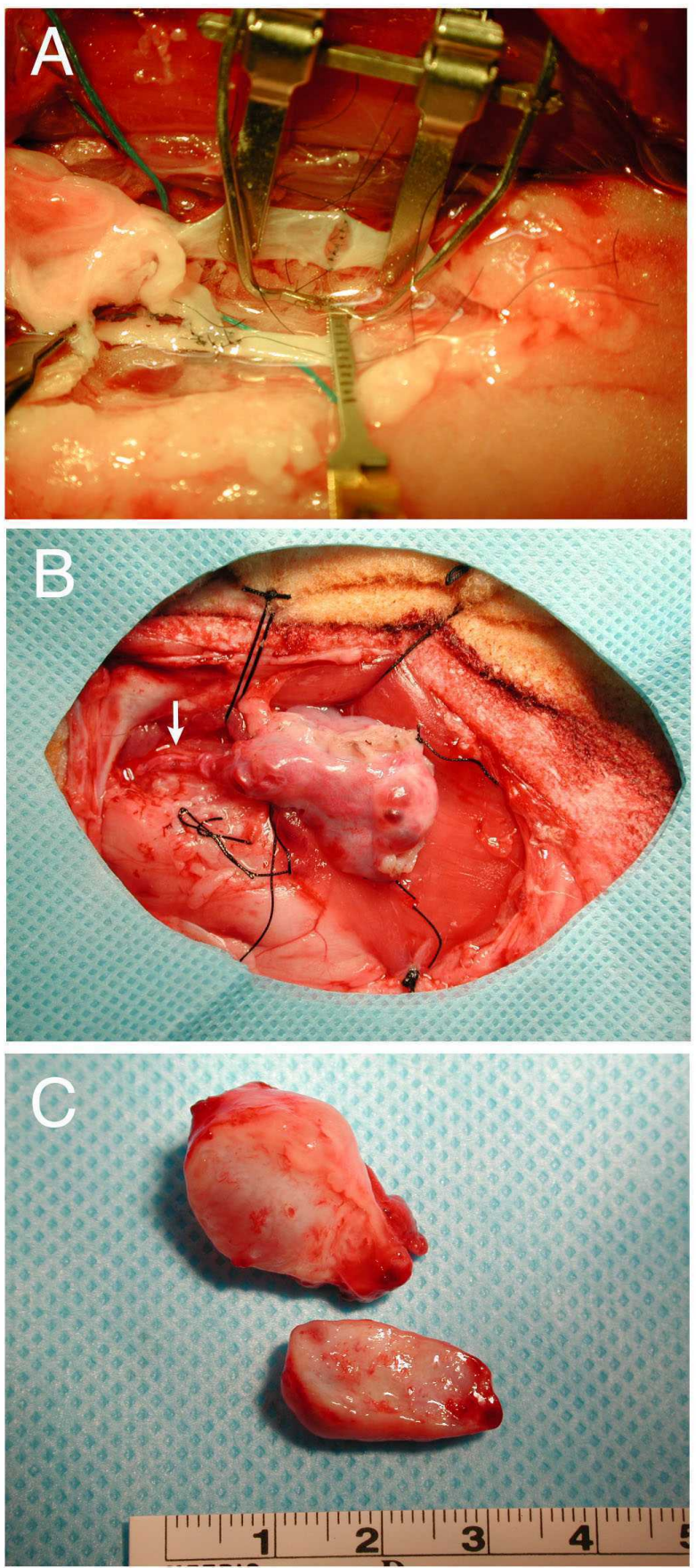

Figure 1: Tecnique for ovarian transplantation to the deep inferior epigastric vessels with microvascular anastomosis. The deep inferior epigastric vessels were skeletonized (Figure 1-A). Immediate vascular patency was tested for 20 minutes in all transplants (Figure 1-B). The transplant was then bisected (Figure 1-C) and removed for further evaluation. 
fused with Leibovitz L-15 medium supplemented with 10\% fetal calf serum using the same flow rate as described earlier for 20 minutes. The cryoprotectant was gradually eliminated by pumping Leibovitz L- 15 supplemented with $10 \%$ fetal calf serum into the reservoir.

\section{Autotransplantation}

\section{1- Dissection of the deep inferior epigastric vessels and preparation of the transplantation site:}

The animal was prepared as mentioned previously. An incision $(3-4 \mathrm{~cm})$ was performed on the anterior abdominal wall near the site of the 5-mm trocar to expose the deep inferior epigastric vessels (Figure 1-A). The deep inferior epigastric artery and vein were identified and dissected. The dissection was performed using standard microsurgical instruments and Acland vascular microclamps.

\section{2- Microvascular anastomosis:}

The anastomosis of the ovarian vessels to the deep inferior epigastric vessels was performed using 8-10 interrupted sutures (9-0 or10-0 prolene). All steps were performed under magnification using Zeiss surgical microscope (Carl Zeiss, Germany). Three different approaches were used to have the anastomosis completed based on the calibers of the ovarian and the deep inferior epigastric vessels:

\section{A- End to end anastomosis:}

Vessels with matching calibers ( 8 animals; 2 fresh and $6 \mathrm{C}-\mathrm{T}$ ) were anastomosed to the deep inferior epigastric vessels using end-to-end anastomosis (Figure 2-A). The selected segment of the deep inferior epigastric vessel was double clamped and transected. The ovarian vessels were prepared and trimmed to match exactly the caliber of the recipient vessel. The vein was anastomosed first followed by the artery. We started the anastomosis process on the dorsal aspect of vessels and the process was completed by suturing the ventral side at the end. The sutures were placed at equidistance from each other.

Figure 2: Microvascualr anastomosis technique using end to end anastomosis (figure 2-A), end to side anastomosis (figure2-B) and fish mouth modification (figure 2-C). $\mathrm{A}=$ artery; $\mathrm{V}=$ vein.

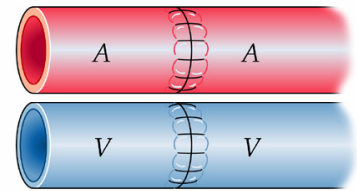

A

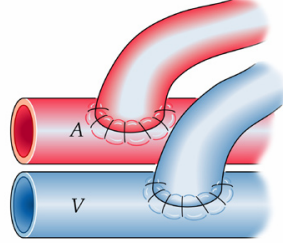

B

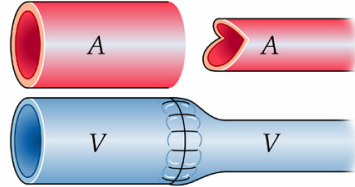

C 


\section{B- End to side anastomosis}

Vessels with caliber discrepancy were anastomosed using end to side anastomosis (6 animals; 2 fresh and $4 \mathrm{C}-\mathrm{T}$ ). If the caliber of the ovarian vessel looked smaller than any accessible portion of the deep inferior epigastric vessels, the latter was clamped and an opening matching the caliber of the ovarian vessels was created on the ventral aspect of the epigastric vessels. The anastomosis was then completed as shown in Figure 2-B.

\section{C- Fish mouth modification}

Vessels with size discrepancy were also anastomosed using a different approach called the fish mouth modification (7 animals; 2 fresh and 5 C-T). The terminal end of the ovarian vessel was split open to expand on the opening to make it match the caliber of the terminal opening of the deep inferior epigastric vessel. The anastomosis was then completed as shown in figure 2-C).

\section{3- Testing the immediate patency and finishing the procedure:}

Diluted heparin was applied topically as required. Immediate vascular patency was tested for 20 minutes in all transplants (Figure 1-B). Then, the ovary was fixed by a single stitch to the rectus muscle. The rectus sheath, subcutaneous tissue and the skin were closed using interrupted stitches. All animals were anticoagulated using 5000 IU sodium heparin (Eli Lilly, Indianapolis, IN, USA) subcutaneously, twice a day, for three days.

\section{4- Harvesting the reimplanted ovary:}

After 8-10 days, the transplant was inspected for macroscopic appearance, pulsations at the arterial anastomosis and patency of microvascular anastomosis. Viability of the ovarian transplant was also evaluated by checking the bleeding from edges at a small incision. The transplant was then bisected (Figure 1-C), removed for further evaluation.

\section{Hormonal assay and histological evaluation}

Hormonal assay and histological evaluation were performed following the protocol described earlier. Briefly, serum estradiol quantitative measurement was performed using the Automated Chemiluminescence Immunoassay System (ACS: 180®, Bayer, Tarrytown, NY, USA). FSH levels were measured by radioimmunoassay. This measurement was done using $\mathrm{NIH}$ anti-ovine FSH (A780) as FSH-antibody and A853 (ARGG) 
as second antibody. The data were analyzed using the RIANAL program. E2 and FSH levels were obtained on the day of surgery prior to operating and on the day the transplant was removed.

The ovarian tissues were Bouin-fixed, paraffin-embedded and haematoxylin and eosin stained for histological evaluation of the primordial follicle count, the presence of primary and secondary follicles, infarction and apoptosis following previously established criteria. To account for the non-uniform distribution of primordial follicles, a thorough examination of representative sections of all aspects of ovarian cortex was performed. However, we did not perform follicle counts on a small sample of fresh ovary prior to freezing to probably ensure more efficient cryopreservation and thawing process. Using the infusion pump system needs a closed circuit to ensure adequate distribution/washing of the cryoprotectants. Breaching the continuity of the ovarian cortex will disturb the closed circuit and may lead to uneven perfusion/wash of the cryoprotectant.

\section{Human experiment:}

We so far harvested 4 intact ovaries with their vascular pedicles from two patients for cryopreservation purposes after institutional board approval. The first patient was 46 years old, presented with menorrhagia and symptomatic fibroid uterus. She underwent total vaginal hysterectomy with bilateral salpingo-oophrectomy, McCall culdoplasty and cystoscopy. Intraoperative findings included bulky uterus and normal-appearing ovaries. The second patient was 44 years old, presented with sever premenstrual dysphoric disorders. She underwent laparoscopic bilateral salpingo-ophrectomy. Normal appearing uterus, tubes and ovaries were detected. Both ovaries and their pedicles, from both patients, were processed immediately for intact ovary cryopreservation. The results of all in vitro studies on these ovaries as well as the controls were presented in our earlier publication (Bedaiwy et al. 2006). Here we present the technical precautions that should be taken on harvesting the ovaries prior to freezing or transplantation. We will also present our proposed model of autotransplantion for intact human ovaries with microvascular anastomosis based on our animal experiments and available comparative anatomy data.

\section{Harvesting the ovaries}

\section{1-Harvesting the ovary by laparoscopy}

Laparoscopic oophorectomy is the preferred approach for the purposes of cryopreservation and subsequent transplantation to maintain the minimally invasive nature of the procedure. In our case, it was performed using the standard 
described elsewhere. For the purposes of subsequent cryopreservation and possible transplantation several precautions should be taken into consideration. First, the procedure should start with severing the utero-ovarian ligament of the ovary and then advanced cephalad through the mesosalpnix and ends at the infundibulopelvic ligament (Figure 3). Second, sharp dissection and ligation with sutures should be used in preference to electrocoagulation to avoid destruction and thermal injuries of the vascular walls and desiccation of the ovarian tissue. Third, the infundibulopelvic ligament containing the ovarian vessels should be dealt with last to avoid prolonged ischemia of the ovary as it is the main source of the blood supply. Fourth, the ovarian vessels should be ligated as proximal to the origin as possible to provide longer and wider caliber vessels to facilitate subsequent perfusion and transplantation with microvascular anastomosis. Lastly, the ovary with its vascular pedicle should be taken outside the peritoneal cavity in an Endobag through the $10 \mathrm{~mm}$ trocar and if needed through an extended port incision to avoid crushing the ovary and the blood vessels against narrow port site.

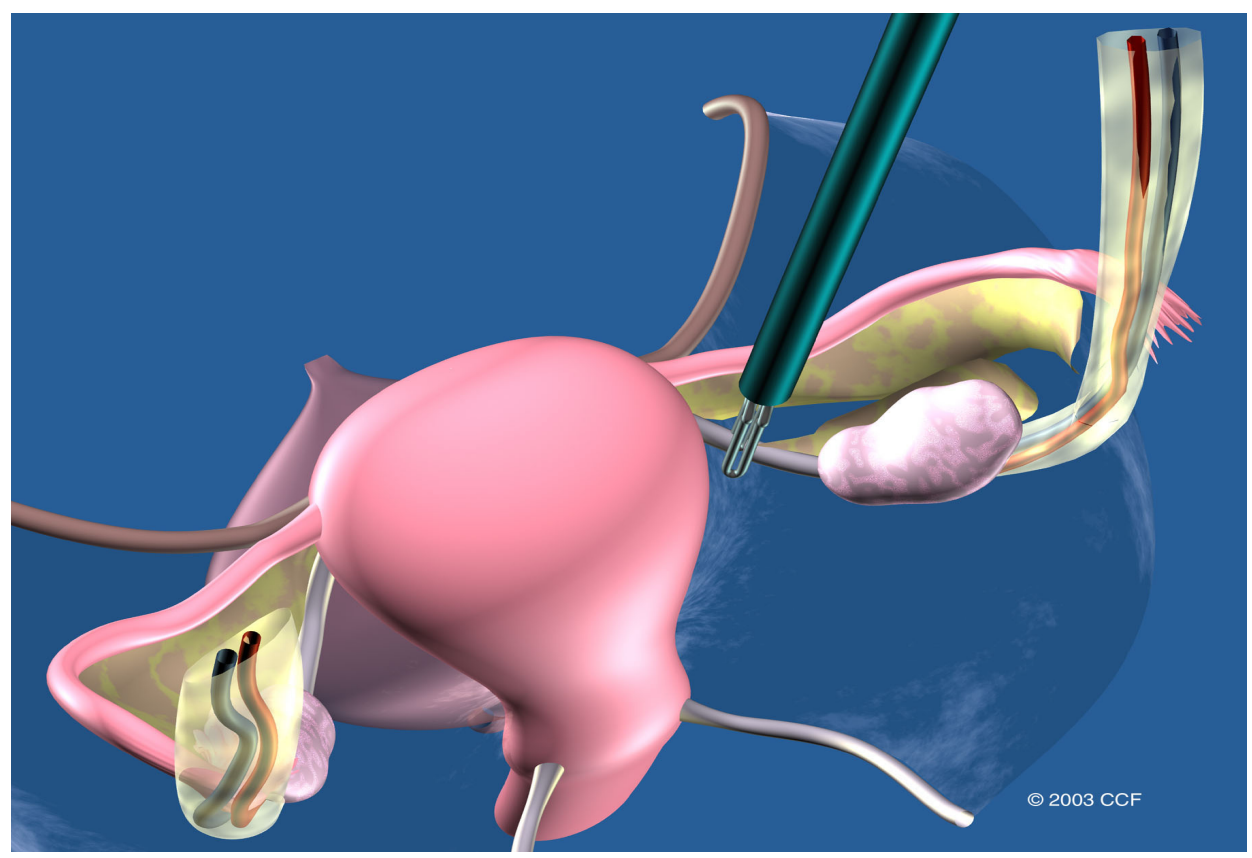

Figure 3: Technique of laparoscopic oophorectomy in human for the purpose of cryopreservation with subsequent transplantation. The procedure started with severing the suspensory ligament of the ovary and then advanced cephalad through the mesovarium and ends at the infundibulopelvic ligament. 


\section{2-Harvesting the ovary transvaginaly}

If oophorectomy is to be combined with vaginal hysterectomy, then the preferred approach for harvesting will be the vaginal route. That is what we did in our other case. Obtaining the ovary with its vascular pedicle transvaginally is technically challenging. Devascularization of the uterus performed from below the cephalad will save the infundibulopelvic ligament and the ovarian vessels until the very end of the procedure minimizing the ischemia time. Having a longer portion of the ovarian vessels via the vaginal route is not as easy as by laparoscopy. A longer portion of the pedicle could be obtained after releasing the ovary and the uterus from one side. This will provide more room and easy accessibility to the contralateral infundibulopelvic ligament at a more proximal location. From our experience, we recommend handling one ovary at a time for cryopreservation to minimize the ischemia time. The surgeon should not wait for both ovaries to be harvested concomitantly.

\section{Autotransplantation}

Although we have not done any autotransplantation of intact human ovaries yet, we did extensive research and created a model for potential recipient sites. The selected sites were picked based on several inclusion criteria. Firstly, the accessibility of the recipient site for transplantation with microvascular anastomosis. Secondly, the caliber of the recipient vessels at the target site and their compatibility with the ovarian vessel caliber. Thirdly, how amenable the recipient site is for frequent blood sampling, ultrasound monitoring and possible egg retrieval. Fourthly, the proximity to other sensitive structures. Fifthly, proximity of the selected site to pressure surfaces (e.g bones) and weight bearing areas. Lastly, the recipient site should be cosmetically acceptable by the patient because there will be a scar and bulge at the transplantation site.

\section{Surgical anatomy of the inferior epigastric vessels in humans}

The inferior epigastric and the deep circumflex iliac arteries are branchs of the external iliac artery at the level of the internal inguinal ring. The inferior epigastric artery arises from the anterior surface of the external iliac, passing forward and upward on the anterior abdominal wall between peritoneum and fascia transversalis. It penetrates the fascia below the arcuate line, entering the rectus abdominis muscle or coursing along its inferior surface to anastomose with the superior epigastric which is the terminal branch of the internal mammary artery. The inferior epigastric artery 
forms the lateral boundary of the Hesselbach's triangle. It frequently gives off a branch to the inguinal canal, as well as a branch to the pubis (pubic artery), which anastomoses with twigs of the obturator artery. The pubic branch of the inferior epigastric often becomes the obturator artery.

\section{Statistical analysis}

Analysis of variance (ANOVA) was used to compare the pre-operative to post-operative values $(p<0.05)$ using SAS version 11 software (SAS Institute Inc, Cary, NC, USA).

\section{Results}

\section{Animal experiments:}

\section{Cryopreserved-thawed transplants}

The first 6 animals were used to test the feasibility of the autotransplantation technique of intact fresh ovaries with their vascular pedicles to the deep inferior epigastric vessels with microvascular anastomosis. The vascular patency was documented in 50\% (3/6) of these transplants at the end of the follow up period. The results of this experiment were discussed previously and cannot be discussed here (Jeremias et al. 2002). The following 11 animals were used to test the applicability of the above technique using intact C-T ovaries. Vascular patency was documented in $27 \%(3 / 11)$ of these transplants at the end of the follow up period (Bedaiwy et al. 2003).

We performed the same techniques adopted in the second experiment on 4 more animals to further explore the best approach to perform microvascular anastomosis using C-T intact ovaries particularly when there is vascular discrepancy between the ovarian vessels and the deep inferior epigastric vessels. The results of the 4 new C$\mathrm{T}$ transplants were added to the results of the previous 11 animals in group 2 and analysed. A total of 4 transplants out of the $15 \mathrm{C}-\mathrm{T}$ transplants were found to have patent anastomosis at end of the follow up period (26.7\%; table 1 ). In these cases, arterial bleeding occurred at incision made in the ovarian cortex, documenting the long-term patency of the anastomosis. In animals with occluded anastmosis $(n=11)$, the anastomosed vessels were occluded completely, leading to great tissue loss. The ischemia time, that was defined as the sum of the time from removal of the ovary to cryopreservation and from thawing to transplantation, was not significantly different between patent and occluded vessel groups $(3.84+0.33$ versus $4.03 \pm 0.17$ hours; Table1). 
Table 1: Assessment of baseline and post-grafting endocrine functions in cryopreserved-thawed transplants.

\begin{tabular}{|c|c|c|c|c|c|c|}
\hline & \multicolumn{3}{|c|}{$\begin{array}{l}\text { Patent vascular anastomosis } \\
\qquad(n=4)\end{array}$} & \multicolumn{2}{|c|}{$\begin{array}{l}\text { Occluded vascular anastomosis } \\
\qquad(\mathrm{n}=11)\end{array}$} & $p$ value \\
\hline $\begin{array}{l}\text { Ischaemia time } \\
\text { (hours) }\end{array}$ & $3.84 \pm 0.33$ & & & $4.03 \pm 0.17$ & & NS \\
\hline \multirow{2}{*}{$\begin{array}{l}\text { Primordial follicular } \\
\text { count }\end{array}$} & $3.25 \pm 1.9$ & & & $0.23 \pm 0.44$ & & 0.005 \\
\hline & $\begin{array}{l}\text { Baseline } \\
\text { mean } \pm \text { SD }\end{array}$ & $\begin{array}{l}\text { Post-grafting } \\
\text { mean } \pm \text { SD }\end{array}$ & $p$ value & $\begin{array}{l}\text { Baseline } \\
\text { mean } \pm \text { SD }\end{array}$ & $\begin{array}{l}\text { Post-grafting } \\
\text { mean } \pm \text { SD }\end{array}$ & $p$ value \\
\hline FSH (pg/mL) & $202.44 \pm 70.34$ & $\begin{array}{l}180.36 \pm \\
38.1\end{array}$ & NS & $\begin{array}{l}93.65 \pm \\
77.06\end{array}$ & $260.83 \pm 9.47$ & 0.0009 \\
\hline Oestradiol (ng/mL) & $151.25 \pm 50.22$ & $\begin{array}{l}164.91 \pm \\
28.9\end{array}$ & NS & $\begin{array}{l}212.73 \pm \\
118.14\end{array}$ & $222.0 \pm 98.32$ & NS \\
\hline
\end{tabular}

NS $=$ not statistically significant.

In C-T transplants, there was no significant change in serum E2 levels before and after transplantation in either the patent vessel group or the non-patent vessel group indicating that a small remnant of surviving ovarian cortex tissue was sufficient for the resumption of E2 production (Table1). Serum FSH in the patent vessel group did not change significantly from pre- to post-transplantation, whereas a significant rise was observed in the non-patent vessel group $(93.65 \pm 77.06$ versus $260.83 \pm 9.47 \mathrm{ng} / \mathrm{ml}$, $p=0.009$ ), suggesting ovarian failure.

There were growing follicles detected in the surviving grafts. That could explain in part the hormonal perturbations observed by monitoring. However, most of the growing follicles are more vulnerable to freez-thaw injury as documented by many previous publications. We thought that it is more practical to count the primordial follicles to indirectly estimate the extent of damage to the ovarian reservoir. The surviving primordial follicles are the ones to be recruited and undergo growth within several weeks after transplantation.

The mean count of primordial follicle number, per high magnification field, after transplantation revealed a significantly higher number of follicles in the patent as compared to the non-patent vessel group $(3.25+1.9$ vs $0.23+0.44, p=0.005)$. Scattered areas of necrosis were observed on histological assessment of the patent vessel group, whereas transplants in the non-patent vessel group showed severe necrosis with thin peripheral rim of viable tissue. 


\section{Fresh and C-T transplants: anastomosis techniques}

In order to evaluate the impact of the anastomosis technique on the outcome, we evaluated the outcome of all fresh and C-T transplants as one group. Despite the fact that the short term vascular patency was observed in all transplants, patency at the end of the follow up period was different according to the way the anastomosis was performed. When end to end anastomosis was performed, long term vascular patency was the highest as $62 \%$ (5/8; group I) of the transplants showed patency at the time of the transplant removal (table 2). On the other side, when there is disparity between the caliber of the ovarian vessels and the deep inferior epigastric vessels, patency at the end of the follow up period was much lower. When this discrepancy was dealt with by end to side anastomosis, long term patency was documented in 2/6 $(33.3 \%$, group II) of the transplants as compared to $0 / 7$ ( $0 \%$, group III) when fish mouth modification was used. On comparing all three groups, vascular patency in group I was significantly higher than groups II and III ( $P=0.04$ and $<0.01)$ respectively. Group II had significantly higher patent transplants than group III as well $(p<0.01)$. Similarly, the ischemia time reflecting -in part- the duration of the procedure was significantly higher in group III than in groups I and II $(P<0.01$ and $=0.05)$ respectively.

Table 2: Assessment of vascular patency and ischaemia time in fresh and cryopreserved-thawed ovarian transplants.

\begin{tabular}{|c|c|c|c|c|c|c|}
\hline \multirow[t]{2}{*}{ Parameters } & \multirow{2}{*}{$\begin{array}{l}\text { End to end } \\
\text { (Group I; } n=8 \text { ) }\end{array}$} & \multirow{2}{*}{$\begin{array}{l}\text { End to side } \\
\text { (Group II; } n=6 \text { ) }\end{array}$} & \multirow{2}{*}{$\begin{array}{l}\text { Fish Mouth } \\
\text { (Group III; } n=7 \text { ) }\end{array}$} & \multicolumn{3}{|l|}{$P$ value } \\
\hline & & & & | vs. || & | vs. I|| & II vs. III \\
\hline $\begin{array}{l}\text { Immediate } \\
\text { patency (\%) }\end{array}$ & $8 / 8(100)$ & $6 / 6(100)$ & $7 / 7(100)$ & NS & NS & NS \\
\hline $\begin{array}{l}\text { Patency at } \\
\text { the end of the } \\
\text { follow up } \\
\text { period (\%) }\end{array}$ & $5 / 8(62.5)$ & 2/6 (33.3) & $0 / 7(0)$ & 0.04 & $<0.01$ & $<0.01$ \\
\hline $\begin{array}{l}\text { Ischaemia } \\
\text { time (hours) }\end{array}$ & $2.1 \pm 0.2$ & $3.8 \pm 0.4$ & $4.7 \pm 0.5$ & 0.05 & $<0.01$ & 0.04 \\
\hline
\end{tabular}




\section{Humans}

Following the harvesting technique described above, we were able to obtain all ovaries with adequate length of the vascular pedicle using the laparoscopic approach and a shorter pedicle using the vaginal route. We also managed to perform a successful cryopreservation of intact human ovaries with their vascular pedicles adopting the same protocol used in our animal experiments (Bedaiwy et al. 2006). As our next step will be the identification of a suitable heterotopic transplantation site, we identified the following target regions due to their rich blood supply; the neck, pectoral region, antecubital fossa, lower part of the anterior abdominal wall and the inguinal region (figure 4). The carotid vessels, the cutaneous branches of the internal mammary vessels, the antecubital vessels, the inferior epigastric vessels and the femoral vessels are the feeding vessels to be anastomosed to the ovarian vessels in their respective regions.

Based on the selection criteria set before in the methods sections, the advantages and the disadvantages of each transplantation site are shown in table 3. From that table, it is obvious that the deep inferior epigastric vessels are probably the most suitable vessels to vascularize human ovarian grafts, should heterotopic vascularized ovarian transplantation be an option. This is in the same line as the results of our animal experiments. The surgical anatomy of that vessel is provided in the methods section.

Table 3: Criteria of the vessels proposed to vascularize ovarian grafts with microvascular anastomosis.

\begin{tabular}{|c|c|c|c|c|c|c|c|}
\hline & Accessibility & $\begin{array}{l}\text { Caliber match } \\
\text { to the ovarian } \\
\text { vessels }\end{array}$ & Safety & $\begin{array}{l}\text { Amenability } \\
\text { to } \\
\text { monitoring }\end{array}$ & $\begin{array}{l}\text { Liability } \\
\text { to trauma }\end{array}$ & $\begin{array}{l}\text { Hard surfaces } \\
\text { behind }\end{array}$ & $\begin{array}{l}\text { Cosmetic } \\
\text { factors }\end{array}$ \\
\hline Carotid vessels & Accessible & Not matched & $\begin{array}{l}\text { Close to } \\
\text { sensitive } \\
\text { structures } \\
\text { May be risky }\end{array}$ & $\begin{array}{l}\text { Amenable but } \\
\text { could be } \\
\text { uncomfortable }\end{array}$ & Liable & None & $\begin{array}{l}\text { Scar and } \\
\text { bulge } \\
\text { in the } \\
\text { neck }\end{array}$ \\
\hline $\begin{array}{l}\text { Cutaneous } \\
\text { mammary } \\
\text { branches }\end{array}$ & Accessible & Matched & $\begin{array}{l}\text { No sensitive } \\
\text { structures }\end{array}$ & $\begin{array}{l}\text { Amenable and } \\
\text { comfortable } \\
\text { around }\end{array}$ & Liable & Chest wall & $\begin{array}{l}\text { Hidden } \\
\text { scar } \\
\text { and bulge }\end{array}$ \\
\hline $\begin{array}{l}\text { Antecubital } \\
\text { vessels }\end{array}$ & Accessible & Matched & $\begin{array}{l}\text { No sensitive } \\
\text { structures } \\
\text { around }\end{array}$ & $\begin{array}{l}\text { Amenable and } \\
\text { comfortable }\end{array}$ & Liable & None & $\begin{array}{l}\text { Scar and } \\
\text { bulge in } \\
\text { the } \\
\text { forearm }\end{array}$ \\
\hline $\begin{array}{l}\text { Inferior } \\
\text { epigastric } \\
\text { vessels }\end{array}$ & Accessible & Matched & $\begin{array}{l}\text { No sensitive } \\
\text { structures } \\
\text { around }\end{array}$ & $\begin{array}{l}\text { Amenable and } \\
\text { comfortable }\end{array}$ & Not liable & None & $\begin{array}{l}\text { Hidden } \\
\text { scar and } \\
\text { bulge }\end{array}$ \\
\hline Femoral vessels & Accessible & Not matched & $\begin{array}{l}\text { No sensitive } \\
\text { structures } \\
\text { around }\end{array}$ & $\begin{array}{l}\text { Amenable and } \\
\text { comfortable }\end{array}$ & Liable & None & $\begin{array}{l}\text { Hidden } \\
\text { scar and } \\
\text { bulge }\end{array}$ \\
\hline
\end{tabular}




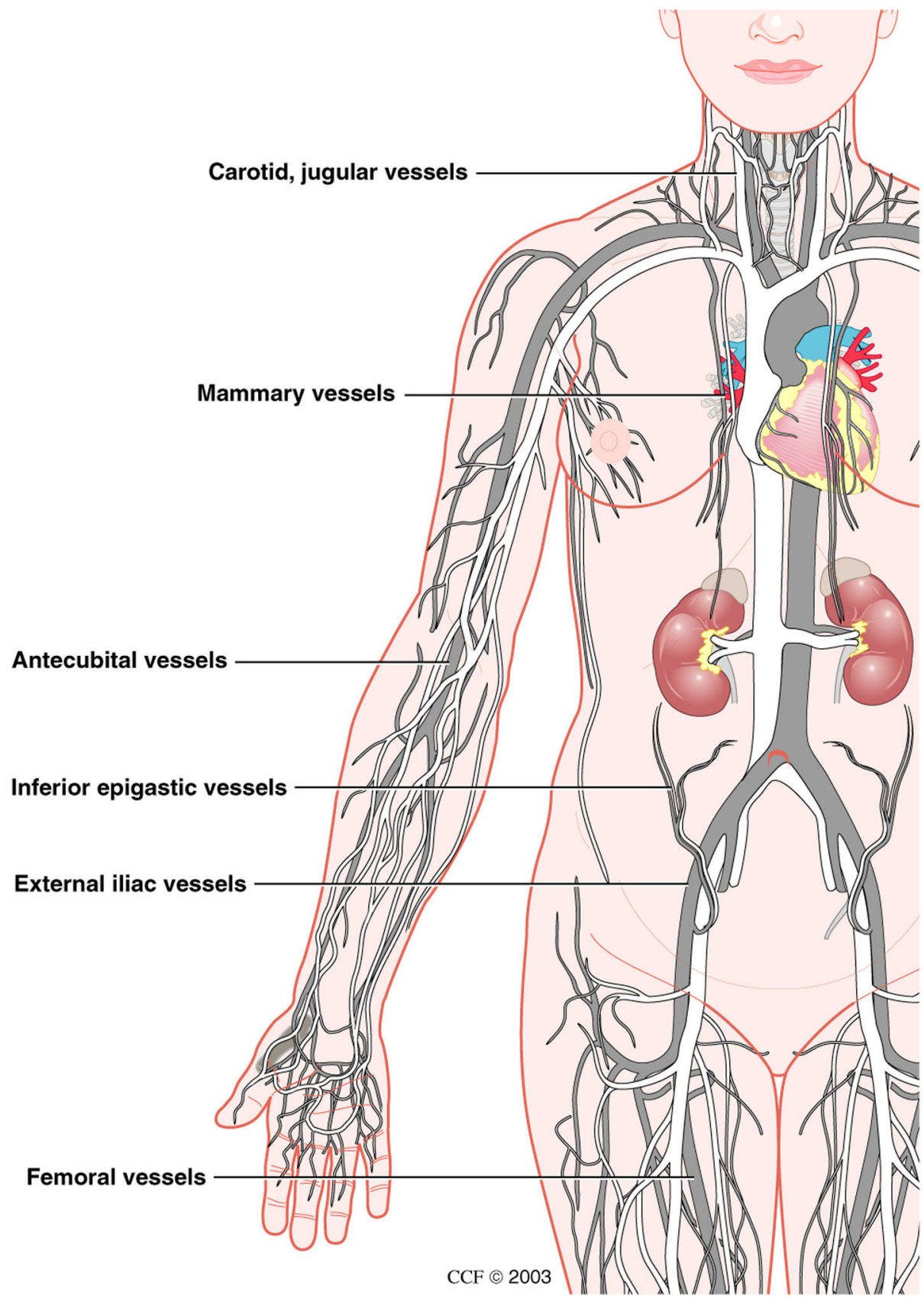

Figure 4: Proposed transplantation sites in humans: The neck, pectoral reigon, antecubital fossa, lower part of the anterior abdominal wall and the inguinal region could be recipient sites. The carotid vessels, the cutaneous branches of the internal mammary vessels, the antecubital vessels, the inferior epigastric vessels and the femoral vessels are the ones to be anastomosed to the ovarian vessels in their respective regions as shown in the figure. 


\section{Discussion}

We described the surgical techniques for ovarian harvesting and heterotopic ovarian transplantation to the anterior abdominal wall using microvascular anastomosis. Our main focus was to provide the different surgical tips on how to deal with ovaries at the time of harvesting to optimize the subsequent cryopreservation and autotransplantation. In addition, we tested two different approaches to overcome size discrepancy in the caliber between the ovarian and the epigastric vessels. Size discrepancy was defined as the inequality of vessel diameters at a ratio of $1: 1.5$ or greater. Size discrepancy was found in approximately $1 / 3$ of anastomoses in reconstructive surgeries (Cakir et al. 2003), the most frequent being in vein anastomoses performed during free flap transfers. The sudden change of caliber may cause turbulence to the blood flow and predisposes to platelet aggregation.

Discrepancies in the cut end diameters have been managed by many geometrical methods in order to reduce the risk of thrombosis (Lopez-Monjardin and de la PenaSalcedo 2000). Simple discrepancies less than $1: 1.5$ are usually dealt with by dilatation with the use of a jeweller's forceps (Cakir et al. 2003). Discrepancies exceeding $1: 1.5$ are usually dealt with the oblique cut, fish mouth cut, or end-to-side anastomosis (Cakir et al. 2003). When a great discrepancy may be anticipated and the upstream donor vessel is smaller than the recipient one, a sleeve anastomosis can be performed (de la Pena-Salcedo et al. 2000). Other geometrical designs (oblique cut or Y cut), devices, glues or adhesives and laser-assisted anastomosis are to be considered according the surgeon's experience (Lopez-Monjardin and de la Pena-Salcedo 2000). In a nice review, it has been concluded that there is not an ideal technique to manage every size discrepancy (Lopez-Monjardin and de la Pena-Salcedo 2000). However, the authors suggested looking for the best method with least complications and the best procedure to fit a specific case or body area.

Ovarian tissue viability was demonstrated both by estrogen production and significantly higher primordial follicle count in transplants with patent anastomosis at the end of the follow up period. Although no transplants were patent when fish mouth modification was used to overcome vascular discrepancy, one out of four C-T and one out of two fresh transplants were patent when end to side anastomosis was adopted. However, partial vascular damage due to cryopreservation insults cannot be excluded in the C-T ovaries. This could be easily extrapolated from the overall $50 \%$ patency rate at the end of the follow up period when fresh ovaries were transplanted compared to only $26.6 \%$ when C-T ovaries were transplanted (Jeremias et al. 2002). Consequently, survival of $\mathrm{C}-\mathrm{T}$ transplants is almost half the survival of fresh transplants. 
Obviously, end to end anastomosis appears to be the ideal approach to perform the anastomosis procedure with a patency rate $>60 \%$. However, if vascular discrepancy between the ovarian vessels and the inferior epigastric vessels is inevitable, end-to-side anastomosis, rather than fish mouth incisions should be adopted. Further advances in the anastomosis technique may help to improve the overall patency of the transplants. Trying sutureless approaches, glues or adhesives and laser-assisted anastomosis are to be considered according the surgeon's experience or in consultation with a plastic surgeon (Lopez-Monjardin and de la Pena-Salcedo 2000).

In addition, there is an increasing interest in the use of the more sophisticated microvascular free flap techniques instead of the standard local or regional flap technique to provide reconstructive options for urogenital indications (Ninkovic and Dabernig 2003). Free tissue transplantation (transfer) is a procedure that involves microvascular transplantation of a flap (a fasciocutaneous, muscle or composite flap) in one stage from a donor site in the body to a distant recipient site. The viability of the transplanted flap is maintained by microvascular anastomosis between the flap's vessels (at least one artery and one vein) and recipient vessels (Hoefter et al. 2005). With this fact in mind, it is expected to obtain optimal anatomical and functional reconstruction with minimal donor site morbidity particularly if an interdisciplinary approach is adopted.

Follicular loss after transplantation was found by Baird et al., to be during the initial ischemia after re-implantation and not due to the cryopreservation procedure (Baird et al. 1999). In addition, a primate study comparing heterotopically transplanted fresh and C-T ovarian cortical strips did not show significant differences in outcome (Schnorr et al. 2002). Hormonal functions were equally restored and mature oocytes were recovered in both groups. Hence, the majority of the primordial follicular loss is due to ischaemic injury rather than cryopreservation insults. Consequently, immediate revascularization could limit this accelerated follicular loss. However, this was not the case in a recent study which evaluated contralateral orthotopic autotransplantation of cryopreserved whole ovaries with microanastomosis of the ovarian vascular pedicle (Imhof et al. 2006). Although 4 sheep showed postoperative luteal function and 1 sheep conceived after spontaneous intercourse and delivered a healthy lamb 545 days after transplantation, histological examination of the ovaries 18-19 months after transplantation showed that follicular survival rate in the grafted ovaries was only 1.77.6\% (Imhof et al. 2006).

The ischaemia time in this study was relatively long. This was probably because it incorporated the time since the ligation of the ovarian vessels, the microdissection of the pedicle under the microscope, cannulation of the ovarian vessels, perfusion of 
the cryoprotectant for almost half an hour, slow freezing time, perfusion during the thawing process and the microanastomosis time. We noticed progressive decrease in the ischemia time throughout the experiments. We think that the ischemia time could be further shortened in future experiments.

In transplants with occluded blood supply, we did not observe revascularisation from the surrounding tissue to any ovary to compensate for the loss of the main blood supply. However, survival of some cortical tissue in transplants with occluded anastomosis could not be ruled out as perfusion of the peripheral ovarian tissue from the surroundings could happen.

Transplantation of intact ovary with its vascular pedicle to the anterior abdominal wall could have some advantages compared with other heterotopic and orthotopic techniques previously reported (Oktay et al. 2001a; Oktay et al. 2004). Firstly, the ovarian graft over the rectus abdominis muscles gives better protection to the graft compared to other more exposed sites as the forearm. Secondly, the anterior abdominal wall transplantation technique could be performed under local infiltration anaesthesia rather than general anaesthesia. Thirdly, the transplantation technique is much easier and more practical than orthotopic sites particularly if microvascular anastomosis is adopted. Fourthly, graft monitoring is easier and the graft could be removed if infracted. Fifthly, if fertility is desired, oocytes could be retrieved percutaneously without anaesthesia. However, the main disadvantage is that IVF is a must to achieve pregnancy.

On trying to duplicate these findings in humans, we found that the ovarian harvesting technique should probably be modified to nullify mechanical and ischemic damage of the ovary. Laparoscopic harvesting should be the first option for this purpose. Using the transvaginal route, enough pedicle with adequate length should be obtained. In addition, unnecessary trauma to the ovary and prolonged ischemia should be avoided. Achieving a successful cryopreservation of an entire human ovary with its vascular pedicle has been shown to be associated with reasonable post-thaw survival rates of follicles, small vessels, and stromal cells and a normal histological structure in all the ovarian components after thawing (Martinez-Madrid et al. 2004). We also showed that adopting a different slow freezing protocol, freezing an intact ovary was not associated with significant molecular alterations (Bedaiwy et al. 2006).

With all these data in mind we thought that it is time to consider intact human ovary transplantation. Until we can find a willing candidate we explored the possibilities of defining a suitable recipient vessel for this technique to come. It is expected that anastomosis of the ovarian vessels in humans would be less technically challenging because of the straight course and wider caliber of the ovarian vessels provided 


\section{Chapter 8}

that the recipient vessels have a matching caliber. From the criteria set before, we found that from all vessels evaluated that the deep inferior epigastric vessels stand as the best available option. Studying the surgical anatomy of that vessel highlighted its suitability for such a procedure as shown in table 3 . However, this proposition should be tested in a patient who is willing to volunteer to try this approach. The main limitation of this study was the short follow up duration. In addition, we did not quantify the size discrepancy ratio between the donor and the recipient vessels. However, we believe that sharing these surgical tips might be helpful for future experiments.

In conclusion, we have shown that the adoption of a microvascular technique could help intact fresh and $\mathrm{C}$-Tovaries retain reasonable function upon replantation. End to- side anastomosis is more efficient in overcoming size discrepancies than the fish mouth modification. Inferior epigastric vessels were proposed to be the most suitable heterotopic transplantation site in humans. Long-term survival, endocrinal function and fertility of oocytes derived from transplanted intact ovaries with microvascular anastomosis should be investigated.

\section{Acknowledgments}

The authors would like to acknowledge Raffi Gurunluoglu MD and Elisabeth Jeremias MD for their great help. 


\section{References}

Aubard Y, Piver P, Cogni Y et al. 1999 Orthotopic and heterotopic autografts of frozen-thawed ovarian cortex in sheep. Human Reproduction 14, 2149-2154.

Baird DT, Webb R, Campbell BK et al. 1999 Long-term ovarian function in sheep after ovariectomy and transplantation of autografts stored at -196 C. Endocrinology 140, 462-471.

Bedaiwy MA, Hussein MR, Biscotti C, Falcone T 2006 Cryopreservation of intact human ovary with its vascular pedicle. Human Reproduction (Epub ahead of print)

Bedaiwy MA, Jeremias E, Gurunluoglu R et al. 2003 Restoration of ovarian function after autotransplantation of intact frozen-thawed sheep ovaries with microvascular anastomosis. Fertility and Sterility 79, 594-602.

Cakir B, Akan M, Akoz T 2003 [The management of size discrepancies in microvascular anastomoses]. Acta Orthopaedica et Traumatologica Turnica 37, 379-385. de la Pena-Salcedo JA, Cuesy C, Lopez-Monjardin H 2000 Experimental microvascular sleeve anastomosis in size discrepancy vessels. Microsurgery 20, 173-175.

Donnez J, Dolmans MM, Demylle D et al. 2004 Livebirth after orthotopic transplantation of cryopreserved ovarian tissue. Lancet 364, 1405-1410.

Gosden RG, Baird DT, Wade JC, Webb R 1994 Restoration of fertility to oophorectomized sheep by ovarian autografts stored at -196 degrees C. Human Reproduction $\mathbf{9}$, 597-603.

Hoefter E, Holm C, Dornseifer U et al. 2005 [Free and pedicled muscle transfer as a therapy option in urological surgery]. Der Urologe A 44, 743-750.

Hussein MR, Bedaiwy MA, Falcone T 2006 Analysis of apoptotic cell death, Bcl-2, and p53 protein expression in freshly fixed and cryopreserved ovarian tissue after exposure to warm ischemia. Fertility and Sterility 85 Suppl 1, 1082-1092.

Imhof M, Bergmeister H, Lipovac Met al. 2006 Orthotopic microvascular reanastomosis of whole cryopreserved ovine ovaries resulting in pregnancy and live birth. Fertility and Sterility 85, Suppl 1, 1208-1215.

Jeremias E, Bedaiwy MA, Gurunluoglu R et al. 2002 Heterotopic autotransplantation of the ovary with microvascular anastomosis: a novel surgical technique. Fertility and Sterility 77, 1278-1282.

Jeremias E, Bedaiwy MA, Nelson D et al. 2003 Assessment of tissue injury in cryopreserved ovarian tissue. Fertility and Sterility 79, 651-653.

Lopez-Monjardin H, de la Pena-Salcedo JA 2000 Techniques for management of size discrepancies in microvascular anastomosis. Microsurgery 20, 162-166.

Martinez-Madrid B, Dolmans MM, Van Langendonckt A et al. 2004 Freeze-thawing intact human ovary with its vascular pedicle with a passive cooling device. Fertility and Sterility 82, 1390-1394.

Meirow D, Levron J, Eldar-Geva T et al. 2005 Pregnancy after transplantation of cryopreserved ovarian tissue in a patient with ovarian failure after chemotherapy. New England Journal of Medicine 353, 318-321.

Ninkovic M, Dabernig W 2003 Flap technology for reconstructions of urogenital organs. Current Opinions in Urology 13, 483-488

Oktay K, Aydin BA, Karlikaya G 2001a A technique for laparoscopic transplantation of frozen-banked ovarian tissue. Fertility and Sterility 75, 1212-1216.

Oktay K, Buyuk E, Veeck L et al. 2004 Embryo development after heterotopic transplantation of cryopreserved ovarian tissue. Lancet 363, 837-840.

Oktay K, Economos K, Kan M et al. 2001b Endocrine function and oocyte retrieval after autologous transplantation of ovarian cortical strips to the forearm. JAMA 286, 1490-1493. 
Radford JA, Lieberman BA, Brison DR et al. 2001 Orthotopic reimplantation of cryopreserved ovarian cortical strips after high-dose chemotherapy for Hodgkin's lymphoma. Lancet 357, 1172-1175.

Schnorr J, Oehninger S, Toner J et al. 2002 Functional studies of subcutaneous ovarian transplants in non-human primates: steroidogenesis, endometrial development, ovulation, menstrual patterns and gamete morphology. Human Reproduction 17, 612-619.

Scott JE, Carlsson IB, Bavister BD, Hovatta O 2004 Human ovarian tissue cultures: extracellular matrix composition, coating density and tissue dimensions. Reproductive BioMedicine Online 9, 287-293.

Silber SJ, Lenahan KM, Levine DJ et al. 2005 Ovarian transplantation between monozygotic twins discordant for premature ovarian failure. New England Journal of Medicine 353, 58-63.

Wang $\mathrm{X}$, Chen $\mathrm{H}$, Yin $\mathrm{H}$ et al. 2002 Fertility after intact ovary transplantation. Nature 415, 385. 




\section{Chapter 9}

Reproductive outcome after transplantation of ovarian tissue: a systematic review of observational studies and an individual patient data meta-analysis

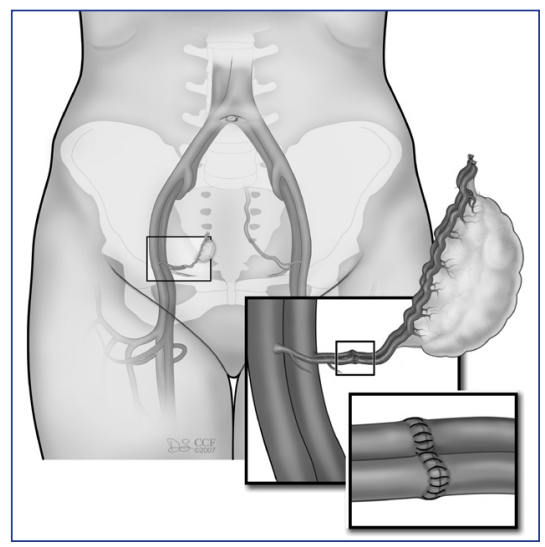

Mohamed A. Bedaiwy, Sherif A. El-Nashar Johannes L.H. Evers, Nina Desai, Tommaso Falcone

Submitted 


\section{Abstract}

Background: Despite interest in ovarian tissue transplantation (OTT) as a promising procedure for fertility preservation in women at high risk of premature ovarian failure (POF), to date, no precise data is available about its effectiveness. Methods: We performed a systematic review of observational studies to evaluate the reproductive outcome after OTT. A systematic search of the relevant databases up to June 2007 was performed. The review included peer-reviewed reports on OTT in humans with no language restriction. Women with follicle stimulating hormone (FSH) $>30 \mathrm{IU} / \mathrm{L}$ at the time of OTT were included in a meta-analysis of individual-patient data to evaluate the time to re-establishment of ovarian function (ROF). Secondary outcomes included short-term ( $<12$ months) and long-term ( $>12$ months) ovarian function (OvF) and pregnancy after OTT.

Findings: The review included 47 cases from 22 reports. OTT was performed to treat POF, to prevent POF, to treat infertility, and accidentally in $(28,16,2$ and 1) patients respectively. In all 24 women with $\mathrm{FSH}>30 \mathrm{IU} / \mathrm{L}$ at the time of OTT, OvF was re-established with a median time to ROF of 120 days (range, 60-244). Fresh, heterologous and larger size OTT increased the likelihood of return of OvF [HR of $2.4(95 \% \mathrm{Cl}, 1-5.8), 10(95 \% \mathrm{Cl}, 2.6-48.3), 1.7(95 \% \mathrm{Cl} 1.1-2.5)$, respectively]. Within 6 months after ROF, 4 women had recurrent ovarian failure. All 4 had cryopreserved, autologous grafts using cortical strips, and in all ROF occurred $>90$ days after OTT. Data was not sufficient to evaluate the long-term OvF ( $>12$ months). In the 27 women who sought pregnancy, 8 women had 9 pregnancies with 12-month cumulative pregnancy rate of $36 \%(95 \% \mathrm{Cl}, 18-59 \%)$.

Interpretation: Transplantation of ovarian tissue can re-establish ovarian function in women with premature ovarian failure; however, the current evidence is not sufficient to evaluate the long-term efficacy and longevity of ovarian grafts. A controlled multicenter clinical trial with sufficient follow up would provide clinicians and patients with valid evidence of the potential benefit of this procedure.

Keywords: Meta-analysis, Ovarian transplantation; Ovarian function; Pregnancy; Cancer. 


\section{Introduction}

Ovarian tissue transplantation (OTT) is becoming an increasingly popular strategy for fertility preservation. This procedure entails harvesting of ovarian tissue -with or without cryopreservation- from women who are at high risk of premature ovarian failure (POF) followed by subsequent transplantation. While the original indication was to preserve fertility in cancer patients (autologous transplantation), the spectrum has now expanded to incorporate OTT in twins discordant for POF and to restore ovarian function in women with ovarian dysgenesis (heterologous transplantation) ${ }^{1-3}$. Another proposed indication, yet not pursued, is to prolong the reproductive life in otherwise healthy women ${ }^{2}$.

Despite the experimental nature of the procedure, there is an increasing public awareness of its availability as a potential fertility preservation strategy for those at risk. The American Society of Reproductive Medicine (ASRM) practice committee categorized the use of ovarian tissue cryopreservation with subsequent transplantation as an experimental option for fertility preservation with the notion that it should be performed after obtaining Institutional Review Boards (IRB) approval ${ }^{4}$. In addition, ovarian tissue banking has been offered to patients as a clinical service for almost 2 decades by many clinical centers around the globe with sparse evidence of its clinical usefulness ${ }^{5-8}$. This service was mostly offered as a potential fertility preservation option in patients about to receive gonadotoxic treatment for a malignancy. The 3 potential uses proposed for harvested fresh or frozen ovarian tissue were in vitro maturation of primordial follicles, xenografting of ovarian tissue or subsequent ovarian transplantation. To date, only the latter has been successfully attempted in humans ${ }^{2,9}$.

In theory, two important ischemic episodes may affect the outcome of OTT in a negative way, the first after harvesting the tissue and preparing it for either fresh transplantation or cryopreservation, the second (warm ischemia time) during the period of revascularization immediately following transplantation.

Successful attempts of OTT have been reported using a variety of ovarian tissue sizes ranging from cortical strips to the transplantation of the whole ovary with or without its vascular pedicle ${ }^{3,9-19}$. While fresh transplant was possible for all these variety of sizes, transplant of previously frozen ovarian tissues was only reported using cortical strips. Most of the reported ovarian tissue cryopreservation protocols were modifications of the original one reported by Gosden and his colleagues ${ }^{20}$. In addition, wide varieties of alternative sites and surgical techniques have been reported. Orthotopic ovarian transplantation has been tried to the ovarian stump or to the periovarian region 2,17,21. Alternatively, heterotopic ovarian transplantation has been also performed to a variety 
of locations including the arm ${ }^{10,13}$, the forearm ${ }^{14,22}$, rectus abdominis muscle ${ }^{19}$, the subcutaneous tissue of the abdominal wall ${ }^{23}$ and the suprapubic area ${ }^{24}$. In addition, a combined orthotopic and heterotopic approach has been utilized as well ${ }^{25,26}$. The orthotopic transplantation process has been accomplished either via laparoscopy ${ }^{17}$ or laparotomy ${ }^{2,21}$.

Despite the relatively large number of reports on OTT approaches and techniques, to date, there is no precise data on the reproductive outcomes after OTT. This is in part due to the small numbers of patients and the wide range of indications, surgical techniques and wide variability of the follow up duration. All these factors limited the external validity of the inferences of these studies and precluded the utilization of their outcomes. In addition, the experimental natures as well as the ethical concerns prevented the execution of larger well designed studies to answer these important questions. Such information would help physicians counsel patients regarding this treatment option and will direct the future research efforts in this field.

In an effort to address this gap in the literature, we performed a systematic review of the literature to summarize the reproductive outcome after transplantation of ovarian tissue (OTT) for fertility preservation purposes including prevention and or reversal of POF.

\section{Methods}

A systematic review approach was performed to evaluate the reproductive outcomes after ovarian tissue transplantation (OTT). This review was conducted according to the Meta-analysis Of Observational Studies in Epidemiology (MOOS) group statement 27 .

\section{Study Selection, Study Characteristics and Methodological Quality Evaluation}

We included published peer reviewed studies on the reproductive outcomes after OTT in humans including re-establishment of ovarian function evidenced by ovarian follicular growth or menstruation, and pregnancy. No language restriction was applied. A systematic search on the MEDLINE, EMBASE, Cochrane Systematic Reviews, CENTRAL, Web of Science, Scopus databases from inception until June, 2007 was performed. In this search, we used terms referring to "ovarian tissue transplantation" and "reproductive outcomes" (Table 1). Two reviewers (M.A.B. and S.A.E.) independently reviewed the identified reports. Disagreements in study inclusion were resolved by consensus and agreement in the selection of the studies was evaluated using $\mathrm{K}$ statistics ${ }^{28}$. In addition, both reviewers (M.A.B., S.A.E.) independently reviewed the bibliographies of the retrieved articles and the recent reviews for additional studies. 
The methodological characteristics of the included studies including study design, number of participants, and procedure specific characteristics of OTT were collected. The methodological quality of the included reports was evaluated using the NewcastleOttawa Scale (NOS) ${ }^{29}$. The Newcastle Ottawa Scale has been developed to assess the quality of observational studies in a systematic review. A "star system" had been developed in which a study is judged on three broad categories: the selection of the study participants, the comparability of the groups, and the assessment of the outcome of interest. A study can be awarded a maximum of one star for each individual item within the selection and outcome, and a maximum of two stars can be given for comparability. An ideal study would be awarded 9 stars ${ }^{29}$. A modified NOS form was developed to match the objectives and outcomes of the current review (Appendix I). Quality evaluation was also performed by 2 reviewers independently (M.A.B., S.A.E.) and the agreement was reported.

\section{Outcomes of Interest and Subgroup Analyses}

The primary outcome for this review was the re-establishment of ovarian function after OTT as defined by evidence of follicular growth and/or the return of menstruation with the time to reestablishment of ovarian function as the primary endpoint for this outcome. Secondary outcomes included short term ( $<12$ months) and long-term ( $>12$ months) maintenance of ovarian function and the occurrence of pregnancy after the procedure OTT. Subgroup analyses were planned a priori and performed based on study characteristics (study design and the number of participants in each study), patients' characteristics (etiology of OTT, age at POF, age at OTT, baseline follicle stimulating hormone (FSH)), procedure specific variables (fresh vs. frozen, autologous vs. heterologous and orthotopic vs. heterotopic), and the amount of the transplanted tissues (whole ovary, whole or most of the cortex and cortical strips). The sizes of the cortical strips transplanted ranged from $1 \times 5 \times 5 \mathrm{~mm}$ to $1 \times 5 \times 15 \mathrm{~mm}$. Patients who received ovarian cortical strips OTT will be categorized into 2 subgroups according to the number of strips transplanted $>10$ and $\leq 10$. We will also present the data for the subgroup of women who sought pregnancy including those who underwent in vitro fertilization (IVF).

\section{Quantitative Data Synthesis}

A standardized data extraction sheet was developed and 2 reviewers (M.A.B. and S.A.E.) independently extracted the individual data from each included report. Disagreements were resolved by consensus. The baseline individual patientlevel data in the sheet included age at the time of OTT, indication for OTT, wish 
for pregnancy, medical and surgical history, documented occurrence of POF, the baseline FSH level and the age of the patient at POF, and previous chemotherapy or radiotherapy. The procedural specific data included the technique and the approach used for OTT along with the amount of transplanted tissues. Retrieved data also included the reestablishment of ovarian functions, the recurrence of ovarian failure and the occurrence of pregnancy after the procedure. The duration of the follow up was recorded in all patients. The subgroup of patients that sought pregnancy was identified. Another subgroup of women that underwent in vitro fertilization (IVF) was also evaluated. In those who underwent IVF, the controlled ovarian stimulation (COS) protocol used (natural, antagonist or agonist protocols), the duration of COS, the FSH dose, the number of follicles at the day of HCG administration, number of oocyctes retrieved and the total number of embryos developed will be reported. Reasons of treatment cycle cancellation will be also reported as either no follicle available for retrieval, failed fertilization or failed embryonic development with no embryos available for embryo transfer (ET). Pregnancies will be reported as chemical or clinical pregnancies. Pregnancy rate was calculated per patient, per cycle started and per cycle completed.

\section{Statistical Analysis}

Count and percentages along with their exact binomial 95\% confidence intervals $(95 \% \mathrm{Cls})$ were reported for categorical data ${ }^{30}$. Mean and standard deviation (SD) were used for continuous variables with normal distribution while median and interquartile range ( $25^{\text {th }}$ percentile and the $75^{\text {th }}$ percentile) were used for skewed data. The primary outcome for this review was the re-establishment of ovarian function after OTT as defined by evidence of follicular growth and/or the return of menstruation with the time to reestablishment of ovarian function as the primary endpoint for this outcome. For evaluation of this outcome, we only included women with evidence of premature ovarian failure (POF) diagnosed by follicle stimulating hormone (FSH) level $>30$ $\mathrm{IU} / \mathrm{L}$ before the procedure. Secondary outcomes included short term ( $<12$ months) and long-term (>12 months) maintenance of the re-established ovarian function and the occurrence of pregnancy after the procedure. In women who re-established their ovarian function, the time to recurrent ovarian failure was calculated and in the subgroup of women who sought pregnancy after OTT, the time to pregnancy was used as a secondary endpoint. The Kaplan-Meier method was used to estimate the median time to re-establishment of ovarian function after OTT. In addition, KaplanMeier method was used to estimate the cumulative rate for each outcome and its corresponding $95 \%$ confidence interval ${ }^{31}$. 
For the primary outcome, inconsistency across studies was quantified using the $\mathrm{I}^{2}$ statistic for each endpoint ${ }^{32}$. A P value of 0.1 was selected as a cut point for rejection of the null hypothesis of study homogeneity due to the lack of power and to limit type II errors ${ }^{33}$. In addition to the statistical testing for heterogeneity of the primary outcome, we planned subgroup analyses to identify the potential explanations for outcomes across strata based on patient and methodological differences among studies. We hypothesized that the likelihood for developing each outcome might vary depending on study characteristics, patients' characteristics, procedure specific variables, and the amount of the transplanted tissues. In the subgroup analyses for the primary outcome, the hazard ratios (HR) were used to represent the relative chance of the re-establishment of ovarian function in one group of patients compared to another group, and then we conducted a statistical test of interaction to evaluate the extent to which subgroup results differed. A P-value of 0.05 was selected as cut off for interaction testing ${ }^{34}$. We also tested the proportionality assumption of the Cox proportional hazards models for each subgroup analysis by including an interaction term for the stratifying variable with the logarithm of time. For the secondary outcomes, comparisons between strata were performed using Fisher exact test (for categorical variables) and Wilcoxon rank sum test (for continuous variables).

The agreement at each step of the selection and the methodological quality evaluation of the included reports was evaluated using $\mathrm{k}$ statistics. $\mathrm{K}$ estimates were interpreted according to Landis and Koch $[<0$ indicating no agreement; 0.0-0.19, poor agreement; 0.20-0.39, fair agreement; 0.40-0.59, moderate agreement; 0.60-0.79, substantial agreement; and 0.80-1.00, almost perfect agreement ${ }^{28}$. Statistical analyses in this study were performed using RevMan software version 4.2.8 (The Cochrane Collaboration, Oxford, United Kingdom) and JMP version 6.0 (SAS Institute Inc, Cary, North Carolina, United States).

\section{Results}

\section{Study Selection}

Out of 744 reports identified in the search, 25 reports met the inclusion criteria of the review (Figure 1 ). All identified studies were observational studies including 3 cohort studies, 1 case series and 21 case reports. 2,3,9-19,21-26,35-40. The agreement in the selection of studies between the 2 reviewers was almost perfect with kappa $=0.9$ $(95 \% \mathrm{Cl}, 0.8-1.0)$. Out of these 25 reports, 3 reports included further technical and follow up data about the same cases included in other studies by the same research groups 10,11,14,16,26,36. Finally, the review included 22 unique reports including 47 women who underwent transplantation of ovarian tissues (OTT) from 1985 through 2007. 
The methodological characteristics of the included studies and their methodological quality evaluation using a modified NOS questionnaire were presented (Table 2). The agreement in the quality evaluation of the included studies between the 2 reviewers was substantial with kappa $=0.7(95 \% \mathrm{Cl}, 0.5-0.8)$. Authors were contacted to verify unclear information in a few instances ${ }^{2}$.

\section{Clinical Characteristics and Indications of Ovarian Tissue Transplantation}

Individual patient data was available for all 47 patients included in the selected 22 studies. The median age was 36 years (IQR, 28-41 years, and range from 15-49 years). Ovarian tissue transplantation (OTT) was performed to treat already diagnosed premature ovarian failure (POF) in 28 women, to avoid the development of POF in 16 women, to treat infertility in 2 women, and in 1 woman evidence of return of ovarian function was documented after accidental entrapment of some ovarian tissues in the abdominal wall after laparoscopic oopherectomy for a benign indication.

To date, only 3 out of 47 women had one or more whole ovaries freshly transplanted (no cryopreservation was performed) with or without microvascular attachment of their pedicle ${ }^{3,10,18}$. In 2 of these 3 women, the patients' own ovaries were transplanted to their upper limb to avoid the effect of pelvic radiation as a treatment of Hodgkin lymphoma in one patient and uterine cervical cancer in the second one ${ }^{10,18}$. In the remaining patient, the transplant was performed to reestablish ovarian function in a patient with ovarian dysgenesis (Turner's syndrome). In that patient, a complete ovary with its vascular pedicle was removed form a HLA matched donor (her 26 year old sister) and transplanted into the pelvis with the ovarian vascular pedicle attached to the inferior epigastric vessels ${ }^{3}$. In all 3 women, no documentations of ovarian failure by FSH elevation before ovarian transplant were reported. Nevertheless, ovarian function was reported in all 3 patients after transplant 3,10,18. However, long-term ovarian function beyond 1 year and up to 18 years was only reported by Leporrier and colleagues ${ }^{41}$.

\section{Primary Outcome (Re-establishment of Ovarian function)}

Out of 47 women included in this study, 28 women underwent OTT to reestablish their ovarian function after diagnosis of POF. Four of these women did not have documented FSH levels at the time of OTT and were excluded from the analysis $3,9,18$. Thus, only 24 patients who had pre OTT FSH $>30 \mathrm{IU} / \mathrm{L}$ were included in the analysis. Data needed for evaluation of the primary outcome were complete in all 24 patients. Patient characteristics and procedure specific variables were presented (Table 3). The return of ovarian function was based on the return of follicular growth 
and menstruation in 20 cases (19 spontaneous and 1 induced), and only on the detection of follicular growth in 4 cases (all had hysterectomies). The time needed to reestablish ovarian function ranged from 60 to 244 days and the median time to return of ovarian function was 120 days (IQR, 82-175) with all patients [100\% $(95 \% \mathrm{Cl}, 91-100)]$ having shown at least some evidence of ovarian function at 244 days using Kaplan Meier Plot (Figure 2).

A significant heterogeneity in the time to reestablishment of ovarian function was reported in each study $\left(I^{2}=92 \%, P<0.001\right)$. To explore heterogeneity, we compared the risk ratios for the return of ovarian function between different subgroups depending on patient characteristics and procedure specific variables. The likelihoods for the return of ovarian function were not significantly affected by study design, age of patients at time of the procedure, age at time of POF, or the method used to identify the return in ovarian function (follicular growth or menstruation) (Table 4). Only the subgroup analysis based on the type of patients revealed a higher likelihood of return of ovarian function in monozygotic twins who were discordant for POF and received OTT from their twin sister compared to other patients [HR of $7.8(95 \% \mathrm{Cl}, 1.8-44.3$, $\mathrm{P}=0.006)$ ]. For procedure related variable, fresh and heterologous OTT significantly increased the likelihood of return of ovarian function [HR of $2.4(95 \% \mathrm{Cl}, 1-5.8$, $\mathrm{P}=0.059)$, and $10(95 \% \mathrm{Cl}, 2.6-48.3, \mathrm{P}<0.001)$, respectively]. In addition, larger sized grafts were more likely to reestablish ovarian function [HR of $1.7(95 \% \mathrm{Cl} 1.1-2.5$, $P=0.013)$ ] (Figure 3). To further evaluate the possibility of an interaction between the heterologous OTT and fresh OTT, a stratified analysis revealed significant interaction between heterologous graft and fresh graft (a larger proportion of heterologous grafts were fresh) which might explain the higher likelihood of the return in ovarian function with heterologous grafts [Interaction $\mathrm{HR}$ of $4.595 \% \mathrm{Cl} 1.1-8.4, \mathrm{P}=0.007)$ ].

\section{Time to Recurrent Ovarian Failure (Graft Exhaustion)}

Data needed for the evaluation of the time to recurrent ovarian failure was complete for all 24 patients; however, the median follow up time after re-establishment of ovarian function was only 210 days (range, 30-845 days). At 6 months after the procedure, 4 out of 24 women had recurrence of ovarian failure with a cumulative recurrent failure rate of $21 \%(95 \%, 8-44 \%)$. This early recurrent failure was evidenced by increased FSH ( $>30 \mathrm{IU} / \mathrm{L}$ ), reduced estrogen production and the failure of detection of follicular growth despite induction with high doses of FSH in all 4 patients. The time to recurrence of ovarian failure in those 4 patients ranged from 76 to 150 days after the date of documented re-establishment of function. Long-term evaluation of ovarian function was not possible due to the insufficient length of follow up in the published 
reports. Follow up of ovarian function beyond 12 months was only available for 9 cases $(37.5 \%)^{2,14,25,26}$. In these 9 patients, the re-established ovarian function was documented till the end of the follow up.

To explore possible heterogeneity, we performed subgroup analyses based on the comparison of the patients' characteristics and procedural specific variables in patients who had recurrent failure compared to those that did not fail during the follow up. Women who had recurrent ovarian failure were significantly older at OTT and developed their original POF at an older age compared to those who did not fail ( $\mathrm{P}=$ $0.036,0.021$, respectively). In addition, all 4 women who had recurrent failure had autologous, cryo-preserved and smaller cortical grafts, however, due to small numbers this was not statistically significant $(P=0.114,0.283,0.260$, respectively). Finally, all 4 women who had early recurrent failure did re-establish their ovarian function after 90 days (Table 5).

\section{Pregnancy after ovarian transplantation}

Out of the 47 cases included in the review, 20 women were excluded from this part of the analysis as they had hysterectomy and none of them was reported to have sought surrogate pregnancy since the OTT procedure $12,13,18,19,35,40$. Thus, 27 women with intact uteri were included in the final analysis for pregnancy after OTT. These women included 21 women with evidence of POF before OTT (FSH $>30 \mathrm{IU} / \mathrm{L}$ ) 2,14,15,17,21-26,38,39, 2 women with endometriosis who underwent OTT for preservation of ovarian tissue from an ovary that was not possible to conserve ${ }^{37}, 2$ young women with Turner's syndrome who underwent heterologous fresh orthotopic OTT using partial cortex in one and the whole ovary in the other ${ }^{3}, 1$ patient who underwent chemotherapy for Hodgkin's but did not have evidence of ovarian failure at time of OTT ${ }^{10}$, and the last patient had bilateral oopherectomy and OTT before evidence of $\mathrm{POF}^{14}$. In these 27 women, a total of 11 pregnancies in 9 women were reported. However, one of these women became pregnant spontaneously twice after heterotopic OTT in the suprapubic area of the abdominal wall without performing IVF and was censored from the analysis at the time of her first pregnancy ${ }^{24}$.

Thus, the final analysis included a total of 9 pregnancies in 8 women in 5 reports ${ }^{2,17,21,25,38}$. The median follow up was 9 months (range, 1-28 months). The 12month cumulative pregnancy rate was $36 \%(95 \% \mathrm{Cl}, 18-59 \%)$ (Figure 5). In those 8 women; the first pregnancy was achieved after a median duration of 9 months after OTT (range, 5.6- 16 months). In one woman, a second pregnancy was achieved 25.5 months after OTT and in the $8^{\text {th }}$ menstrual cycle after delivery ${ }^{2}$. In 4 out of those 8 women, autologous OTT using cryopreserved ovarian tissues were performed 
17,21,25,38, while in the remaining 4 women heterologous OTT using fresh ovarian tissue from their monozygotic twins discordant for ovarian failure was performed ${ }^{2}$. To date, no pregnancies have been reported after the 3 published cases of intact fresh human ovary transplantation. While all three had intact uteri, none of them has been reported to pursue pregnancy yet $3,10,18$.

Pregnancies were achieved spontaneously in 5 women (6 pregnancies), while in the remaining 3 women pregnancies were achieved through IVF (natural cycle IVF in 2 and antagonist IVF protocol in 1). The diagnosis of pregnancy was biochemical in one patient ${ }^{25}$, while in the other 7 women, clinical pregnancy was diagnosed based on the detection of gestational sac and embryonic pole by ultrasound assessment 2,17,21,38. To explore potential heterogeneity in the pregnancy outcome among the included studies, we performed a stratified analysis based on study and patient characteristics (Table 6).

To date, 3 out of those 8 women carried their pregnancy till term and each delivered a healthy female baby [2 woman who became pregnant after autologous orthotopic transplantation of cryopreserved ovarian tissue transplantation ${ }^{17,21}$, and 1 women after heterologous orthotopic transplantation of fresh ovarian tissue ${ }^{2}$ ]. In addition, currently 4 women (including one who had already delivered before) are still pregnant. All these 4 ongoing pregnancies were after heterologous orthotopic transplantation of fresh ovarian tissue in monozygotic twins discordant for ovarian failure reported by the same group ${ }^{2}$. The remaining 2 pregnancies, one was a chemical pregnancy after IVF that did not continue ${ }^{25}$, and the second ended in a miscarriage and the conceptus was found to have triploidy ${ }^{38}$.

\section{Outcome of IVF cycles after ovarian transplantation}

Out of 47 women who had OTT, 8 women had attempted to become pregnant using in vitro fertilization (IVF). In these 8 women, a total of 20 IVF cycles were reported $2,14,21,23,25,26$. Seventy percent of these cycles (14/20) were cancelled due to poor response. Treatment cycles proceeded to embryo transfer in only 8 cycles. Three pregnancies were reported ( 2 using natural cycle IVF protocol and 1 using antagonist protocol) ${ }^{2,21,25}$. The median number of IVF cycles needed was 3 cycles (range 2-4 cycles) with a median time to occurrence of pregnancy of 9 months from the OTT procedure (range, 6.5-16 months). Only one pregnancy resulted in full term delivery 21. The details of these 20 cycles were summarized (Table 7 ). 
Table 1: Search strategy on MEDLINE, EMBASE, Cochrane Systematic Reviews, CENTRAL, Web of Science, Scopus databases from inception until June 2007 using terms referring "Ovarian Transplant" and "Reproductive Outcomes"

\section{MEDLINE AND EMBASE}

\section{MEDLINE}

1 ovarian failure, premature/su 8 DISPLAY

2 exp Ovary/tr [Transplantation] 0 -

3 tissue transplantation/ or transplantation, autologous/ or transplantation, heterologous/ or replantation/ 15100 DISPLAY

4 cryopreservation/ or organ preservation/ 12247 DISPLAY

51 or 2 or infertility, female/ 8571 DISPLAY

6 ( 3 or 4 ) and 5304 DISPLAY

7 (2 or 3 ) and 638 DISPLAY

8 limit 7 to humans 37 DISPLAY

9 [from 8 keep 1-208]

\section{EMBASE}

10 female fertility/ or infertility therapy/ or ovary insufficiency/or early menopause/ 9519 DISPLAY

11 organ transplantation/ or autotransplantation/ or heterotopic transplantation/ or tissue transplantation/ or orthotic transplantation/ 17459 DISPLAY

12 (3 or 4 or 11) and 10679 DISPLAY

13 limit 12 to human 629 DISPLAY

14 Ovary/ 8494 DISPLAY

1513 and 1486 DISPLAY

16 female fertility/ or ovary insufficiency/ or early menopause/ 5456 DISPLAY

1713 and 16260 DISPLAY

18 *0vary/ and 1740 DISPLAY

1912 and *ovary/ 57 DISPLAY

2015 or 1999 DISPLAY

$21 . . / 20$ hu=y 86 DISPLAY
2217 and (treatment outcome/ or follow-up study/ or outcome $\$$.mp. or pregnancy outcome/) [mp =title, abstract, subject headings, heading word, drug trade name, original title, device manufacturer, drug manufacturer name] 59 DISPLAY

$23 . .1 / 2 \mathrm{hu}=\mathrm{y} 0$ -

$24 . . / / 22$ hu=y 59 DISPLAY

2521 or 24138 DISPLAY

II. For the text-based databases (Web of Science, Scopus, Cochrane Systematic Review and CENTRAL)

\section{Web of Science}

\#1 1,290 TS $=($ (ovarian or ovary or ovaries $)$ SAME (transplant* $0 \mathrm{R}$ cryopreserv* OR preserv* OR autotransplant* or replant*))

\#2 $>100,000$ TS $=$ (fail* OR menopaus* OR function* $O R$ infertil* $O R$ fertil* $O R$ function*)

\#3 783 \#2 AND \#1

\#4 $>100,000 \mathrm{TS}=$ (rat or rats or ovine or murine or mouse or rabbit* or pig*)

\#5 529 \#3 NOT \#4

\#6 $>100,000 \mathrm{TI}=$ (in vitro OR ivf)

\#7 500 \#5 NOT \#6

\section{SCOPUS}

TITLE-ABS-KEY((ovary OR ovaries OR ovarian) AND (tissue OR cortex OR cortical) AND (cryopreserv* OR transplant* OR autotransplant* OR heterotransplant*))

TITLE-ABS-KEY((ovary OR ovaries OR ovarian) AND (graft* OR autograft*) AND (success* OR pregnan* OR fertil* OR outcome* OR follow*))

\section{Cochrane systematic review and CENTRAL}

No related studies were found in those 2 databases. 
Human ovarian tissue transplantation

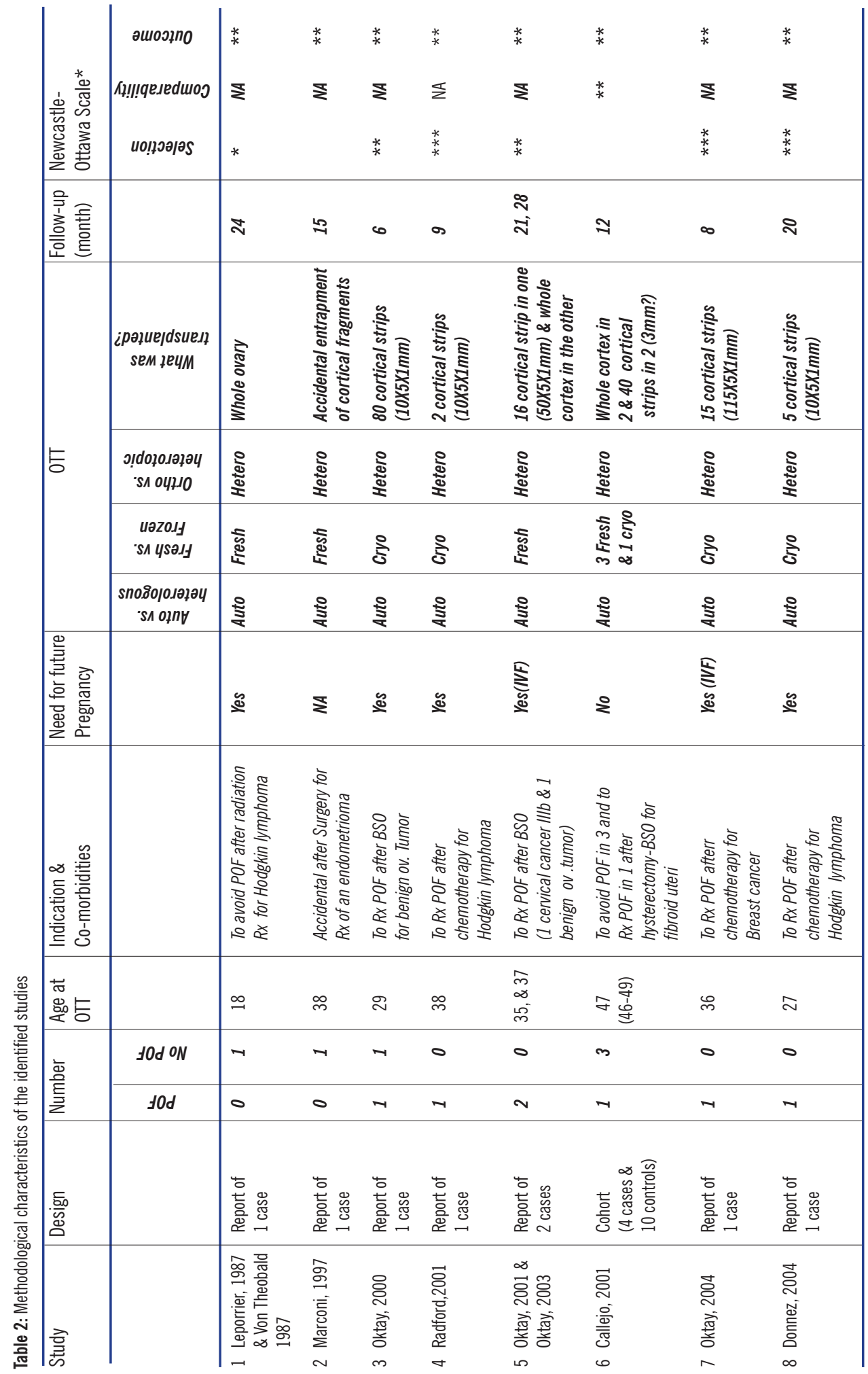




\section{Chapter 9}

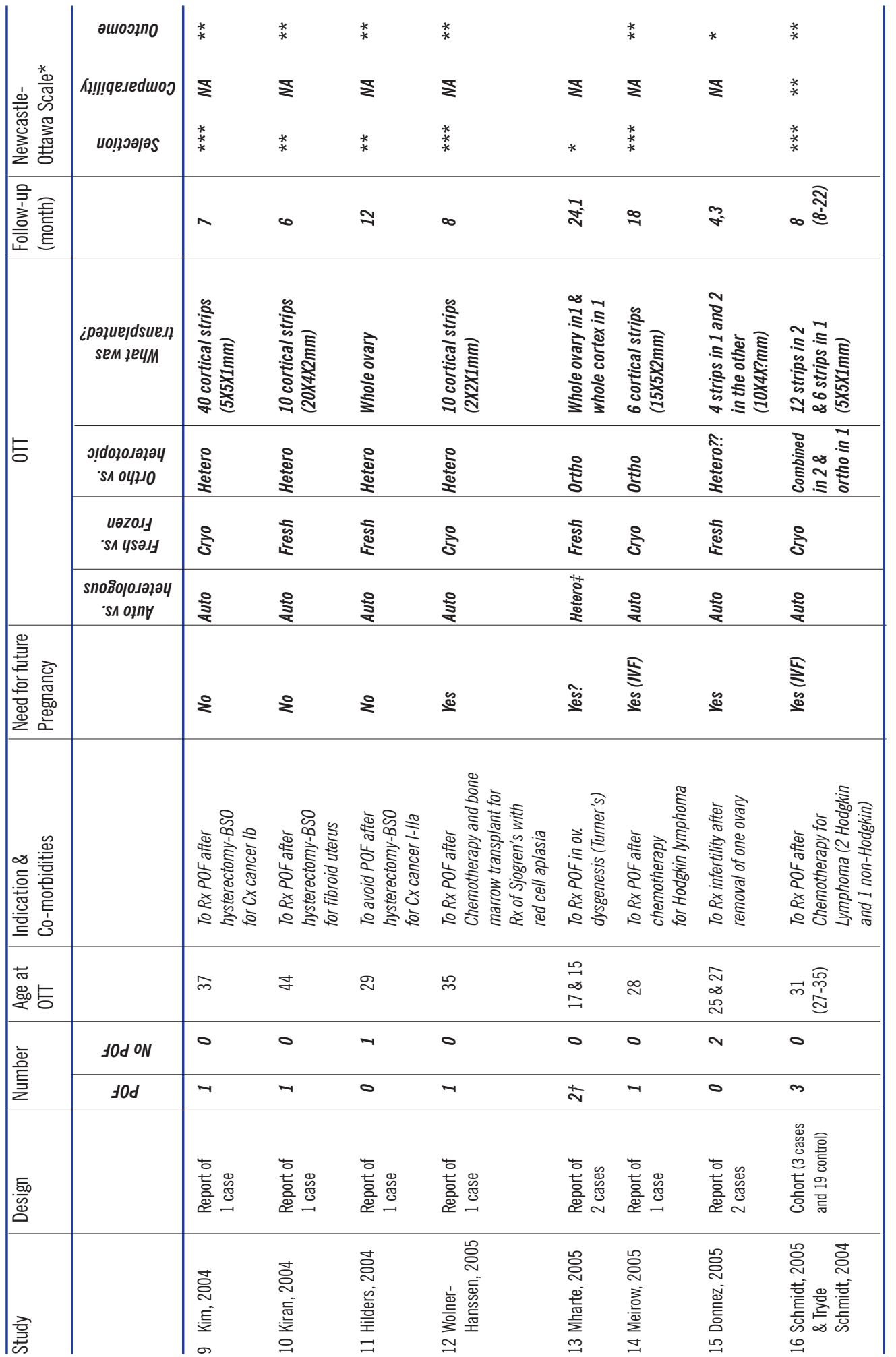




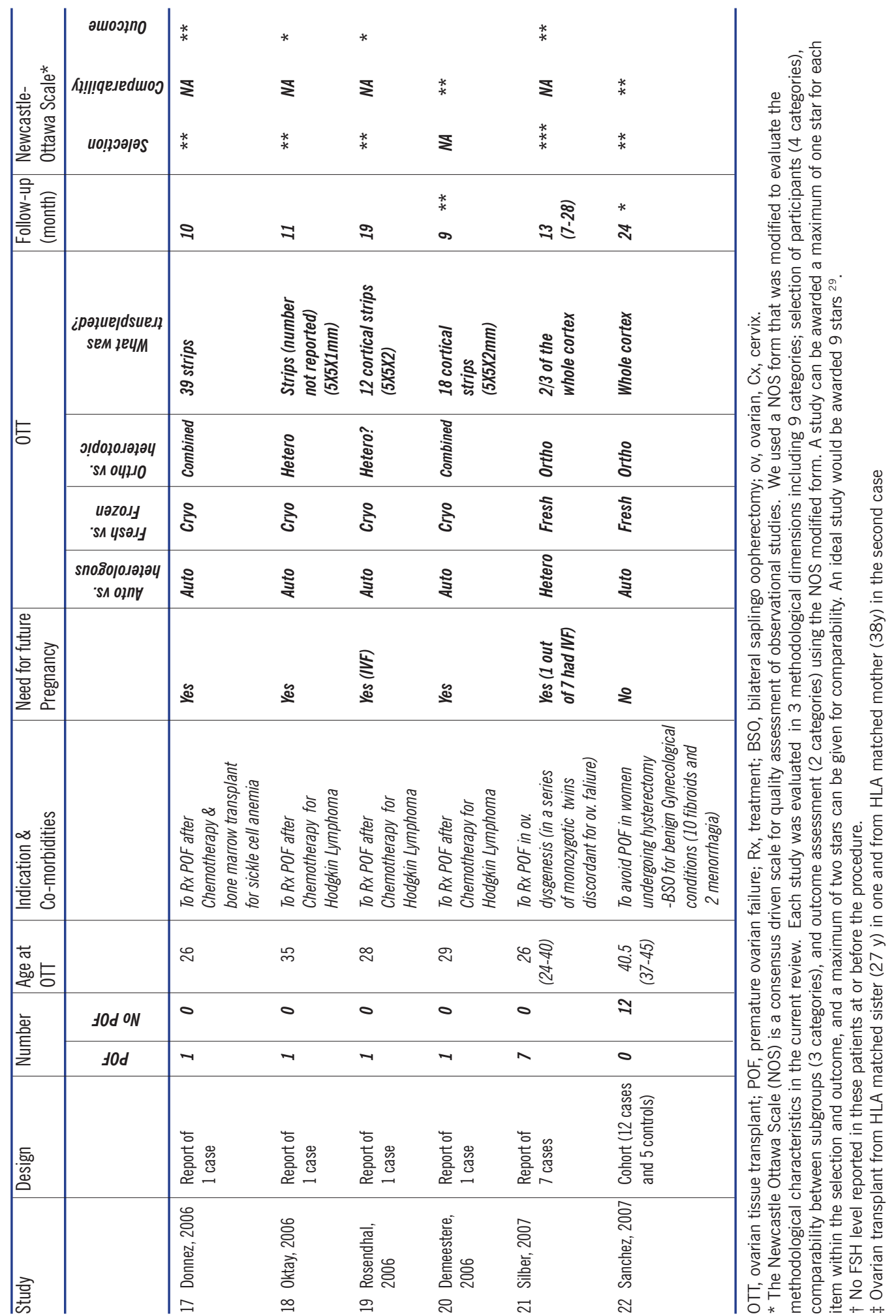


Table 3: Clinical and procedural characteristics of the women who underwent ovarian tissue transplant with FSH $>30 \mathrm{IU} / \mathrm{L}$ at time of transplantation.

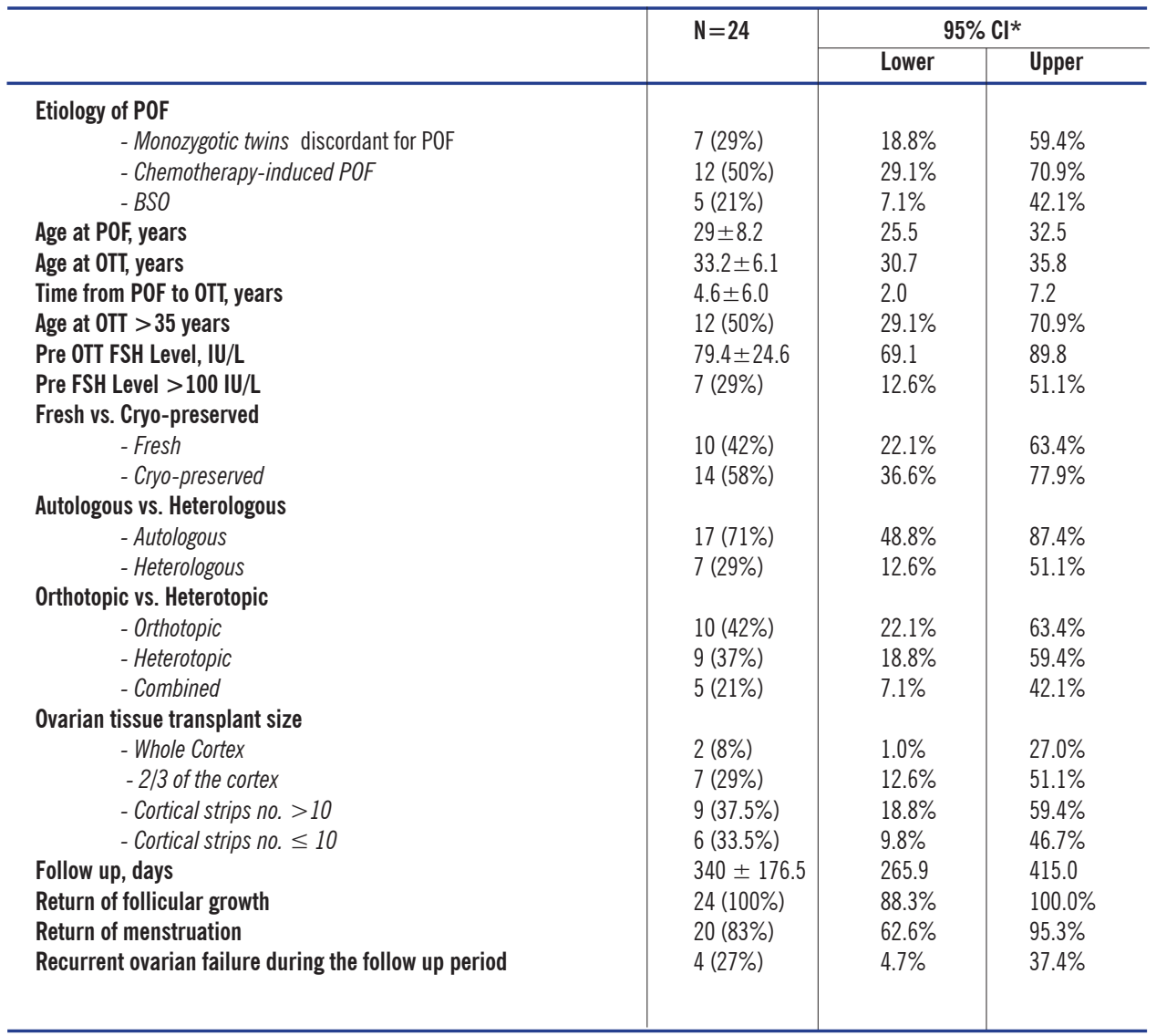

95\% Cl, 95\% confidence interval; POF, premature ovarian faliure; OTT, ovarian tissue transplantation; FSH, follicle stimulating hormone; BSO, bilateral salpingo-oophorectomy.

* $95 \% \mathrm{Cl}$ was calculated using binomial exact method for categorical variables. 
Table 4: The likelihood of the re-establishment of ovarian function in various subgroups of women who underwent ovarian tissue transplantation.

\begin{tabular}{l|l|l|l}
\hline & Hazard Ratio (95\%Cl) & P value & $\begin{array}{l}\text { P value for Interaction } \\
\text { Interaction with log time } \\
\text { (proportionality } \\
\text { assumption testing) }\end{array}$ \\
\hline Study design (case reports vs. cohort) & & & 0.331 \\
Etiology of POF & $0.99(0.52-2.49)$ & 0.981 & \\
- BSO (reference) & & - & 0.201 \\
- POF in monozygotic twins & 1.00 & 0.006 & 0.282 \\
- Chemotherapy induced POF & $7.75(1.77-44.33)$ & 0.522 & 0.854 \\
Age at OTT, per year & $0.69(0.24-2.28)$ & 0.224 & 0.578 \\
Age at POF, per year & $0.97(0.90-1.05)$ & 0.234 & 0.430 \\
Time from POF to OTI, per year & $0.96(0.90-1.02)$ & 0.181 & 0.530 \\
Pre 0TT FSH Level IU/L & $1.06(0.97-1.13)$ & 0.225 & 0.699 \\
Fresh vs. Cryo-preserved & $1.01(0.99-1.03)$ & 0.059 & 0.206 \\
Heterologous vs. Autologous & $2.5(1.0-5.8)$ & $<0.001$ & 0.677 \\
Orthotopic vs. Heterotopic & $10.0(2.6-48.3)$ & 0.394 & 0.807 \\
Size of tissue transplanted & $1.5(0.6-4.0)$ & 0.010 & \\
(whole cortex: or 2/3 of the cortex) vs. cortical strips & $3.5(1.4-8.5)$ & & \\
\hline
\end{tabular}

95\% Cl, 95\% confidence interval; POF, premature ovarian failure; OTT, ovarian tissue transplantation; $\mathrm{FSH}$, follicle stimulating hormone; BSO, bilateral salpingo-oophorectomy.

* $95 \% \mathrm{Cl}$ were calculated using exact methods of a binomial parameter. 
Table 5: Clinical and procedural characteristics of the women who had early recurrent ovarian failure (within 3 months after the reestablishment of ovarian function) compared to women who did not have recurrent failure during the follow up*.

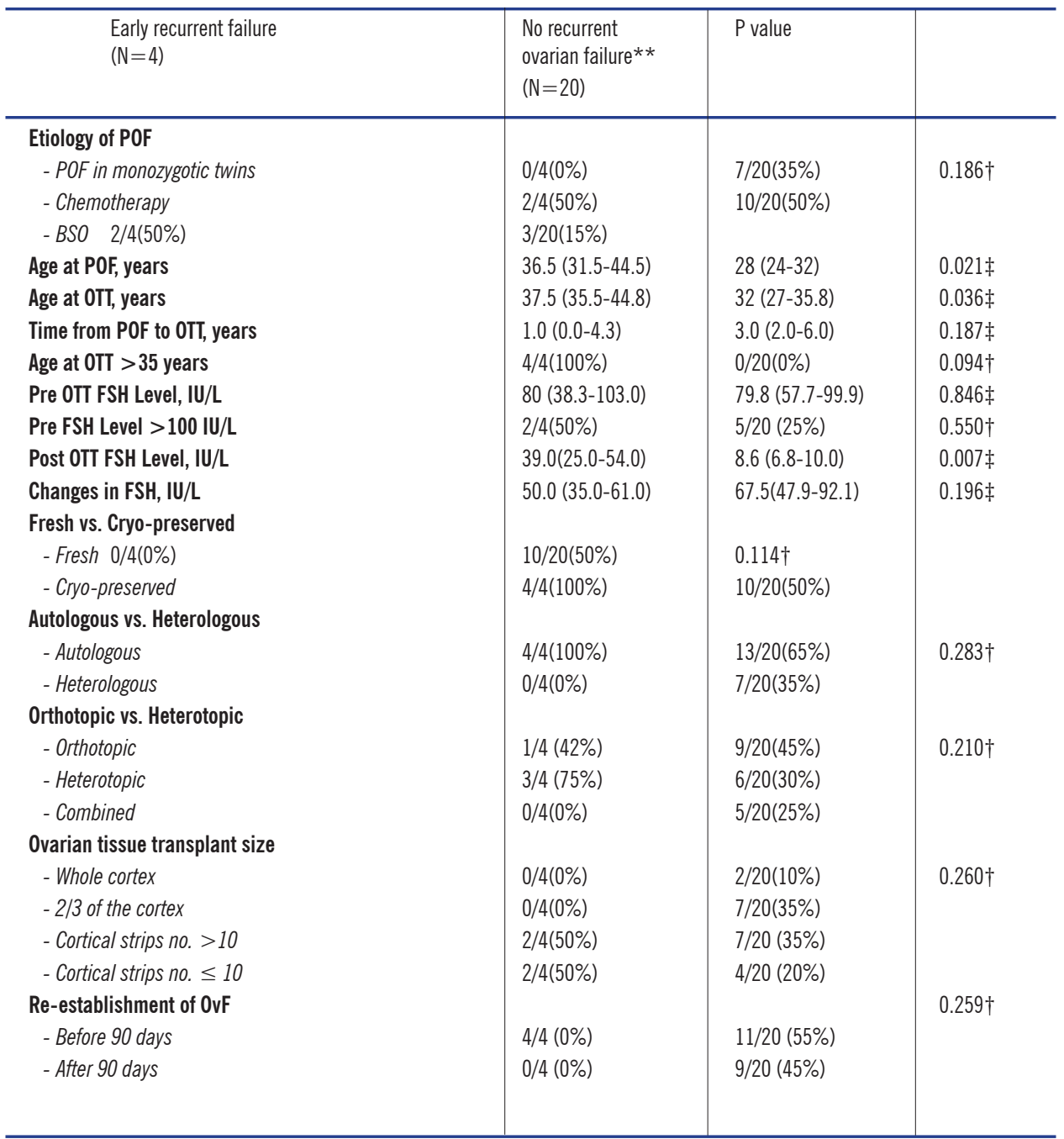

POF, premature ovarian faliure; OTT, ovarian tissue transplantation; FSH, follicle stimulating hormone; OvF, ovarian function, BSO; bilateral salpingo-oophorectomy.

* Categorical variables were presented as count and percentage and the median and interquartile range was used to present continuous variables.

** In the 20 patients who did not develop recurrent ovarian failure, only 4 women had follow up $>12$ months and none of them was followed up $>24$ months after the reestablishment for ovarian function.

$\dagger$ Fisher Exact test

$\ddagger$ Wilcoxon rank sum test. 
Table 6: Characteristics of women who achieved pregnancy and those who did not after $0 \mathrm{TT}(\mathrm{N}=27)$

\begin{tabular}{|c|c|c|c|}
\hline & $\begin{array}{l}\text { Pregnancy } \\
(\mathrm{N}=8)\end{array}$ & $\begin{array}{l}\text { No Pregnancy } \\
(\mathrm{N}=19)\end{array}$ & Pvalue \\
\hline Age at $0 \mathrm{TT}$, years & $29.5(27.3-33.8)$ & $29(25-35)$ & $0.873 \dagger$ \\
\hline Age at $0 \mathrm{TT}>35$ years & $1 / 8(12.5 \%)$ & $8 / 19(42 \%)$ & $0.201 \ddagger$ \\
\hline Patients with FSH $>30 \mathrm{ml} . \mathrm{IU}$ at $0 \mathrm{TT}$ & $8 / 8(100 \%)$ & $13 / 19(68 \%)$ & $0.136 \ddagger$ \\
\hline Patients with Turner's syndrome & $0 / 8(0 \%)$ & $2 / 19(11 \%)$ & $1.000 \ddagger$ \\
\hline Patients with endometriosis and infertility & $1 / 8(12.5 \%)$ & $1 / 19(5 \%)$ & $0.232 \ddagger$ \\
\hline PF0 in monozygotic twins & $4 / 8(50 \%)$ & $3 / 19(16 \%)$ & $0.145 \ddagger$ \\
\hline \multicolumn{4}{|l|}{ Method of conception } \\
\hline - Spontaneous & $5 / 8(62.5 \%)$ & $14 / 19(74 \%)$ & $0.658 \ddagger$ \\
\hline$-I V F$ & $3 / 8(37.5 \%)$ & $5 / 19(26 \%)$ & \\
\hline \multicolumn{4}{|l|}{ Fresh vs. Cryo-preserved } \\
\hline - Fresh & $4 / 8(50 \%)$ & $9 / 19(47 \%)$ & $1.000 \ddagger$ \\
\hline - Cryo-preserved & $4 / 8(50 \%)$ & $10 / 19(53 \%)$ & \\
\hline \multicolumn{4}{|l|}{ Autologous vs. Heterologous } \\
\hline - Autologous & $4 / 8(50 \%)$ & $14 / 19(74 \%)$ & $0.375 \ddagger$ \\
\hline - Heterologous & $4 / 8(50 \%)$ & $5 / 19(26 \%)$ & \\
\hline \multicolumn{4}{|l|}{ Orthotopic vs. Heterotopic } \\
\hline - Orthotopic & $5 / 8(62.5 \%)$ & $7 / 19(37 \%)$ & $0.230 \ddagger$ \\
\hline - Heterotopic & $1 / 8(12.5 \%)$ & $9 / 19(47 \%)$ & \\
\hline - Combined & $2 / 8(25 \%)$ & $3 / 19(16 \%)$ & \\
\hline \multicolumn{4}{|l|}{ Ovarian tissue transplant size } \\
\hline - Whole ovarian transplant & $0 / 8(0 \%)$ & $2 / 19(10 \%)$ & $0.193 \ddagger$ \\
\hline - Whole cortex & $0 / 8(0 \%)$ & $3 / 19(16 \%)$ & \\
\hline$-2 / 3$ of the cortex & $4 / 8(50 \%)$ & $3 / 19(16 \%)$ & \\
\hline - Cortical strips no. $>10$ & $2 / 8(25 \%)$ & $6 / 19(32 \%)$ & \\
\hline - Cortical strips no. $\leq 10$ & $2 / 8(25 \%)$ & $5 / 19(26 \%)$ & \\
\hline Total number of pregnancies & 9 in 8 women $\|$ & & \\
\hline \multicolumn{4}{|l|}{ Type of pregnancy diagnosis } \\
\hline - Chemical & $1 / 9$ & - & \\
\hline - Chemical and clinical & $8 / 9$ & - & \\
\hline \multicolumn{4}{|l|}{ Outcomes of pregnancies } \\
\hline - Abortion & $2 / 9 \delta$ & - & \\
\hline - Ongoing pregnancy & $4 / 9 \S$ & - & \\
\hline - Delivery at full term & $3 / 9$ & - & \\
\hline
\end{tabular}

Cl 95\%, 95\% confidence interval; IVF, in vitro fertilization; POF, premature ovarian failure; OTT, ovarian tissue trnasplanation.

* $95 \% \mathrm{Cl}$ were calculated using exact methods of a binomial parameter ${ }^{30}$.

$\dagger$ Wilcoxon rank sum test

$\ddagger$ Fisher Exact test

" 9 pregnancies in 8 women. One woman included in the report by Silber's and colleagues ${ }^{2}$, had 2 deliveries.

$\delta$ One abortion with triploid genotype and one chemical pregnancy

$\S 4$ ongoing pregnancies included in the report by Silber's and colleagues ${ }^{2}$. 


\section{Chapter 9}

Table 7: Outcome of 20 IVF cycles in 8 patients after ovarian tissue transplantation.

\begin{tabular}{l|l}
\hline & $\mathrm{N}=20$ \\
Type of stimulation IVF cycles & \\
$\quad$ - Natural cycle protocol & $6 / 20(30 \%)$ \\
$\quad$ - Antagonist protocol & $9 / 20(45 \%)$ \\
$\quad$ - Agonist protocol & $5 / 20(25 \%)$ \\
Duration of COS, days & $10.5($ range, $2-17)$ \\
Dose of FSH, Units & $4087.5($ range, 300-7650) \\
Number of follicles at the day of hCG & 1.00 (range, 0-4) \\
Number retrieved oocycte & $1.00($ range, 0-4) \\
Canceled cycle ( no embryo transfer) & $14 / 20[70 \%(95 \% \mathrm{Cl}, 46-88 \%)]$ \\
$\quad$ - Failed retrieval & $5 / 14(36 \%)$ \\
$\quad$ - Failed or abnormal Fertilization & $8 / 14(57 \%)$ \\
$\quad$ - Failed embryonic development & $1 / 14(7 \%)$ \\
Completed cycles (+embryo transfer) & $6 / 20[30 \%(95 \% \mathrm{Cl}, 12-54 \%)]$ \\
Total Pregnancies & 3 pregnancies and only 1 delivery \\
$\quad$ - Chemical Pregnancy & $1 / 3(33.3 \%)$ \\
$\quad$ - Ongoing Pregnancy & $1 / 3(33.3 \%)$ \\
$\quad$ - Full term delivery & $1 / 3(33.3 \%)$ \\
Pregnancy rate per patient & $3 / 8[37.5 \%(95 \% \mathrm{Cl}, 9-76 \%)]$ \\
Pregnancy per cycle started & $3 / 20[15 \%(95 \% \mathrm{Cl}, 3-38 \%)]$ \\
Pregnancy per cycle completed & $3 / 6[50 \%(95 \% \mathrm{Cl}, 12-88 \%)]$ \\
\hline
\end{tabular}

Cl 95\%, 95\% confidence interval; IVF, in vitro fertilization; COS, controlled ovarian stimulation, $\mathrm{FSH}$, follicle stimulating hormone,

* $95 \% \mathrm{Cl}$ were calculated using exact methods of a binomial parameter 
Figure 1: Flow chart for selection of included reports

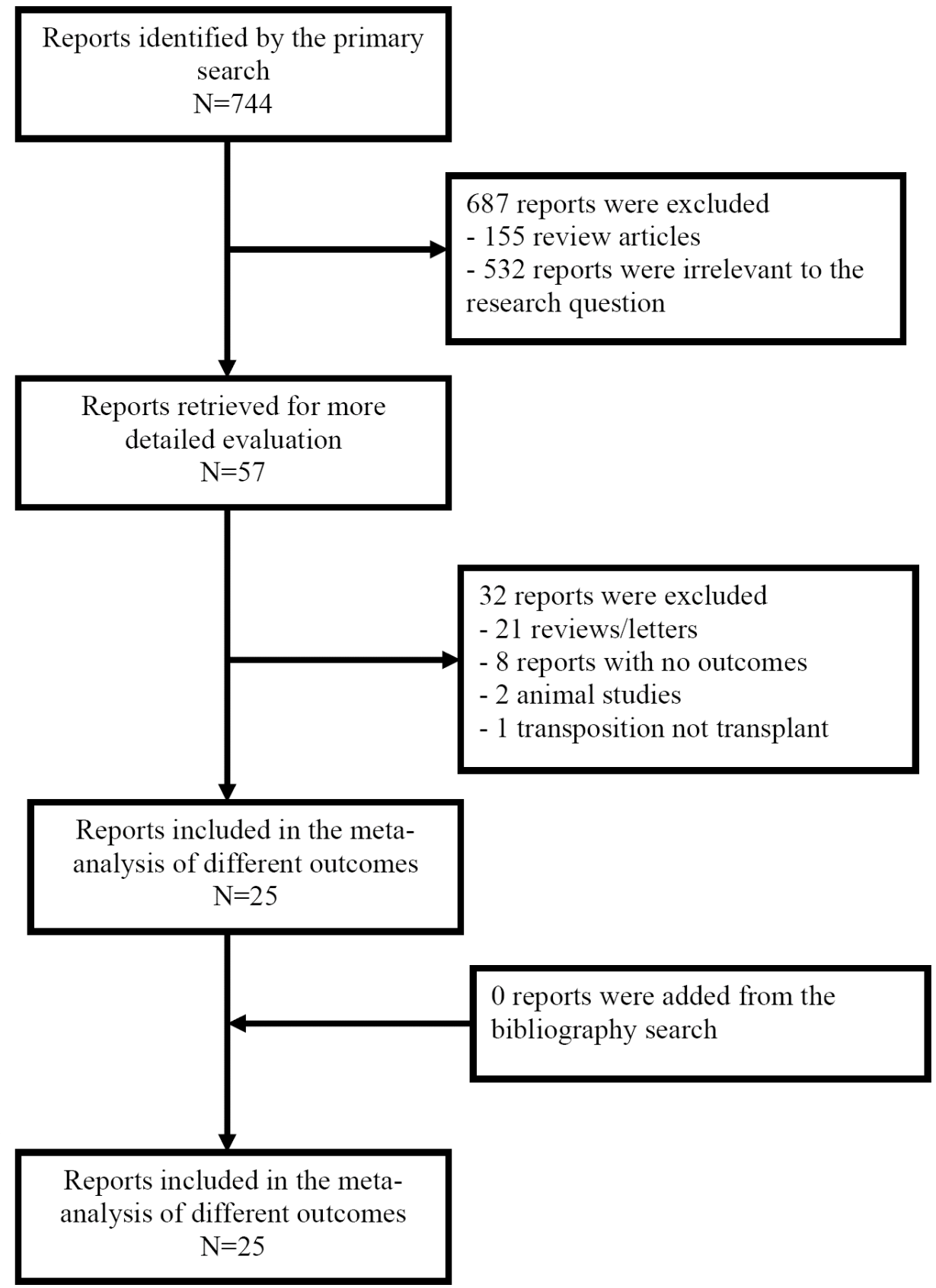


Figure 2: Time to the return of ovarian function and the corresponding $95 \%$ confidence interval after Ovarian Tissue Transplantation $(\mathrm{N}=24)$

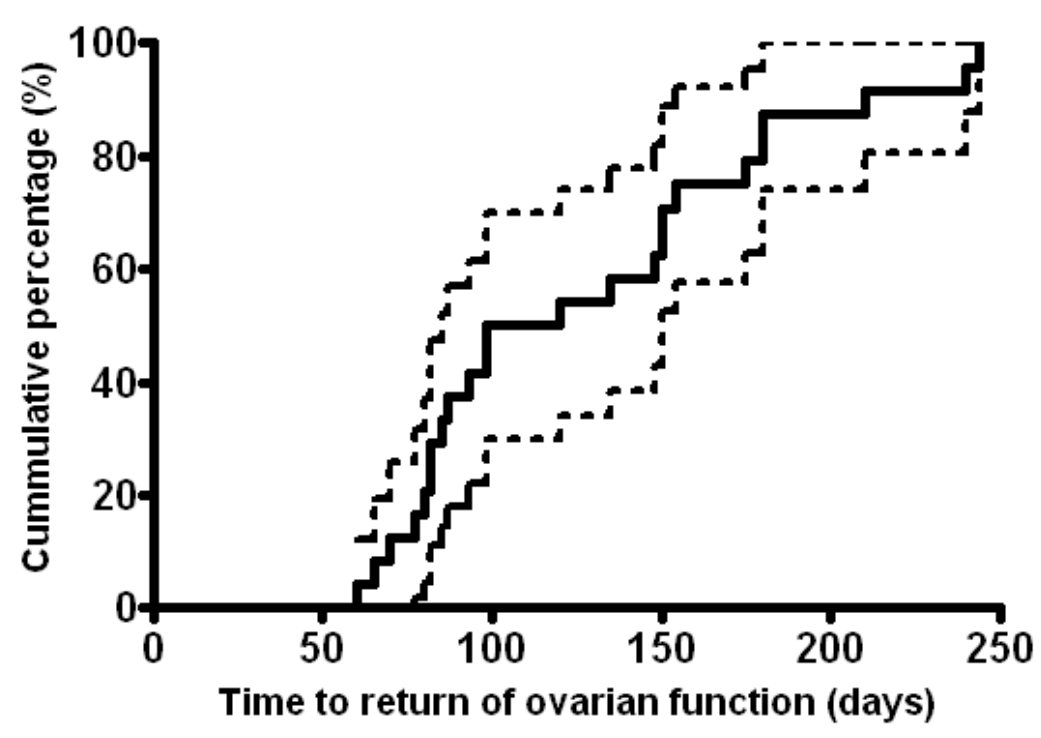

24

14

9

5

0 
Figure 3: Reestablishment of ovarian function after various techniques used for ovarian tissue transplantation. A, Fresh versus Cryopreserved; B, Autologous versus Heterologous transplant; C, Orthotopic versus Heterotopic transplant; D, Whole cortex versus cortical strips.
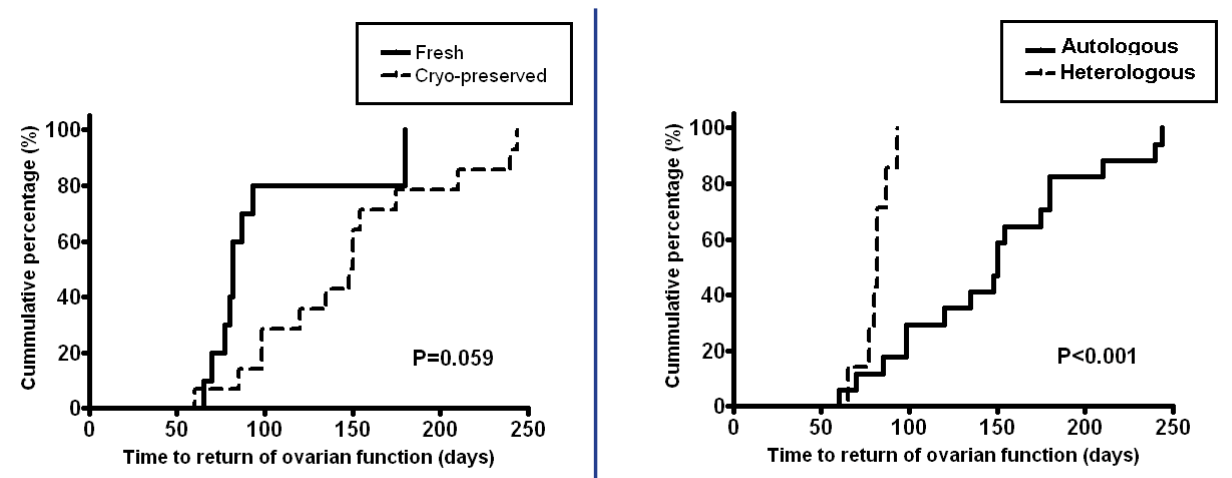

A
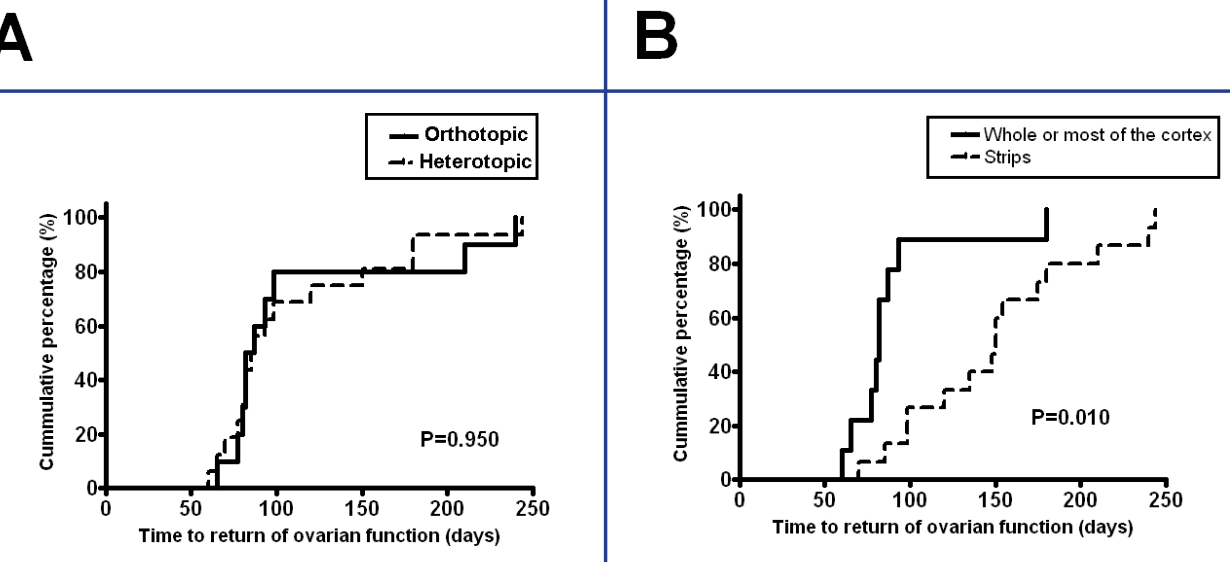

C

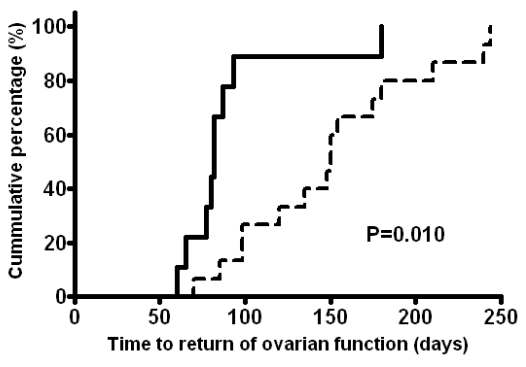

D 


\section{Chapter 9}

Figure 4: Cumulative rate for early recurrent ovarian failure in women who reestablished ovarian function after ovarian tissue transplantation $(\mathrm{N}=24)$.

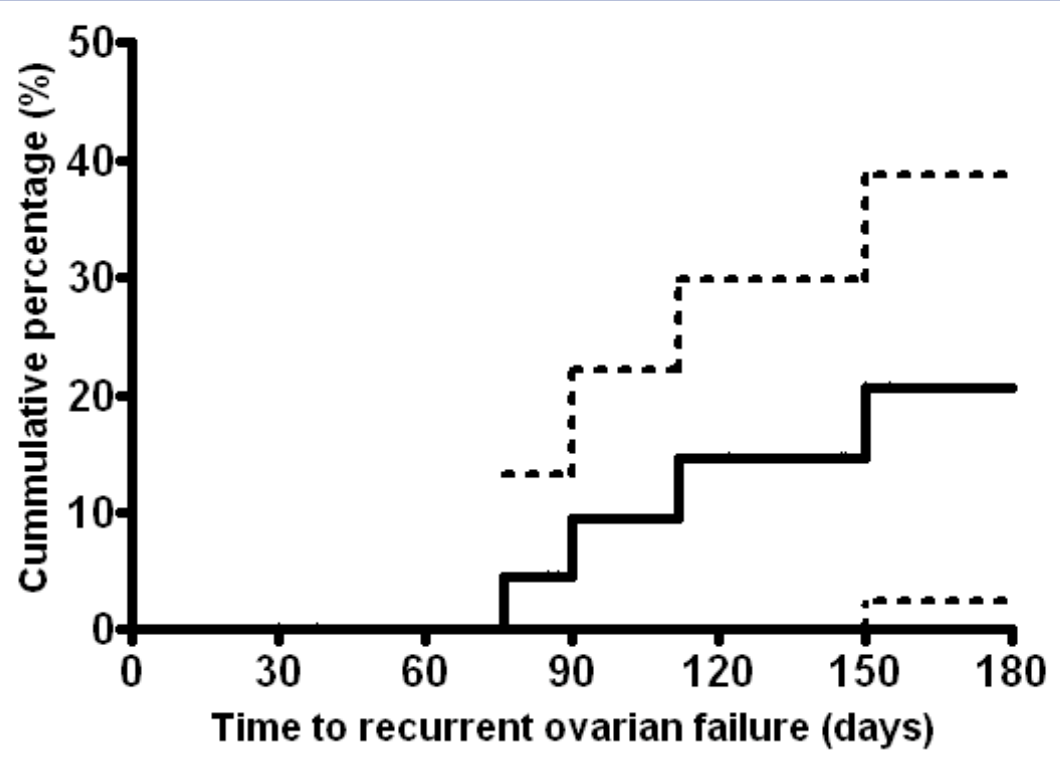

$\begin{array}{llllllll}\text { At Risk } & 24 & 24 & 23 & 19 & 18 & 11 & 8\end{array}$

Figure 5: Cumulative pregnancy rate in women who sought pregnancy after ovarian tissue transplantation $(n=27)$.

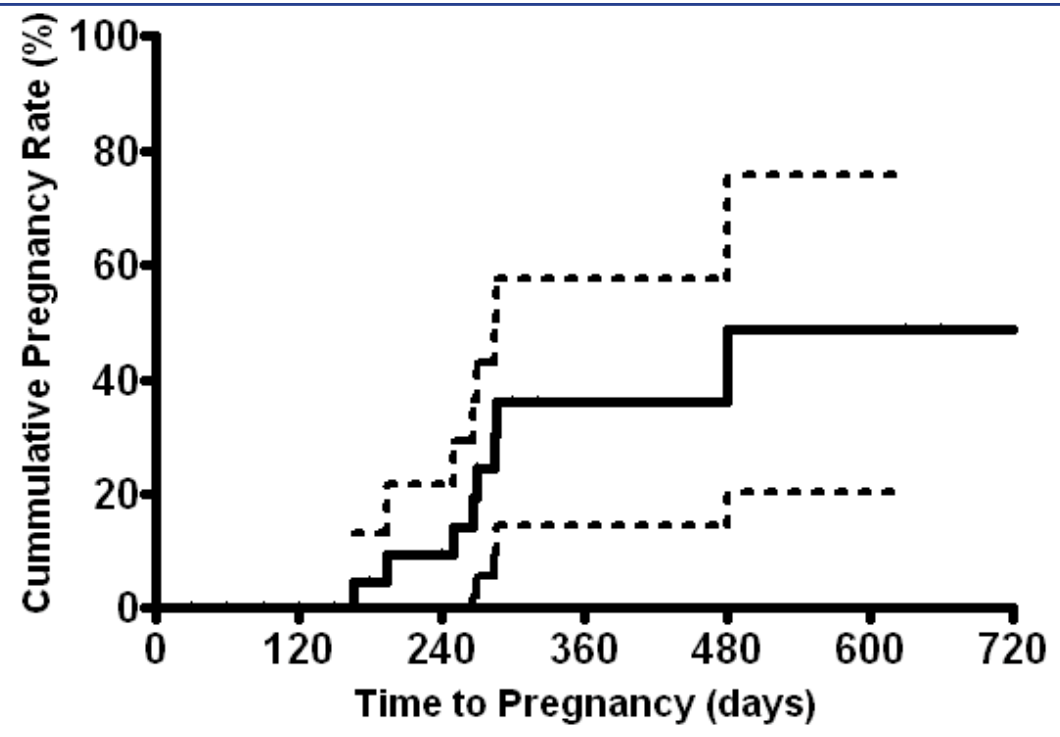

$\begin{array}{llllllll}\text { At Risk } & 27 & 24 & 19 & 7 & 5 & 5 & 3\end{array}$




\section{Discussion}

Since the first report of fresh heterotopic ovarian tissue transplantation (OTT) in humans, this procedure has attracted the attention of the scientific community and the public as well ${ }^{10}$. Despite the technical success of this procedure, it is not suitable for all patients at risk of POF especially those receiving systemic chemotherapy. Efforts were then subsequently directed towards transplantation of cryopreserved-thawed ovarian tissue ${ }^{9}$. While OTT was initially proposed as a method to preserve fertility in young women undergoing radiotherapy, other potential indications included reestablishment of ovarian function in women with ovarian dysgenesis (e.g. Turner's syndrome) or in monozygotic twins discordant for ovarian failure ${ }^{2,3}$. Another proposed indication -yet to be pursued- is prolonging reproductive life span in normal healthy women ${ }^{2}$. In this study, we systematically reviewed the literature on OTT and reported on the reproductive outcome after the procedure including the re-establishment of ovarian function, the possibility of recurrent ovarian failure, and pregnancy after OTT.

An important finding of this study is that regardless of the technique used or the approach of OTT, some degree of ovarian function was restored in all patients who had documented ovarian failure. This observation supports the short-term efficacy of the procedure and gives preliminary assurance about the technique's potential in humans. However, the time needed for the re-establishment of ovarian function varied between techniques and early recurrence of ovarian failure was reported in $20 \%$ of cases within the first 6 months after re-establishment of ovarian function. These finding suggests the need for further improvements in the cryopreservation protocol and the surgical technique to optimize the outcome.

Utilizing the current information can provide preliminary insight into the predictors of a better reproductive outcome after OTT. The transplantation of fresh, heterologous and larger size grafts increased the likelihood for return of ovarian functions and to less extent can be linked to a possible delay in ovarian graft exhaustion. The increased likelihood of return of ovarian function in fresh grafts compared to cryopreserved grafts found in this analysis is simply due to the fact the most of these cases entailed transplantation of most of the cortical tissue from one ovary of the donor to the recipients with all its follicular population which could be adequate enough for replenishment of the ovarian reserve ${ }^{2}$. Given the fact that previous animal studies suggested that cryopreservation of ovarian tissues does not substantially change the reproductive outcome after OTT, this observation could not be explained solely by the possible negative effects of the cryopreservation protocol ${ }^{42-44}$. However, further improvement in the cryopreservation techniques is still required to optimize the outcome after OTT of 
cryopreserved ovarian tissues in humans ${ }^{45-47}$. The association between heterologous grafts and higher likelihood of re-establishment of ovarian function can be explained by the fact that all heterologous grafts were also fresh. Another important finding is the significant association between the amount of transplanted ovarian tissues and the increased likelihood of re-establishment of ovarian function. Delayed reestablishment of ovarian function $>90$ days was significantly associated with higher likelihood for early recurrent ovarian failure. This is most likely the result of the warm ischemic insult after OTT. For this reason ovarian transplants with a vascular pedicle are currently being explored to ensure immediate graft revascularization, possible reduction in ovarian failure recurrence and prolongation of graft survival ${ }^{45,48,49}$. The site of OTT -whether orthotopic or heterotopic- did not seem to affect the return of ovarian function or recurrent ovarian failure. The age of the patient did also not affect the likelihood of return of ovarian function however; older women were more likely to have recurrent ovarian failure.

To date, there is insufficient evidence to support long-term efficacy of OTT or to determine the longevity of different types of ovarian grafts. For whole ovarian transplant, the first case reported by Leporrier in 1987 was reported to still have evidence of ovarian function in $2002^{10,50}$. However, this patient has her other ovary in place and was reported to have follicular growth in her pelvic ovary 6 months after OTT. In patients with evidence of POF at time of OTT, only 9 patients out of 24 (37.5\%) had follow up $>12$ months. For studies reporting on cryopreserved OTT, only 4 women had $>12$ months follow up after the re-establishment of ovarian function ${ }^{14,25,36}$. Despite the fact that at the end of the follow up period all these 4 cases had evidence of ovarian function, early recurrent ovarian failure was documented in 4 out of 14 (29\%) women. The largest case series of OTT to date published recently by Silber and colleagues included 7 cases of OTT in monozygotic twins discordant for ovarian failure with a follow up $>12$ months in 5 out of 7 cases included in that study. All received fresh OTT grafts from their sisters and all re-established ovarian function and all cases were reported to maintain menstruation till the end of the follow up despite increase in FSH when followed up $>24$ months $^{2}$. The small number of patients followed up after 12 months and heterogeneity observed among the published reports in the technique used precluded valid evaluation of the long-term efficacy and longevity of ovarian grafts after different types of OTT.

Pregnancy is an important reproductive outcome after OTT and for some group of women it represents one of the main goals of the technique. To date, 27 women who had OTT sought pregnancy and a total of 9 pregnancies from the transplanted ovarian tissues in 8 women were documented. To date 3 women gave birth to 3 full term 
babies and 4 women are still having ongoing pregnancies. Two deliveries were after autotransplantation of cryopreserved-thawed ovarian tissue 17,21 and the third was after transplantation of heterologous transplantation of fresh cortical tissue between twins discordant for $\mathrm{POF}^{1}$. To date, no pregnancies have been reported after intact fresh human ovary transplantation with microvascular anastomosis 3,10,18. However, all 3 patients who had intact ovarian transplant did not seek pregnancy yet. The highest pregnancy rate was reported in the 7 cases of heterologous OTT in monozygotic twins reported by Silber, to date 5 pregnancies have been reported ${ }^{1,2}$. However, the source of the oocyte that resulted in spontaneous pregnancy after orthotopic OTT can not be certain especially in cases of POF after chemotherapy as there are reports of spontaneous pregnancy in women with documented POF after chemotherapy with heterotopic and not orthotopic transplantation ${ }^{24}$ or even without transplantation of the cryopreserved ovarian tissue ${ }^{51}$. Nevertheless, the possibility of pregnancy after treatment of cancer is by itself an important step that provides hope for those patients with cancer.

Looking into the outcome of IVF cycles after OTT, some noteworthy observations deserve specific mentioning. First, several treatment cycles should be attempted before a clinically meaningful outcome could be achieved. Second, a higher demand for gonadotrophins and longer duration of COS are often observed. Third, there was cycle cancellation rate of up to $70 \%$. Fourth, there was an overall poor response in completed cycles with few follicles available on the day of retrieval and limited numbers of increasingly immature oocytes retrieved. Finally, increased incidence of developmental arrest of embryos with only 3 term pregnancies reported so far.

This systematic review was limited by the constraints of the published data and small number of patients as well as the fact that data are either case reports or small case series. While most of these reports included detailed and valuable information about the outcomes of interest, they lacked the appropriate follow up needed to evaluate the longevity of the reestablished ovarian function. This precluded any valid conclusion about the long-term efficacy of OTT. Nevertheless, this review provided a detailed description of the short-term efficacy and the predictors of favorable reproductive outcome after OTT. Publication bias is an important threat to the validity of the review especially with the inclusion of case reports. Since failed attempts will be less likely submitted, accepted and/or published, we may be just looking to the tip of the iceberg of efforts and the finish line of a long race aiming to optimize this new technology. In addition, almost all the available reports are from experts, and wider scale use of this technique is expected to result in less favorable outcomes. Publication bias generally results in overestimation of the effects expected in the overall analyses. Thus, caution 
is recommended in the interpretation of the success rates of the procedure. Another important limitation is the heterogeneity in the methods and surgical approach of the operation as well as the various indications. To explore this heterogeneity, we performed stratified analyses based on study design, various patients' characteristics, and procedure specific variables. To limit the effect of heterogeneity on the primary outcome we only included patients with robust evidence of ovarian failure before the procedure to decrease the heterogeneity at baseline. In addition, Kaplan Meier curves were constructed to adjust for the heterogeneity in the follow up period reported in each study. Another important limitation of the available literature is the small total sample; this small sample precluded the use of multivariate regression models to adjust for confounding and to detect independent predictors of outcomes. In addition, this small sample and low event rates -especially in the secondary outcome- decreased the precision of the analysis. To increase precision, we used time to event as our endpoint to increase the statistical power of our analysis and used stratified analysis to explore the sources of methodological heterogeneity irrespective of the presence of statistically significant heterogeneity. Last yet of great importance, the absence of a control group in these studies is another limitation. Despite the high likelihood of ovarian failure in young women undergoing chemotherapy and radiotherapy for treatment of cancer, spontaneous restoration of ovarian function after documented POF was documented in 2 published reports. In the first, spontaneous pregnancy was reported in a young woman 6 years after receiving combined chemotherapy and radiation for treatment for Ewing's sarcoma without receiving any ovarian transplants ${ }^{51}$ and in the second pregnancy occurred in a young woman 2.5 years after chemotherapy for Hodgkin's lymphoma ${ }^{24}$. These findings support the need for a control group to systematically evaluate the procedure before any wide clinical utilization.

In summary, the current evidence suggests that OTT is a promising technique for restoration of ovarian function after POF. OTT resulted in restoration of ovarian function evident follicular growth, return of menstruation, and even pregnancy. Women who had fresh, heterologous and larger ovarian grafts were more likely to have faster return of their ovarian function. However, this restoration of ovarian function was not maintained and 1 in 5 women had recurrent ovarian failure within 6 months after the re-establishment of ovarian function. In addition, there is insufficient data to accurately evaluate the long-term efficacy of OTT beyond 12 months. Future research should be directed towards optimization of the technology utilized in cryopreservation of ovarian tissue and in the standardization of the laboratory and surgical technology used ${ }^{47}$ as well as the use of vascularized grafts to minimize ischemic damage ${ }^{45}$. Clinical studies comparing different techniques with the time to recurrent ovarian failure outcome 


\section{Chapter 9}

as the primary endpoint should be conducted to systematically select the best technique for OTT which is associated with sustained restoration of ovarian function. After optimization of the technique, the next step would be to conduct a multicenter controlled clinical trial with sufficient follow up (5 years) to systematically evaluate the efficacy of this procedure before wide clinical utilization. The sample needed for such study is expected to be small given the previously reported large high efficacy of ovarian transplantation. The suggested primary endpoint will be the proportion of recurrent ovarian failure at certain time points and the cumulative pregnancy rate. Stratification based on the type of cancer and the chemotherapy regimen used and other relevant patient and procedural characteristics is recommended.

In conclusion, transplantation of ovarian tissues can re-establish ovarian and reproductive function in women with POF. However, the current evidence is not sufficient to evaluate the long-term efficacy and longevity of ovarian grafts. A controlled multicenter clinical trial with sufficient follow up would provide clinicians and patients with valid evidence of the potential benefit of OTT. 


\section{References}

1. Silber SJ, Lenahan KM, Levine DJ, et al. Ovarian transplantation between monozygotic twins discordant for premature ovarian failure. N Engl J Med 2005;353(1):58-63.

2. Silber SJ, Gosden RG. Ovarian transplantation in a series of monozygotic twins discordant for ovarian failure. N Engl J Med 2007;356(13):1382-4.

3. Mhatre P, Mhatre J, Magotra R. Ovarian transplant: a new frontier. Transplant Proc 2005;37(2):1396-8.

4. ASRM-Guidelines. Ovarian tissue and oocyte cryopreservation. Fertil Steril 2004;82(4):993-8.

5. Grischenko V, Chub N, Lobyntseva G. Creation of bank of cryopreserved human ovarian for allotransplantation in gynecology. Kriobiologia 1987;3:7-11.

6. Poirot CJ, Martelli H, Genestie C, et al. Feasibility of ovarian tissue cryopreservation for prepubertal females with cancer. Pediatr Blood Cancer 2007;49(1):74-8.

7. Weintraub M, Gross E, Kadari A, et al. Should ovarian cryopreservation be offered to girls with cancer. Pediatr Blood Cancer 2007;48(1):4-9.

8. Martin JR, Kodaman P, Oktay K, Taylor HS. Ovarian cryopreservation with transposition of a contralateral ovary: a combined approach for fertility preservation in women receiving pelvic radiation. Fertil Steril 2007;87(1):189 e5-7.

9. Oktay K, Karlikaya G. Ovarian function after transplantation of frozen, banked autologous ovarian tissue. N Engl J Med 2000;342(25):1919.

10. Leporrier M, von Theobald P, Roffe JL, Muller G. A new technique to protect ovarian function before pelvic irradiation. Heterotopic ovarian autotransplantation. Cancer 1987;60(9):2201-4.

11. Von Theobald P, Roffe JL, Berrocal J, Le Porrier M, Levy G, Muller G. [Heterotopic autotransplantation of the ovary in women]. Presse Med 1987;16(25):1239-41.

12. Marconi G, Quintana R, Rueda-Leverone NG, Vighi S. Accidental ovarian autograft after a laparoscopic surgery: case report. Fertil Steril 1997;68(2):364-6.

13. Callejo J, Salvador C, Miralles A, Vilaseca S, Lailla JM, Balasch J. Long-term ovarian function evaluation after autografting by implantation with fresh and frozen-thawed human ovarian tissue. J Clin Endocrinol Metab 2001;86(9):4489-94.

14. Oktay K, Economos K, Kan M, Rucinski J, Veeck L, Rosenwaks Z. Endocrine function and oocyte retrieval after autologous transplantation of ovarian cortical strips to the forearm. JAMA 2001;286(12):1490-3.

15. Radford JA, Lieberman BA, Brison DR, et al. Orthotopic reimplantation of cryopreserved ovarian cortical strips after high-dose chemotherapy for Hodgkin's lymphoma. Lancet 2001;357(9263):1172-5.

16. Oktay K, Buyuk E, Rosenwaks Z, Rucinski J. A technique for transplantation of ovarian cortical strips to the forearm. Fertil Steril 2003;80(1):193-8.

17. Donnez J, Dolmans MM, Demylle D, et al. Livebirth after orthotopic transplantation of cryopreserved ovarian tissue. Lancet 2004;364(9443):1405-10.

18. Hilders CG, Baranski AG, Peters L, Ramkhelawan A, Trimbos JB. Successful human ovarian autotransplantation to the upper arm. Cancer 2004;101(12):2771-8.

19. Kim SS, Hwang IT, Lee HC. Heterotopic autotransplantation of cryobanked human ovarian tissue as a strategy to restore ovarian function. Fertil Steril 2004;82(4):930-2.

20. Gosden RG, Baird DT, Wade JC, Webb R. Restoration of fertility to oophorectomized sheep by ovarian autografts stored at -196 degrees C. Hum Reprod 1994;9(4):597-603.

21. Meirow D, Levron J, Eldar-Geva T, et al. Pregnancy after transplantation of cryopreserved ovarian tissue in a patient with ovarian failure after chemotherapy. N Engl J Med 2005;353(3):318-21. 
22. Wolner-Hanssen P, Hagglund L, Ploman F, Ramirez A, Manthorpe R, Thuring A. Autotransplantation of cryopreserved ovarian tissue to the right forearm 4(1/2) years after autologous stem cell transplantation. Acta Obstet Gynecol Scand 2005;84(7):695-8.

23. Oktay K, Buyuk E, Veeck L, et al. Embryo development after heterotopic transplantation of cryopreserved ovarian tissue. Lancet 2004;363(9412):837-40.

24. Oktay K. Spontaneous conceptions and live birth after heterotopic ovarian transplantation: is there a germline stem cell connection? Hum Reprod 2006;21(6):1345-8.

25. Rosendahl M, Loft A, Byskov AG, et al. Biochemical pregnancy after fertilization of an oocyte aspirated from a heterotopic autotransplant of cryopreserved ovarian tissue: case report. Hum Reprod 2006;21(8):2006-9.

26. Schmidt KL, Andersen CY, Loft A, Byskov AG, Ernst E, Andersen AN. Follow-up of ovarian function post-chemotherapy following ovarian cryopreservation and transplantation. Hum Reprod 2005;20(12):3539-46.

27. Stroup DF, Berlin JA, Morton SC, et al. Meta-analysis of observational studies in epidemiology: a proposal for reporting. Meta-analysis Of Observational Studies in Epidemiology (MOOSE) group. Jama 2000;283(15):2008-12.

28. Landis JR, Koch GG. An application of hierarchical kappa-type statistics in the assessment of majority agreement among multiple observers. Biometrics 1977;33(2):363-74.

29. The Newcastle-Ottawa Scale (NOS) for assessing the quality of nonrandomized studies in meta-analyses [program]. Ottawa, Canada: The Ottawa Health Research Institute, 2005.

30. Newcombe RG. Two-sided confidence intervals for the single proportion: comparison of seven methods. Stat Med 1998;17(8):857-72.

31. Cox D. Regression models and life tables. J Stat Soc 1972;34:187-220.

32. Higgins JP, Thompson SG. Quantifying heterogeneity in a meta-analysis. Stat Med 2002;21(11):1539-58.

33. Petitti DB. Approaches to heterogeneity in meta-analysis. Stat Med 2001;20(23): 3625-33.

34. Altman DG, Bland JM. Interaction revisited: the difference between two estimates. Bmj 2003;326(7382):219.

35. Kiran G, Kiran H, Coban YK, Guven AM, Yuksel M. Fresh autologous transplantation of ovarian cortical strips to the anterior abdominal wall at the pfannenstiel incision site. Fertil Steril 2004;82(4):954-6.

36. Tryde Schmidt KL, Yding Andersen C, Starup J, Loft A, Byskov AG, Nyboe Andersen A. Orthotopic autotransplantation of cryopreserved ovarian tissue to a woman cured of cancer - follicular growth, steroid production and oocyte retrieval. Reprod Biomed Online 2004;8(4):448-53.

37. Donnez J, Squifflet J, Dolmans MM, Martinez-Madrid B, Jadoul P, Van Langendonckt A. Orthotopic transplantation of fresh ovarian cortex: a report of two cases. Fertil Steril 2005;84(4):1018.

38. Demeestere I, Simon P, Buxant F, et al. Ovarian function and spontaneous pregnancy after combined heterotopic and orthotopic cryopreserved ovarian tissue transplantation in a patient previously treated with bone marrow transplantation: case report. Hum Reprod 2006;21(8):2010-4.

39. Donnez J, Dolmans MM, Demylle D, et al. Restoration of ovarian function after orthotopic (intraovarian and periovarian) transplantation of cryopreserved ovarian tissue in a woman treated by bone marrow transplantation for sickle cell anaemia: case report. Hum Reprod 2006;21(1):183-8. 
40. Sanchez M, Alama P, Gadea B, Soares SR, Simon C, Pellicer A. Fresh human orthotopic ovarian cortex transplantation: long-term results. Hum Reprod 2007;22(3):786-91.

41. Leporrier M, Roffe JL, Von Theobald P, Muller G. Autologous transplantation of whole ovaries vs ovarian cortical strips.[comment]. JAMA 2002;287(1):44-5.

42. Aubard Y, Piver P, Cogni Y, Fermeaux V, Poulin N, Driancourt MA. Orthotopic and heterotopic autografts of frozen-thawed ovarian cortex in sheep. Hum Reprod 1999;14(8):2149-54.

43. Baird DT, Webb R, Campbell BK, Harkness LM, Gosden RG. Long-term ovarian function in sheep after ovariectomy and transplantation of autografts stored at -196 C. Endocrinology 1999;140(1):462-71.

44. Candy CJ, Wood MJ, Whittingham DG. Restoration of a normal reproductive lifespan after grafting of cryopreserved mouse ovaries. Hum Reprod 2000;15(6):1300-4.

45. Bedaiwy MA, Hussein MR, Biscotti C, Falcone T. Cryopreservation of intact human ovary with its vascular pedicle. Hum Reprod 2006;21(12):3258-69.

46. Bedaiwy MA, Falcone T. Harvesting and autotransplantation of vascularized ovarian grafts: approaches and techniques. Reprod Biomed Online 2007;14(3):360-71.

47. Torrents E, Boiso I, Barri PN, Veiga A. Applications of ovarian tissue transplantation in experimental biology and medicine. Hum Reprod Update 2003;9(5):471-81.

48. Martinez-Madrid B, Dolmans MM, Van Langendonckt A, Defrere S, Donnez J. Freezethawing intact human ovary with its vascular pedicle with a passive cooling device. Fertil Steril 2004;82(5):1390-4.

49. Jadoul P, Donnez J, Dolmans MM, Squifflet J, Lengele B, Martinez-Madrid B. Laparoscopic ovariectomy for whole human ovary cryopreservation: technical aspects. Fertil Steril 2007;87(4):971-5.

50. Leporrier M, Roffe JL, Von Theobald P, Muller G. Autologous transplantation of whole ovaries vs ovarian cortical strips. Jama 2002;287(1):44-5.

51. Bath LE, Tydeman G, Critchley HO, Anderson RA, Baird DT, Wallace WH. Spontaneous conception in a young woman who had ovarian cortical tissue cryopreserved before chemotherapy and radiotherapy for a Ewing's sarcoma of the pelvis: case report. Hum Reprod 2004;19(11):2569-72. 


Chapter 10

General Discussion

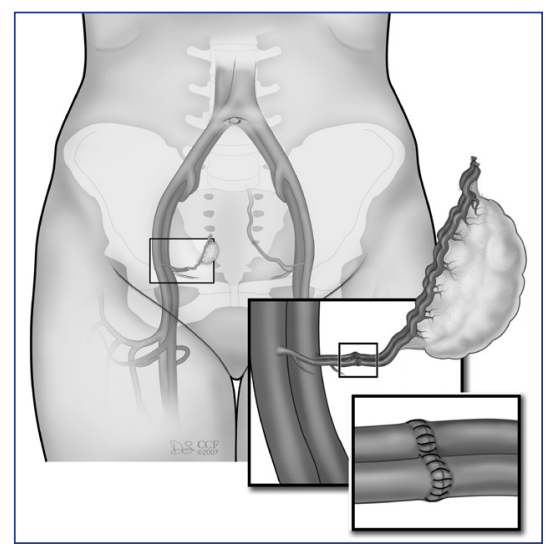


Options for preserving fertility in women are increasing, but most are still experimental. One option in particular, though-ovarian tissue cryopreservation and transplantation-is promising. Little success has been achieved thus far in developing efficient cryopreservation and transplantation protocols for intact ovaries with their vascular pedicles. In order to achieve a functioning ovarian implant, the ovarian fragment and or intact ovary must be able to 1) survive the freeze-thaw trauma with minimal damage to the follicular structure, 2) establish blood supply immediately upon transplantation, 3 ) regain endocrine and reproductive functions and 4) survive for a considerable time.

To gain more insight into the possibility of developing an efficient intact ovary cryopreservation and transplantation technique, we conducted a series of in vitro and in vivo experiments using pigs and merino sheep animal models and human ovaries. Three levels of experimentation were performed. In the first level, we studied the impact of ovarian cortical tissue size and the processing time before cryopreservation (warm ischemia time) on follicular survival. We also evaluated the effect of ischemia time on the expression of molecular markers of apoptosis, namely Bcl-2 and p53 proteins, on freshly-fixed and cryopreserved-thawed ovarian tissue. In the second level, the feasibility of transplanting an entire fresh ovary with anastomosis of the ovarian vascular pedicle was assessed. Subsequently, the feasibility of transplanting an intact frozen-thawed ovary with microvascular anastomosis of the ovarian vascular pedicle to the deep inferior epigastric vessels was evaluated. Whether orthotopic transplantation of a cryopreserved ovary or ovarian cortical strips can result in antibody formation against ovarian tissue antigens was also studied. The third experimental level was implemented to assess two outcomes: 1) the immediate post-thawing injury to a human ovary that was cryopreserved, either as a whole with its vascular pedicle or as ovarian cortical strips and 2) the different surgical approaches involved in the harvesting and the heterotopic autotransplantation of intact ovaries using microvascular anastomosis. In addition, we conducted a systematic review of observational studies and an individual patient data meta-analysis to evaluate the reproductive outcome after transplantation of ovarian tissue (OTT) for fertility preservation in women at high risk of premature ovarian failure (POF). The results of the studies and their possible clinical implications are discussed in this chapter.

In our trial, there was no significant damage to the ovarian cortical tissue, even in the large cortical strips $\left(5 \mathrm{~mm}^{2}\right)$ and in those exposed to warm ischemia for up to 30 minutes. Consequently, cryopreservation of cortical pieces $5 \mathrm{~mm}^{2}$ in size is preferable, although the cryopreservation of such segments requires an adapted protocol that is based on cryoperfusion rather than passive diffusion (1). Optimizing the procedural 
steps involved in thawing of ovarian tissue may improve tissue survival. However, there would be little benefit from doing the same for the procedures used before grafting, including cryopreservation, as they account for relatively little tissue injury in ovarian grafts.

Upon exposure to various insults, molecular alterations in oocytes and the supporting granulosa cells occur, and these alterations are the key determinants of future cell function. In our study, we evaluated whether an ischemic-type or cryopreservationtype insult of the ovarian tissues is associated with alterations of the proapoptotic and the antiapoptotic molecules. Despite the fact that the $\mathrm{Bcl}-2$ and the proapoptotic p53 molecules may be involved in apoptotic cell death in the ovary (freshly fixed and cryopreserved tissues), Bcl-2, but not p53, can be induced by warm ischemic injury of the ovary, mostly in the healthy follicles. However, cryopreservation has little effect on the $\mathrm{Bcl}-2 / \mathrm{p} 53$ protein expression. This provides further support at the molecular level of the initial observation made by Baird and associates based on follicular count that most follicular loss during transplantation of cryopreserved ovarian tissue is due to ischemic insult and not to cryopreservation insult (2). Consequently, in the present thesis, evidence is provided to support the contention that cryopreservation and thawing of ovarian cortical strips larger than those presented in the initial work by Gosden et al., did not seem to have any effects on the pattern of pro- and antiapoptotic protein molecules expression (3).

On developing a model for autotransplantation of an intact ovary with its vascular pedicle, we first tested the feasibility of this proposed model by transplanting an intact fresh sheep ovary into the abdominal wall with microvascular anastomosis of the deep inferior epigastric vessels. We demonstrated that with adequate vascular patency, loss of ovarian tissue was minimal, the primordial follicle count was high and hormonal function resumed completely. In a case of heterotopic transplantation of ovarian cortical strip to the forearm, spontaneous ovulation did not occur during the observation period of 18 months. High-dose gonadotropin stimulation for one IVF cycle produced three oocytes, but no fertilization occurred (4). However, spontaneous ovulation was documented in another patient who underwent the same procedure. In both patients, it took many weeks for FSH levels to normalize, indicating that the ovarian graft experiences significant ischemia before revascularization is established (4). Consequently, with non vascular grafts, most tissue loss occurs after transplantation due to postgrafting ischemia.

Minimizing ischemia between grafting of the organ and revascularization of the tissue is therefore crucial for tissue survival and the reproductive potential of ovarian transplants. Different attempts to minimize ischemic damage have been made using 
a variety of options other than microvascular anastomosis (5-8). Unfortunately, none of these treatments has sufficiently improved the post-transplantation survival of the tissue. Despite the limitations, we propose that immediate revascularization of ovarian transplants can be achieved by performing vascular anastomosis.

Encouraged by the results of this experiment, recent improvements in freezing protocols for vessel grafts (9) and reports of cryopreservation of composite tissue and animal organs $(10,11)$, we moved to the next step of duplicating the results of this study using a cryopreserved intact ovary with its vascular pedicle. Using the protocol described in this thesis, we found that the process of graft preparation, from removal of the ovary to the end of cryopreservation, was not associated with increased apoptosis, emphasizing the impact of postgrafting revascularization in graft survival. These results are in agreement with a recent report by Liu and associates (12).

Our cryopreservation protocol proved to be satisfactory as evidenced by the in vitro assessments performed in the study and presented in this thesis, including primordial follicle viability and apoptotic markers (10). The absence of apoptotic signals in the primordial follicles lends further support to the fact that apoptosis is a downstream event that requires active metabolism and that is usually takes several hours or even days to occur (13-15). Although immediate patency of the vascular pedicle was demonstrated in all of the transplanted ovaries, long-term patency was obtained only in $27 \%$ of the vascularized grafts with active endocrine activity. This could be due to the extreme tortuosity of the ovarian vessels; such vessels are at high risk for thrombosis. In addition, cryopreservation might have adversely affected the intima of the blood vessels, predisposing them to thrombosis and anastomotic failure.

A number of variables may encourage the development of autoantibodies, including manipulation during ovarian autotransplantation, altered expression of selfantigens that result from physical damage to ovarian cells during in vitro handling, cryopreservation and heterotopic transplantation. One sheep in our study developed titer antiovarian antibodies after failed autotransplantation and vessel thrombosis. The study results suggest that successful heterotopic transplantation of an entire ovary or ovarian cortical strips does not induce immune responses against the ovarian antigens. However, additional prospective studies are needed to evaluate the possible role -if any- that antiovary antibodies play in fertilization and pregnancy outcome in patients undergoing ovary autotransplantation.

The next step in our experiments was to replicate these animal findings in humans. Although the technical challenges of the microvascular anastomosis in humans can be circumvented by appropriate training, the main determinant of success is the ability to develop an appropriate cryopreservation protocol of an entire ovary with its vascular 
pedicle. The study presented in this thesis attempted to develop an effective protocol in humans.

The same cryopreservation protocol used for the intact sheep ovaries was used in 2 patients. We found that the viable primordial follicular count in the intact ovaries in both of these patients (75 and 78\%) was comparable with the $75.1 \%$ follicular viability reported by Martinez-Madrid et al. (16), who tried a different freezing protocol for intact human ovary. At the molecular level, cryopreservation and thawing of intact human ovaries had no effects on apoptotic cell death and Bcl-2 and p53 protein expression in both ovarian cortical strips and intact ovaries. This is similar to what we found in sheep ovaries.

The patterns of $\mathrm{Bcl}-2$ and p53 alterations presented in this study are similar to those observed in different organs, namely the heart, retina, liver and brain. It has been reported that ischemic injury of these organs is associated with apoptotic changes. The induction of Bcl-2 and p53 can occur as early as 0.5 and $1 \mathrm{~h}$, respectively, following ischemia $(17,18)$.

The study presented in this thesis also revealed the presence of persistent vascularity and comparable microvessel density in both the control and cryopreserved groups. These findings indicate that our freeze-thawing protocol has no detrimental effects on the integrity of the vascular network of the ovarian tissue. Of note, the status of the ovarian vascular supply is central to dynamic changes that occur during the normal ovarian cycle. Follicular growth and the development of the corpus luteum all depend on intact vasculature. The findings put forward in this study provide further evidence that intact human ovary can be cryopreserved using a slow-freezing protocol.

The next study in this thesis described the surgical techniques for ovarian harvesting and heterotopic ovarian transplantation to the anterior abdominal wall using microvascular anastomosis. It assessed the different surgical approaches used to handle ovaries at the time of harvesting to optimize the subsequent autotransplantation as well as approaches to overcome size discrepancy in the caliber between the ovarian and the epigastric vessels.

End-to-end anastomosis appears to be the ideal approach for performing the anastomosis procedure; the patency rate was $>60 \%$. However, if vascular discrepancy between the ovarian vessels and the inferior epigastric vessels is inevitable, end-to-side anastomosis rather than fish mouth incisions should be adopted. Further advances in the anastomosis technique may help to improve the overall patency of the transplants. Sutureless approaches, glues or adhesives and laser-assisted anastomosis are to be considered only according the surgeon's experience or in consultation with a plastic surgeon (19). 
Despite the fact that immediate revascularization could limit the accelerated ischemia-induced follicular loss, this was not the case in a recent study that evaluated contralateral orthotopic autotransplantation of cryopreserved whole ovaries with microanastomosis of the ovarian vascular pedicle (20). In that study, histological examination of the ovaries 18-19 months after transplantation showed that the follicular survival rate in the grafted ovaries was only 1.7-7.6\% (20). Consequently, continuous improvement on the cryopreservation and transplantation techniques is mandatory to improve on the overall outcome.

On trying to duplicate these findings in humans, we found that the ovarian harvesting technique should probably be modified to nullify mechanical and ischemic damage to the ovary. Laparoscopic harvesting should be the first option for this purpose. Given the fact that autotransplantation of an intact human ovary with its vascular pedicle has yet to be performed; we provided a hypothetical approach towards possible recipient sites. The advantages and the disadvantages of each proposed site were discussed with the conclusion that the inferior epigastric vessels could be the most feasible heterotopic recipient site.

Finally, the information concluded from the meta-analysis of published reports of ovarian tissue transplantation in women with POF can provide preliminary insight about the predictors of better reproductive outcome after the procedure. First, transplantation of fresh, heterologous and larger size grafts increased the likelihood for return of ovarian functions and to less extent can be linked to delay in ovarian graft exhaustion. Second, the site of OTT whether orthotopic or heterotopic did not affect the return of ovarian function or recurrent ovarian failure. The increased likelihood of return of ovarian function in fresh grafts compared to cryopreserved grafts may be explained by the expected effects of cryopreservation on ovarian tissue. This finding can also explain the better outcomes observed in women receiving heterologous grafts which were almost always fresh. This particular finding supports the need for improvement in the technology of cryopreservation of human ovarian tissues (21-23). Third, we could only evaluate the short term efficacy of the grafts ( $<12$ months) with an association between delayed re-establishment of ovarian function and early recurrent failure that could be explained by the occurrence of tissue ischemia from the time period that is required to develop a blood supply. For this reason ovarian transplants with a vascular pedicle are being explored $(16,21,24)$.

Fourth, despite the fact that 9 pregnancies have been reported after OTT, only 3 deliveries were reported. Two deliveries were after autotransplantation of cryopreservedthawed ovarian tissue $(16,25)$ and the third was after after heterologus transplantation of fresh cortical tissue between twins discordant for POF(26). To date, no pregnancies 
have been reported after intact fresh human ovary transplantation with microvascular anastomosis (27-29). The source of oocyte that result in spontaneous pregnancy after orthotopic OTT can not be certain especially in cases of POF after chemotherapy as there are reports of spontaneous pregnancy in women with documented POF after chemotherapy with heterotopic and not orthotopic transplantation (30) or even without transplantation of the cryopreserved ovarian tissue (31).

In addition, looking into the outcome of IVF cycles after OTT; few noteworthy observations deserve specific mentioning. First, several treatment cycles are often needed to achieve any clinical success by completing the treatment cycle or achieving pregnancy. Second, large doses of gonadotrophins and longer duration of COS are often observed. Third, there was cycle cancellation rate of up to $70 \%$. Fourth, an overall poor response in completed cycles as well with few follicles available on the day of retrieval and limited and increasing immature oocytes retrieved. Finally, increased incidence of developmental arrest of embryos with few pregnancies reported so far.

\section{Future perspective}

Despite technical challenges, we consider both the cryopreservation and the autotransplantation protocols of an intact mammalian ovary with microvascular anastomosis reliable for studying the resumption of ovarian function following iatrogenic failure, preserving endangered species and in advancing knowledge of early folliculogenesis.

The limited functional lifespan of transplanted ovarian cortical strips is partly due to a reduced follicle population in the graft. Moreover, an estimated $70 \%$ of primordial follicles in the graft tissue are lost as a result of ischemia-revascularization injury. Consequently, the aim to extend the longevity of ovarian function may be achieved with whole ovary cryopreservation with vascular reanastomosis, as this allows the preservation and transfer of the maximum follicle reserve and the immediate revascularization of the graft, thus reducing follicle loss through post-grafting ischemia.

Whole ovary cryopreservation itself poses several future challenges. Although there are numerous successful reports of whole ovary cryopreservation in rats and mice, in which effective cryoprotectant penetration via simple diffusion and grafts can be non-vascular, there is limited success with larger species whose ovaries are larger and more fibrous. Therefore, the technique of cryoperfusion developed in this thesis has to be refined and used in different mammalian species. Future studies should focus on how the cryopreservation protocol could be optimized for the many different tissue and cell types, i.e. ovarian stroma, follicular cells, oocytes and vascular 
tissue, some of which may be contradictory to each other. The preferential effects of the cryopreservation protocol as well as the ischemic damage on the various cellular components of the ovary should be substantiated in different mammalian species as well as in humans.

The dynamics of transplanted and/or cryopreserved-thawed ovarian tissue are comparable and yet different from those of transplanted fresh ones. Most current studies have reported good follicle viability following cryopreservation comparable with that of fresh tissue. However, this has mostly been assessed using the trypan blue test and histological staining, neither of which measures cell viability in terms of its functional performance. Therefore, there is a need for more detailed functional assessments of ovarian tissue viability following perfusion, cryopreservation and thawing. For instance, studying the use of CFDA SE and PI viability staining to assess the viability of cryopreserved-thawed ovarian tissue could be performed. These viability stains are designed to measure immediate post-thaw survival. No studies so far have measured long-term survival of C-T tissues. A study could be designed to assess the long-term viability by looking into tissue explant cultures for variable durations followed by assessments with a variety of measures as Ki67 expression, BrdU uptake and PCNA immunohistochemical staining.

Given the fact that loss of cell viability following cryopreservation may be not only due to necrosis as a result of intracellular ice formation and osmotic stress but also apoptosis as well, manipulation of the apoptotic pathways could improve the overall outcome. Therefore, the inclusion of anti-apoptotic substances to the cryopreservation media may help prevent some apoptosis, reducing the cell death associated with freeze-thawing and improving efficiency. The Sphingosine-1-phosphate (S-1-P) is one such anti-apoptotic agent. It can block the ceramide-induced apoptotic pathway and has been shown to suppress radiation- and chemotherapy-induced follicular apoptosis and increase follicle survival following autografting in sheep. Consequently, S-1-P could be integrated in whole ovary cryopreservation by adding it to the cryoprotective media not only to reduce the depletion of the follicle reserve by apoptosis but also to improve the longevity of the graft. Similarly, targeting $\mathrm{Bcl}-2$ and p53 molecules may have some therapeutic ramifications in the treatment of ovarian disorders resulting from ischemic Injury.

Further investigations are also necessary to examine different durations of ischemic warming followed by ovarian transplantation. The endocrinological and ovulatory success of the transplants may be measured both against the duration of ischemia and levels of bcl-2 and p53 protein expression. In addition, autoantibody formation upon re-implantation could be assessed. 
The ultimate success of intact ovary cryopreservation and transplantation would be to achieve pregnancy and normal delivery upon re-implantation. After achieving this goal in a wide variety of animal models using C-T ovarian cortical strips, two live births have been recently reported in humans using a similar technology. We believe we are getting close to achieving a similar success in animal models using C-T intact ovary. We also believe that it is time to consider intact human ovary transplantation. It is expected that anastomosis of the ovarian vessels in humans will be less technically challenging because of the straight course and wider caliber of the ovarian vessels provided that the recipient vessels have a matching caliber. From the criteria set in this thesis, we believe that the deep inferior epigastric vessels may stand as the best available option for heterotopic intact ovary transplantation. This proposition should be tested in a willing volunteer patient.

Given the current evidence on OTT in humans from the meta-analysis presented in this thesis, the restoration of ovarian function after OTT was not maintained and 1 in 5 women had recurrent ovarian failure 3 months after the return of ovarian function. Future research should be directed towards optimization of the technology utilized in cryopreservation of ovarian tissue and in the standardization of the laboratory and surgical techniques used as well as the use of vascularized grafts to minimize ischemic damage. Clinical studies comparing different techniques with the time to resumption of ovarian function as the primary endpoint should be conducted to systematically select the best technique for OTT which is associated with sustained restoration of ovarian function. After optimization of the technique, the next step would be to conduct a controlled clinical trial to systematically evaluate the efficacy of this procedure before wide clinical utilization. 


\section{References}

1. Wang X, Chen H, Yin H, Kim SS, Lin Tan S, Gosden RG. Fertility after intact ovary transplantation. Nature 2002;415:385.

2. Baird DT, Webb R, Campbell BK, Harkness LM, Gosden RG. Long-term ovarian function in sheep after ovariectomy and transplantation of autografts stored at -196 C. Endocrinology 1999;140:462-471.

3. Gosden RG, Baird DT, Wade JC, Webb R. Restoration of fertility to oophorectomized sheep by ovarian autografts stored at -196 degrees C. Hum Reprod 1994;9:597-603.

4. Oktay K, Economos K, Kan M, Rucinski J, Veeck L, Rosenwaks Z. Endocrine function and oocyte retrieval after autologous transplantation of ovarian cortical strips to the forearm. Jama 2001;286:1490-1493.

5. Horvath E, Kovacs K, Garg BD, Tuchweber B. Ultrastructure of the rat ovary transplanted into the spleen. Gynecol Invest 1973;4:73-83.

6. Cox SL, Shaw J, Jenkin G. Transplantation of cryopreserved fetal ovarian tissue to adult recipients in mice. J Reprod Fertil 1996;107:315-322.

7. Schnorr J, Oehninger S, Toner J, Hsiu J, Lanzendorf S, Williams R, Hodgen G. Functional studies of subcutaneous ovarian transplants in non-human primates: steroidogenesis, endometrial development, ovulation, menstrual patterns and gamete morphology. Hum Reprod 2002;17:612-619.

8. Imthurn B, Cox SL, Jenkin G, Trounson AO, Shaw JM. Gonadotrophin administration can benefit ovarian tissue grafted to the body wall: implications for human ovarian grafting. Mol Cell Endocrinol 2000;163:141-146.

9. Gosden RG. Low temperature storage and grafting of human ovarian tissue. Mol Cell Endocrinol 2000;163:125-129.

10. Demirci B, Salle B, Frappart L, Franck M, Guerin JF, Lornage J. Morphological alterations and DNA fragmentation in oocytes from primordial and primary follicles after freezing-thawing of ovarian cortex in sheep. Fertil Steril 2002;77:595-600.

11. Yagi T, Hardin JA, Valenzuela YM, Miyoshi H, Gores GJ, Nyberg SL. Caspase inhibition reduces apoptotic death of cryopreserved porcine hepatocytes. Hepatology 2001;33:1432-1440.

12. Liu J, Van Der Elst J, Van Den Broecke R, Dhont M. Early massive follicle loss and apoptosis in heterotopically grafted newborn mouse ovaries. Hum Reprod 2002; 17:605-611.

13. Shamberger RC, Rosenberg SA, Seipp CA, Sherins RJ. Effects of high-dose methotrexate and vincristine on ovarian and testicular functions in patients undergoing postoperative adjuvant treatment of osteosarcoma. Cancer Treat Rep 1981;65:739-746.

14. Scarabelli T, Stephanou A, Rayment N, Pasini E, Comini L, Curello S, Ferrari R, et al. Apoptosis of endothelial cells precedes myocyte cell apoptosis in ischemia/reperfusion injury. Circulation 2001;104:253-256.

15. Stephanou A, Scarabelli TM, Brar BK, Nakanishi Y, Matsumura M, Knight RA, Latchman DS. Induction of apoptosis and Fas receptor/Fas ligand expression by ischemia/ reperfusion in cardiac myocytes requires serine 727 of the STAT-1 transcription factor but not tyrosine 701. J Biol Chem 2001;276:28340-28347.

16. Donnez J, Dolmans MM, Demylle D, Jadoul P, Pirard C, Squifflet J, Martinez-Madrid $\mathrm{B}$, et al. Livebirth after orthotopic transplantation of cryopreserved ovarian tissue. Lancet 2004;364:1405-1410.

17. Peralta C, Bulbena O, Xaus C, Prats N, Cutrin JC, Poli G, Gelpi E, et al. Ischemic preconditioning: a defense mechanism against the reactive oxygen species generated after hepatic ischemia reperfusion. Transplantation 2002;73:1203-1211. 
18. Wang $\mathrm{F}, \mathrm{Hu} \mathrm{YL}$, Li YH. [The expression of $\mathrm{Bcl}-2$ protein on acute myocardial ischemia/ eperfusion and the significance in forensic pathology]. Fa Yi Xue Za Zhi 2003;19: 207-208, 211.

19. Lopez-Monjardin H, de la Pena-Salcedo JA. Techniques for management of size discrepancies in microvascular anastomosis. Microsurgery 2000;20:162-166.

20. Imhof M, Bergmeister H, Lipovac M, Rudas M, Hofstetter G, Huber J. Orthotopic microvascular reanastomosis of whole cryopreserved ovine ovaries resulting in pregnancy and live birth. Fertil Steril 2006;85 Suppl 1:1208-1215.

21. Bedaiwy MA, Hussein MR, Biscotti C, Falcone T. Cryopreservation of intact human ovary with its vascular pedicle. Hum Reprod 2006;21:3258-3269.

22. Bedaiwy MA, Falcone T. Harvesting and autotransplantation of vascularized ovarian grafts: approaches and techniques RBMonline 2007; in press.

23. Torrents E, Boiso I, Barri PN, Veiga A. Applications of ovarian tissue transplantation in experimental biology and medicine. Hum Reprod Update 2003;9:471-481.

24. Jadoul P, Donnez J, Dolmans MM, Squifflet J, Lengele B, Martinez-Madrid B. Laparoscopic ovariectomy for whole human ovary cryopreservation: technical aspects. Fertil Steril 2007;87:971-975.

25. Meirow D, Levron J, Eldar-Geva T, Hardan I, Fridman E, Zalel Y, Schiff E, et al. Pregnancy after transplantation of cryopreserved ovarian tissue in a patient with ovarian failure after chemotherapy. N Engl J Med 2005;353:318-321.

26. Silber SJ, Lenahan KM, Levine DJ, Pineda JA, Gorman KS, Friez MJ, Crawford EC, et al. Ovarian transplantation between monozygotic twins discordant for premature ovarian failure. N Engl J Med 2005;353:58-63.

27. Leporrier M, von Theobald P, Roffe JL, Muller G. A new technique to protect ovarian function before pelvic irradiation. Heterotopic ovarian autotransplantation. Cancer 1987;60:2201-2204.

28. Hilders CG, Baranski AG, Peters L, Ramkhelawan A, Trimbos JB. Successful human ovarian autotransplantation to the upper arm. Cancer 2004;101:2771-2778.

29. Mhatre P, Mhatre J, Magotra R. Ovarian transplant: a new frontier. Transplant Proc 2005;37:1396-1398.

30. Oktay K. Spontaneous conceptions and live birth after heterotopic ovarian transplantation: is there a germline stem cell connection? Hum Reprod 2006;21: 1345-1348.

31. Bath LE, Tydeman G, Critchley HO, Anderson RA, Baird DT, Wallace WH. Spontaneous conception in a young woman who had ovarian cortical tissue cryopreserved before chemotherapy and radiotherapy for a Ewing's sarcoma of the pelvis: case report. Hum Reprod 2004;19:2569-2572. 


\section{Summary}

Ovarian tissue cryopreservation and transplantation is a viable fertility preservation option in patients at risk of loosing their ovarian functions to cancer therapy or otherwise. Ovarian cortical strips cryopreservation and transplantation has been studied extensively with variable successes due to the ischemia revascularization injury upon transplantation. Intact ovary cryopreservation and transplantation with microvascualr anastomosis is thought to be a better alternative. The purpose of this thesis is to introduce the concept of intact ovary cryopreservation and transplantation. Although few studies have been published on that topic, it remains a relatively novel technique with a limited number of groups working in the field. This thesis aims to shed light on different aspects of intact ovary cryopreservation and subsequent transplantation.

In chapter 1 basic oocyte biology, pathophysiology of chemotherapy/radiotherapy induced ovarian failure and the diagnosis and prediction of POF as well as the indications of fertility preservation are summarized. Fertility preservation options including chemo-protection, ovariopexy, oocyte cryopreservation, embryo cryopreservation are described in details focusing on cryopreservation and transplantation of ovarian tissue. In addition, the hypothesis and the aims of this thesis are formulated.

In chapter 2 the impact of tissue size and the processing time interval before cryopreservation (warm ischemia time) on follicular survival is described. Various sizes of ovarian cortical strips were subjected to different time intervals in warm ischemia, after which a fresh part was immediately fixed and the other cryopreserved according to standard protocol. Stratifying the cryopreserved ovarian tissue group according to size showed a significant higher follicle count for larger tissue sections while the number is comparable to its fresh counterpart. In addition, the ischemia time factor had no additional effect on any of the described changes in the cryopreserved group, nor did increasing exposure to warm ischemia (up to $30 \mathrm{~min}$ ) result in significant damage to the freshly fixed samples. This study suggested that handling larger ovarian cortex pieces facilitates cryopreservation as well as autotransplantation procedures. Moreover, processing time up to 30 minutes will not have significant damaging effects on the ovarian tissue.

In chapter 3 the effect of ischemia time on the expression of Bcl-2 and p53 proteins on freshly-fixed and cryopreserved-thawed ovarian tissue is described. Using a similar design as in chapter 2, apoptosis (TUNEL assay) and Bcl-2, p53 protein expression (immunoperoxidase method) were assessed. Irrespective of the warm ischemia time, the apoptotic indices were statistically significantly higher in the atretic than in the non-atretic follicles with no differences between freshly-fixed and cryopre- 
served tissues. In addition increased duration of ischemia was not associated with any changes in the patterns of $\mathrm{P} 53$ and $\mathrm{Bcl}-2$ expression. This study demonstrates that cryopreservation insult does not alter the apoptotic signals with short tissue preparation time.

In chapter 4 the feasibility of transplanting an entire ovary with anastomosis of the ovarian vascular pedicle is tested. Using a merino sheep animal model, laparoscopic bilateral oophorectomy was performed. Ovaries were autotransplanted into the abdominal wall, and microsurgical vascular anastomosis of the ovarian to the inferior epigastric vessels was performed. The transplants were assessed after 7-10 days. At follow-up, three transplants were viable; they showed no signs of necrosis, and patency of the vascular anastomosis was confirmed. Serum E2 levels did not change significantly after transplantation in the patent vessel group. Serum FSH level in the patent vessel group did not change significantly from before to after transplantation, whereas a large increase in FSH level was observed in the non patent vessel group. In addition the patent vessel group had significantly more follicles after transplantation than did the non patent vessel group. This study introduced the concept of a possible successful autotransplatation of the ovary with microvascular anastomosis to the anterior abdominal wall.

In chapter 5 the feasibility of transplanting an intact frozen-thawed ovary with microvascular anastomosis of the ovarian vascular pedicle to the deep inferior epigastric vessels is tested. Bilateral laparoscopic oophorectomy was performed on 17 synchronized ewes. In one group of animals, both ovaries were cryopreserved intact with their vascular pedicles. In another group of animals, ovarian cortical strips were prepared from each ovary and cryopreserved. After thawing, follicular viability and apoptosis rates were assessed using one ovary. The other ovary was transplanted to the abdominal wall with microvascular anastomosis (Group I). In Group II, the ovarian cortical strips were placed in the anterior abdominal wall. Ovaries were harvested after 8-10 days in situ and subjected to histological evaluation. No significant differences were found in the mean values of apoptosis and follicular viability in both groups. In Group I, immediate and long-term patency was documented in 100\% and $27 \%$ of the grafts, respectively; and postoperative FSH levels were similar to preoperative values in animals with patent vessels. In Group II, postoperative FSH levels were significantly higher than the preoperative ones. This study introduces the concept of intact ovary cryopreservation by perfusion and strengthens the concept of transplantation of an intact frozen-thawed or fresh ovary to the anterior abdominal wall with restoration of vascular supply and ovarian hormonal functions. 
In chapter 6 a study is presented to examine whether orthotopic transplantation of cryopreserved entire ovary or ovarian cortical strips can result in antibody formation against ovarian tissue antigens. Anti-ovarian antibodies (AOA) in serum were detected by indirect immunofluorescence assay using commercially available slides of monkey ovarian sections and unfixed 5-m-thick frozen section of sheep ovary as antigen. Ovarian antibody was found only in 1 postoperative serum sample following intact ovary transplantation with occluded vessels at follow up compared to none in the sera obtained preoperatively or at transplantation. The study results suggest that orthotopic transplantation of entire ovary or ovarian cortical strips do not induce the immune responses against the ovarian antigens.

In chapter 7 a study is presented to test the feasibility of intact human ovary cryopreservation compared to ovarian cortical strips. Two women donated their ovaries after oophorectomy for benign conditions for experimental research. In both patients, one of the harvested ovaries was sectioned and cryopreserved (by slow freezing) as ovarian cortical strips. The other ovary was cryopreserved intact with its vascular pedicle. After thawing, follicular viability, histology, terminal TUNEL assay, immunoperoxidase staining of the ovarian tissue were performed. Tissues from non-cryopreserved ovaries served as control specimens. The overall viability of the primordial follicles was 75 and $78 \%$ in intact cryopreserved-thawed (C-T) ovaries and 81 and $83 \%$ in ovarian cortical strips respectively. Comparable primordial follicle counts, absence of features of necrosis, mean values of apoptosis and weak Bcl-2 and p53 protein expressions were observed both in the intact C-T ovary and in the C-T ovarian cortical strips. This study suggests that cryoperfusion and cryopreservation of entire human ovary can be achieved with the maintenance of excellent viability of the superficial and the deeper tissues using a slow-freezing protocol.

In chapter 8 the different surgical approaches involved in the harvesting and the heterotopic autotransplantation of intact ovaries with microvascular anastomosis are described. Twenty-one synchronized Merino sheep underwent harvesting of their intact ovaries along with their vascular pedicles. Autotransplantation of fresh ovaries was performed in 6 while autotransplantation of cryopreserved-thawed ovaries was performed in 15 animals. The ovarian vessels were anastomosed to the deep inferior epigastric vessels using end-to-end, end-to side and fish mouth modification techniques in 8, 6 and 7 animals respectively. Patency of the anastomosis, ischemia time, hormonal functions and histology were evaluated. In addition, in this study ovarian harvesting techniques in 2 human subjects were described. Possible autotransplanation sites in humans were also suggested. We found that the use of the fish mouth modification technique to overcome vascular discrepancy was associated with significantly higher 
ischemia time compared to end-to-end and to end-to-side anastomosis. Should this technique ever been proposed to humans, a laparoscopic approach appears to be the most convenient approach for ovarian harvesting. This study also suggested that the inferior epigastric vessel is probably the most suitable heterotopic vascularizing vessel. In addition end to end anastomosis approach yields the highest patency rate of vascularized grafts. On the other side, end to side anastomosis is superior to fish mouth modification in overcoming vascular discrepancy during transplantation.

In chapter 9 a systematic review was conducted to evaluate the reproductive outcome after transplantation of ovarian tissue for fertility preservation in women at high risk of premature ovarian failure. The search used terms referring to ovarian transplant and reproductive outcomes. The review included peer reviewed reports on the reproductive outcomes after OTT in humans regardless of the language of publication. Patients with $\mathrm{FSH}>30 \mathrm{IU} / \mathrm{L}$ at the time of OTT were included in a meta-analysis of individual patient data to evaluate the time to reestablishment of ovarian function (OvF) (defined as follicular growth or menstruation). Secondary outcomes included short and long-term ovarian function and pregnancy after OTT. The review included 47 cases from 22 original reports. The median age was 36 years (range, 15-49). OTT was performed to treat POF in 28 women, to prevent POF in 16 women, to treat infertility in 2 women, and accidentally in 1 during oophorectomy. In all 24 patients with $\mathrm{FSH}>30 \mathrm{IU} / \mathrm{L}$ at the time of OTT, OvF returned with median time to return of 120 days (range, 60-244). Fresh, heterologous and larger size OTT increased the likelihood of return of OvF [HR of $2.4(95 \% \mathrm{Cl}, 1-5.8, \mathrm{P}=0.059), 10$ (95\% Cl, 2.6-48.3, $\mathrm{P}<0.001), 1.7$ (95\% Cl 1.1-2.5, $\mathrm{P}=0.013$, respectively]. Within 6 months after ROF, 4 women had recurrent ovarian failure. All 4 had cryo-preserved, autologous grafts using cortical strips, and in all ROF occurred $>90$ days after OTT. Data was not sufficient to evaluate the long-term OvF (>12 months). In the 27 women who sought pregnancy, 8 women had 9 pregnancies with 12-month cumulative pregnancy rate of 36\% (95\% $\mathrm{Cl}, 18-59 \%)$. Those women who elected to undergo IVF demonstrated poor response with only 3 pregnancies to date. This analysis suggests that although OTT resulted in return of OvF in women with POF, this return of function is inconsistent, intermittent with shortened longevity of the graft survival. Transplantation of ovarian tissue can reestablish ovarian function in women with premature ovarian failure; however, the current evidence is not sufficient to evaluate the long-term efficacy and longevity of ovarian grafts. A controlled multicenter clinical trial with sufficient follow up would provide clinicians and patients with valid evidence of the potential benefit of this procedure.

In chapter 10 the results of this thesis are discussed. Perspectives for future studies are given. 


\section{Samenvatting}

De behandeling van kanker bij jonge vrouwen leidt vaak tot het verlies van hun ovariumfunctie en dus van hun vruchtbaarheid. Indien het zou lukken om ovariumweefsel in te vriezen, te bewaren, later te ontdooien en terug te transplanteren zou dat tot herstel van de fertiliteit kunnen leiden. Cryopreservatie en transplantatie van ovariële corticale strips is uitvoerig bestudeerd. Het slagingspercentage van de procedure is afhankelijk van de duur van de periode van ischemie, zowel vóór het invriezen, als na het transplanteren. Het cryopreserveren van een ovarium in toto en transplantatie met microchirurgische vaatanastomoses zou een beter alternatief kunnen vormen. Het doel van dit proefschrift is het concept te introduceren van het cryopreserveren en transplanteren van een intact ovarium. Hoewel er al enkele onderzoeken gepubliceerd zijn over dit onderwerp, blijft het toch een relatief nieuwe techniek waar slechts een beperkt aantal onderzoeksgroepen aan werkt. Het doel van dit proefschrift is verscheidene aspecten te belichten van het cryopreserveren en transplanteren van een heel ovarium.

In hoofdstuk 1 worden besproken de biologie van eicellen, de pathofysiologie van ovarieel falen t.g.v. chemotherapie en radiotherapie, en de diagnose en het voorspellen van het optreden van prematuur ovarieel falen (POF), alsmede de indicaties voor het op deze wijze proberen te behouden van de vruchtbaarheid. De thans voorhanden zijnde mogelijkheden tot vruchtbaarheidsbehoud omvatten chemoprotectie, ovariopexie, eicelcryopreservatie en embryocryopreservatie. Zij worden beschreven en vergeleken met cryopreservatie van ovariumweefsel. Hoofdstuk 1 sluit af met het formuleren van een hypothese en de doelstellingen van dit proefschrift.

In hoofdstuk 2 wordt de invloed beschreven van de afmetingen van het te transplanteren weefsel en van de duur van de bewerking voorafgaand aan de cryopreservatie (warme ischemie tijd) op het overleven van follikels. Ovariële corticale strips van verschillende afmetingen werden gedurende verschillende tijdsperioden blootgesteld aan warmte ischemie, waarna een gedeelte onmiddellijk werd gefixeerd voor nader onderzoek en het andere gedeelte gecryopreserveerd volgens het standaardprotocol. Grotere weefselfragmenten hadden, na invriezen en ontdooien, significant meer follikels dan kleinere fragmenten, terwijl het aantal follikels vergelijkbaar was met het vers onderzochte ovariumfragment. Bovendien had de ischemietijd geen invloed op de veranderingen in het gecryopreserveerde weefsel, noch had toenemend langdurige expositie aan warmte-ischemie (tot 30 minuten) significante schade in de vers gefixeerde weefselfragmenten tot gevolg. Onze studie laat zien dat het verwerken van grotere fragmenten cryopreservatie en autotransplantatie vergemakkelijkt. Het verwerken 
van het weefsel tot een periode van 30 minuten heeft geen significante schadelijke invloed op het ovariumweefsel.

In hoofdstuk 3 wordt beschreven hoe de ischemie tijd de expressie beïnvloedt van $\mathrm{Bcl}-2$ en p53 eiwitten, zowel in vers gefixeerd als in ingevroren en weer ontdooid ovariumweefsel. Met gebruikmaking van een vergelijkbare studie-opzet als in hoofdstuk 2 werden de apoptose (met een TUNEL assay) en Bcl-2 en p53 eiwitexpressie (immunoperoxidase methode) onderzocht. Onafhankelijk van de duur van de warmteischemie waren de apoptotische indices statistisch significant sterker geëxprimeerd in atretische vergeleken met niet-atretische follikels, terwijl er geen verschillen werden gevonden tussen vers gefixeerde en bevroren /ontdooide weefselfragmenten. Bovendien bleek een toename van de duur van de ischemie te correleren met enige veranderingen in de expressiepatronen van p53 en $\mathrm{Bcl}-2$. Dit onderzoek toonde aan dat cryopreservatieschade bij een korte weefselverwerkingstijd niet tot verhoogde apoptose leidt.

In hoofdstuk 4 wordt onderzocht of het mogelijk is een ovarium in toto te transplanteren met een anastomose van de ovariële vaten. In het Merinoschaap werd een laparoscopische bilaterale ovariectomie uitgevoerd. De ovaria werden getransplanteerd in de buikwand van het zelfde schaap en de vaten van het ovarium werden microchirurgisch geanastomoseerd op de arteria en vena epigastrica inferior. Na 7 tot 10 dagen werden de transplantaten onderzocht. Drie transplantaten sloegen aan, zij toonden geen tekenen van necrose, en de doorgankelijkheid van de vasculaire anastomose kon worden bevestigd. Serum oestradiol gehaltes veranderden niet significant na transplantatie in de groep met een doorgankelijke anastomose. Serum FSH spiegels bij de schapen met een doorgankelijke anastomose veranderden niet significant vergeleken met de situatie vóór transplantatie, terwijl een sterke toename van FSH werd gevonden in schapen waarbij de anastomose niet doorgankelijk was. Bovendien toonden de getransplanteerde ovaria met een doorgankelijke anastomose significant meer follikels na transplantatie dan de ovaria waarbij de anastomose niet doorgankelijk was. Dit onderzoek laat zien dat het mogelijk is om een ovarium met succes te transplanteren (en de vaatsteel microchirurgisch te anastomoseren) naar de voorste buikwand.

In hoofdstuk 5 wordt onderzocht of het mogelijk is een heel ovarium uit te nemen, in te vriezen, te ontdooien, en te transplanteren met microchirurgische anastomose van de ovariële vaten op de diepe inferieure epigastrische vaten. Er werd een bilaterale laparoscopische ovariectomie uitgevoerd bij 17 gesynchroniseerde ooien. In een deel van de dieren werden beide eierstokken gecryopreserveerd met behoud van 
hun vaatsteel. In een deel van de dieren werden beide eierstokken gecryopreserveerd met behoud van hun vaatsteel. In een tweede groep dieren werden ovariële corticale strips afgenomen van elk ovarium en gecryopreserveerd. Na ontdooien werden de folliculaire vitaliteit en apoptose beoordeeld in één ovarium. Het andere ovarium werd getransplanteerd met microchirurgische technieken naar de buikwand (groep 1). In groep 2 werden de corticale strips op de voorste buikwand gehecht. De ovaria en de corticale strips werden na 8 tot 10 dagen verwijderd en histologisch onderzocht. Er werden geen significante verschillen gevonden in de apoptose waarden en de folliculaire vitaliteit tussen de 2 groepen. In groep 1 was in alle gevallen sprake van een doorgankelijkheid van de anastomose onmiddellijk nadat deze werd aangelegd, en in $27 \%$ na 8 tot 10 dagen. Postoperatieve FSH spiegels waren gelijk aan de preoperatieve waarden bij dieren met een doorgankelijke anastomose. In groep 2 waren de postoperatieve FSH spiegels significant hoger dan de preoperatieve. Dit onderzoek laat zien dat het invriezen, ontdooien en transplanteren van hele ovaria een haalbare optie is terwijl het eveneens aantoont dat het transplanteren van verse of bevroren/ ontdooide ovaria naar de voorste buikwand met anastomose van de vaatvoorziening tot een herstel van ovariumfunctie kan leiden.

In hoofdstuk 6 wordt onderzocht of het transplanteren van hele ovaria of ovariële corticale strips antistofvorming tegen ovariumweefsel tot gevolg kan hebben. Anti-ovarium antistoffen (AOA) werden in serum gemeten d.m.v. een indirecte immunofluorescentie assay die gebruikt maakt van commercieel beschikbare apen- en schapenovariumpreparaten als antigeen. Anti-ovarium antistoffen werden slechts in 1 postoperatief serumsample aangetroffen na transplantatie van een heel ovarium met een occlusie van de anastomose bij follow-up onderzoek, vergeleken met geen enkele positieve serumbevinding preoperatief of ten tijde van de transplantatie. Dit onderzoek laat zien dat orthotope transplantatie van een heel ovarium of van ovariële corticale strips geen immuunrespons induceert tegen ovariële antigenen.

In hoofdstuk 7 wordt een onderzoek beschreven dat het invriezen van een heel ovarium vergelijkt met het invriezen van ovariële corticale strips. Twee vrouwen, die wegens benigne afwijkingen een ovariëctomie ondergingen doneerden hun ovaria voor wetenschappelijk onderzoek. Bij beide patiënten werd 1 van de ovaria gebruikt om ovariële corticale strips te verkrijgen en te cryopreserveren (met een langzaam invriesprotocol). Het andere ovarium werd in zijn geheel ingevroren met behoud van de vaatsteel.

$\mathrm{Na}$ ontdooien werd de follikelvitaliteit begroot, werd histologisch onderzoek gedaan, werd een TUNEL assay verricht en een immunoperoxidasekleuring van het ovarium- 
weefsel. Niet gecryopreserveerd ovariumweefsel diende als controle. De overall vitaliteit van de primordiale follikels bedroeg $75 \%$ respectievelijk $78 \%$ in de in hun geheel ingevroren en ontdooide ovaria, en $81 \%$ respectievelijk $83 \%$ in de ingevroren ovariële corticale strips. De primordiale follikelaantallen, tekenen van necrose, apoptose en de expressie van $\mathrm{Bcl}-2$ en p53 eiwitten verschilden niet tussen de in hun geheel ingevroren ovaria en de ingevroren ovariële corticale strips. Dit onderzoek laat zien dat cryoperfusie en cryopreservatie van hele humane ovaria kan worden verricht met behoud van een uitstekende vitaliteit van de oppervlakkige en diepe weefsels indien gebruik gemaakt wordt van een langzaam vriesprotocol.

In hoofdstuk 8 worden de diverse chirurgische technieken beschreven die gebruikt werden bij het wegnemen en heterotopisch terugtransplanteren van hele ovaria met microchirurgische anastomosering. 21 gesynchroniseerde Merinoschapen werden gebruikt om de ovaria (met behoud van hun vaatvoorziening) weg te nemen. Bij 6 dieren werd een verse autotransplantatie van de ovaria uitgevoerd, terwijl bij 15 dieren een autotransplantatie van ingevroren en weer ontdooide ovaria werd uitgevoerd. De ovariële vaten werden geanastomoseerd op de diepe inferieure epigastrische vaten met gebruikmaking van end-to-end, end-to-side, respectievelijk fishmouth technieken, bij respectievelijk 8, 6 en 7 schapen. De doorgankelijkheid van de anastomose, de ischemietijd en hormonale functies alsmede histologie werden onderzocht. Bovendien werd de chirurgische techniek van het uitnemen van de ovaria bij twee vrouwen beschreven. Ook werden de mogelijke autotransplantatieplaatsen bij vrouwen beschreven. De fishmouth techniek, die bedoeld is om een discrepantie tussen vaatdiameters te compenseren, ging gepaard met een significant langere ischemie tijd vergeleken met de end-to-end en met de end-to-side anastomose. Mocht er ooit overwogen worden om op deze wijze ovaria te verwijderen bij vrouwen dan lijkt een laparoscopische techniek de meest aangewezene. Dit onderzoek laat tevens zien dat de arteria en vena epigastrica inferior waarschijnlijk de meest geschikte vaten zijn voor heterotopische anastomosering van de ovariële vaatsteel. Bovendien laat de end-toend anastomosetechniek de beste doorgankelijkheid zien van de transplantaten. De end-to-side anastomose daarentegen is superieur aan de fishmouthanastomose voor het compenseren van een verschil in vasculaire diameter tijdens de transplantatie.

In hoofdstuk 9 wordt een systematisch review gepresenteerd van het resultaat van transplantatie van ovariumweefsel voor het behoud van de vruchtbaarheid bij vrouwen met een hoog risico op prematuur ovarieel falen. De literature search gebruikte zoektermen die betrekking hadden op ovariumtransplantatie en reproductieve uitkomst. Het aldus samengestelde literatuuroverzicht betrof 'peer reviewed' artikelen over zwanger- 
schappen na ovariumweefseltransplantatie (Ovarian Tissue Transplantation, OTT) bij mensen. Er was geen taalrestrictie voor de publicaties. Patiënten met een FSH >30 IU/L ten tijde van de OTT werden geïncludeerd in de meta-analyse om de tijd tot het weer op gang komen van ovariële functie (OvF) (gedefinieerd als menstruatie of follikelgroei bij echoscopie) vast te stellen. Secundaire uitkomstmaten waren korte- en lange-termijn OvF en zwangerschap na OTT. Voor dit review werden 47 casus (22 originele artikelen) opgespoord. De mediane leeftijd van de vrouwen was 36 jaar (spreiding 15-49 jaar). OTT werd uitgevoerd om POF te behandelen bij 28 vrouwen, om POF te voorkomen bij 16 vrouwen, om infertiliteit te behandelen bij 2 vrouwen, en bij toeval bij één vrouw tijdens ovariectomie. Bij alle 24 vrouwen met een FSH $>30$ IU/L ten tijde van de OTT trad herstel van OvF op na een mediane tijd van 120 dagen (spreiding 60-244 dagen). Verse, heterologe en grotere OTT deden de kans op herstel van OvF toenemen [Hazard Ratio 2,4 (95\% Cl 1-5.8, p=0,059), resp. $10.0(95 \% \mathrm{Cl}$ 2.6-48.3, $\mathrm{p}<0,001)$, resp. $1.7(95 \% \mathrm{Cl} 1.1-2.5, \mathrm{p}=0,013)$ ]. Bij geen enkele vrouw is de gerapporteerde follow-upduur na herstel van OvF momenteel al meer dan twee jaar. Bij 4 vrouwen was er nog actieve OvF 1 jaar na het begin van het herstel van OvF. Binnen 6 maanden na herstel van OvF trad bij 4 vrouwen opnieuw POF op. Alle 4 hadden zij gecryopreserveerde, autologe ovariële corticale strips ontvangen en allen hadden herstel van OvF meer dan 90 dagen na OTT. Van alle 47 vrouwen die OTT ondergingen waren er 27 die vervolgens zwanger wilden worden. Tijdens de periode van follow-up werden 9 zwangerschappen bij 8 vrouwen gemeld. Dit leidt tot een geschatte cumulatieve zwangerschapsfrequentie binnen 12 maanden van $36 \%(95 \% \mathrm{Cl}$ $18-59 \%$ ). De geboorte van een gezond kind à terme werd tot heden 3 keer $(11 \%$, 95\% Cl 2-29\%) gemeld. Alle vrouwen die na OvF-herstel IVF ondergingen toonden een 'poor response'. Na IVF werden 3 zwangerschappen gemeld.

Deze analyse toont dat, hoewel herstel van OvF voorkomt na OTT bij vrouwen met POF, de mate van functieherstel wisselt en slechts van beperkte duur is, met een korte 'graft survival'.

In hoofdstuk 10 worden de resultaten van het eigen onderzoek besproken en worden toekomstige onderzoeksmogelijkheden beschreven.

Toekomstperspectief.

Technisch is het een hele uitdaging maar toch beschouwen wij de cryopreservatie en autotransplantatie van hele ovaria bij zoogdieren met gebruikmaking van microchirurgische technieken als een betrouwbare mogelijkheid voor het onderzoek naar het herstel van ovarieel falen na het uitvallen van ovariële functies, het voorkomen van uitsterven van bedreigde diersoorten, en voor het onderzoek naar de vroege follikel- 
rijping. De beperkte functionele overleving van getransplanteerde ovariële corticale strips is gedeeltelijk het gevolg van de lagere totale follikelaantallen in het transplantaat vergeleken met het getransplanteerde hele ovarium. Bovendien gaat een geschat percentage van $70 \%$ der primordiale follikels in het transplantaat verloren als gevolg van ischemie- revascularisatieschade. Een langdurig herstel van ovariële functie kan worden bereikt met het cryopreserveren en transplanteren van hele ovaria aangezien dit niet alleen het maximum aantal follikels voor transplantatie oplevert maar ook, t.g.v. de onmiddellijke revascularisatie van het transplantaat, het secundaire verlies van follikels t.g.v. ischemie na het transplanteren vermindert. Het cryopreserveren van hele ovaria kent nog diverse technische uitdagingen. Ondanks de talrijke berichten over het succes van cryopreservatie van hele ovaria bij ratten en muizen t.g.v. effectieve cryoprotectant penetratie via eenvoudige diffusie is er veel minder succes bij grotere zoogdieren, wier ovaria groter zijn en meer fibreus weefsel bevatten.

Daarom dient de techniek van cryoperfusie die in dit proefschrift beschreven wordt verfijnd te worden en uitgeprobeerd bij diverse andere diersoorten. Toekomstig onderzoek dient zich te richten op de vraag hoe cryopreservatieprotocollen kunnen worden geoptimaliseerd voor de vele verschillende weefsel- en celtypes in het ovarium, zoals stroma, follikelcellen, eicellen en vaatweefsel, waarbij men zich dient te realiseren dat er waarschijnlijk geen invriesmethode bestaat die voor al deze afzonderlijke weefseltypes tegelijkertijd optimale resultaten laat zien. De resultaten van cryopreservatieprotocollen alsmede ischemische beschadiging van de diverse cellulaire componenten van het ovarium dienen in verschillende diersoorten onderzocht te worden, alsook bij de mens. De dynamiek van getransplanteerd en/of gecryopreserveerd/ontdooid ovariumweefsel is vergelijkbaar, maar verschilt van de dynamiek van vers getransplanteerd ovariumweefsel. Het meeste onderzoek tot heden laat een goede follikelvitaliteit zien na cryopreservatie, vergelijkbaar met vers ovariumweefsel, echter dit is meestal onderzocht met behulp van de trypaanblauw-exclusietest en histologische kleuringen. Geen van beide meet echter celvitaliteit in de zin van functionele activiteit. Er bestaat derhalve behoefte aan een meer gedetailleerde functionele onderzoeksmethodiek van de vitaliteit van ovariumweefsel na cryoperfusie, cryopreservatie en ontdooien. Hierbij kan men denken aan CFDA SE en PI vitaliteitskleuringen om de vitaliteit van gecryopreserveerd en weer ontdooid ovariumweefsel te onderzoeken. Deze kleuringstechnieken meten de onmiddellijke overleving na ontdooien. Er is tot nu toe geen onderzoek verricht naar de lange termijnoverleving van gecryopreserveerd en weer ontdooid ovariumweefsel. Er zou onderzoek kunnen worden gedaan naar de lange termijnoverleving met behulp van het bepalen van bijvoorbeeld Ki67 expressie, BrdU 
uptake en PCNA immunohistochemische kleuring.

Vanwege het feit dat het verlies van celvitaliteit na cryopreservatie niet alleen het gevolg kan zijn van necrose t.g.v. intracellulaire ijskristalformatie en osmotische stress maar ook van apoptose zou ingrijpen in apoptotische pathways de overall uitkomst kunnen verbeteren. Het toevoegen van anti-apoptotische middelen aan cryopreservatiemedia valt dan ook te overwegen. Dit zou celdood t.g.v. vriezen/dooien kunnen verminderen en daarmee de efficiency van de procedure verbeteren. Sfingosine-1 fosfaat (S-1-P) is zo'n anti-apoptotisch middel dat de ceramide-geïnduceerde apoptotische pathway kan blokkeren en waarvan is aangetoond dat het folliculaire apoptose t.g.v. bestraling of chemotherapie kan verminderen en follikeloverleving na autotransplantatie bij schapen kan verbeteren. Men zou daarom kunnen overwegen S-1-P toe te voegen aan het cryopreservatie medium om het verloren gaan van follikels t.g.v. apoptose te verminderen en aldus de overlevingsduur van de graft te vermeerderen. Evenzo kunnen technieken gericht op Bcl-2 of p53 eiwitexpressie therapeutische consequenties hebben bij het voorkomen van ovariële afwijkingen t.g.v. ischemie schade.

Ook is meer onderzoek nodig naar het effect van verschillende periodes van ischemische opwarming van te transplanteren ovaria. Het endocriene en ovulatoire succes van de transplantatie kan gemeten worden en vergeleken met de duur van de ischemie en de expressie van $\mathrm{Bcl}-2$ en p53. Ook het vormen van auto-antistoffen na reïmplantatie kan worden onderzocht.

De ultieme uitkomstmaat na het cryopreserveren en transplanteren van hele ovaria zou het bewerkstelligen van een zwangerschap na reïmplantatie zijn. Nadat bij verschillende diersoorten dit werd onderzocht voor de transplantatie van ovariële corticale strips werden recent 3 geboortes gemeld na gebruikmaking van een vergelijkbare techniek bij mensen. Wij denken dat wij dicht bij een vergelijkbaar succes in het diermodel zijn wat betreft het transplanteren van gecryopreserveerde hele ovaria. Tegen deze achtergrond denken wij dat wij het transplanteren van hele ovaria bij mensen kunnen gaan overwegen. Verwacht mag worden dat anastomose van de ovariële vaten bij mensen technisch gemakkelijker zal verlopen gezien het rechte verloop van de vaten en de relatief grote diameter, op voorwaarde dat acceptorvaten gevonden kunnen worden met een vergelijkbare diameter.

De criteria die werden vastgelegd in het laatste hoofdstuk van dit proefschrift duiden erop dat waarschijnlijk de arteria en vena epigastrica inferior bij de mens de beste mogelijkheden bieden. Het wachten is op de eerste patiënt die zulk een procedure zou willen ondergaan. 


\section{Abbreviations:}

$\begin{array}{ll}\text { ASRM } & \text { American Society of Reproductive Medicine } \\ \text { AFC } & \text { Antral follicle counts } \\ \text { AMH } & \text { Anti-Mullerian hormone } \\ \text { ANOVA } & \text { Analysis of variance } \\ \text { AOA } & \text { Anti-ovarian antibodies } \\ \text { ART } & \text { Assisted reproductive technologies } \\ \text { Bcl-2 } & \text { B-cell lymphoma gene } \\ \text { Bmp } & \text { Bone morphogenic protein } \\ \text { BMP-15 } & \text { Bone morphogenic protein } \\ \text { BSO } & \text { Bilateral salpigo-oophrectomy } \\ \text { cAMP } & \text { Cyclic adenosine monophosphate } \\ \text { cGy } & \text { Centigray } \\ \text { Cl } & \text { Confidence intervals } \\ \text { CNS } & \text { Central nervous system } \\ \text { COS } & \text { Controlled ovarian stimulation } \\ \text { CPA } & \text { Cryoprotective agent } \\ \text { C-T } & \text { Cryopreserved-thawed } \\ \text { DMSO } & \text { Dimethylsulfoxide } \\ \text { DNA } & \text { Deoxy ribonucleic acid } \\ \text { E2 } & \text { Estradiol } \\ \text { ER- } \square / \square & \text { Estrogen receptor alpha and beta } \\ \text { ET } & \text { Embryo transfer } \\ \text { FCS } & \text { Fetal calf serum } \\ \text { FSH } & \text { Follicle stimulating hormone } \\ \text { FSH/FSHR } & \text { Follicle Stimulating hormone and receptor } \\ \text { GO Phase } & \text { Gap 0 phase } \\ \text { G1 phase } & \text { Gap1 phase } \\ \text { G2 phase } & \text { Gap2 phase } \\ \text { GDF-9 } & \text { Growth differentiation factor-9 } \\ \text { GnRH } & \text { Gonadotropin-releasing hormone } \\ \text { GnRH-a } & \text { Gonadotropin-releasing hormone analogue } \\ \text { HCG } & \text { Human Chorionic gonadotrophins } \\ \text { HR } & \text { Hazard ratio } \\ \text { IACUC } & \text { Institutional Animal Care and Ewe Committee } \\ \text { IRB } & \text { Institutional Review Board } \\ & \end{array}$


IVF

LDL

$\mathrm{LH}$

LH/LHR

Mih \& Msh

MOOS

MVD

NOS

OTT

OvF

P53

PAS

PBS

PGCs

PGE2

POF

$S$ phase

SART

Scf

$\mathrm{Scp}$

SD

SEM

Smad

TGFB

TUNEL
In vitro fertilization

Low density lipoprotein

luteinizing hormone

Luteinizing hormone and receptor

Mismatch recognition and repair proteins

Meta-analysis Of Observational Studies in

Epidemiology

Microvessel density

Newcastle-Ottawa Scale

Ovarian tissue transplantation

Ovarian function

Protein 53

Periodic acid Schiff

Phosphate-buffered saline

Primordial germ cells

Prostaglandin E2 and Cyclo-oxygenase 2

premature ovarian failure

Synthesis phase

Society for assisted reproduction technology

Stem cell factor

Synaptonemal complex protein

Standard deviation

Standard error of the mean

C.elegans gene Sma and Dorsophila gene mad Transforming growth factor- $\beta$

Terminal deoxynucleotidyl transferase (TdT)mediated dUTP Digoxigenin nick-end labeling technique 


\section{Appendix 1}

\section{NEWCASTLE - OTTAWA QUALITY ASSESSMENT SCALE- Modified from COHORT STUDIES [Reproductive outcomes after OTT]}

Note: A study can be awarded a maximum of one star for each numbered item within the Selection and Outcome categories. A maximum of two stars can be given for Comparability

\section{Selection}

1) Representativeness of the exposed cohort

a) Truly representative of the patients who are clinically in need for 0TT

b) Somewhat representative of the patients who are clinically in need for 0TT

c) Selected group of users eg nurses, volunteers

d) No description of the selection of the patients

2) Selection of the non exposed cohort
a) Drawn from a similar population that serve the needs of the comparison
b) Drawn from a different source
c) Did not used a control group at all .

3) Ascertainment of Premature ovarian failure
a) FSH with documented levels before the procedure and amenorrhea
b) Only FSH
c) History of amenohrea without FSH or non menopausal FSH
d) No description

4) Demonstration that outcome of interest (return of ovarian function) was not present at time of transplant
a) yes
b) no

\section{Comparability}

1) Comparability of cohorts on the basis of the design or analysis

a) Study controls for hormonal changes specifically FSH during follow up

b) Study controls for any other variable in addition to FSH $\square$

\section{Outcome}

1) Assessment of outcome
a) Independent blind assessment
b) Record linkage
c) Self report
d) No description

2) Was follow-up long enough for outcomes to occur
a) yes
b) no

3) Adequacy of follow up of cohorts
a) Complete follow up - all subjects accounted for
b) Subjects lost to follow up unlikely to introduce bias - small number lost $<10 \%$
c) Follow up rate $<80 \%$ and no description of those lost
d) No statement 
Appendix 2

\section{Appendix 2}

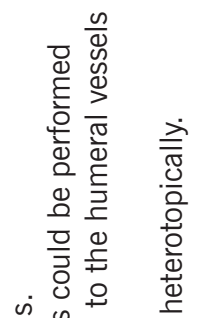

. $\frac{\omega}{\omega} \cdot \frac{n}{n}$ 을

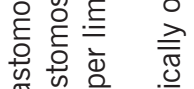

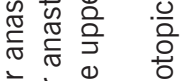

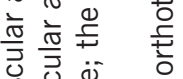

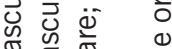

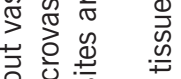

을 告

范势

तั

产产贾

드으드몽

잉 ह

든음 흠

की 힌

휜든

윽 등

엥 응 응 능 음

듕네

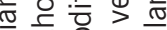

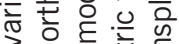

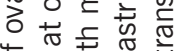

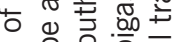

ข 을 응

후을 등흐 항

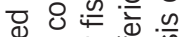

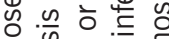

응 은

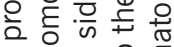

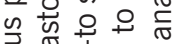

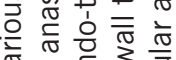

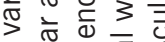

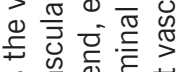

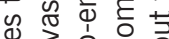

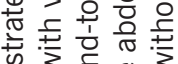

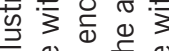

券

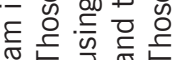

可

告

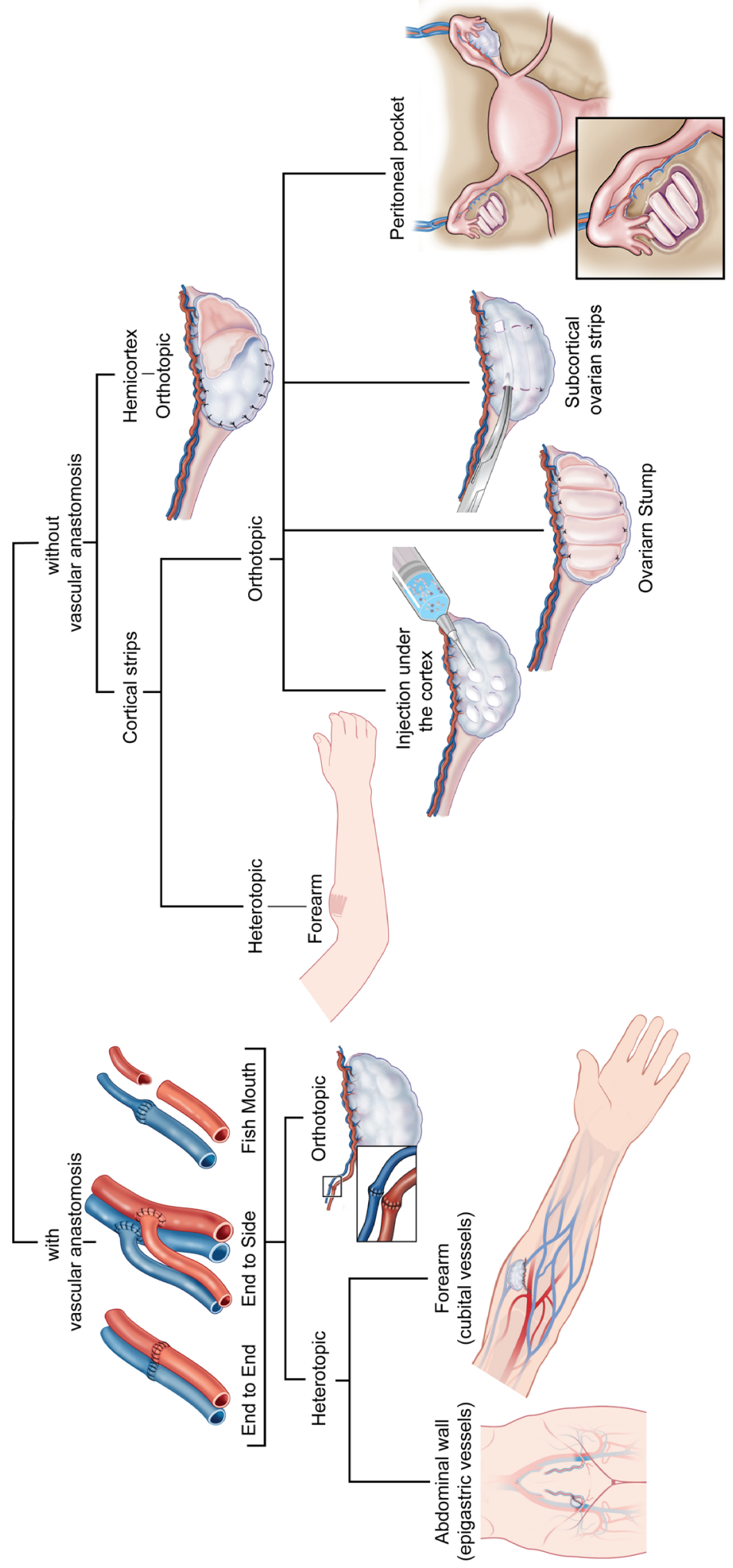




\section{Acknowledgment}

I would like to express my deep gratitude and appreciation to Professor dr. Hans Evers MD, PhD, FRCOG, for his pivotal input, valuable instructions and continuous encouragement during all steps of this thesis from inception to completion. His sincere guidance was of extreme help to complete this work. During the preparation of this thesis, Dr Evers suggestions added much to the hypothesis, quality, format and scientific contents. I very much value his mentorship.

I would like also to express my deepest appreciation to Professor Tommaso Falcone MD, Chief of Surgery and Chairman, Obstetrics and Gynecology, Cleveland Clinic Foundation, Cleveland, Ohio, USA for his valuable assistance, great professional help and fruitful guidance throughout my entire stay in the US. He taught me the principals of reproductive biology and minimally invasive surgery. He provided a wonderful opportunity to improve my clinical and research skills. He initiated, supported and closely supervised this novel technology at the Cleveland Clinic Foundation. His help and support was and will be extremely valuable throughout my career.

I also value very much having the opportunity to learn from and work with Professor Robert F. Casper MD, Professor of Obstetrics and Gynecology, University of Toronto, Ontario, Canada. He taught me the principals of reproductive endocrinology and assisted reproduction during my fellowship under his supervision in the Division of Reproductive Sciences at department of Obstetrics and Gynecology, University of Toronto, Canada. Dr. Casper's help and role in my career is very much appreciated.

I have had the valuable opportunity to be trained at the Obstetrics and Gynecology Departments at the University of Assiut, Egypt; the University of Toronto, Canada; Case Western Reserve University and the Cleveland Clinic Foundation, Cleveland, Ohio, USA. I am greatly thankful to all staff members, colleagues and scientists in these reputable institutes for tremendous assistance and generous help.

Finally, this work could not have happened without the extraordinary help, continuous support and generosity of my family and without the divine blessings of God, the Merciful and the Compassionate. 


\section{Curriculum Vitae}

Dr. Mohamed Bedaiwy was born in El-Badary, Assiut, the Arab Republic of Egypt in 1968. He graduated from Assiut School of Medicine, Egypt in 1993 with an excellent grade with first class honors. He completed a residency in Obstetrics and Gynecology at the Department of Obstetrics and Gynecology, Assiut University Hospitals, Assiut, Egypt in 1997. He received his doctorate in 2003 through a combined program between the Cleveland Clinic Foundation (CCF)/ Lerner College of Medicine /Case Western Reserve University, Oh, USA and the University of Assiut, Egypt. The title of his doctorate thesis was (Prediction of Assisted Reproduction Outcome). He completed a fellowship in reproductive biology and minimally invasive surgery in the Cleveland Clinic Foundation, Cleveland, Ohio, USA under the supervison of Prof. Tommaso Falcone, chief of surgery and chairman of the Department of Obstetrics and Gynecology, CCF, USA. He also completed a reproductive endocrinology and IVF fellowship in the Division of Reproductive Sciences at department of Obstetrics and Gynecology, University of Toronto, Canada under the supervision of Prof. Robert F. Casper. He is a staff member in the department of Obstetrics and gynecology, University of Assiut, Egypt. Dr Bedaiwy authored and co-authored 51 peer-reviewed papers, 8 book chapters, presented 82 presentations in international meetings. Dr. Bedaiwy received the Society of Reproductive Surgeons Award (SRS) in 2001 for his research and the Australian Fertility Society Travel Award from the European Society for Human Reproduction and Embryology (ESHRE) in 2003. He also received the Trainee Merit Award by the National Institute of Health and International Society of Andrology in 2001. He received the Serono In-Training Award by the Pacific Coast Reproductive Society (PCSR) in 2002 and three times the Best Video Award from the American Society for Reproductive Medicine (ASRM), at the 2001, 2002, and 2003 annual meetings. His special interest has been in the area of, ovarian tissue cryopreservation and transplantation, endometriosis pathophysiology, ovulation induction in poor responders and embryonic growth and IVF culture conditions. 


\section{Publications}

\section{Papers}

1. Bedaiwy MA, El-Nashar SA, Sharma RK, Falcone T. Effect of ovarian involvement on peritoneal fluid cytokine concentrations in endometriosis patients. Reprod Biomed Online 2007;14:620-625.

2. Bedaiwy MA, Falcone T. Harvesting and autotransplantation of vascularized ovarian grafts: approaches and techniques. Reprod Biomed Online 2007;14:360-371.

3. Bedaiwy MA, Mousa NA, Esfandiari N, Forman R, Casper RF. Follicular phase dynamics with combined aromatase inhibitor and follicle stimulating hormone treatment. J Clin Endocrinol Metab 2007;92:825-833.

4. Cogan S, Bedaiwy MA, Paraiso MF, Biscotti C. Healing patterns of bladder injuries incurred at laparoscopic hysterectomy: a histologic assessment. Int Urogynecol J Pelvic Floor Dysfunct 2007;18:49-52.

5. Mousa NA, Bedaiwy MA, Casper RF. Aromatase Inhibitors in the Treatment of Severe Endometriosis. Obstet Gynecol 2007;109:1421-1423.

6. Agarwal A, Said TM, Bedaiwy MA, Banerjee J, Alvarez JG. Oxidative stress in an assisted reproductive techniques setting. Fertil Steril 2006;86:503-512.

7. Bedaiwy M, Agarwal A, Said TM, Goldberg JM, Sharma RK, Worley S, Falcone T. Role of total antioxidant capacity in the differential growth of human embryos in vitro. Fertil Steril 2006;86:304-309.

8. Bedaiwy MA. Evaluation of the effect of the adoption of ultrasound guidance for embryo replacement on the pregnancy outcome for multiple providers. . MEFSJ 2006; Vol 11 No 2:127-134.

9. Bedaiwy MA, Casper RF. Treatment with leuprolide acetate and hormonal add-back for up to 10 years in stage IV endometriosis patients with chronic pelvic pain. Fertil Steril 2006;86: 220-222.

10. Bedaiwy MA, Falcone T, Goldberg JM, Sharma RK, Nelson DR, Agarwal A. Peritoneal fluid leptin is associated with chronic pelvic pain but not infertility in endometriosis patients. Hum Reprod 2006;21:788-791.

11. Bedaiwy MA, Falcone T, Mascha EJ, Casper RF. Genetic polymorphism in the fibrinolytic system and endometriosis. Obstet Gynecol 2006;108:162-168.

12. Bedaiwy MA, Forman R, Mousa NA, Al Inany HG, Casper RF. Cost-effectiveness of aromatase inhibitor co-treatment for controlled ovarian stimulation. Hum Reprod 2006;21:2838-2844.

13. Bedaiwy MA, Hussein MR, Biscotti C, Falcone T. Cryopreservation of intact human ovary with its vascular pedicle. Hum Reprod 2006;21:3258-3269. 
14. Bedaiwy MA, Paraiso MF. Reply to letter by Dionne. Int Urogynecol J Pelvic Floor Dysfunct 2006;17:302.

15. Goldberg JM, Bedaiwy MA. Transvaginal local injection of hyperosmolar glucose for the treatment of heterotopic pregnancies. Obstet Gynecol 2006;107:509-510.

16. Hussein MR, Bedaiwy MA, Falcone T. Analysis of apoptotic cell death, Bcl-2, and p53 protein expression in freshly fixed and cryopreserved ovarian tissue after exposure to warm ischemia. Fertil Steril 2006;85 Suppl 1:1082-1092.

17. Bedaiwy MA. Strategies for fertility preservation and gonadal protection during gonadotoxic chemotherapy and radiotherapy MEFSJ 2005; Vol 10 No 1, :342-349.

18. Bedaiwy MA, Falcone T. Technical challenges in freeze-thawing of human ovary. Fertil Steril 2005;83:1068-1069; author reply 1069-1070.

19. Bedaiwy MA, Falcone T, Goldberg JM, Attaran M, Sharma R, Miller K, Nelson DR, et al. Relationship between cytokines and the embryotoxicity of hydrosalpingeal fluid. J Assist Reprod Genet 2005;22:161-165.

20. Falcone T, Bedaiwy MA. Cryopreservation of intact ovaries--size is a variable? Fertil Steril 2005;83:1587; author reply 1588.

21. Falcone T, Bedaiwy MA. Fertility preservation and pregnancy outcome after malignancy. Curr Opin Obstet Gynecol 2005;17:21-26.

22. Hussein MR, Abou-Deif ES, Bedaiwy MA, Said TM, Mustafa MG, Nada E, Ezat A, et al. Phenotypic characterization of the immune and mast cell infiltrates in the human testis shows normal and abnormal spermatogenesis. Fertil Steril 2005;83:1447-1453.

23. Hussein MR, Bedaiwy MM, Ezat A, Ibraheem AF, Nayel M. Role of fine needle aspirate mapping and touch imprint preparations in the evaluation of azoospermia. Anal Quant Cytol Histol 2005;27:67-70.

24. Rizk A, Bedaiwy MA, Al- Inany H. Clomiphene-acetylcysteine combination as a new protocol to a friendly IVF cycle MEFSJ 2005; Vol 10 No 2:130-134.

25. Rizk AY, Bedaiwy MA, Al-Inany HG. N-acetyl-cysteine is a novel adjuvant to clomiphene citrate in clomiphene citrate-resistant patients with polycystic ovary syndrome.

Fertil Steril 2005;83:367-370.

26. Said TM, Agarwal A, Falcone T, Sharma RK, Bedaiwy MA, Li L. Infliximab may reverse the toxic effects induced by tumor necrosis factor alpha in human spermatozoa: an in vitro model. Fertil Steril 2005;83:1665-1673.

27. Bedaiwy MA, Falcone T. Ovarian tissue banking for cancer patients: reduction of post-transplantation ischaemic injury: intact ovary freezing and transplantation. Hum Reprod 2004;19:1242-1244.

28. Bedaiwy MA, Falcone T. Laboratory testing for endometriosis. Clin Chim Acta 2004; 340: 41-56. 
29. Bedaiwy MA, Falcone T, Mohamed MS, Aleem AA, Sharma RK, Worley SE, Thornton J, et al. Differential growth of human embryos in vitro: role of reactive oxygen species. Fertil Steril 2004;82:593-600.

30. Bedaiwy MA, Paraiso MF. Reply to letter by Dionne. Int Urogynecol J Pelvic Floor Dysfunct 2004.

31. Bedaiwy MA, Paraiso MF. Pelvic organ prolapse after uterine artery embolization for uterine myoma. Int Urogynecol J Pelvic Floor Dysfunct 2004;15:214-215.

32. Falcone T, Attaran M, Bedaiwy MA, Goldberg JM. Ovarian function preservation in the cancer patient. Fertil Steril 2004;81:243-257.

33. Noriega J, Bedaiwy M, Sharma R, Falcone T. Effect of tumor necrosis factor-alpha blocker (infliximab) on blastocyst development in vitro. Fertil Steril 2004;81:1704-1706.

34. Rezk A, Al-Inany H, Bedaiwy M. Multiple intravenous oxytocin injection may yield sperm in azoospermic men scheduled for TESE. . MEFSJ 2004; Vol 9 No 3:123-127.

35. Sokol Al, Paraiso MF, Cogan SL, Bedaiwy MA, Escobar PF, Barber MD. Prevention of vesicovaginal fistulas after laparoscopic hysterectomy with electrosurgical cystotomy in female mongrel dogs. Am J Obstet Gynecol 2004;190:628-633.

36. Agarwal A, Saleh RA, Bedaiwy MA. Role of reactive oxygen species in the pathophysiology of human reproduction. Fertil Steril 2003;79:829-843.

37. Bedaiwy MA, Falcone T. Peritoneal fluid environment in endometriosis. Clinicopathological implications. Minerva Ginecol 2003;55:333-345.

38. Bedaiwy MA, Jeremias E, Gurunluoglu R, Hussein MR, Siemianow M, Biscotti C, Falcone T. Restoration of ovarian function after autotransplantation of intact frozen-thawed sheep ovaries with microvascular anastomosis. Fertil Steril 2003;79:594-602.

39. Bedaiwy MA, Sharma RK, Alhussaini TK, Mohamed MS, Abdel-Aleem AM, Nelson DR, Thomas AJ, Jr., et al. The use of novel semen quality scores to predict pregnancy in couples with male-factor infertility undergoing intrauterine insemination. J Androl 2003;24:353-360.

40. Desai MM, Gill IS, Goel M, Abreu SC, Ramani AP, Bedaiwy MA, Kaouk JH, et al. Ureteral tissue balloon expansion for laparoscopic bladder augmentation: survival study. J Endourol 2003;17:283-293.

41. Esfandiari N, Falcone T, Bedaiwy MA, Agarwal A, Jeremias E, Sharma RK. Autologous transplantation of cryopreserved ovary induces the generation of antiovary antibodies in sheep. Fertil Steril 2003;80:1062-1064.

42. Jeremias E, Bedaiwy MA, Nelson D, Biscotti CV, Falcone T. Assessment of tissue injury in cryopreserved ovarian tissue. Fertil Steril 2003;79:651-653. 
43. Bedaiwy MA, Falcone T, Sharma RK, Goldberg JM, Attaran M, Nelson DR, Agarwal A. Prediction of endometriosis with serum and peritoneal fluid markers: a prospective controlled trial. Hum Reprod 2002;17:426-431.

44. Bedaiwy MA, Goldberg JM, Falcone T, Singh M, Nelson D, Azab H, Wang X, et al. Relationship between oxidative stress and embryotoxicity of hydrosalpingeal fluid. Hum Reprod 2002;17:601-604.

45. Cogan SL, Paraiso MF, Bedaiwy MA. Formation of vesicovaginal fistulas in laparoscopic hysterectomy with electrosurgically induced cystotomy in female mongrel dogs. Am J Obstet Gynecol 2002;187:1510-1513; discussion 1513-1514.

46. Falcone T, Bedaiwy MA. Minimally invasive management of uterine fibroids. Curr Opin Obstet Gynecol 2002;14:401-407.

47. Jeremias E, Bedaiwy MA, Gurunluoglu R, Biscotti CV, Siemionow M, Falcone T. Hetero topic autotransplantation of the ovary with microvascular anastomosis: a novel surgical technique. Fertil Steril 2002;77:1278-1282.

48. Shaker Sel D, Bedaiwy MA. Split testicular function testing in testicular reserve assessment. Lancet 2002;359:802.

49. Bedaiwy MA, Goldberg JM, Biscotti CV. Recurrent osseous metaplasia of the cervix after loop electrosurgical excision. Obstet Gynecol 2001;98:968-970.

50. Bedaiwy MA, Miller KF, Goldberg JM, Nelson D, Falcone T. Effect of metformin on mouse embryo development. Fertil Steril 2001;76:1078-1079.

51. Daitch JA, Bedaiwy MA, Pasqualotto EB, Hendin BN, Hallak J, Falcone T, Thomas AJ, Jr., et al. Varicocelectomy improves intrauterine insemination success rates in men with varicocele. J Urol 2001;165:1510-1513.

\section{Book Chapters}

1. Falcone T, Bedaiwy MA: Fertility preservation and pregnancy outcome after malignancy. In : Current Opinion in Obstetrics and Gynecology, Williams and Wilkins, London, 2005 Feb;17(1):21-6.

2. Falcone T, Bedaiwy MA: Minimally Invasive management of uterine fibroids. In: Current Opinion in Obstetrics and Gynecology, Williams and Wilkins, London, 2002 Aug;14(4):401-7.

3. Falcone T, Bedaiwy MA: Serum and Peritoneal Markers of Endometriosis. In, Endometriosis: advances and Controversies, Togas Tulandi and David Redwine 2004.

4. Bedaiwy MA, Falcone T. Endometriosis. In: Encyclopedia of Women's Health. Kluwer Academic/Plenum Publisher. Editors: Sana Lou and Martha Sajatovic.

Pages 246-8; 2005.

5. Bedaiwy MA, Falcone T. Laparoscopy. In: Encyclopedia of Women's Health. Kluwer Academic/Plenum Publisher. Editors: Sana Lou and Martha Sajatovic.

Pages 257-8; 2005. 
6. Bedaiwy MA, Falcone T. Endometriosis and Adenomyosis. In: Sokol \&Sokol: Requists in Obstetrics and Gynecology: General Gynecology. Elsevier, Philadelphia, USA. 2007, 321-347.

7. Bedaiwy MA, Falcone T. Fertility preservation in cancer patients. In: Textbook of Clinical Reproductive Medicine and Surgery. Editors: Tommaso Falcone and William W. Hurd, Elsevier, Philadelphia, USA. 2007, 485-497.

8. Bedaiwy MA, Falcone T. Fertility preservation in cancer patients. In: Title: Textbook of Infertility and Assisted Reproduction Editor: Botros Rizk, Juan Garcia-Velasco, Hassan Sallam, Antonis Makrigiannakis. Publisher: Cambridge University Press

\section{Abstracts}

1. Pasqualotto, E.B., Bedaiwy M A., Daitch, J.A., Hendin, B.N., Thomas, A.J., Jr., Nelson, D.R., and Agarwal, A. (1999): Fertility outcome in patients undergoing intrauterine insemination after varicocelectomy. In: 55th Annual Meeting of the American Society for Reproductive Medicine, Toronto, Ontario, Canada, September 25-30, Abstract \#153.

2. X. Wang, Bedaiwy M., M. Singh, J.M. Goldberg, R.K. Sharma, A. Agarwal, M. Attaran, and T. Falcone (2000): Is there a relationship between oxidative stress and the embryotoxicity of hydrosalpinx fluid on mouse embryo development? In: Cleveland Clinic Foundation 20th Annual Research Day, October 29.

3. Singh M Bedaiwy M A., Sharma R, Miller K Attaran M, Goldberg J, Falcone T Agarwal A (2000) Relatinship between oxidative stress parametrs and embryotoxicity of hydrosalpingeal fluid?. In: 56th Annual Meeting of the American Society for Reproductive, Medicine, San Diego CA.

4. Bedaiwy M.A.,T.K. Alhaussaini, M.S. Mohamed, A.M. Abdel Aleem, R.K. Sharma, D.R. Nelson, T. Falcone, A.J. Thomas, Jr., and A. Agarwal (2001): Novel semen quality scores can predict pregnancy in patients with male factor infertility undergoing intrauterine insemination, In: VII International Congress of Andrology, June 15-19, Montreal Canada, Abstract \#P3/4-116.

5. Bedaiwy, M., Al-Hussaini, T., Mohamed, M.S., Abdel-Aleem, A.M., Nelson, D.R., and Agarwal, A. (2001): Use of semen quality scores in advising patients with male factor infertility considering intrauterine insemination. In: 57th Annual Meeting of the American Society of Reproductive Medicine, October 20-25, Orlando, FL, Abstract\#38, p S15.

6. Bedaiwy M.A., Goldberg J., Wang X., Sharma R .K., Miller K., Agarwal A., Attaran M., and Falcone T. (2001): Is there a relationship between cytokines and the embryotoxicity of hydrosalpinx fluid? In: 17th Annual Meeting of the European Society of Human Reproduction and Embryology, July 1-4, Lausanne, Switzerland, Abstract \#189 vol 16 p174.

7. Bedaiwy M.A., Falcone, T., Sharma, R.K., Goldberg, J.M., Attaran, M., Nelson, D.R., Agarwal, A (200I) Prediction of endometriosis with serum and peritoneal fluid markers: a prospective controlled trial. In; The second Royan international award, September, 9-11, Tehran, Iran, p 25. 
8. Bedaiwy M. A., Jeremias E., Guruniuoglu R., Miller K., Harasaki H., Falcone T Novel Approach for Cryopreservation and Transplantation of Intact Ovary. In: 21st Annual Research day of the cleveland clinic foundation, 25 October 2001, The Cleveland Clinic Foundation, Cleveland, Oh, USA.

9. Bedaiwy, M.A., Miller, J.F., Goldberg, J.M., Attaran, M., Nelson, D.R., Agarwal, A., and Falcone, T. (2001): Is there any embryotoxic effect of metformin? In: CCF 21st Annual Research Day, October 25, Abstract \#114.

10. Bedaiwy, M.A., Falcone, T., Goldberg, J.F., Attaran, M., Nelson, D.R., Sharma, R.K., and Agarwal, A. (2001): systemic cytokine production in endometriosis patients: prospective controlled study, In: CCF 21st Annual Research Day, October 25, Abstract \#115.

11. Bedaiwy, M.A., Falcone, T., Goldberg, J.F., Attaran, M., Nelson, D.R., Sharma, R.K., (2001): Local cytokine production and reactive oxygen species in the peritoneal fluid of endometriosis patients: prospective controlled study. In: CCF 21st Annual Research Day, October 25, Abstract \# 116.

12. Bedaiwy M A, AL-Hussaini T, Mohamed M S, Abdel-Aleem A M, Nelson D, Agarwal A(2001): Utility of novel semen quality scores in advising patients with male factor infertility considering intrauterine insemination, In: CCF 21st Annual Research Day, October 25, Abstract \#117.

13. Bedaiwy M A, Jeremias, E, Margossian H, Biscotti C, Sharma R, Falcone T. Assessment of apotosis in cryopreserved ovarian tissue: Sopurces of tissue injury, In: CCF 21st Annual Research Day, October 25, Abstract \#118.

14. Bedaiwy M A, Falcone T, Goldberg J M, Attaran M, Nelson D, Sharma R. Systemic cytokine production in endometriosis patients: prospective controlled study In:

57th Annual Meeting of the American Society of Reproductive Medicine, October 20-25, Orlando, FL, Abstract \#112, p S150.

15. Bedaiwy M A, Falcone T, Goldberg, J M, Attaran M, Sharma R K, Nelson D. Local cytokine production and reactive oxygen species in the peritoneal fluid of endometriosis patients: prospective controlled study. In: 57th Annual Meeting of the American Society of Reproductive Medicine, October 20-25, Orlando, FL, Abstract \#174, p S65.

16. Bedaiwy M A, Jeremias E, Margossian H, Biscotti C, Sharma R, Falcone T The importance of ischemia time and tissue size in the preparation of ovarian tissue for cryopreservation. In: 57th Annual Meeting of the American Society of Reproductive Medicine, October 20-25, Orlando, FL, Abstract \#210, p S79.

17. Bedaiwy M A, Jeremias E, Guruniuoglu R, Miller K, Harasaki H, Falcone T, Cryoperfusion protocol for the long-term preservation of an entire ovary In: 57th Annual Meeting of the American Society of Reproductive Medicine, October 20-25, Orlando, FL, Abstract \#209, p S79.

18. Jeremias E, Bedaiwy M A, Gurunluoglu R, Biscotti C, Siemionow M, Falcone T Novel surgical technique for ovarian autotransplantation,. In: 57th Annual Meeting of the American Society of Reproductive Medicine, October 20-25, Orlando, FL, Abstract \#112, p S43. 
19. Singh, I., Bedaiwy, M., Hatwal, A., Kumar, A., and Agarwal, A. (2001): Increased pregnancy rates with metformin and clomiphene citrate in non-obese patients with polycystic ovarian syndrome: prospective randomized study. In: 57th Annual Meeting of the American Society of Reproductive Medicine, October 20-25, Orlando, FL, Abstract \#248, p S94.

20. Cogan, S L. Paraiso M R., Bedaiwy M A,. (2001) Formation of Vesicovaginal Fistulas in Laparoscopic Hysterectomy with Electrosurgical Induced Cystotomy.In: 22nd annual Sceintific meeting of The American Urogynecology Society (AUGS), October 25-27, Chicago,IL Abstract \#58, p 78.

21. Cogan, S L. Paraiso M R., Bedaiwy M A,. (2001) The role of coagulation and suture placement into the bladder in forming vesicovaginal fistulas after laparoscopic hysterectomy. In: 30th annual meeting of The American Association of Gynecologic Laproscopists (AAGL), Novemeber 16-19, San Fransico, Ca, Abstract \#26, p S8.

22. Bedaiwy M A, Jeremias E., Guruniuoglu R., Miller K., Harasaki H., Falcone T. (2001) Novel Approach for Cryopreservation and Transplantation of Intact Ovary. In: Middle east fertility society, 8 th annual meeting Novemeber, 7-10, Manama, Bahrin.

23. Bedaiwy M A, Falcone, T., Sharma, R.K., Goldberg, J.M., Attaran, M., Nelson, D.R., Agarwal, A.(2002) Effect of ovarian involvement on peritoneal fluid cytokine levels in endometriosis patients. In: VIII World Congress of Endometriosis by the American Society for Reproductive Medicine, February 24-27, San Diego, CA, Abstract \#028, p S10.

24. Bedaiwy, M.A., Falcone, T., Goldberg, J., Attaran, M., Nelson, D.R., and Agarwal, A.(2002): Prediction of endometriosis with serum and peritoneal fluid markers: a prospective controlled trial. In: VIII World Congress of Endometriosis by the American Society for Reproductive Medicine, February 24-27, San Diego, CA, Abstract \#013, p S5.

25. Bedaiwy M A, Jeremias E, Guruniuoglu R, Biscotti C, Siemianow M, Falcone T, (2002): Autotransplantation of intact cryopreserved-thawed ovary: a minimally invasive approach In: 50th Pacific Coast Reproductive Society (PCRS) Meeting, April 17-21, Palms Springs Ca, USA, Abstract \#015, p S11.

26. Bedaiwy M A, Jeremias E, Gurunluoglu R, Hussein M, Biscotti C, Siemionow M, Falcone T. (2002): Combined approach for detection of apoptosis in cryopreserved thawed ovarian tissue prior to autotransplantation.In: The 4th Annual Transplant research day Case Western Reserve University May 10, Cleveland, Oh, Abstract\#34.

27. Bedaiwy MA, Jeremias E, Gurunluoglu R, Hussein M, Biscotti C, Siemionow M, Falcone T. (2002): Restoration of endocrine function after autologous transplantation of intact frozen-thawed mammalian ovary: a novel approach In: The 4th Annual Transplant research day Case Western Reserve University May 10, Cleveland, Oh, Abstract\#52.

28. Bedaiwy MA, Jeremias E, Gurunluoglu R, Hussein M, Biscotti C, Siemionow M, Falcone T. (2002): Follicular viability and apoptosis rates after cryoperfusion of intact mammalian ovary. In: The 4th Annual Transplant research day Case Western Reserve University May 10, Cleveland, Oh, Abstract\#1. 
29. Bedaiwy M A, , Kurt Miller Falcone T, Nelson D, AbdelAleem A, Mohamed M, Al Haussaini T, Agarwal. (2002): Differential growth of human embryos in vitro: role of reactive oxygen species In: ESHRE 18th Annual meeting, July 1-3, Vienna, Austeria, Abstract\#109 p 38.

30. Bedaiwy M A, Jeremias E, Guruniuoglu R, Hussein M R, Biscotti C, Falcone T, (2002): Transplantation of Intact Frozen-thawed Mammalian Ovary with Vascular Anastomosis at the 58th Annual meeting of the American Society for Reproductive Medicine, Seatle, Wa, USA October 17-22, Abstract \#100231.

31. Bedaiwy, MA, Hussein, MR, Jeremias, E, Sharma, RK, Agarwal, A, and Falcone, T (2002): Histological evaluation and in situ localization of apoptosis in fresh and cryopreserved ovarian tissue. In: 58th Annual Meeting of the American Society for Reproductive Medicine, Oct 12-17, Seattle, WA, Abstract \#100233.

32. Bedaiwy, MA, Falcone, T, Goldberg, JM, Sharma, RK, Nelson, DR, and Agarwal, A (2002): Assessment of leptin levels in the peritoneal fluid of patients with pelvic endometriosis and idiopathic infertility. In: 58th Annual Meeting of the American Society for Reproductive Medicine, Oct 12-17, Seattle, WA, Abstract \#100326.

33. Bedaiwy, MA, Miller, K, Goldberg, JM, Nelson, DR, and Agarwal, A (2002): Assessment of the predictive value of follicular fluid cytokines and reactive oxygen species in IVF cycles. In: 58th Annual Meeting of the American Society for Reproductive Medicine, Oct 12-17, Seattle, WA, Abstract \#101080.

34. Bedaiwy, MA, Miller, K, Goldberg, JM, Attaran, J, Agarwal, A, and Falcone, T (2002): Evaluation of the outcome of assisted reproductive techniques in patients with inflammatory bowel disease: a cross sectional study. In: 58th Annual Meeting of the American Society for Reproductive Medicine, Oct 12-17, Seattle, WA, Abstract \#101094.

35. Bedaiwy, MA, Falcone, T, Miller, K, Abdel-Aleem, A, Al-Hussaini, T, and Agarwal, A (2002): Reactive oxygen species: a biological marker for early embryonic development in intracytoplasmic sperm injection (ICSI) cycles. In: 58th Annual Meeting of the American Society for Reproductive Medicine, Oct 12-17, Seattle, WA, Abstract \#101125.

36. Esfandiari, N, Bedaiwy, MA, Agarwal, A, Jeremias, E, Sharma, RK, and Falcone, T (2002): Does autologous transplantation of cryopreserved ovary result in induction of anti-ovarian antibodies? In: 58th Annual Meeting of the American Society for Reproductive Medicine, Oct 12-17, Seattle, WA, Abstract \#100235.

37. Oder, M, Saleh, RA, Kattal, N, Bedaiwy, MA, Thomas, AJ, Jr, and Agarwal, A (2002): Outcome of intracytoplasmic sperm injection (ICSI) using epididymal and testicular sperm from azoospermic men: the Cleveland Clinic experience. In: 58th Annual Meeting of the American Society for Reproductive Medicine, Oct 12-17, Seattle, WA, Abstract \#100312.

38. Muir TA, Bedaiwy MA, Brainard j,, Goldberg J, Worley S, Falcone T. The histology and strength of laparoscopic uterine incisions made with monopolar, plasma kinetic, ultrasonic, and laser energy sources in the porcine model. 23rd annual Sceintific meeting of The American Urogynecology Society (AUGS) 2003. 
39. Bedaiwy M A, Jeremias E, Guruniuoglu R, Hussein M R, Biscotti C, Falcone T, (2003): The use of epigastric vessels to vascularize fresh and cryopreserved-thawed ovarian transplants: technique and short term function In: ESHRE 19th Annual meeting, Jun 29-July 2, Madrid, Spain.

40. Bedaiwy M A, Tommaso Falcone, Jeffery Goldberg, Rakesh Sharma, Julie Thornton, Ashok Agarwal, Relationship of serum and peritoneal fluid cytokines with pregnancy in endometriosis patients. In: 59th Annual Meeting of the American Society for Reproductive Medicine (2003), October 11-15, 2003, San Antonio, Texas.

41. Javier Noriega, Bedaiwy M A, R. Sharma, Ashok Agarwal and T. Falcone. Effect ot tnf- $\alpha$ blocker (infliximab) on blastocyst development rate. In: 59th Annual Meeting of the American Society for Reproductive Medicine (2003), October 11-15, 2003, Henry B. Gonzalez Convention Center, San Antonio, Texas.

42. Bedaiwy M A, Tommaso Falcone, Jeffery M Goldberg, Marjan Attaran, Kurt Miller, Ashok Agarwal. Assessmenet of the predictive value of follicular fluid il-6 in IVF cycles. In: 59th Annual Meeting of the American Society for Reproductive Medicine (2003), October 11-15, 2003, Henry B. Gonzalez Convention Center, San Antonio, Texas.

43. Javier Noriega, Bedaiwy M A, Sarah Worley, R. Sharma, Ashok Agarwal and Tommaso Falcone. Differential contribution of reactive oxygen species and tumor necrosis factor- $\alpha$ to the peritoneal fluid-induced embryotoxicity in endometriosis patients. In: 59th Annual Meeting of the American Society for Reproductive Medicine (2003), October 11-15, 2003, San Antonio, Texas.

44. Bedaiwy M A., Goldberg J, Mahmoud T.S., Barber M., Sharma R., and Falcone T. Relationship between growth factors and the embryotoxicity of hydrosalpingeal fluid. In: 59th Annual Meeting of the American Society for Reproductive Medicine (2003), October 11-15, 2003, San Antonio, Texas.

45. Bedaiwy M A, Said T, Agarwal A, Pasqualotto, E.B Relationship Of Follicular Fluid Growth Factors With IVF Outcome. In: 59th Annual Meeting of the American Society for Reproductive Medicine (2003), October 11-15, 2003, San Antonio, Texas.

46. Said T, Agarwal A, Bedaiwy M A Role of seminal growth factors in infertile men with varicocele. In: 59th Annual Meeting of the American Urological association, San Francisco, California, May 8-13, 2004.

47. Bedaiwy M, Falcone T, Biscotti C, Hussein M, Cryopreservation of intact human ovary with its vascular pedicle. In: ESHRE 20th Annual meeting, Jun27-30, Berlin, 2004, Germany, 2004,19: i77.

48. Rezk A, Bedaiwy M, Al-Inany $\mathrm{H}, \mathrm{N}$ acetyl cystein is a potent adjuvant to clomiphene citrate in PCOS patients. In: ESHRE 20th Annual meeting, Jun27-30, Berlin, Germany.

49. Said T. M., Sharma R. K., Bedaiwy M. A., Agarwal A., Falcone T.; Toxicity of tumor necrosis factor (TNF)- $\alpha$ on human spermatozoa - possible role in endometriosis associated infertility. In: 60 th Annual Meeting of the American Society for Reproductive Medicine (2004), October 16-20, 2004, Philadelphia, Pennsylvania, USA. 
50. Said T. M., Agarwal A., Sharma R. K., Bedaiwy M. A., Falcone T.; Reversibility of tumor necrosis factor (TNF)- $\alpha$ induced toxic effects by infliximab in human spermatozoa; In: 60th Annual Meeting of the American Society for Reproductive Medicine (2004), October 16-20, 2004, Philadelphia, Pennsylvania, USA.

51. Bedaiwy M. A., Agarwal A., Said T. M., Worley S., Thornton J., Falcone T.;Evidence of transforming growth factor $\beta$ - 1 production by human embryos in conventional IVF cycles; In: 60 th Annual Meeting of the American Society for Reproductive Medicine (2004), October 16-20, 2004, Philadelphia, Pennsylvania, USA.

52. Bedaiwy M. A., Agarwal A., Said T. M., Worley S., Thornton J., Falcone T.; Differential growth of human embryos in vitro: role of total antioxidant capacity; In: 60th Annual Meeting of the American Society for Reproductive Medicine (2004), October 16-20, 2004, Philadelphia, Pennsylvania, USA.

53. Bedaiwy M. A., Hussein M., Jeremias E., Falcone T.; Analysis of bcl-2 and p53 protein expression in ovarian tissue following exposure to warm ischemia; In: 60th Annual Meeting of the American Society for Reproductive Medicine (2004), October 16-20, 2004, Philadelphia, Pennsylvania, USA.

54. Bedaiwy M. A., Falcone T., Katz E., Noriega J., Assad R., Thornton J.; Effect of time to surgery on the outcome of subsequent IVF cycles in endometriosis patients; In: 60th Annual Meeting of the American Society for Reproductive Medicine (2004), October 16-20, 2004, Philadelphia, Pennsylvania, USA.

55. Abdelmoneim A., Hussein M. R., Bedaiwy M. A., Ibraheem A., Osman M. E., Agarwal A.; Touch imprint preparation is a useful adjunct to fine needle aspiration cytology in azoospermic men; In: 60th Annual Meeting of the American Society for Reproductive Medicine (2004), October 16-20, 2004, Philadelphia, Pennsylvania, USA.

56. Bedaiwy M, Falcone, Rezk A, Al-Inany $\mathrm{H} \mathrm{N}$-acetyl cystein improves pregnancy ratein long standing unexplained infertility: a novel mechanism of ovulation induction; In: 60th Annual Meeting of the American Society for Reproductive Medicine (2004), October 16-20, 2004, Philadelphia, Pennsylvania, USA.

57. Rezk A, Bedaiwy M, Al-Inany $\mathrm{H}$, Oxytocin improves the yield in azospermic men undergoing ICSI. In: 60th Annual Meeting of the American Society for Reproductive Medicine (2004), October 16-20, 2004, Philadelphia, Pennsylvania, USA.

58. Bedaiwy MA, Falcone T, Casper RF. Role of fibrinolytic system insufficiency in the initiation of endometriosis: a novel mechanism. In: ESHRE 21th Annual meeting, Jun 19-24, Copenhagen, Denmark, 2005,19: i77.

59. Bedaiwy M. A., Agarwal A., Falcone T., Goldberg J. M., Arrigain S., Mascha E.. Relationship of peritoneal fluid oxidative stress status and subsequent pregnancy in endometriosis patients In: 61th Annual Meeting of the American Society for Reproductive Medicine (2005), October 16-20, 2005, Montreal, Qubec, Canada.

60. Bedaiwy M. A., Agarwal A., Falcone T., Goldberg J. M., Arrigain S., Mascha E. Relationship of the follicular fluid oxidative stress parameters and the outcome of intracytoplasmic sperm injection. In: 61th Annual Meeting of the American Society for Reproductive Medicine (2005), October 16-20, 2005, Montreal, Qubec, Canada. 
61. Bedaiwy M. A., Falcone T., Said T. M., Worley S., Thornton J., Agarwal A. Evidence of transforming growth factor B-2 production in culture media by human embryos. In: 61th Annual Meeting of the American Society for Reproductive Medicine (2005), October 16-20, 2005, Montreal, Qubec, Canada.

62. Bedaiwy MA, Robert F Casper. Leuprolide acetate and hormonal add-back in stage IV endometriosis patients with chronic pelvic pain: a 10-year follow up. In: 61th Annual Meeting of the American Society for Reproductive Medicine (2005), October 16-20, 2005, Montreal, Qubec, Canada.

63. Bedaiwy MA, M. Fathalla M., Ragab M. H., Elbaba S., Luciano M., Falcone T.; Reproductive functions in hydrocephalic females treated with endoscopic third ventriculostomy. In: 61th Annual Meeting of the American Society for Reproductive Medicine (2005), October 16-20, 2005, Montreal, Qubec, Canada.

64. Bedaiwy MA, Forman R, Robert F Casper. Cost effectiveness of an aromatase inhibitor and recombinant FSH versus FSH alone in older patients undergoing intrauterine insemination. In: 61th Annual Meeting of the American Society for Reproductive Medicine (2005), October 16-20, 2005, Montreal, Qubec, Canada.

65. Bedaiwy MA, Robert F Casper. Follicular, hormonal and endometrial dynamics in cycles treated with letrozole and recombinant FSH versus FSH alone in patients undergoing intrauterine insemination In: SGI, Toronto, On, Canada, 20-25, March 2006.

66. Bedaiwy MA, Robert F Casper. Is altered fibrinolysis the cause of endometriosis? In: SGI, Toronto, On, Canada, 20-25, March 2006.

67. Bedaiwy MA, Robert F Casper. Follicular, hormonal and endometrial dynamics in cycles treated with letrozole versus natural cycles in patients undergoing intrauterine insemination. In: ESHRE 22th Annual meeting, Jun 19-24, Prague, Czech Republic, 2006.

68. Bedaiwy MA, Hussein M. R., Biscotti C., Falcone T.; Assessment of follicular viability, apoptotic markers and blood vessels status after cryopreservation of intact human ovary with its vascular pedicle In: 62th Annual Meeting of the American Society for Reproductive Medicine, October 16-20, 2006, New Orleans, LA, USA.

69. Bedaiwy, MA Falcone T, Jeffery Goldberg, Marjan Attaran, Ashok AgarwalEmbryonic arrest in vitro is enhanced by free oxygen radicals in icsi cycles In: 62th Annual Meeting of the American Society for Reproductive Medicine, October 16-20, 2006, New Orleans, LA, USA.

70. Bedaiwy MA, M. R. Hussein, C. Biscotti, T. Falcone; Assessment of follicular viability, apoptotic markers and blood vessels status after cryopreservation of intact human ovary with its vascular pedicle In: 62th Annual Meeting of the American Society for Reproductive Medicine, October 16-20, 2006, New Orleans, LA, USA.

71. M. A. Bedaiwy, E. A. Claessens, N. Esfendiari, N. Mousa, L. Gotleib, R. F. Casper; Assessment of aromatase inhibitor co-treatment in patients 39 years and older undergoing intrauterine insemination. In: 62th Annual Meeting of the American Society for Reproductive Medicine, October 16-20, 2006, New Orleans, LA, USA. 
72. M. A. Bedaiwy, R. F. Casper The aromatase inhibitor letrozole prevents the flare-up effect in endometriosis patients treated with a GnRH agonist. In: 62th Annual Meeting of the American Society for Reproductive Medicine, October 16-20, 2006, New Orleans, LA, USA.

\section{Awards and Honors}

1. First video award Reproductive Surgery category titled The use of epigastric vessels to vascularize fresh and cryopreserved-thawed ovarian transplants at: 59th Annual Meeting of the American Society for Reproductive Medicine (2003), October 11-15, 2003, Henry B. Gonzalez Convention Center, San Antonio, Texas USA.

2. ESHRE travel award titled, "The use of the deep inferior epigastric vessels to vascularized fresh and cryopreserved thawed ovarian grafts' at the 19th Annual meeting of the European Society for Human Reproduction and embryology (ESHRE), Madrid, Spain June 30-July 2nd, 2003.

3. Poster award (general program) titled, "Histological evaluation and in situ localization of apoptosis in cryopreserved ovarian tissue' at the 58th Annual meeting of the American Society for Reproductive Medicine, Seatle, Wa, USA October 17-22, 2002.

4. First video award Reproductive Surgery category titled, "Robotically assisted gynecologic surgery' at the 58th Annual meeting of the American Society for Reproductive Medicine, Seatle, Wa, USA October 17-22, 2002.

5. The Society of Reproductive Surgeons Award titled 'Autotransplantation of intact cryopreserved-thawed mammalian ovary with microvascular anastomosis" at the 58th Annual meeting of the American Society for Reproductive Medicine, Seattle, WA, USA October 14-17, 2002.

6. The 3rd Royan International Research Award titled 'Autotransplantation of intact cryopreserved-thawed mammalian ovary with microvascular anastomosis" at the The 3rd Annual meeting of the Royan Institute, Tehran, Iran, Sept 11-13, 2002.

7. Fellow Award titled 'Autotransplantation of intact cryopreserved-thawed ovary with microvascular anastomosis: a novel approach" at the Annual meeting of the Cleveland Society of Obstetrics and Gynecology, Cleveland, Oh, USA, May15, 2002.

8. Serono-In training Award titled 'Autotransplantation of intact cryopreserved-thawed ovary: a minimally invasive approach" at the 50th Annual meeting of the Pacific Coast Reproductive Society PCSR, Palms Springs Ca, USA, April 17-21, 2002.

9. First video award Reproductive Surgery category titled, "Ovarian autotransplantation with vascular anastomosis" at the 57th Annual meeting of the American Society for Reproductive Medicine, Orlando, FL, USA October 20-25, 2001.

10. First video award Assisted Reproduction category, titled "ultrasound guided embryo transfer" at the 57th Annual meeting of the American Society for Reproductive Medicine, Orlando, FL, USA October 20-25, 2001. 
11. Certificate of distinction, Fellow of the year 2001, from the Urological institute and department of Obstetrics and Gynecology, The Cleveland Clinic Foundation, Cleveland, Ohio, USA.

12. Trainee Merit Award by the National Institute of Health and international society of Andrology, titled "Novel semen quality scores can predict pregnancy in patients with male factor infertility undergoing intrauterine insemination" at the 7th International Congress of Andrology, Montreal, Canada, June 13-19, 2001.

13. Second Prize in Cleveland Society of Obstetrics and Gynecology titled "Formation of Vesicovaginal Fistulas in Laparoscopic Hysterectomy with Electrosurgical Induced Cystotomy" at the Annual Cleveland society of Gynecology meeting, 2001 at Cleveland, Ohio.

14. First prize in the 3rd annual transplant day of Cleveland Clinic Foundation, titled "The importance of ischemia time and tissue size in the preparation of ovarian tissue for cryopreservation" April, 20, 2001. 






